Portland State University

PDXScholar

\title{
Applications of Digital Signal Processing with Cardiac Pacemakers
}

Merry Thi Tran

Portland State University

Follow this and additional works at: https://pdxscholar.library.pdx.edu/open_access_etds

Part of the Electrical and Electronics Commons, and the Signal Processing Commons Let us know how access to this document benefits you.

\section{Recommended Citation}

Tran, Merry Thi, "Applications of Digital Signal Processing with Cardiac Pacemakers" (1992). Dissertations and Theses. Paper 4582.

https://doi.org/10.15760/etd. 6466

This Thesis is brought to you for free and open access. It has been accepted for inclusion in Dissertations and Theses by an authorized administrator of PDXScholar. Please contact us if we can make this document more accessible: pdxscholar@pdx.edu. 
AN ABSTRACT OF THE THESIS OF Merry Thi Tran for the Master of Science in Electrical Engineering presented May 20, 1992.

Title: Applications of Digital Signal Processing with Cardiac Pacemakers.

APPROVED BY THE MEMBERS OF THE THESIS COMMITTEE:
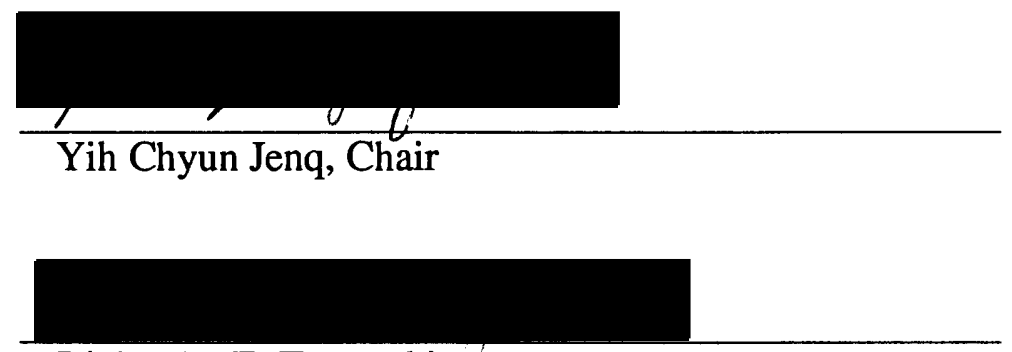

Richard P.E. Tymerski

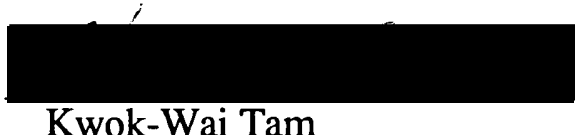

Because the voltage amplitude of a heart beat is small compared to the amplitude of exponential noise, pacemakers have difficulty registering the responding heart beat immediately after a pacing pulse. This thesis investigates use of digital filters, an inverse filter and a lowpass filter, to eliminate the effects of exponential noise following a pace pulse. The goal was to create a filter which makes recognition of a haversine wave less dependent on natural subsidence of exponential noise.

Research included the design of heart system, pacemaker, pulse generation, and sensor system simulations. The simulatin model includes the following components:

- Signal source, A MATLAB generated combination of a haversine signal, exponential noise, and myopotential noise. The haversine signal is a test signal used to simulate the QRS complex which is normally recorded on an ECG trace as a representa- 
tion of heart function. The amplitude is approximately $10 \mathrm{mV}$. Simulated myopotential noise represents a uniformly distributed random noise which is generated by skeletal muscle tissue. The myopotential noise has a frequency spectrum extending from 70 to $1000 \mathrm{~Hz}$. The amplitude varies from 2 to $5 \mathrm{mV}$. Simulated exponential noise represents the depolarization effects of a pacing pulse as seen at the active cardiac lead. The amplitude is about $\sim 1$ volt, large in comparison with the haversine signal.

- A/D converter, A combination of sample \& hold and quantizer functions translate the analog signal into a digital signal. Additionally, random noise is created during quantization.

- Digital filters, An inverse filter removes the exponential noise, and a lowpass filter removes myopotential noise.

- $\quad$ Threshold level detector, A function which detects the strength and amplitude of the output signal was created for robustness and as a data sampling device.

The simulation program is written for operation in a DOS environment. The program generates a haversine signal, myopotential noise (random noise), and exponential noise. The signals are amplified and sent to an A/D converter stage. The resultant digital signal is sent to a series of digital filters, where exponential noise is removed by an inverse digital filter, and myopotential noise is removed by the Chebyshev type I lowpass digital filter. The output signal is "detected" if its waveform exceeds the noise threshold level.

To determine what kind of digital filter would remove exponential noise, the spectrum of exponential noise relative to a haversine signal was examined. The spectrum of the exponential noise is continuous because the pace pulse is considered a non-periodic signal (assuming the haversine signal occurs immediately after a pace pulse). The spectrum of the haversine is also continuous, existing at every value of frequency $\omega$. The spectrum of the haversine is overlapped by the spectrum of and amplitude of the 
exponential, which is several orders of magnitude larger. The exponential cannot be removed by conventional filters. Therefore, an inverse filter approach is used to remove exponential noise. The transfer function of the inverse filter of the model has only zeros. This type of filter is called FIR, all-zero, non recursive, or moving average.

Tests were run using the model to investigate the behavior of the inverse filter. It was found that the haversine signal could be clearly detected within a 5\% change in the time constant of the exponential noise. Between $5 \%$ and $15 \%$ of change in the time constant, the filtered exponential amplitude swamps the haversine signal. The sensitivity of the inverse filter was also studied: when using a fixed exponential time constant but changing the location of the transfer function, the effect of the exponential noise on the haversine is minimal when zeros are located between 0.75 and 0.85 of the unit circle.

After the source signal passes the inverse filter, the signal consists only of the haversine signal, myopotential noise, and some random noise introduced during quantization. To remove these noises, a Chebyshev type I lowpass filter is used. 


\section{APPLICATIONS OF DIGITAL SIGNAL PROCESSING WITH CARDIAC PACEMAKERS}

by

MERRY THI TRAN

A thesis submitted in partial fulfillment of the requirements for the degree of

MASTER OF SCIENCE in

ELECTRICAL ENGINEERING

Portland State University

1992 
TO THE OFFICE OF THE GRADUATE SUDIES:

The members of the committee approve the thesis of Merry Thi Tran presented May 20, 1992.
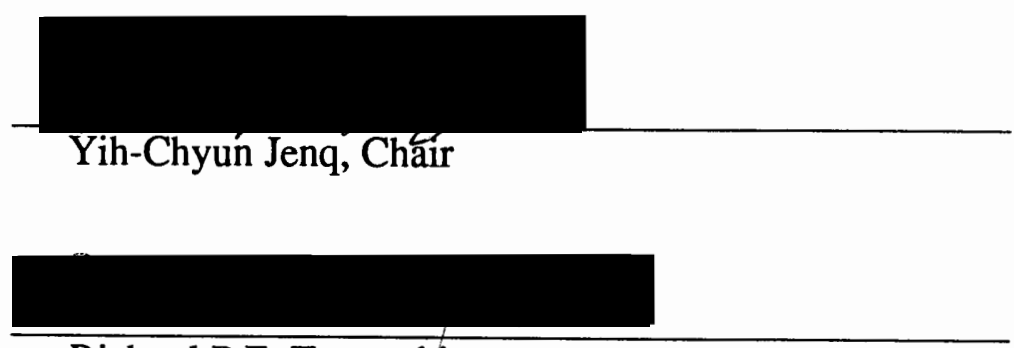

Richard P.E. Tymerski

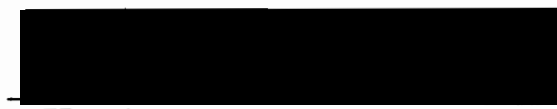

Kwok-Wai Tam

APPROVED:

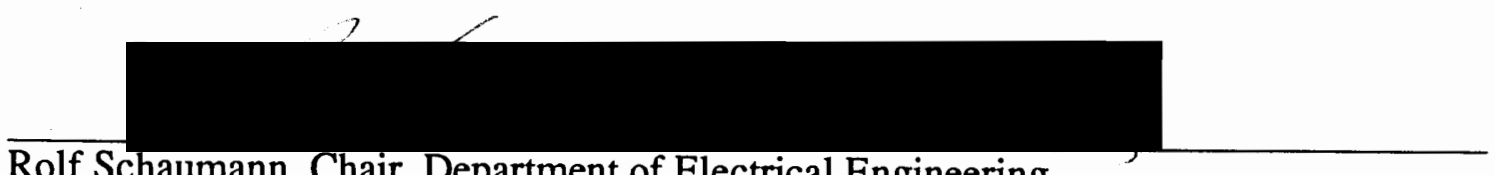

Rolf Schaumann, Chair, Department of Electrical Engineering

C. William Savery, Interim Vice Provost for Gratuate Studies and Research 


\section{ACKNOWLEDGEMENTS}

I would like to take this opportunity to thank those who have contributed to the completion of this thesis. First, I deeply appreciate contributions from Dr. Y.C. Jenq, professor at Portland State University; Mr. Bob Weyant, Vice President of System Design and Development at Micro Systems Engineering, Inc.; and Mr. Dick Schomburg, Principal Engineer from the same above company, for their guidance during the writing of this paper. I would also like to thank Miss Laura Riddell for her typing contribution. Finally, I greatly appreciated my friends Mr. John Sandbo, Mr. Rick Sanborn, Mr. Roger Hoffman, engineers at Micro Systems Engineering, Inc. who have provided me with their support thoughout the execution of this thesis. 


\section{TABLE OF CONTENTS}

\section{PAGE}

ACKNOWLEDGEMENTS.....................................................................iii

LIST OF TABLES...............................................................................vii

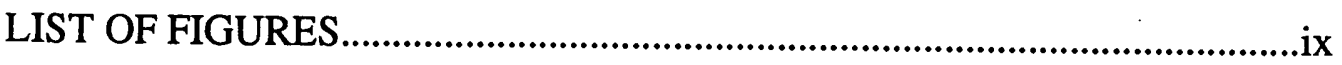

\section{CHAPTER}

I INTRODUCTION.............................................................

Pacemakers............................................................1

The Problem.............................................................2

The Solution...........................................................2

Conclusions..............................................................4

Organization of the Thesis............................................4

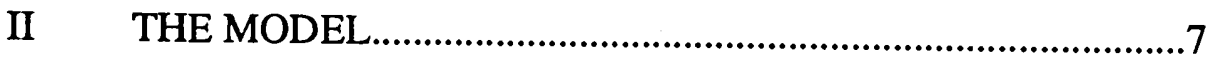

III HAVERSINE SIGNAL ................................................

Cardiac Conduction System.......................................9

Atrial Representation..............................................15

Atrial Waveform

Atrial Spectrum

Ventricular Representation

Ventricular Waveform

Ventricular Spectrum

Atrial/Ventricular Representation.

Atrial/Ventricular Waverform 


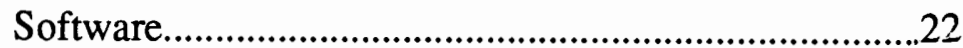

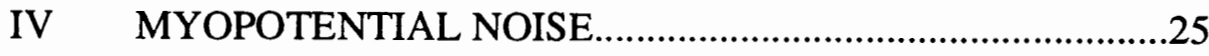

Uniformly Distributed Noise.........................................25

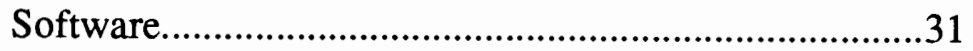

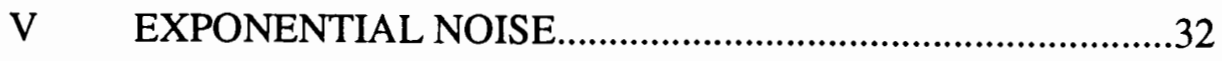

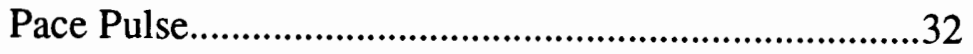

Spectrum of Exponential Noise

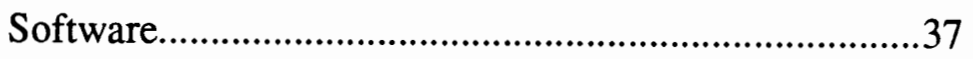

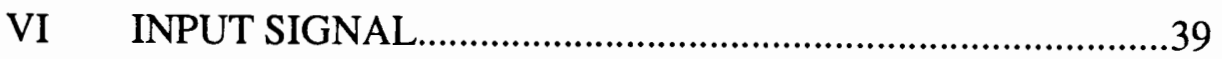

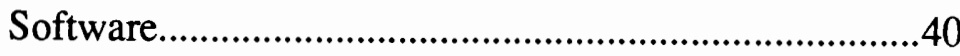

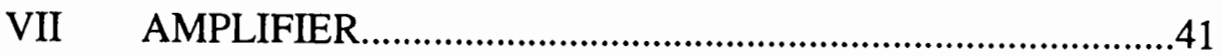

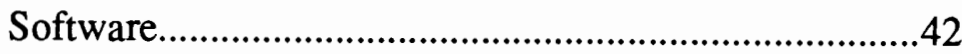

VIII A/D CONVERTER..............................................................43

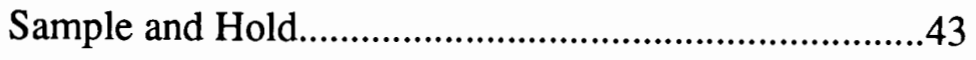

Software

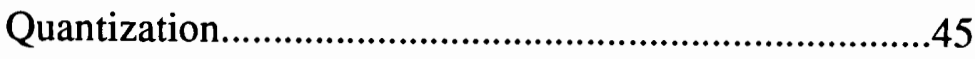

Software

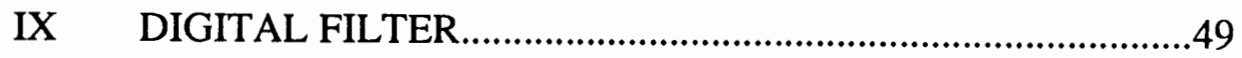

Inverse Digital Filter......................................................49

Software

Lowpass Digital Filter......................................................111

Software

Threshold Level Detector................................................115

Software 


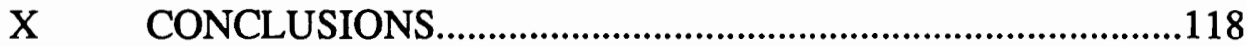

Procedure Summary.......................................................118

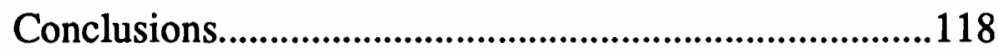

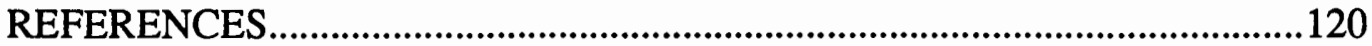

APPENDICES

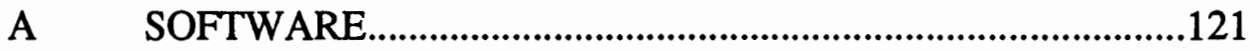

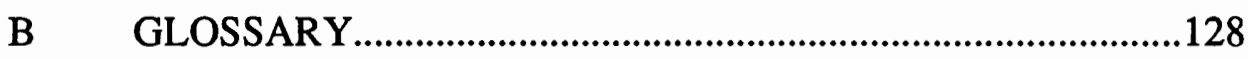




\section{LIST OF TABLES}

I Inverse Filter (2nd Order) Behavior, Where

$$
\begin{aligned}
& \text { Input Signal = Exponential Only: at 0\%, } \\
& b=-400(1 / \mathrm{sec}), a=0.5 \text { in } a * \exp (-b t) \ldots . .
\end{aligned}
$$

II Inverse Filter Behavior (2nd Order) Resulting

from Changing $a$ and $b$ in $a^{*} \exp (-b t)$.

Input Signal $=$ Exponential + Haversine

III Inverse Filter (1st Order) Behavior Resulting

from Changing in $a^{*} \exp (-b t)$.

Input Signal $=$ Exponential Only

IV Inverse Filter (1st Order) Behavior Resulting

from Changing in $a^{*} \exp (-b t)$.

Input Signal $=$ Exponential + Haversine

V Inverse Filter (2nd Order) Behavior Resulting

from Changing the Location of Zeros.

Input $=$ Exponential + Haversine

VI Inverse Filter (2nd Order) Behavior Resulting

from Changing the Location of Zeros.

Input $=$ Exponential Only

VII Inverse Filter (1st Order) Behavaior Resulting

from Changing the Location of Zeros.

Input $=$ Exponential Only 
VIII Inverse Filter (2nd Order) Behavior Resulting

from Changing the Location of Zeros.

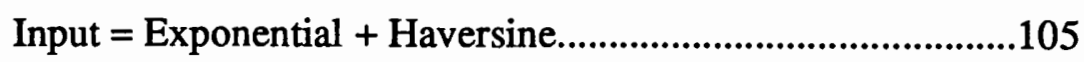

IX Location of Poles, and Zeros by order...........................................112 


\section{LIST OF FIGURES}

FIGURE

PAGE

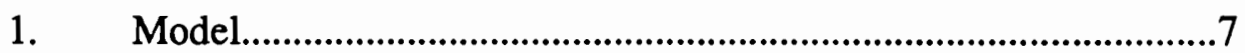

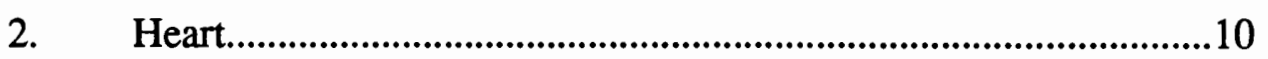

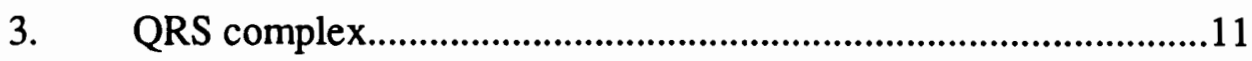

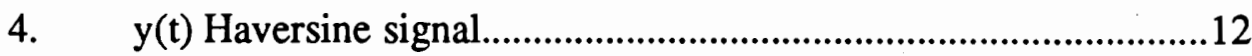

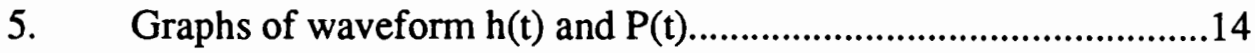

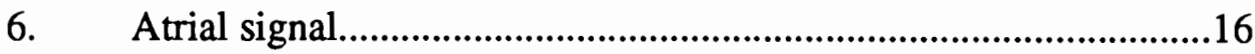

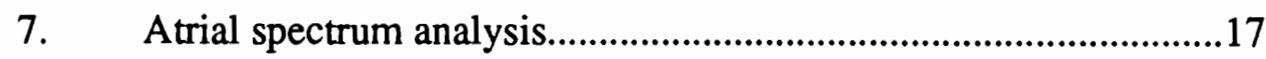

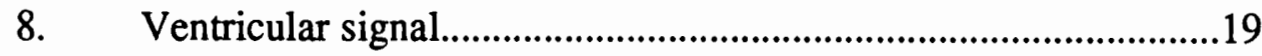

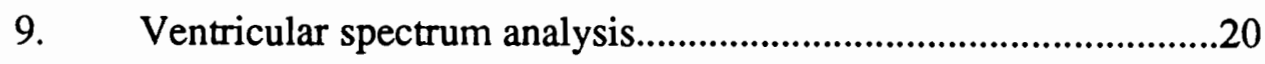

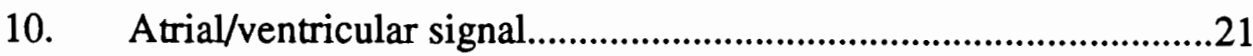

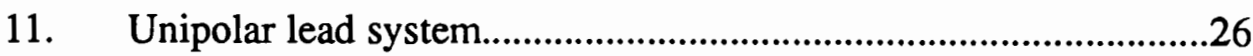

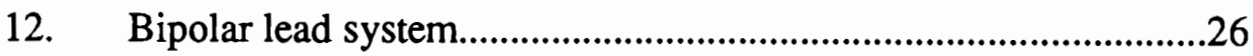

13. Sensitivity curve for sensing $\mathrm{R}$ waves............................................27

14. An atrial pacing with myopotential interference.

During the interference, the ventricular lead sences muscle activity and inhibits ventricular

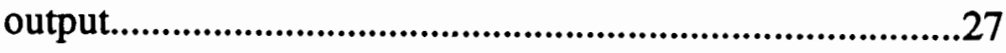

15. Examples of tape recorded myoelectric signals............................28

16. Uniformly distributed random noise...........................................29 
17. Chebyshev typeI, bandpass filter order 8th,

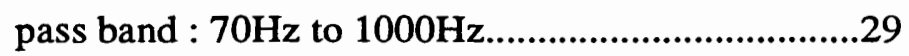

18. Myopotential noise.........................................................................30

19. Spectrum of myopotential noise......................................................30

20. The pacing artifact.............................................................................33

21. Pulse width $=530 \mathrm{uS}$ Amplitude $=-4.8 \mathrm{~V}$, LeCroy

9400A Dual 175 MHz scope......................................33

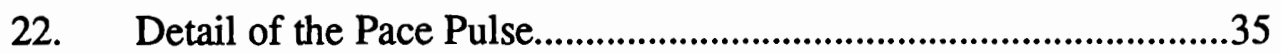

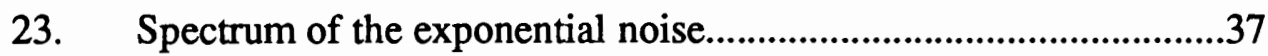

24. Haversine + exponential + myopotential......................................39

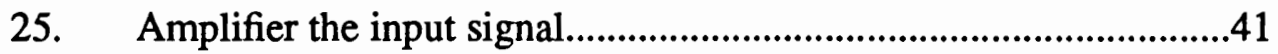

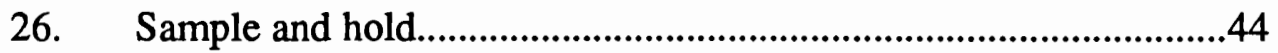

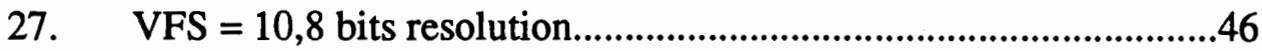

28. After quantizer, signal gains some random noise............................47

29. Inverse filter removes the exponential.........................................52

30. Magnitude of inverse filter (2nd order) at different zero location..54

31. Magnitude of inverse filter (1st order) at different zero location...54

32. Fixer inverse filter (2nd order) coefficients, $0 \% \mathrm{a} \& \mathrm{~b}$......................55

33. Fixed inverse filter. (2nd order) coefficients, $2 \% \mathrm{a} \& \mathrm{~b}$....................55

34. Fixed inverse filter (2nd order) coefficients, $5 \%$ a\&b.....................56

35. Fixed inverse filter ( 1 st order) coefficients, $0 \% \mathrm{a} \& \mathrm{~b}$......................56

36. Fixed inverse filter (1st order) coefficients, $2 \%$ a\&b.....................57

37. Fixed inverse filter (1st order) coefficients, 5\% a\&b.....................57 
38. Change zero location (2nd order inverse filter), zero $=0.7 \ldots \ldots \ldots \ldots . .58$

39. Change zero location (2nd order inverse filter), zero $=0.8 \ldots \ldots \ldots \ldots . .58$

40. Change zero location (2nd order inverse filter), zero $=0.9$..............59

41. Change zero location (1st order inverse filter), zero $=0.7 \ldots \ldots \ldots \ldots . . .59$

42. Change zero location (1st order inverse filter), zero $=0.8 \ldots \ldots \ldots \ldots . . . .60$

43. Change zero location (1st order inverse filter), zero $=0.9$..............60

44. Magnitude of lowpass filter, Chebyshev type I................................114

45. Lowpass filter filters out myopotential........................................115

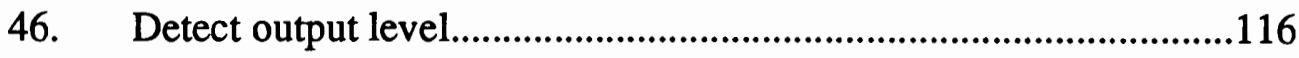




\section{CHAPTER I}

\section{INTRODUCTION}

\section{PACEMAKERS}

A pacemaker feeds electrical stimulating pulses to the heart to keep the heart beating at a steady, healthy rhythm. The pacemaker is a pulse generating system, including a battery and a circuit. The unit operates continuously from the day of manufacture.

The circuit is sometimes encapsulated in epoxy and silicone rubber, and is always covered with metal (titanium). The unit contains a battery, usually of 4 or 5 cells. Almost all pacemakers made today use mercury-zinc cell battery packs with lithium anodes. A flexible electrical wire (pacing lead) is plugged into the pulse generator, and carries the stimulating pulses to the heart. The pacing lead is also used as a sensor which receives heart status data. The received data are used to control the output of the pulse generator.

Several lead configurations exist. A unipolar lead has one conducting wire and an electrode. The pulse generator uses body fluids for its return pathway. A bipolar lead has two conducting wires inside its insulation. The electrical signal travels down one wire to an electrode, passes through the myocardium, causes the heart tissue to depolarize, and then returns by the second electrode. Multiple lead configurations also exist.

The simplest pulse generator consists of a power source and a timing device which deliver electrical signals often enough to maintain an adequate cardiac output. A small electrical charge is delivered from the pulse generator, through the pacing lead, and to 
the heart in pulses separated by an appropriate interval to produce a desired heart rate.

\section{THE PROBLEM}

Contact between the pacing lead and tissue produces noise which is called exponential noise. Exponential noises have a large voltage amplitude. Because the voltage amplitude of a heart beat is small compared to the amplitude of exponential noise, pacemakers have difficulty registering the responding heart beat immediately after a pacing pulse.

This problem is called a "stimulus recognition" problem. This problem is very important because it controls the actions of the pacemaker. As soon as the heart beat can be sensed, the pacemaker emits or suppresses a pace pulse based on the strength of the heart beat. Solving the sensing problem requires a filter structure that will sense haversine type signals in the presence of non-periodic exponential signals resulting from a pace pulse and myopotential noise.

This thesis investigates use of digital filters, an inverse filter and a lowpass filter, to eliminate the effects of exponential noise following a pace pulse. The goal was to create a filter which will eliminate the effect of the large exponential noise and make recognition of a haversine wave easier. Comparison of Figures 4 and 22 (exponential \#3) shows that the exponential noise is several orders of magnitude larger than the typical haversine signal.

\section{THE SOLUTION}

In order to research the problem stated above, it was necessary to design heart system, pacemaker, pulse generation, and sensor system simulations. The simulation model includes the following components: 
- Signal source, A MATLAB generated combination of a haversine signal, exponential noise, and myopotential noise. The haversine signal is a test signal used to simulate the QRS complex which is normally recorded on an ECG trace as a representation of heart function. The amplitude is approximately $10 \mathrm{mV}$. Simulated myopotential noise represents a uniformly distributed random noise which is generated by skeletal muscle tissue. The myopotential noise has a frequency spectrum extending from 70 to $1000 \mathrm{~Hz}$. The amplitude varies from 2 to $5 \mathrm{mV}$. Simulated exponential noise represents the depolarization effects of a pacing pulse as seen at the active cardiac lead. The amplitude is about $~ 1$ volt, large in comparison with the haversine signal.

- A/D converter, A combination of sample \& hold and quantizer functions translate the analog signal into a digital signal. Additionally, random noise is created during quantization.

- Digital filters, An inverse filter removes the exponential noise, and a lowpass filter removes myopotential noise.

- Threshold level detector, A function which detects the strength and amplitude of the output signal was created for robustness and as a data sampling device.

The simulation program is written for operation in a DOS environment. The program generates a haversine signal, myopotential noise (random noise), and exponential noise. The signals are amplified and sent to an $\mathrm{A} / \mathrm{D}$ converter stage. The resultant digital signal is sent to a series of digital filters, where exponential noise is removed by an inverse digital filter, and myopotential noise is removed by the Chebyshev type I lowpass digital filter. The output signal is "detected" if its waveform exceeds the noise threshold level.

To determine what kind of digital filter would remove exponential noise, the spectrum of exponential noise relative to a haversine signal was examined. The spectrum of 
the exponential noise is continuous because the pace pulse is considered a non-periodic signal (assuming the haversine signal occurs immediately after a pace pulse). The spectrum of the haversine is also continuous, existing at every value of frequency $\omega$. The spectrum of the haversine is overlapped by the spectrum of and amplitude of the exponential, which is several orders of magnitude larger. The exponential cannot be removed by conventional filters. Therefore, an inverse filter approach is used to remove exponential noise. The transfer function of the inverse filter of the model has only zeros. This type of filter is called FIR, all-zero, non recursive, or moving average.

\section{CONCLUSIONS}

Tests were run using the model to investigate the behavior of the inverse filter. It was found that the inverse filter method is very effective. Sensing problems were also studied and it was found that the haversine signal can be clearly sensed if there is a $5 \%$ change in the time constant of the exponential. Between $5 \%$ and $15 \%$ of change in the time constant, the filtered exponential amplitude swamps the haversine signal (Presented in Tables I, II, III, and IV). The sensitivity of the inverse filter was also studied. When using a fixed exponential time constant but changing the location of the zeros, the effect of the exponential noise on the haversine is minimal when zeros are located between 0.75 and 0.85 of the unit circle (Presented in Tables V, VI, VII, and VIII).

After the source signal passes the inverse filter, the signal consists only of the haversine signal, myopotential noise, and some random noise introduced during quantization. To remove these noises, a Chebyshev type I lowpass filter is used.

\section{ORGANIZATION OF THE THESIS}

- Chapter I describes the difficulties pacemakers have with myopotential and exponential noise. The solution discussed in this thesis is also outlined. 
- Chapter II describes the simulation model which consist of a source signal generator, an amplifier, an A/D converter, digital filters, and a threshold detector. The model in this chapter provides a context for discussion by isolating and identifying components and their relationships to one another. Further details about each stage of the model appear in later chapters.

- Chapter III describes normal cardiac contraction, the QRS wave which describes contraction on an ECG trace, and the haversine signal which can replace the QRS for laboratory purposes. The chapter then describes the atrial waveform of the haversine signal, the ventricular waveform of the haversine signal, the ventricular wave spectrum, and the atrial ventricular representation by haversine signals. Finally, the chapter provides a MATLAB listing of the FFT translation of ECG data to a haversine signal.

- Chapter IV describes natural occurrence of myopotential noise, the sensitivity range for detection of myopotential noise, and the conflict between myopotential noise and ventricular output. Finally, code for creation of laboratory simulated myopotential noise is presented.

- Chapter V defines and describes the "pulse interval". The division of a pacing pulse into 2 parts, the conflict between exponential noise and the pacemaker's ability to register the heart's response to a pacing pulse, the possible causes of exponential noise, and the reasons a bandpass filter can not remove exponential noise are described. Finally, the code used to simulate exponential noise is presented.

- Chapter VI describes the test input signal and provides a code sample that combines haversine, exponential, and myopotential signals to create the test input.

- Chapter VII describes the need for a signal amplifier and provides a code sample which simulates the signal amplification done by a normal pacemaker. 
- Chapter VIII describes an analog to digital converter, the sample and hold function, and presents the code sample for the test sample and hold functionality. The chapter then describes the quantization process and the introduction of random noise into the quantized signal. Finally, the code which represents the quantization process is presented.

- Chapter IX describes the need for and inadequacy of a digital filter, the instability of inverse digital filters, the use of a stable psuedo-inverse filter to remove the presence of the exponential noise, the effects of the filter on the test signal, and the use of a lowpass filter to minimize myopotential noise.

- Chapter X presents conclusions based on the test system. The conclusions include a description of limitations suggested by test runs of the simulation.

- Appendix A contains the simulation software listing. MATLAB was used as supporting software. MATLAB functions are detailed in the body text where necessary.

- Appendix B contains a Glossary of terms used in this document. 


\section{CHAPTER II}

\section{THE MODEL}

This chapter presents the simulation model used to test the inverse filter and the lowpass filter. Figure 1 shows the entire model. The remaining chapter presents details used throughout the remainder of this paper.

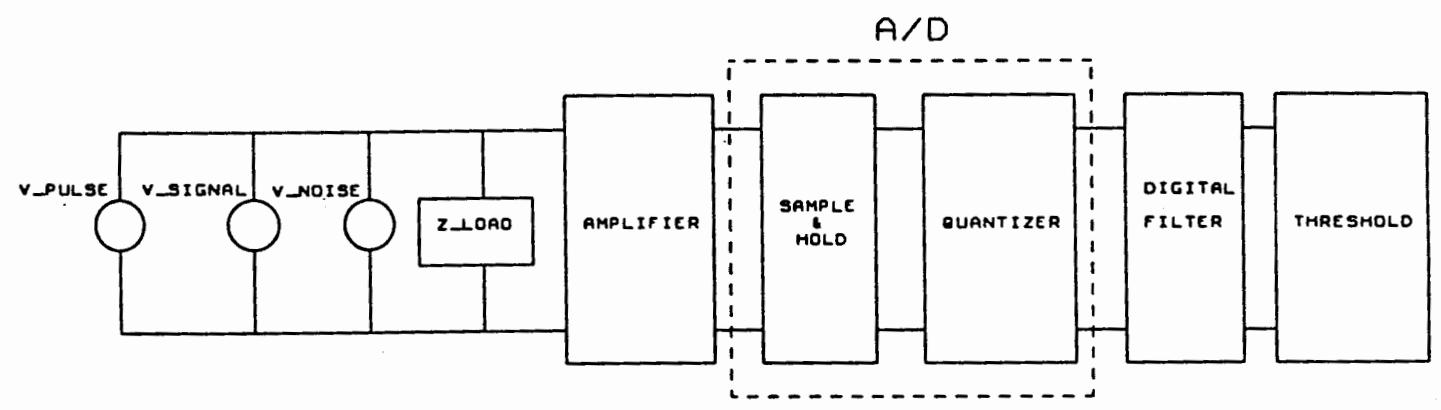

Figure 1. Model.

During normal operation a pacemaker sends a pace pulse. The pace pulse is impressed on the heart by the implanted leads. The heart then contracts, producing the ECG's record of polarization, the QRS trace. How a QRS trace can be replaced with a haversine waveform for test purposes is described in Chapter III. In the model shown in Figure 1, the QRS corresponds to V_signal. The pacemaker can detect the QRS through the implanted leads.

After the trailing edge of the pace pulse, an exponential decay signal appears (exponential noise). V_pulse, shown in Figure 1, represents the appearance of exponential noise. Until the exponential noise subsides, it is difficult for the pacemaker to sense the V_signal. 
To make matters more complicated, the $\mathrm{V} \_$signal is also overlaid with myopotential noise (V_noise in Figure 1) caused by the surrounding skeletal muscle.

Zload in Figure 1 represents a $500 \Omega$ ringers solution load. Ringers solution is a combination of $8.6 \mathrm{~g} \mathrm{NaCl}, 0.3 \mathrm{~g} \mathrm{KCl}, 0.44 \mathrm{~g} \mathrm{CaCl} .2 \mathrm{H} 20$ in one liter of water. It is an essentially isotonic medium present in many animal tissues.

The V_signal amplitude is very small compared to the pacing pulse (V_pulse). Therefore, the signal is passed through an amplification stage before it is manipulated.

The output of the amplifier is sent to an analog to digital converter (A/D converter) which contains a sample and hold function and a quantizer. The signal, which would be used as an analog signal in many applications, is converted to a digital signal previous to manipulation by the filters presented and studied in this paper.

The converted digital signal then passes through a two digital filters, an inverse filter and a lowpass filter. The inverse filter removes the residual exponential noise from the pacing pulse. The lowpass filter removes the myopotential noise. Output of the digital filters is the unencumbered V_signal produced by the heart muscle.

Finally, the threshold detector records the V_signal when the V_signal rises above the level of residual unfiltered noise.

For the purposes of textual discussion, $V_{-}$pulse is referred to as exponential noise; V_signal is referred to as haversine signal; and V_noise is myopotential noise. 


\section{CHAPTER III}

\section{HAVERSINE SIGNAL}

This chapter describes normal cardiac contraction, the QRS wave which describes contraction on an ECG trace, and the haversine signal which can replace the QRS for laboratory purposes. The chapter then describes the atrial waveform of the haversine signal, the ventricular waveform of the haversine signal, the ventricular wave spectrum, and the atrial ventricular representation by haversine signals. Finally, the chapter provides a MATLAB listing of the FFT translation of ECG data to a haversine signal.

\section{CARDIAC CONDUCTION SYSTEM}

The cardiac conduction system is composed of specialized muscle tissues which transfer electrical impulses across the tissue of the heart. The impulses determine the moment of contraction for the various chambers of the heart. This system provides stimulating pulses at a rate appropriate for the body's needs. The system then conducts these impulses rapidly to all the muscle fibers of the ventricular chamber. Figure 2 shows the structures of the cardiac conduction system.

Of specific interest are the sinus-atrial node (the S-A node) and the atrial-ventricular node (A-V node). The former triggers atrial contractions. The latter triggers ventricular contractions.

A muscle cell receiving a stimulus and contracting or a nerve cell receiving stimulus and transmitting the stimulus to the next nerve cell is called depolarization. Recovery of the cell, so that it is ready to receive the next stimulus, is called repolariza- 
tion. A pacemaker provides the trigger stimulation for heart contractions when the A-V node, the S-A node, or both do not properly trigger depolarization.

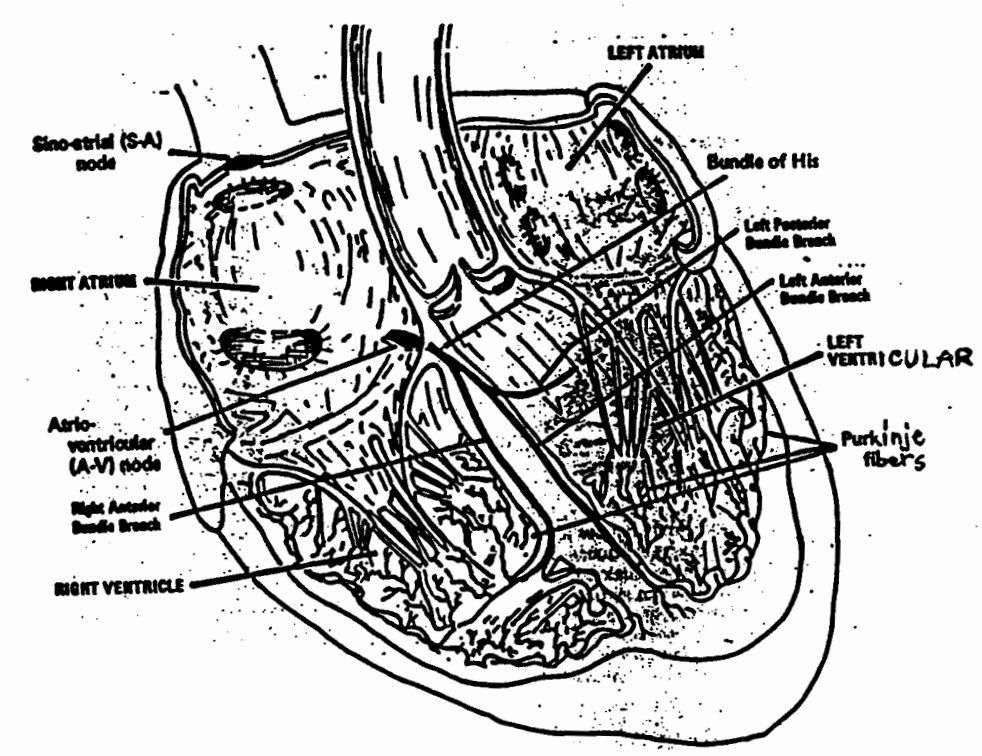

Figure 2. Heart.

From the electrical point of view, one cardiac cycle can be described as follows:

1. Based on chemical information in the blood stream, the Sino-atrial (S-A node) fires and depolarization spreads through the atrial chamber.

2. Depolarization spreads through the atrium and stimulates the Atrio-Ventricular node (A-V node).

3. The atrial chamber starts to contract, emptying blood into the ventricular chamber. The atrial chamber remains at rest for the remainder of the cycle.

4. After a 1/10 - $\mathrm{sec}$ delay during which the atrial empties and the ventricular is filled, the A-V node fires and the ventricular contracts to empty blood into the arteries.

5. The QRS waveform (depicted in Figure 3) is recorded with an ECG. 
6. Repolarization begins immediately.

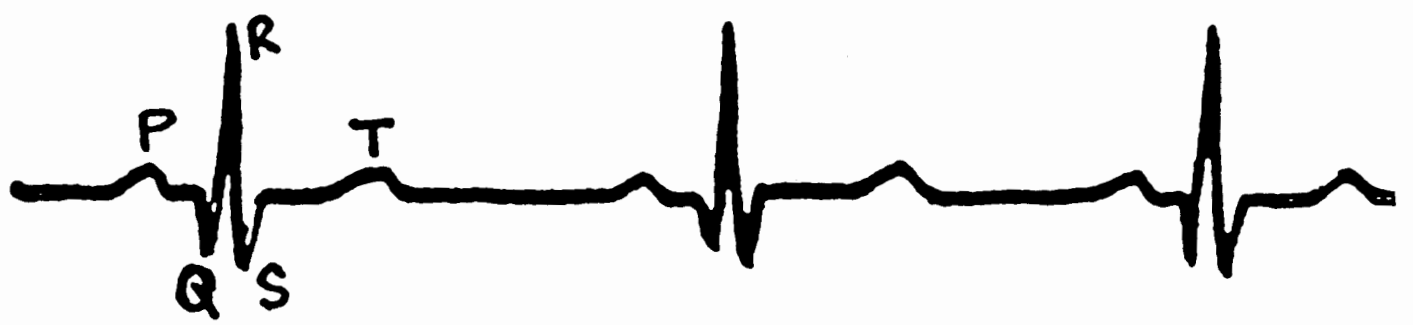

Figure 3. QRS complex.

In Figure 3, the components of the cardiac cycle can be seen on an ECG trace. The small $\mathbf{P}$ wave represents the depolarization of sino-atrial tissues. The QRS wave, or $\mathrm{R}$ wave, is produced by the relatively large voltage caused by the depolarization of the atrio-ventricular tissues. The $T$ wave is very small, and results from ventricular repolarization.

A QRS complex, called the $Q R S$ wave, or simply an $R$ wave, is a large signal generated during depolarization of the ventricular. This is the beginning of ventricular contraction. When a pacing pulse is delivered to the heart, the response is almost immediate. The QRS commences within 1/100 sec.

For laboratory purposes, the QRS complex can be replaced by a single peak signal called the haversine signal. Figure 4 illustrates a haversine signal with an amplitude of $10 \mathrm{mV}$, a pulse width of $40 \mathrm{msec}$, and a period of $480 \mathrm{msec}$.

An expression for the haversine signal is presented below:

$$
\begin{array}{ll}
\text { 1A: } y(t)=A m p / 2 *(1-\cos (2 \pi t / P W)), & 0<t \leq P W \\
\text { 1B: } y(t)=0 & , P W<t \leq P e r
\end{array}
$$



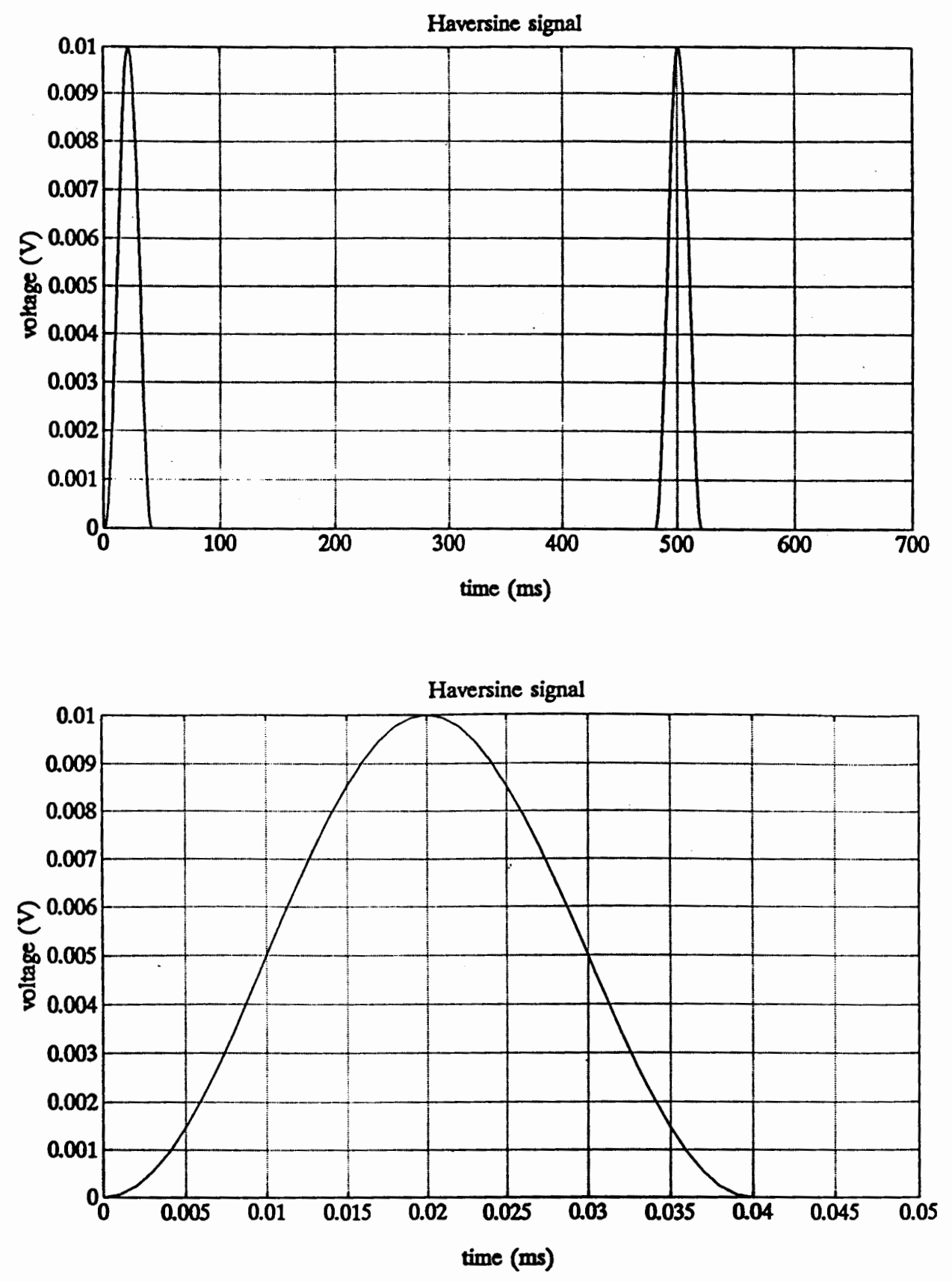

Figure 4. $y(t)$ Haversine signal. 
PW is the pulse width of the haversine in milliseconds (msec), Amp is the amplitude of the haversine in milli-volts $(\mathrm{mV})$, Per is the period of the haversine in milliseconds (msec), and bpm defines the beats per minute (60,000/period), ppm defines the pulses per minute $(60,000 /$ period).

Figure $5 h(t)$ displays the waveform of equation (1A) and Figure $5 p(t)$ displays the rectangular waveform. By analyzing the equation (1A) and the rectangular waveform equation, multiplying the results, the haversine signal is formed as it is displayed in Figure 4. This method is applied in MATLAB to generate the haversine signal. The duty cycle of the rectangular waveform can be adjusted in the simulation to meet with requirements in the simulation.

The results of the Fourier transform applied to achieve the waveform displayed in Figure 4 are as follows:

From definition of the Fourier transform,

$$
\begin{aligned}
& G(w)=\int_{-\infty}^{\infty} g(t) e^{(-j \cdot w \cdot t)} d t \\
& g(t)=h(t)^{*} p(t) \\
& h(t)=\frac{A m p}{2} \cdot\left(1+\cos \left(2 \pi \frac{t}{p w}\right)\right) \\
& g(t)=\frac{A m p}{2} \cdot p(t)+\frac{A m p}{2} \cdot p(t) \cdot \cos \left(\frac{2 \pi t}{p w}\right) \\
& A m p=a m p l i t u d e, p w=p u l s e ~ w i d t h \\
& =\Rightarrow G(w)=\frac{A m p \sin \frac{p w \cdot w}{2}}{w} \cdot \frac{-4 \pi^{2} / p w^{2}}{w^{2}-\frac{4 \pi^{2}}{p w^{2}}}
\end{aligned}
$$



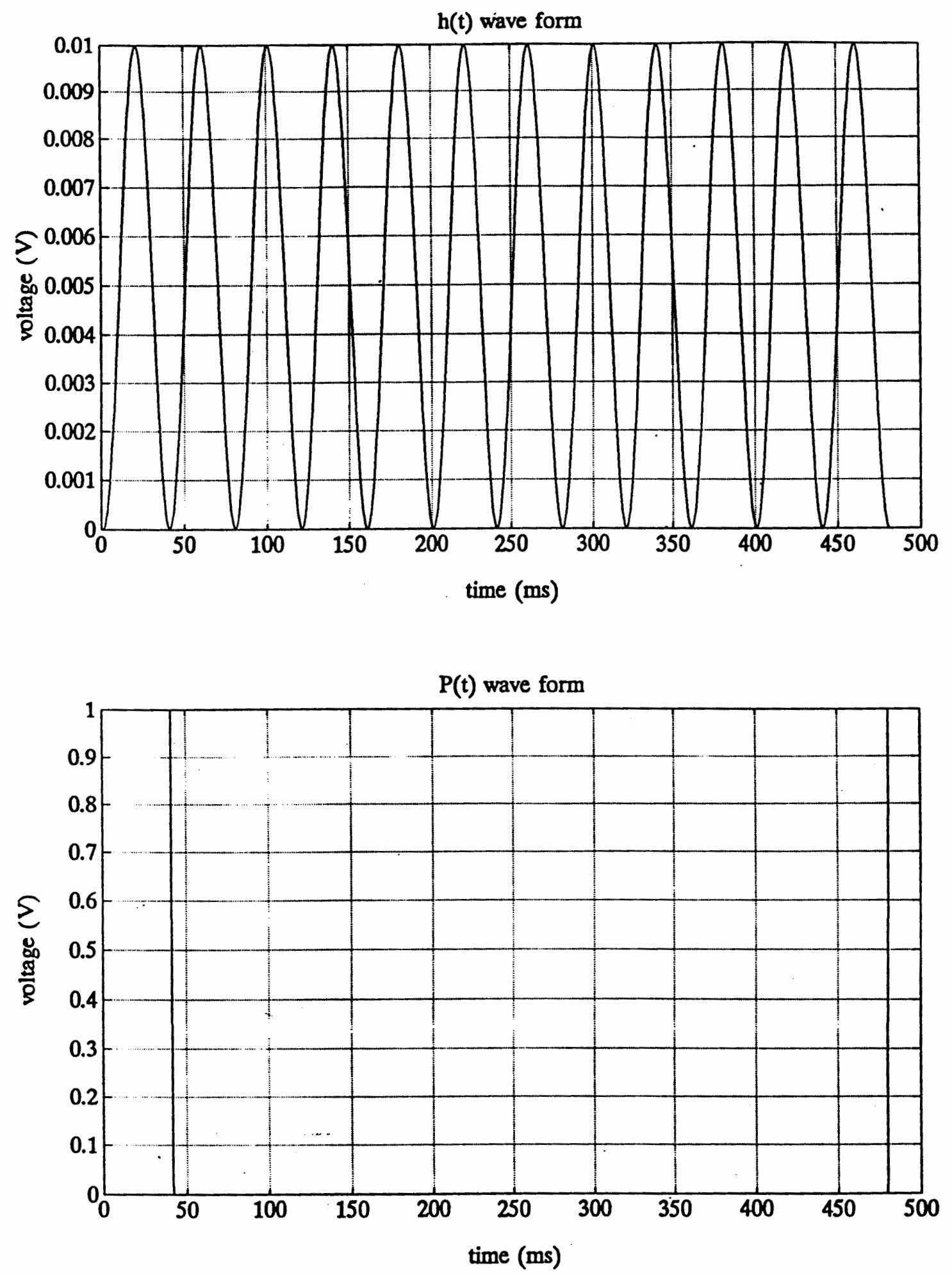

Figure 5. Graphs of waveform $h(t)$ and $P(t)$. 


\section{ATRIAL REPRESENTATION}

In order to create a model to test the proposed filters, it was necessary to simulate the atrial contraction as represented by a haversine signal waveform. The depolarization and subsequent contraction of the atrial produces a $\mathrm{P}$ wave with the following characteristics:

- $\quad$ Amp $=5 \mathrm{mV}$ peak (amplitude)

- $\quad \mathrm{PW}=15 \mathrm{msec}$ (pulse width)

- $\operatorname{Per}=400$ to $1000 \mathrm{msec}$ (period)

\section{Atrial Waveform}

The haversine waveform component represented by: $y(t)=h(t) * P(t), P(t)$ is a square wave. The duty cycle of this wave $(\mathrm{P}(\mathrm{t}))$ can be adjusted in the simulation to meet with requirements in the simulation.

Figure 6 shows the waveform of the atrial haversine signal with the amplitude is 5 $\mathrm{mV}$, pulse width is $15 \mathrm{msec}$, period is $480 \mathrm{msec}$.

\section{Atrial Spectrum}

The spectrum of the atrial haversine is continuous, exiting at every value of $\mathrm{fr}$ equency w.

At $\mathrm{w}=0$, the amplitude of the spectrum represents the area under the haversine curve. FFT is calculated at the sampling frequency of $1000 \mathrm{~Hz}$, with 1024 points FFT, and one period interval.

Since $f(n)=T d * f(n * T d)$, the result of the magnitude spectrum are multiplied by the sampling period.

Figure 7 shows the frequency spectrum of the atrial haversine. At w $=0 \mathrm{~Hz}$, the 
magnitude spectrum is 0.0375 . So, the dc level of the atrial haversine is $0.0375 \mathrm{mV}$ (a dc signal has only one frequency component at $\mathrm{w}=0$ ).
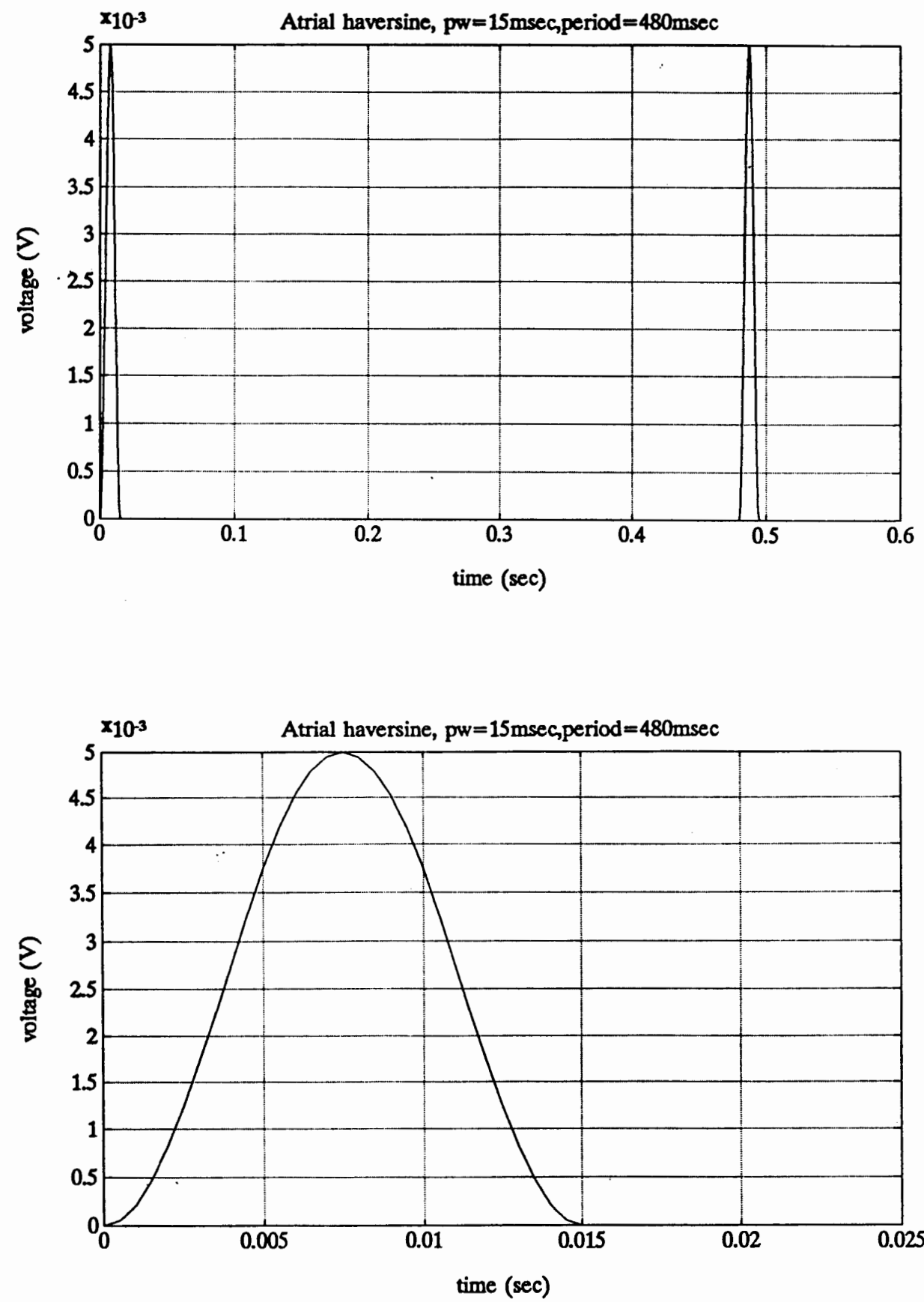

Figure 6. Atrial signal. 


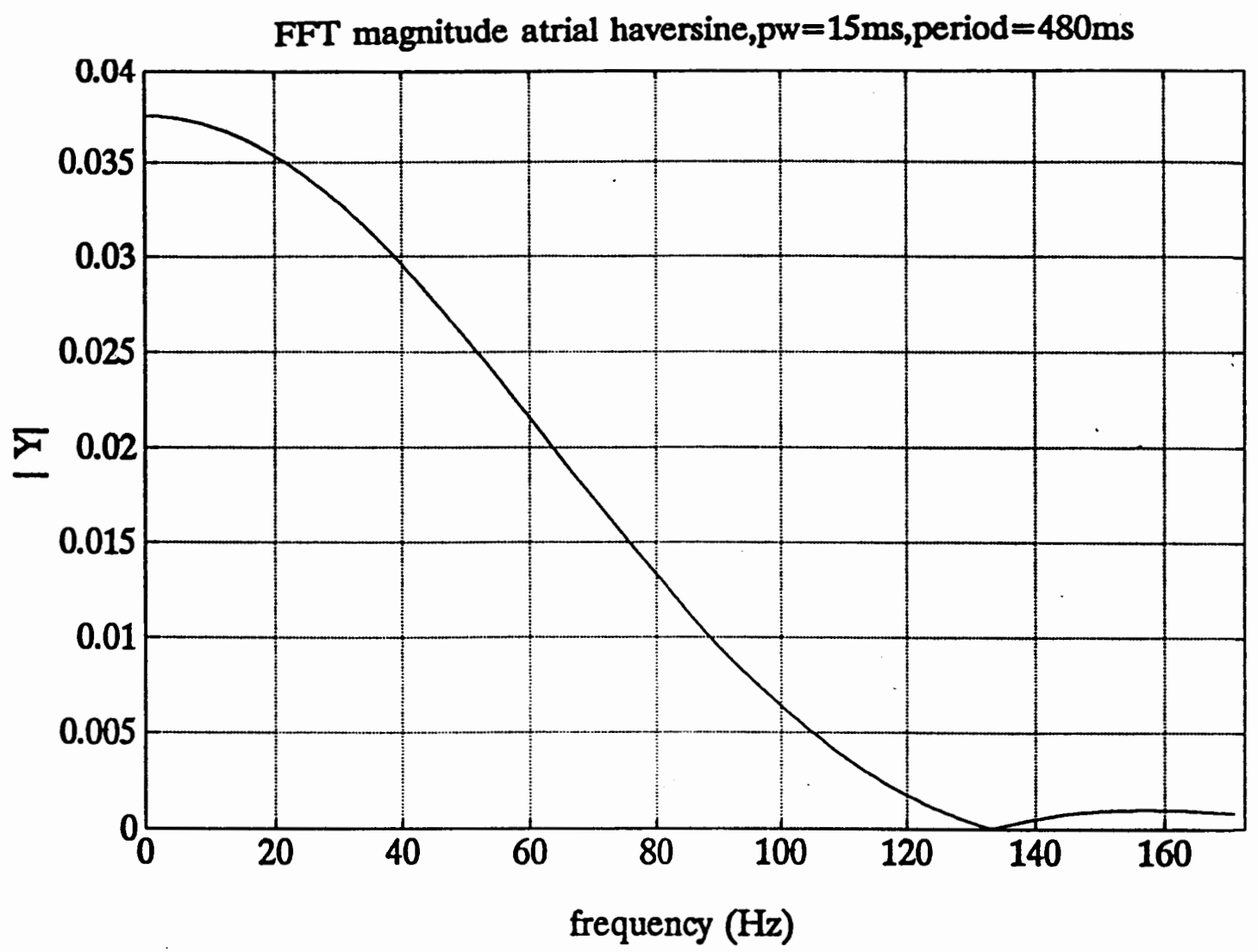

Figure 7. Atrial spectrum analysis.

\section{VENTRICULAR REPRESENTATION}

In order to create a model to test the proposed filters, it was necessary to simulate the ventricular contraction as represented by a haversine signal waveform. The depolarization and subsequent contraction of the ventricular produces a QRS wave with the following characteristics:

- $\quad A m p=10 \mathrm{mV}$ peak (amplitude)

- $\quad \mathrm{PW}=40 \mathrm{msec}$ (pulse width)

- $\quad$ Per $=400$ to $1000 \mathrm{msec}$ (period) 


\section{Ventricular Waveform}

In Figure 8, the haversine waveform component represented by: $y(t)=h(t) * P(t)$, $\mathrm{P}(\mathrm{t})$ is a square wave. The duty cycle of this wave can be adjusted in the simulation to meet with requirements in the simulation.

\section{Ventricular Spectrum}

The spectrum of the ventricular haversine is continuous, exiting at every value of frequency $w$.

At $\mathrm{w}=0$, the amplitude of the spectrum represents the area under the haversine curve. The FFT is calculated at the sampling frequency of $1000 \mathrm{~Hz}$, with 1024 points FFT, and one period interval.

Since $f(n)=T d * f(n * T d)$, the result of the magnitude spectrum are multiplied by the sampling period.

Figure 9 shows the frequency spectrum of the ventricular haversine. At $\mathrm{w}=0 \mathrm{~Hz}$, the magnitude spectrum is 0.2 . So, the dc level of the ventricular haversine is $0.2 \mathrm{mV}$ (a $\mathrm{dc}$ signal has only one frequency component at $\mathrm{w}=0$ ). This number $0.2 \mathrm{mV}$ is very important because it is compared with the magnitude spectrum of the exponential noise in later chapter.

Calculating the FFT of the haversine signal, the exponential noise and the myopotential noise will define what type of digital filters can be used to remove the exponential noise and the myopotential noise.

Remember that, if the voltage amplitude of the pacing pulse is large enough to stimulate the heart then the haversine signal will respond immediately after the pacing pulse. 

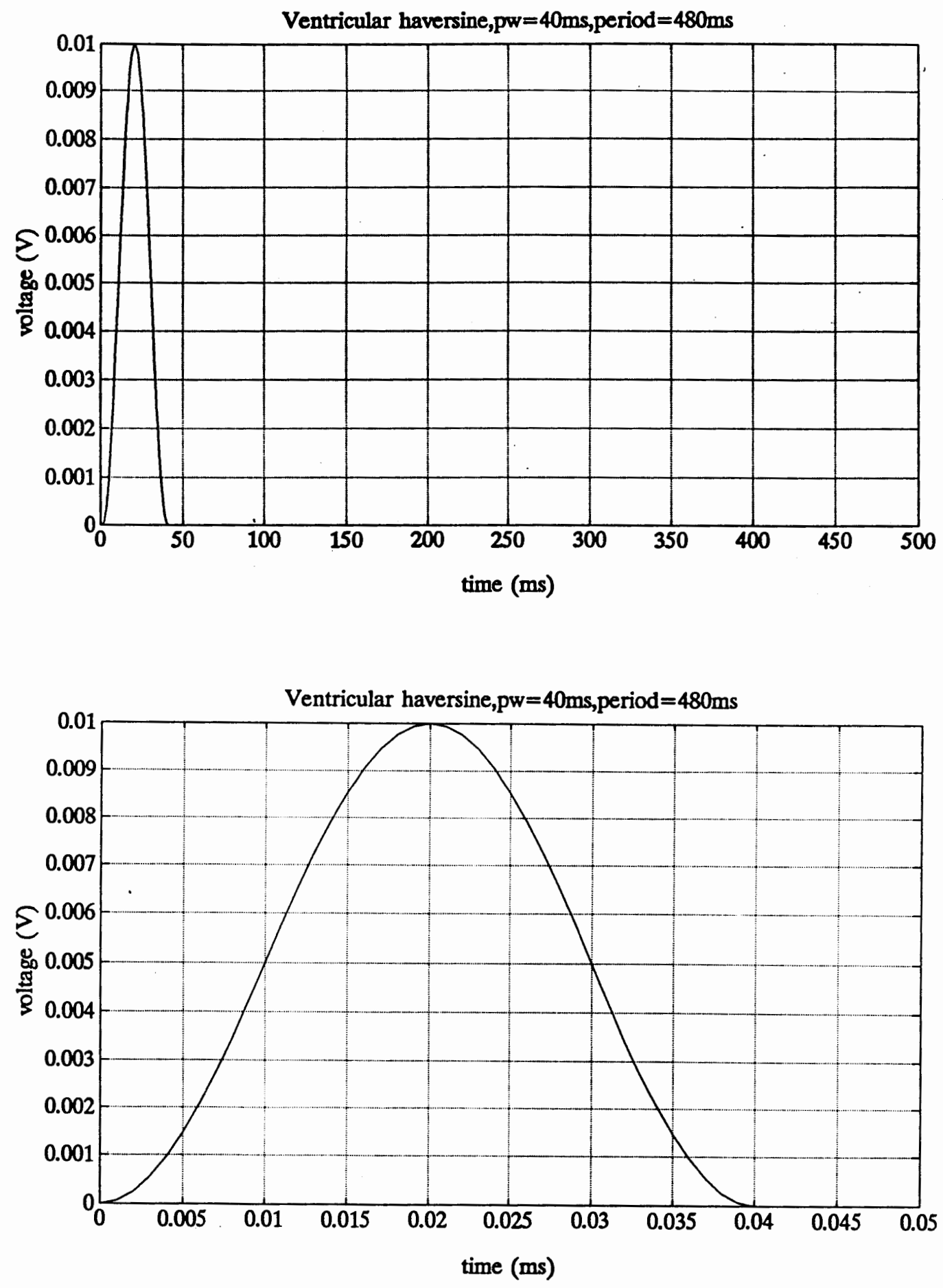

Figure 8. Ventricular signal. 

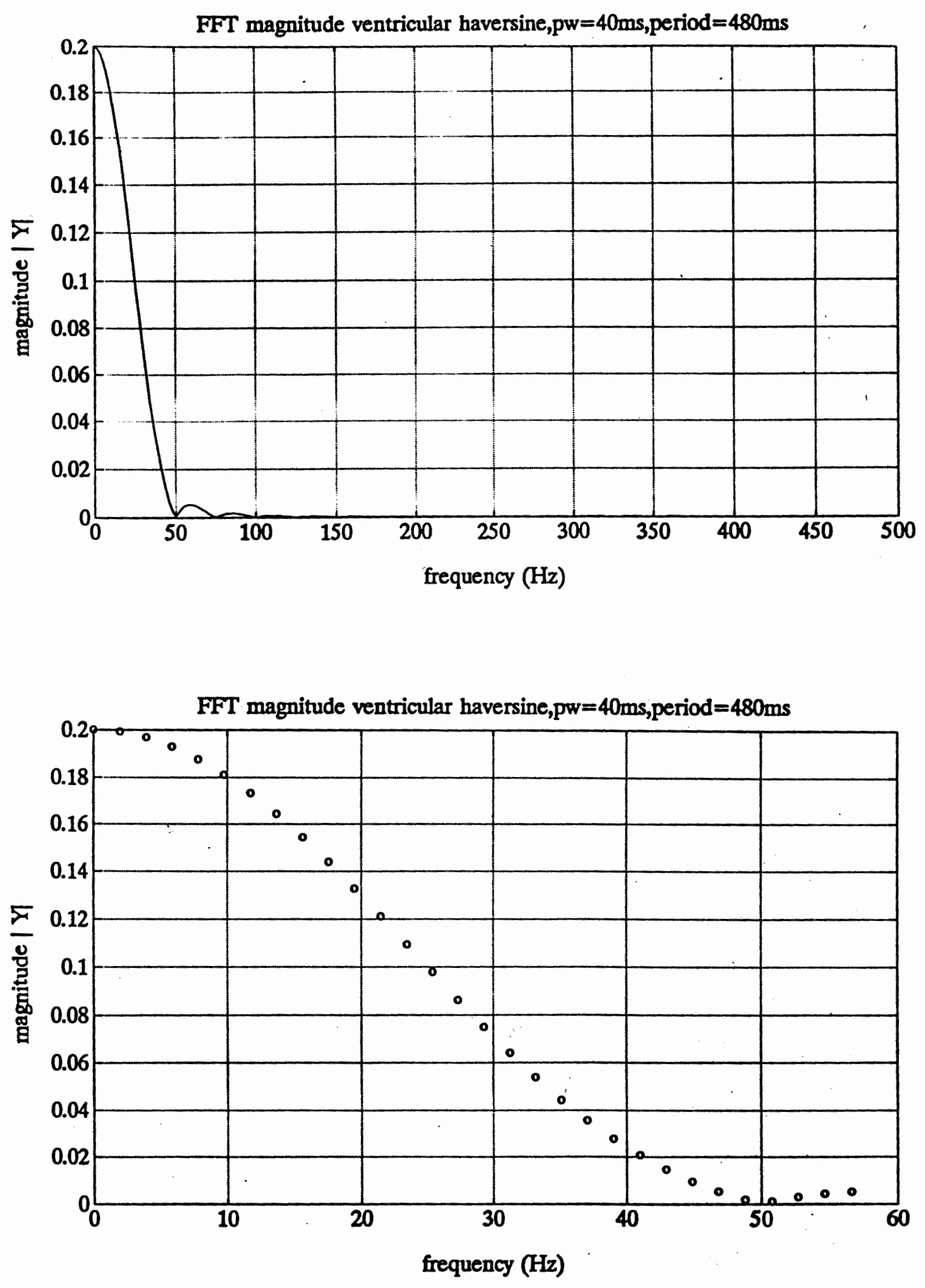

Figure 9. Ventricular spectrum analysis. 


\section{ATRIAL/NENTRICULAR REPRESENTATION}

For practical purposes, it was necessary to simulate the combined atrial/ventricular action. The atrial contracts to empty the blood into the ventricular. After a time interval delay, the ventricular contracts to empty blood into the arterial system. Both the atrial and the ventricular signals are represented in the simulation by with haversine signals.

\section{Atrial/Ventricular Waveform}

Figure 10 shows that the amplitude of the atrial is $5 \mathrm{mV}$ and the amplitude of the ventricular is $10 \mathrm{mV}$. The pulse width of atrial is $15 \mathrm{msec}$, and the pulse width of the ventricular is $40 \mathrm{msec}$. The atrial interval is $480 \mathrm{msec}$, and the ventricular interval is 480 msec. The atrial-ventricular delay is equal to $100 \mathrm{msec}$.

As before, $\mathrm{y}(\mathrm{t})=\mathrm{h}(\mathrm{t}) * \mathrm{P}(\mathrm{t}), \mathrm{P}(\mathrm{t})$ is a square wave, and the duty cycle can be adjusted to meet wave characteristic requirements for the simulation.

The delay interval is computed from tav $=\mathrm{AV}$ delay interval.

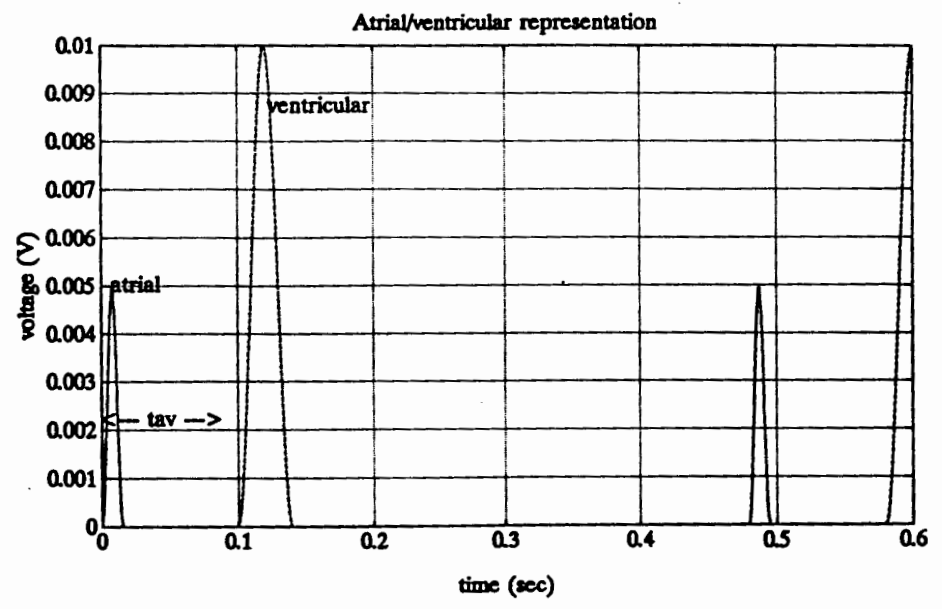

Figure 10. Atrial/ventricular signal. 


\section{SOFTWARE}

This section contains the section of MATLAB code that simulates the atrial pulse (pwa), the ventricular pulse (pwv), the duty cycle, and then produces a ventricular haversine with a period of $480 \mathrm{msec}$ and a pw of $40 \mathrm{msec}$. To achieve an even number of duty cycles, an atrial period of $480 \mathrm{msec}$ was chosen and a ventricular period of $960 \mathrm{msec}$ was chosen.

The FFT is calculated at the sampling frequency $=1000 \mathrm{~Hz}$, and 1024 points FFT.

Again, $f(n)=T d * f(n * T d)$. So, the result of the magnitude spectrum must be multiplied by the sampling period.

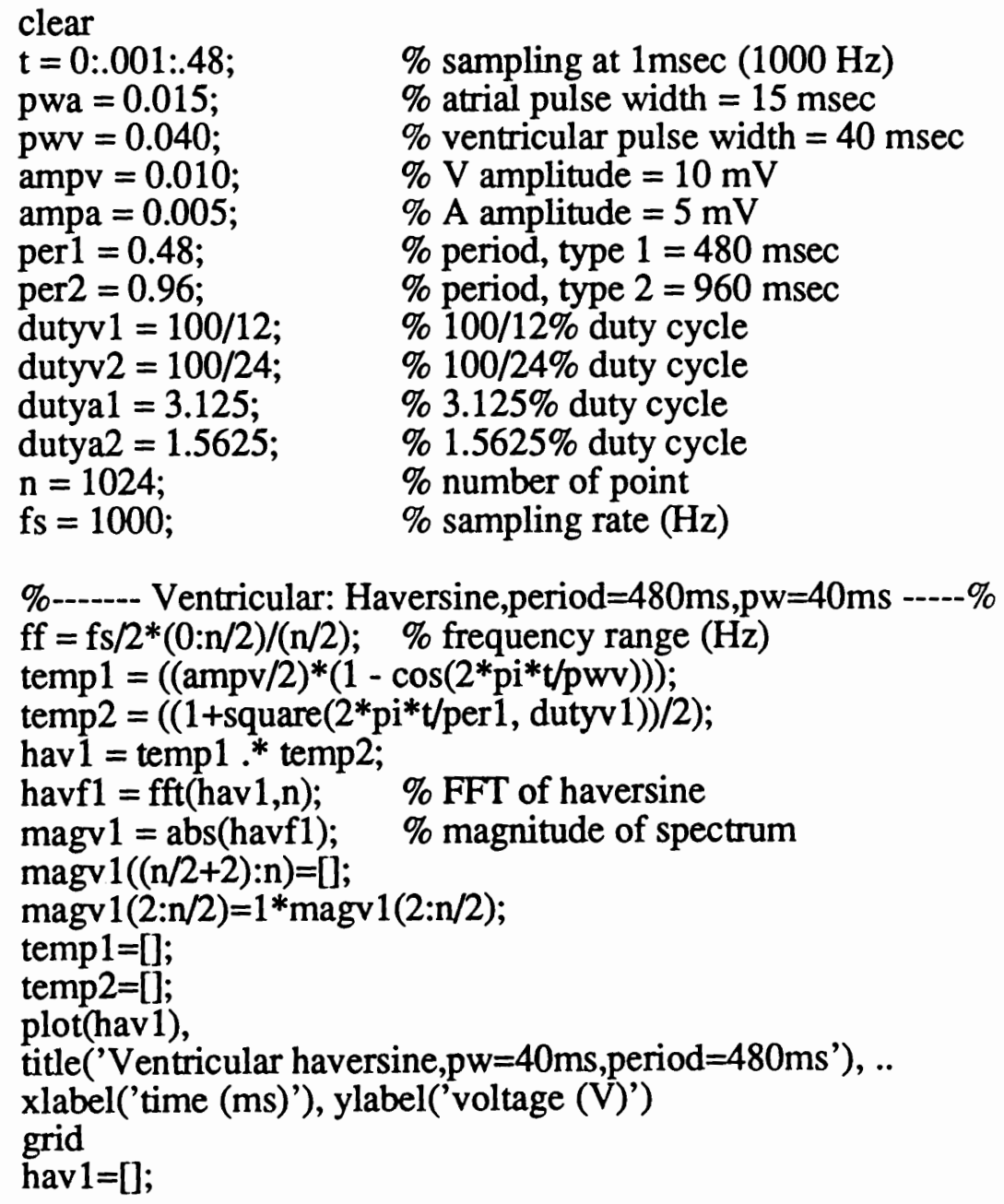


$\operatorname{plot}(\mathrm{ff}(1: 200)$, magv1(1:200)),

title('FFT magnitude ventricular, $\mathrm{pw}=40 \mathrm{~ms}$, period $=480 \mathrm{~ms}$ '), ..

xlabel('frequency (Hz)'), ylabel('|Y|')

grid

magv1=[];

\%--..-- Ventricular: haversine,period $=960 \mathrm{~ms}, \mathrm{pw}=40 \mathrm{~ms}-\ldots . .-. \%$

temp3 $=\left((\operatorname{ampv} / 2) *\left(1-\cos \left(2 * \mathrm{pi}^{*} \mathrm{t} / \mathrm{pwv}\right)\right)\right) ;$

temp $4=((1+$ square $(2 *$ pi*t/per 2 , dutyv 2$)) / 2) ;$

hav2 $=$ temp3 $*$ temp 4

havf $2=\mathrm{fft}($ hav $2, \mathrm{n})$

magv2 = abs(havf2);

$\operatorname{magv} 2((\mathrm{n} / 2+2): \mathrm{n})=[]$

$\operatorname{magv} 2(2: n / 2)=1 * \operatorname{magv} 2(2: n / 2)$;

temp $3=[] ;$

temp4=[];

plot(hav2),

title('Ventricular haversine, $\mathrm{pw}=40 \mathrm{~ms}$, period=960ms'), ..

xlabel('time (ms)'), ylabel('voltage (V)')

grid

hav2=[];

$\operatorname{plot}(f f(1: 200)$,magv2(1:200)),

title('FFT magnitude ventricular haversine, $\mathrm{pw}=40 \mathrm{~ms}$, period $=960 \mathrm{~ms}$ '), ..

xlabel('frequency (Hz)'), ylabel('|Y|')

grid

$\operatorname{magv2}=[]$;

\%-----Atrial: haversine,period $=480 \mathrm{~ms}, \mathrm{pw}=15 \mathrm{~ms}--.-. \%$

temp $5=(($ ampa/2)*(1- $\cos (2 * \mathrm{pi} * \mathrm{t} / \mathrm{pwa})))$

temp $6=((1+$ square $(2 *$ pi*t/per 1, dutya1 $)) / 2) ;$

haa1 $=$ temp5 $*$ temp6;

haaf $1=\mathrm{fft}($ haa $1, \mathrm{n})$;

maga1 = abs(haaf1);

$\operatorname{magal}((\mathrm{n} / 2+2): \mathrm{n})=[]$

$\operatorname{maga} 1(2: \mathrm{n} / 2)=1 * \operatorname{maga} 1(2: \mathrm{n} / 2)$;

temp5=[];

temp6 $=[] ;$

plot(haa1),

title('Atrial haversine,pw $=15 \mathrm{~ms}$, period $=480 \mathrm{~ms}$ '), ..

xlabel('time (ms)'), ylabel('voltage (V)')

grid

plot(ff(1:200),maga1(1:200)),

title('FFT magnitude atrial haversine, $p w=15 \mathrm{~ms}$, period $=480 \mathrm{~ms}$ '), ..

xlabel('frequency (Hz)'), ylabel('|Y|')

grid

maga 1=[];

\%---.-Atrial: haversine,period $=960 \mathrm{~ms}, \mathrm{pw}=15 \mathrm{~ms}-\ldots$

temp $7=\left(\left(\right.\right.$ ampa/2)*(1- cos $\left.\left.\left(2 * \mathrm{pi}^{*} \mathrm{t} / \mathrm{pwa}\right)\right)\right) ;$

temp8 $=((1+$ square $(2 *$ pi $*$ t/per 2, dutya 2$)) / 2)$;

haa2 $=$ temp7 $*$ temp8; 


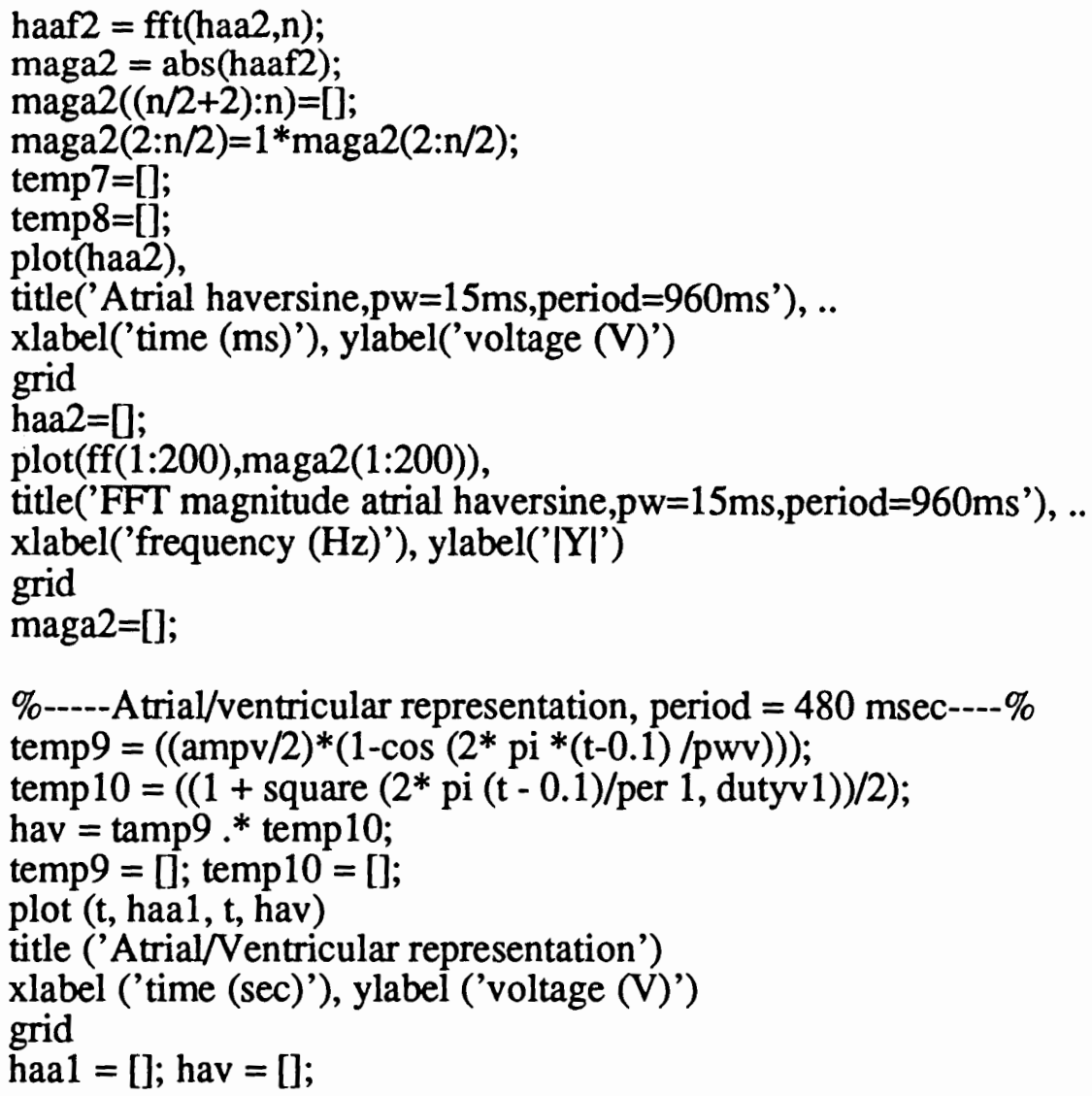




\section{CHAPTER IV}

\section{MYOPOTENTIAL NOISE}

This chapter describes the natural occurrence of myopotential noise, the sensitivity range for detection of myopotential noise, and the conflict between myopotential noise and ventricular output. Finally, code for creation of laboratory simulated myopotential noise is presented.

\section{UNIFORMLY DISTRIBUTED NOISE}

Simulated myopotential noise represents a uniformly distributed random noise which is generated by skeletal muscle tissue. The myopotential noise has a frequency spectrum extending from 70 to $1000 \mathrm{~Hz}$. The amplitude varies from 2 to $5 \mathrm{mV}$. Simulated Exponential noise represents the depolarization effects of a pacing pulse as seen at the active cardiac lead. The amplitude is very large, $\sim 1$ volt.

Myopotential noise results from random signals and can frequently be observed on ECGs. For the purpose of this work, myopotential noises can be assumed to be transient bursts of uniformly distributed noise that typically has a frequency spectrum extending from 70 to $1000 \mathrm{~Hz}$ and amplitudes in the 2 to $5 \mathrm{mV}$ range.

When unwanted signals such as myopotentials are sensed, the pulse generator is often inappropriately inhibited; oversensing myopotential noise is one of the more common failings of unipolar pacing. Sometimes over sensing of myopotential noise occurs with bipolar configurations as well.

A unipolar lead configuration has one conducting wire and an electrode. The pulse 
generator uses body fluids for its return pathway (Figure 11). A bipolar lead has two conducting wires inside its insulation. The electrical signal travels down one wire to an electrode, passes through the myocardium, causing the heart to depolarize and contract, and returns by the second electrode (Figure 12).

Pacemakers designed for atrial application with a sensitivity of 0.5 to $1 \mathrm{mV}$ are always influenced by myopotential noise.

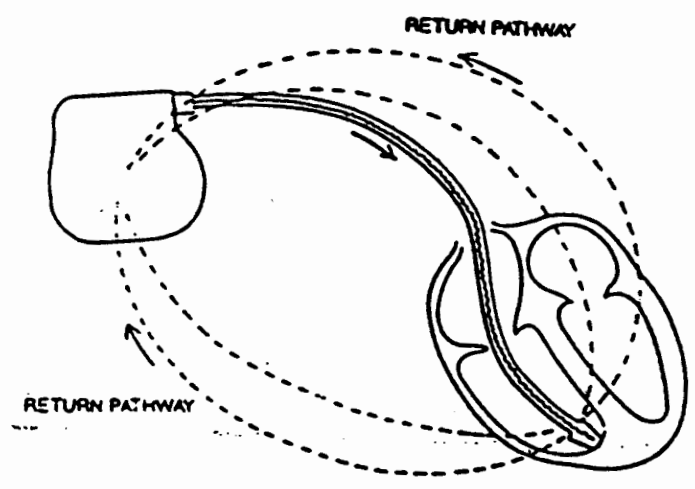

Figure 11. Unipolar lead system.

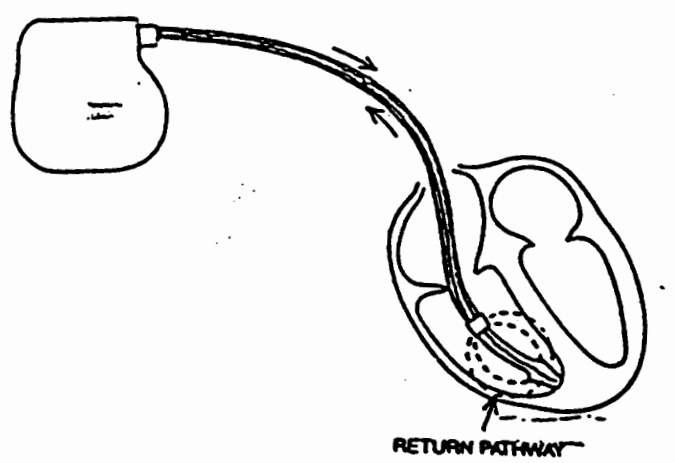

Figure 12. Bipolar lead system. 
Figure 13 shows the sensitivity curve for sensing an $R$ wave. The amplitude of the myopotential is in the 1 to $2.5 \mathrm{mV}$ range and the frequency is in the 70 to $1000 \mathrm{~Hz}$ range. Figure 14 shows the simulated ventricular output with the myopotential noise which inhibits the ventricular output because the ventricular lead senses the muscle activity which interferes with the atrial signal. Figure 15 shows a tape record of the myopotential signals.

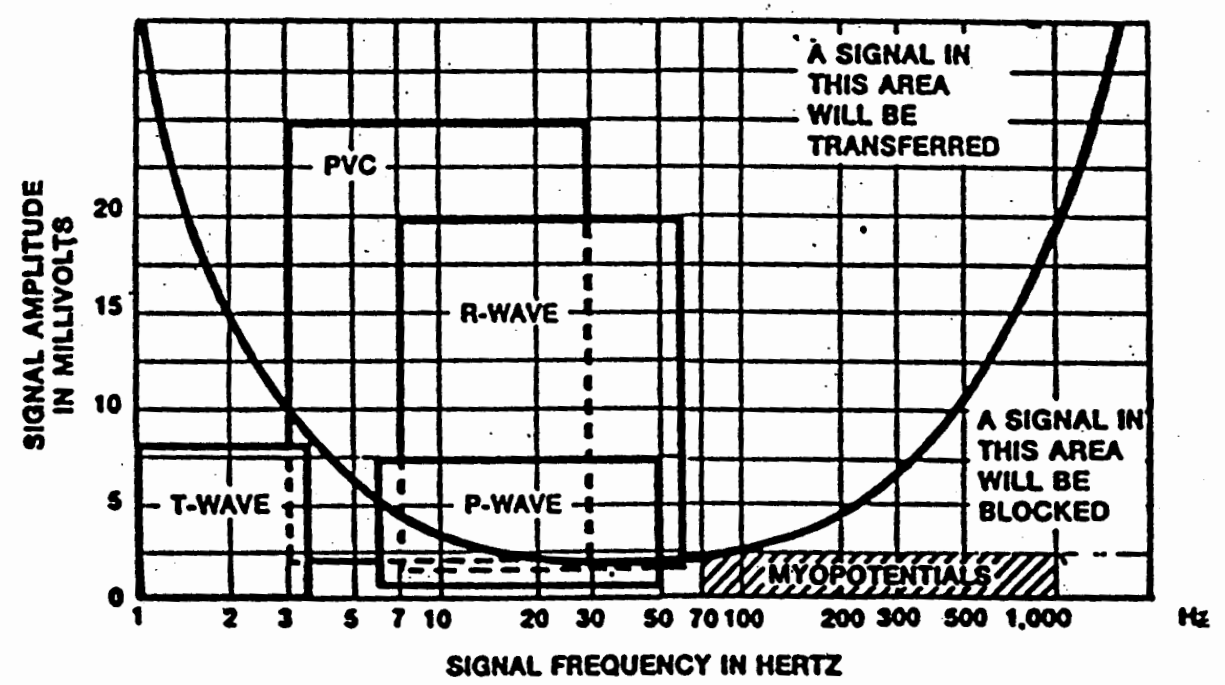

Figure 13. Sensitivity curve for sensing $\mathrm{R}$ waves.

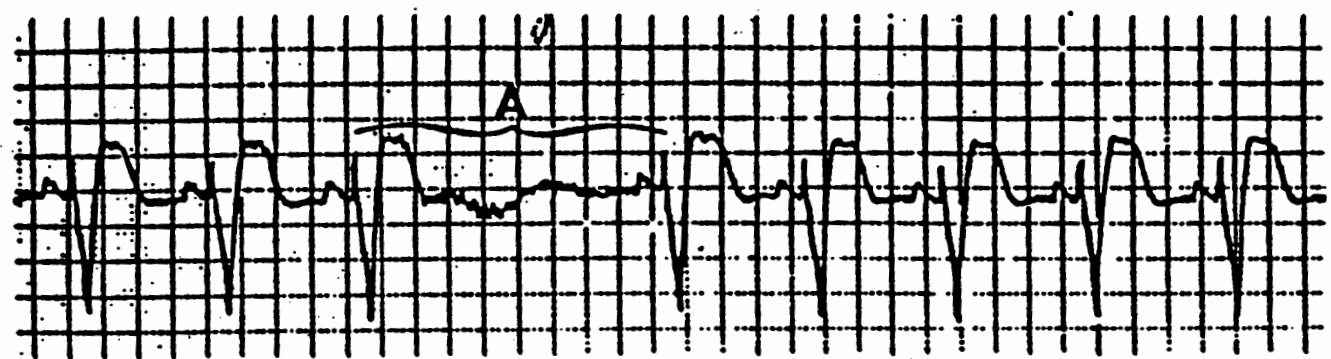

Figure 14. An atrial pacing with myopotential interference. During the interference, the ventricular lead senses muscle activity and inhibits ventricular output. 


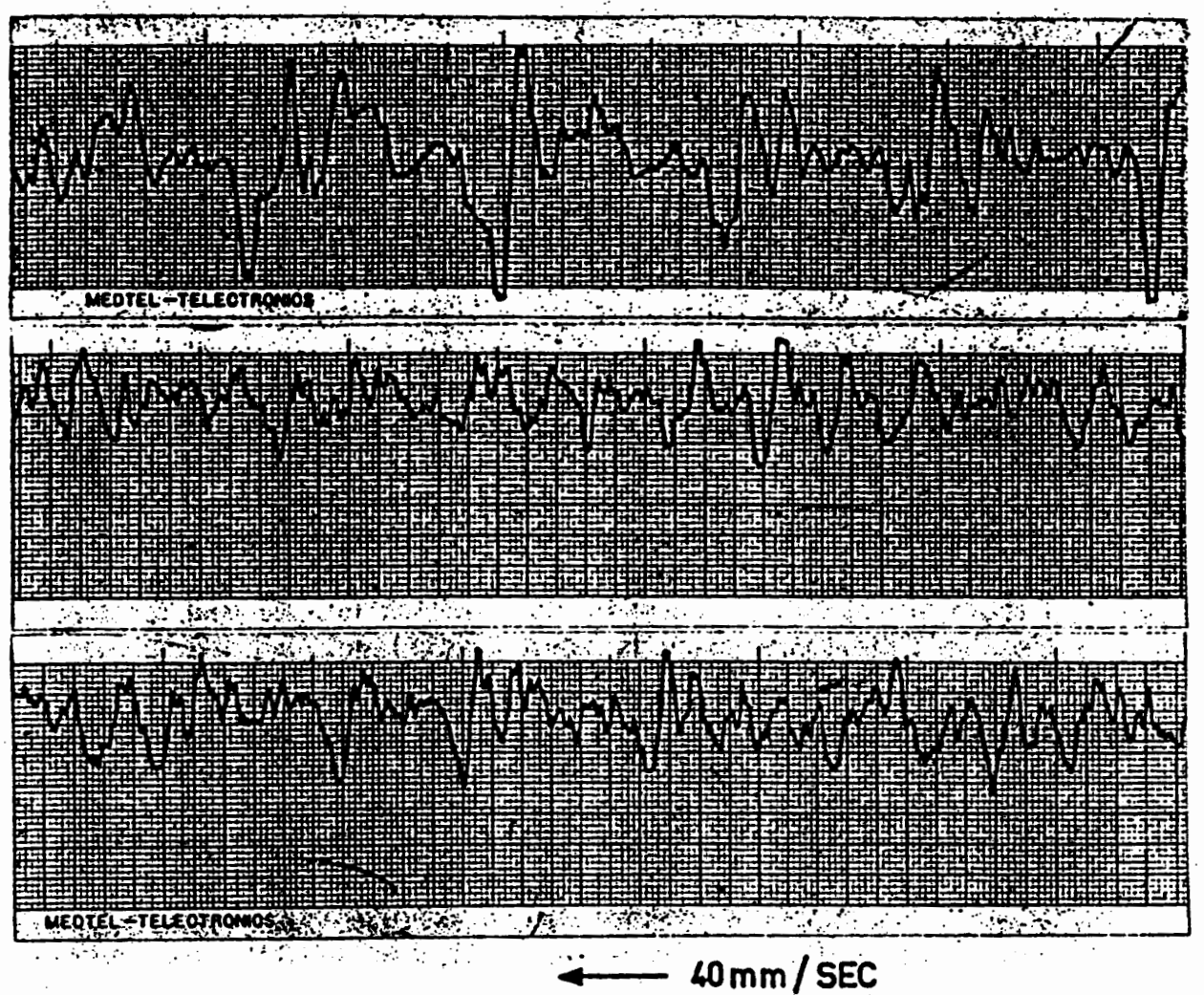

Figure 15. Examples of tape recorded myoelectric signals.

For the simulation, myopotential noise is generated by sending uniformly distributed random noise to through a bandpass filter with a pass band from 70 to $1000 \mathrm{~Hz}$. Figure 16 shows the uniformly distributed random noise with amplitudes in the 1 to 5 $\mathrm{mV}$ range. Figure 17 shows the bandpass filter, a Chebyshev type I set to order 8 , where ripple is equal to $0.1 \mathrm{~dB}$ in the pass band. Figure 18 shows the myopotential noise waveform. Figure 19 shows the frequency spectrum of myopotential noise created by filtering with the bandpass filter, as described above. 


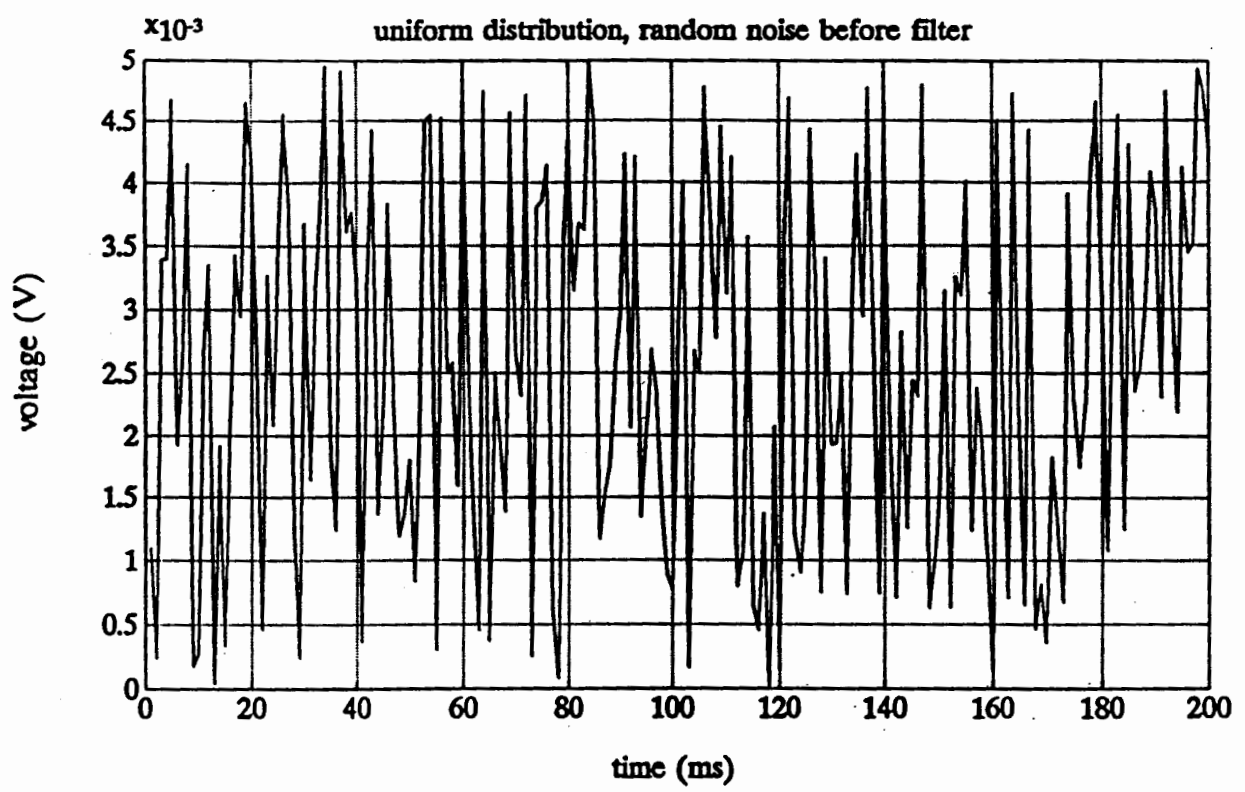

Figure 16. Uniformly distributed random noise.

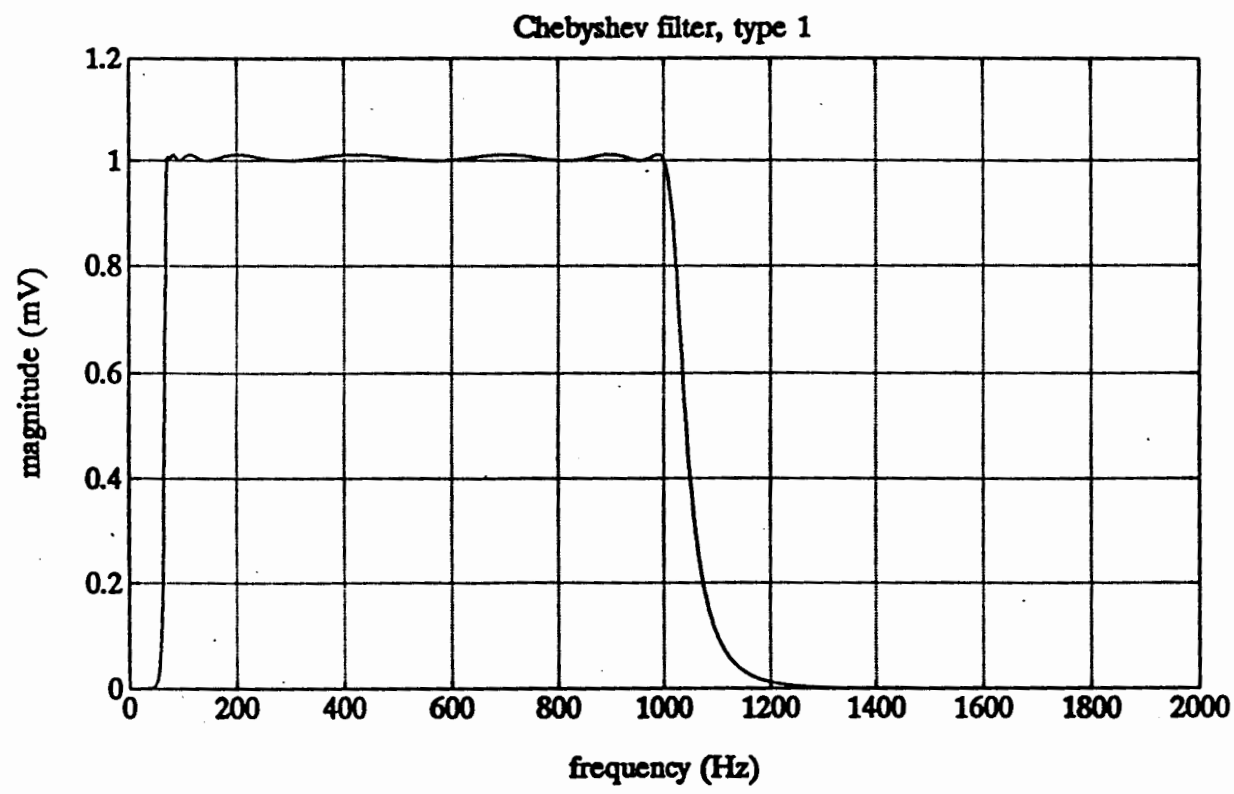

Figure 17. Chebyshev type I, bandpass filter order 8 th, pass band: $70 \mathrm{~Hz}$ to $1000 \mathrm{~Hz}$. 


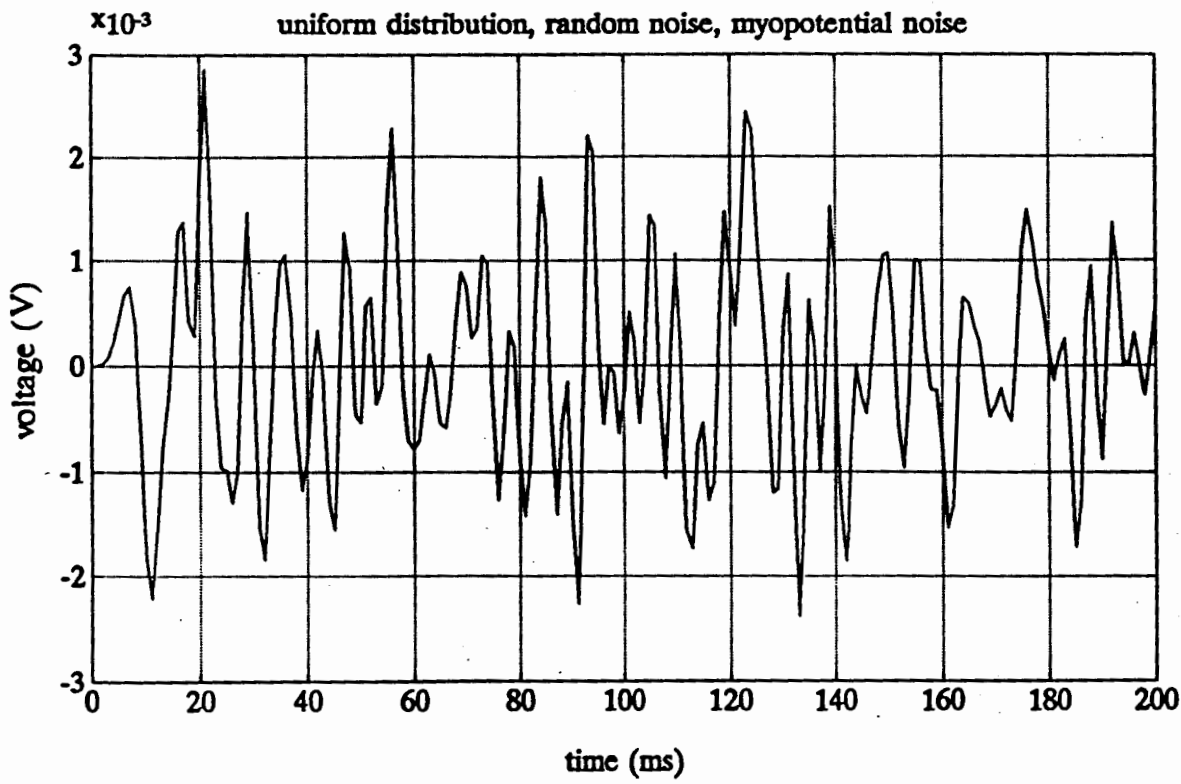

Figure 18. Myopotential noise.

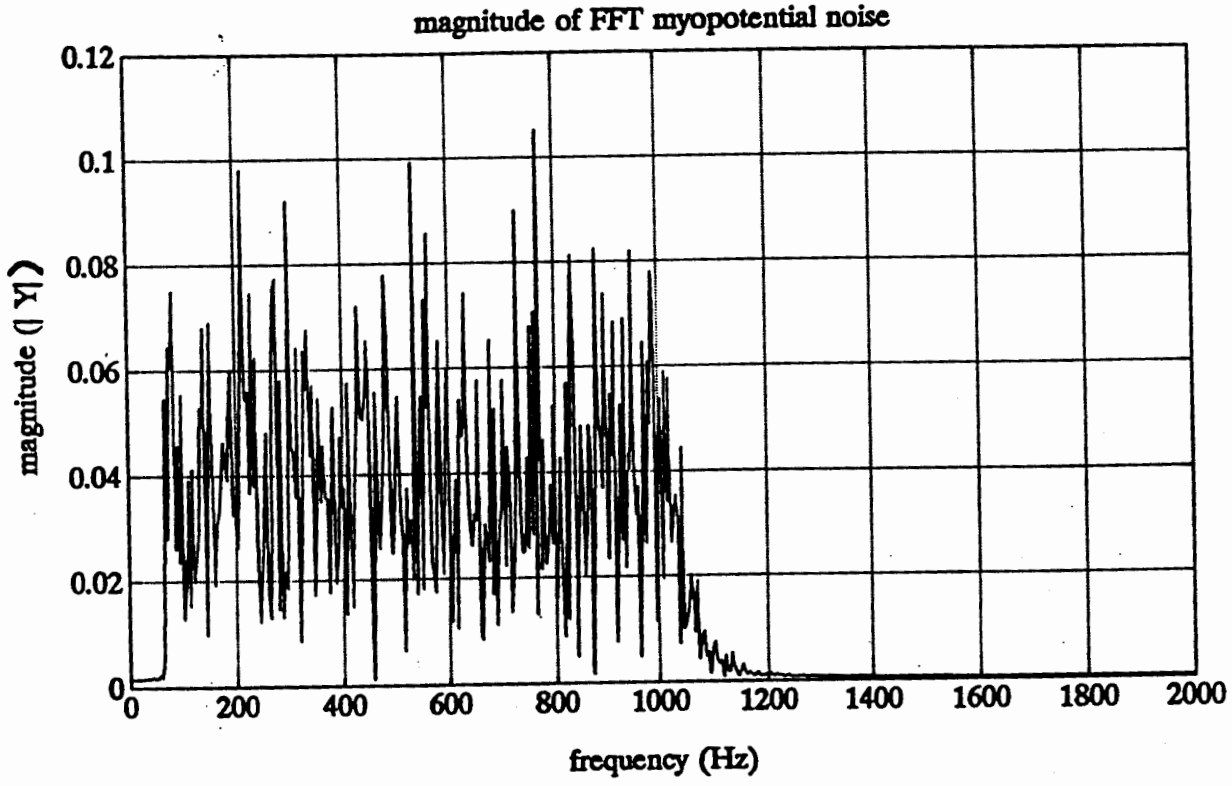

Figure 19. Spectrum of myopotential noise. 


\section{SOFTWARE}

The following MATLAB code was used to simulate myopotential noise. The code creates a uniformly distributed random noise. The signal amplitude is $5 \mathrm{mV}$, and the sampling frequency is $2500 \mathrm{~Hz}$. This signal is filtered by a bandpass filter. The filter is a Chebyshev type I. Ripple is at pass band $.1 \mathrm{db}$, order is 8 th, and the pass band is from 70 to $1000 \mathrm{~Hz}$.

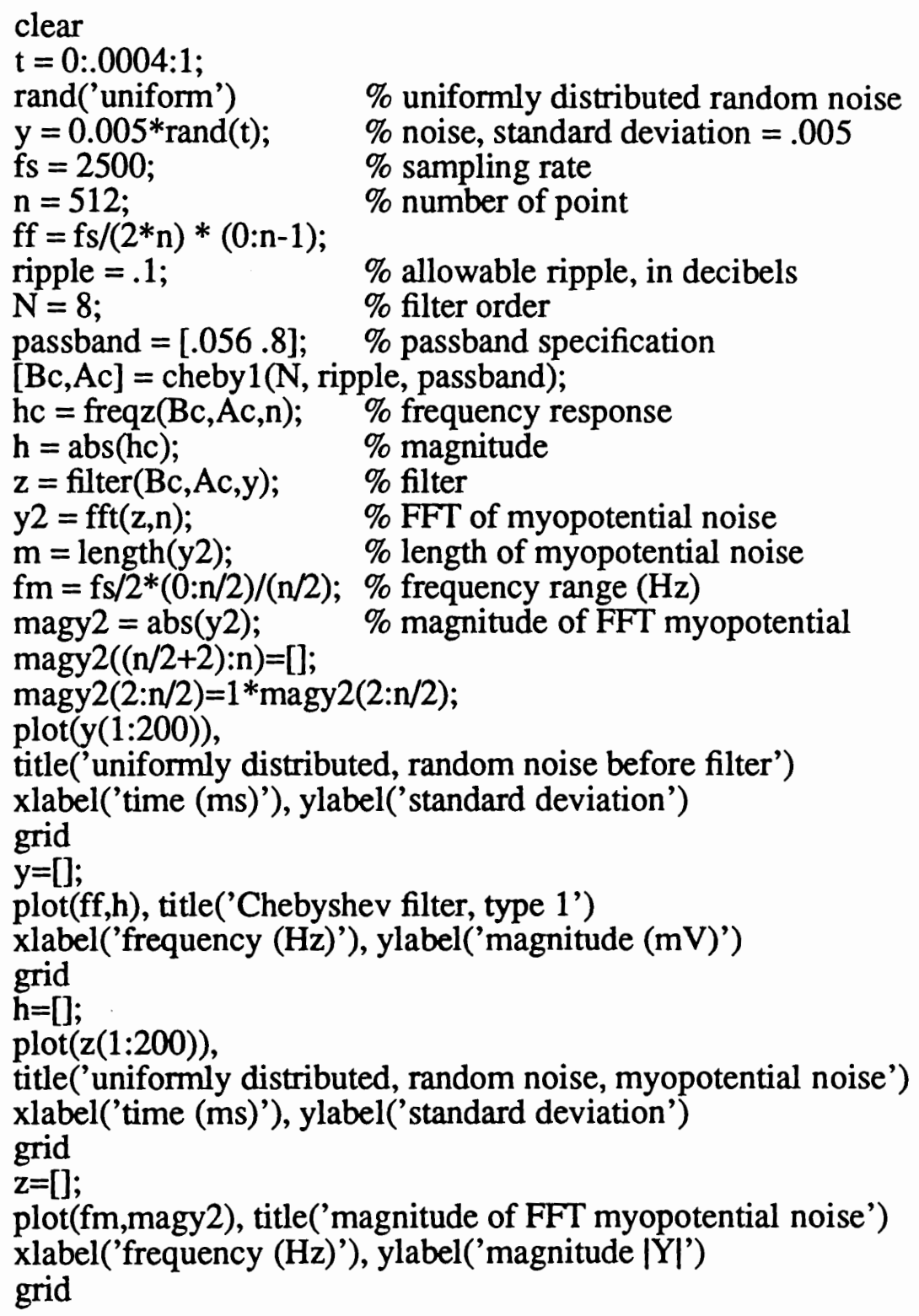




\section{CHAPTER V}

\section{EXPONENTIAL NOISE}

This chapter defines and describes the "pulse interval." The chapter then describes the division of a pacing pulse into 3 parts, the conflict between exponential noise and the pacemaker's ability to register the heart's response to a pacing pulse, the possible causes of exponential noise, and the reasons a bandpass filter can not remove exponential noise. Finally, the code used to simulate exponential noise is presented.

\section{PACE PULSE}

A pacemaker delivers a small electrical pulses during an appropriate millisecond interval to produce a desired heart rate. A typical pulse interval which results in a pulse rate of 72 pulses per minute (ppm) is $833 \mathrm{msec}$. The time periodic between pulses of electrical energy, or the distance between two pacings, is the pulse interval.

The output pulse of a pacemaker has a typical shape and time duration, depending on the type of circuitry. Figure 20 shows a typical artifact magnified on an oscilloscope.

Pulse width is the time during which electrical energy is being delivered to the heart as measured from the leading edge to the trailing edge of the pace pulse.

The voltage amplitude of the output pulse and the impedance of the lead pacing system are related to electrical current flow. The measuring method differs from one manufacture to another.

Figure 21 shows the pulse width and the voltage amplitude of a pacing pulse on an oscilloscope (LeCroy 9400A Dual $175 \mathrm{MHz}$ oscilloscope). 


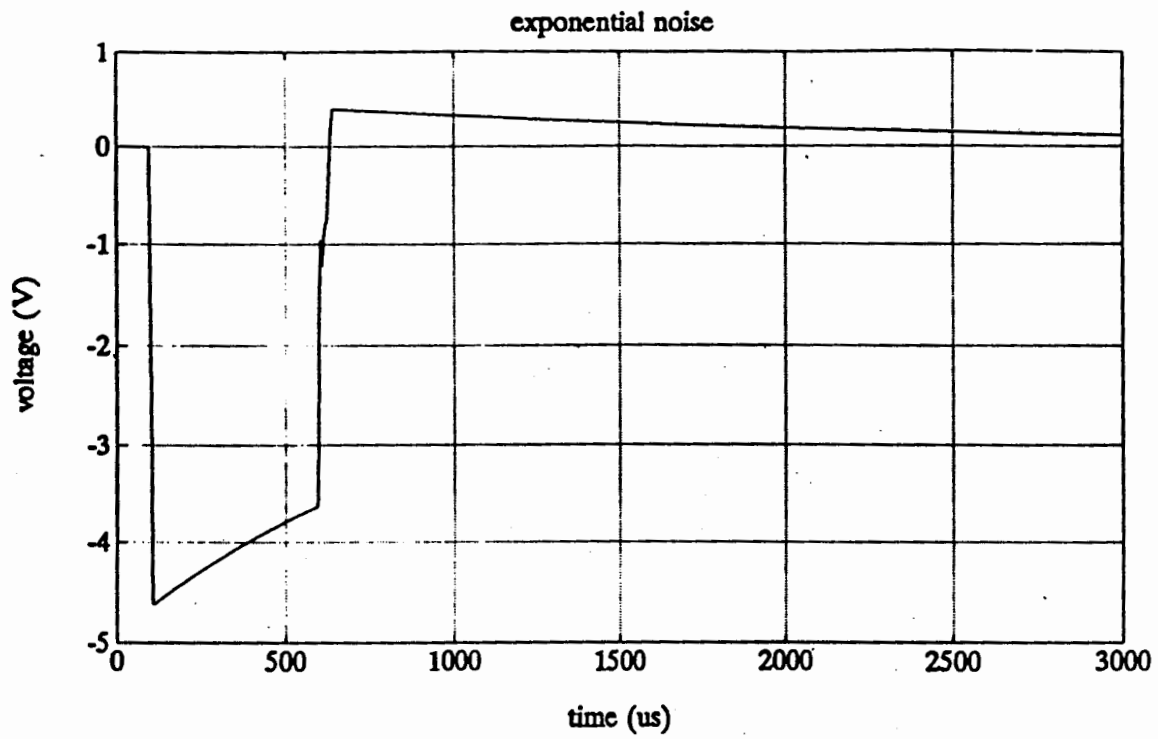

Figure 20. The pacing artifact.

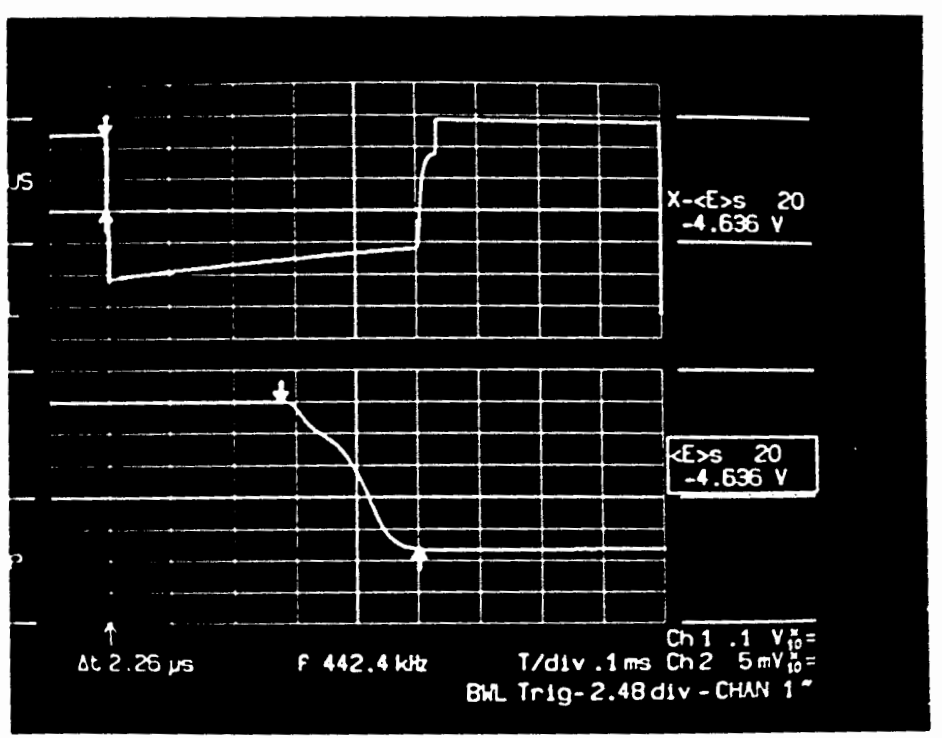

Figure 21. Pulse width $=530 \mathrm{~S}$ Amplitude $=-4.8 \mathrm{~V}$, LeCroy 9400A Dual $175 \mathrm{Mhz}$ scope. 
Normal pacemakers allow pulse width and voltage amplitude to be programmed to satisfy the requirements for each patient. In the simulation model, pulse width and voltage amplitude can be manipulated by changing the initial settings of the corresponding variables.

The pacing pulse shown in Figure 21 can be divided into three parts: exponential \#1; exponential \#2; exponential \#3 (Figure 22). Exponential \#3 is considered exponential noise.

Figure 21 describes the ventricular pacing pulse of the pacemaker. This pacemeker is one of the products of the MicroSystems Engineering company.

After the trailing edge of the pacing pulse, the pulse does not return immediately to ground level; rather, exponential signal decay after the trailing edge demonstrates that additional noises are produced by a pacemaker. This trailing edge noise is called exponential noise.

The amplitude of the exponential noise is very large ( 1 volt) compared to the voltage amplitude of the heart beat $(10 \mathrm{mV})$. The overlap of exponential noise on the $\mathrm{QRS}$ signal which identifies the heart beat makes it is difficult for a pacemaker to register the response of a heart immediately after a pacing pulse. Usually, a pacemaker has to wait a certain time until the voltage amplitude of the exponential noise decreases to a low enough level that the QRS is clear of the exponential noise. Only then the pacemaker can sense the heart beat clearly. At that time the pacemaker can read the QRS and respond by sending the next pace pulse or by suppressing a pace pulse. The important thing is how to design a digital filter to remove the exponential noise, and this problem will be solved in later chapters. 

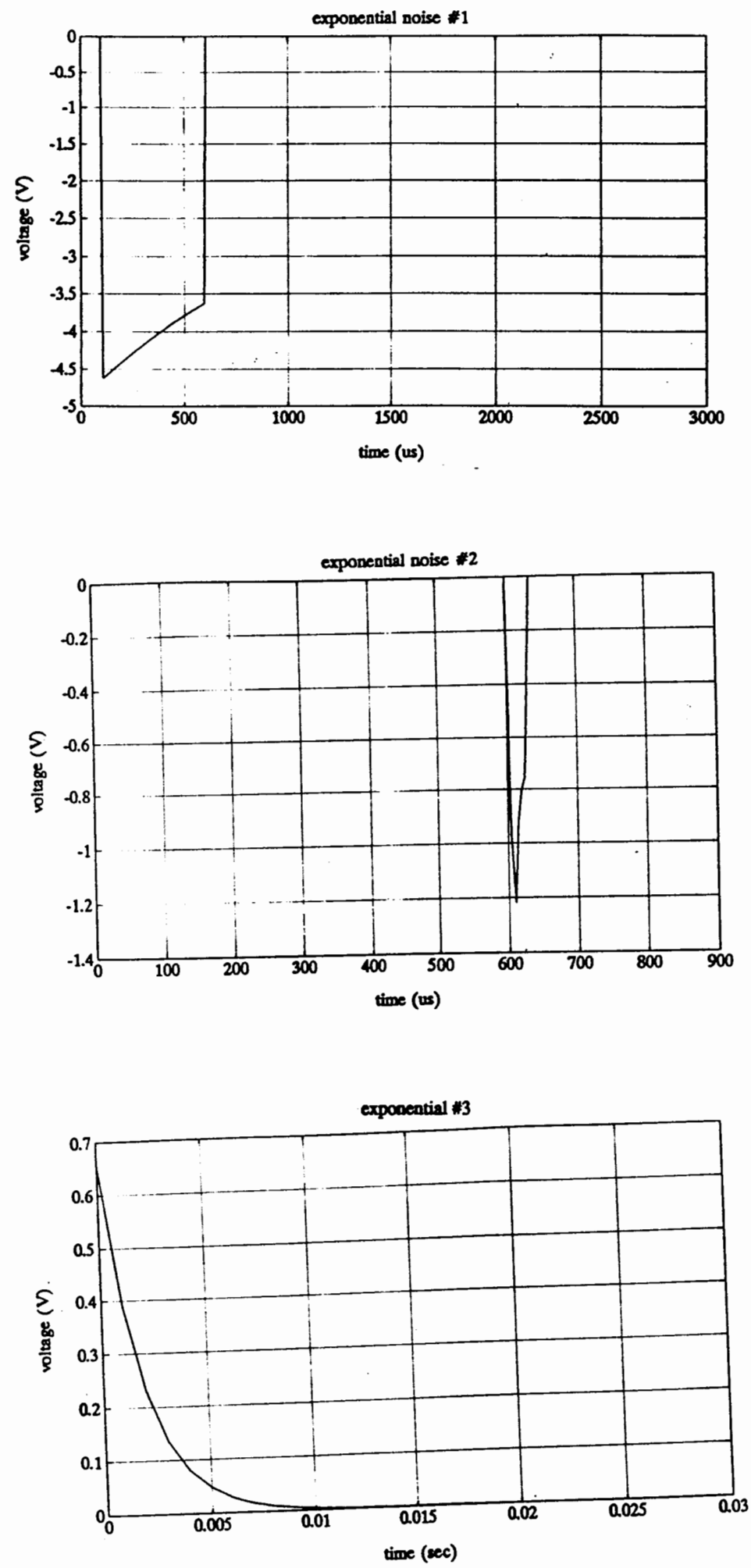

Figure 22. Detail of the pace pulse. 
Exponential noise results from a number of causes; however, the main cause is the contact of the surface lead with the muscle tissue of the body. This contact establishes capacitance between the lead and the muscle tissue. So, the amplitude and the time constant of the exponential ( which is also a function of time) varies from patient to patient, as well as from moment to moment. To minimize noise, manufacturers have designed many different lead configurations that reduce the surface area contact. Professor Dr. Max Schaldach, the author of "Electrotherapy of the Heart," described the electro/myocardium interface very clearly. He also places emphasis on selection of the electrode materials.

\section{Spectrum of Exponential Noise}

The spectrum of exponential noise is shown in Figure 23. At the point of generation in the simulation, the exponential noise spectrum is continuous. The pace pulse is considered a non-periodic signal at this sample point because of the assumption that the haversine happens immediately after the pace pulse. The non-periodic signal has a continuous spectrum. Sometimes the pace pulse is considered a periodic signal when the pacemaker works without sensing a response.

A pacemaker allows the heart to beat by itself if the heart can. The pacemaker will save energy during dormant times. The pacemaker will take over only when a heart cannot supply enough blood to the body.

Figure 23 shows the frequency spectrum of the exponential noise, at $0 \mathrm{~Hz}$ frequency the dc level is read $1.6 \mathrm{mV}$. The ventricular dc level is $0.2 \mathrm{mV}$ and the atrial dc level is $.0375 \mathrm{mV}$. The ratio between the exponential noise and the ventricular signal is 8:1, between the exponential noise and the atrial signal is $42: 1$.

Because the amplitude of the exponential noise is much higher than the amplitude of the haversine, there is no way to remove the exponential noise by using bandpass 
filters. Another difficulty is that the frequency spectrum of the exponential noise overlays the frequency spectrum of the haversine.

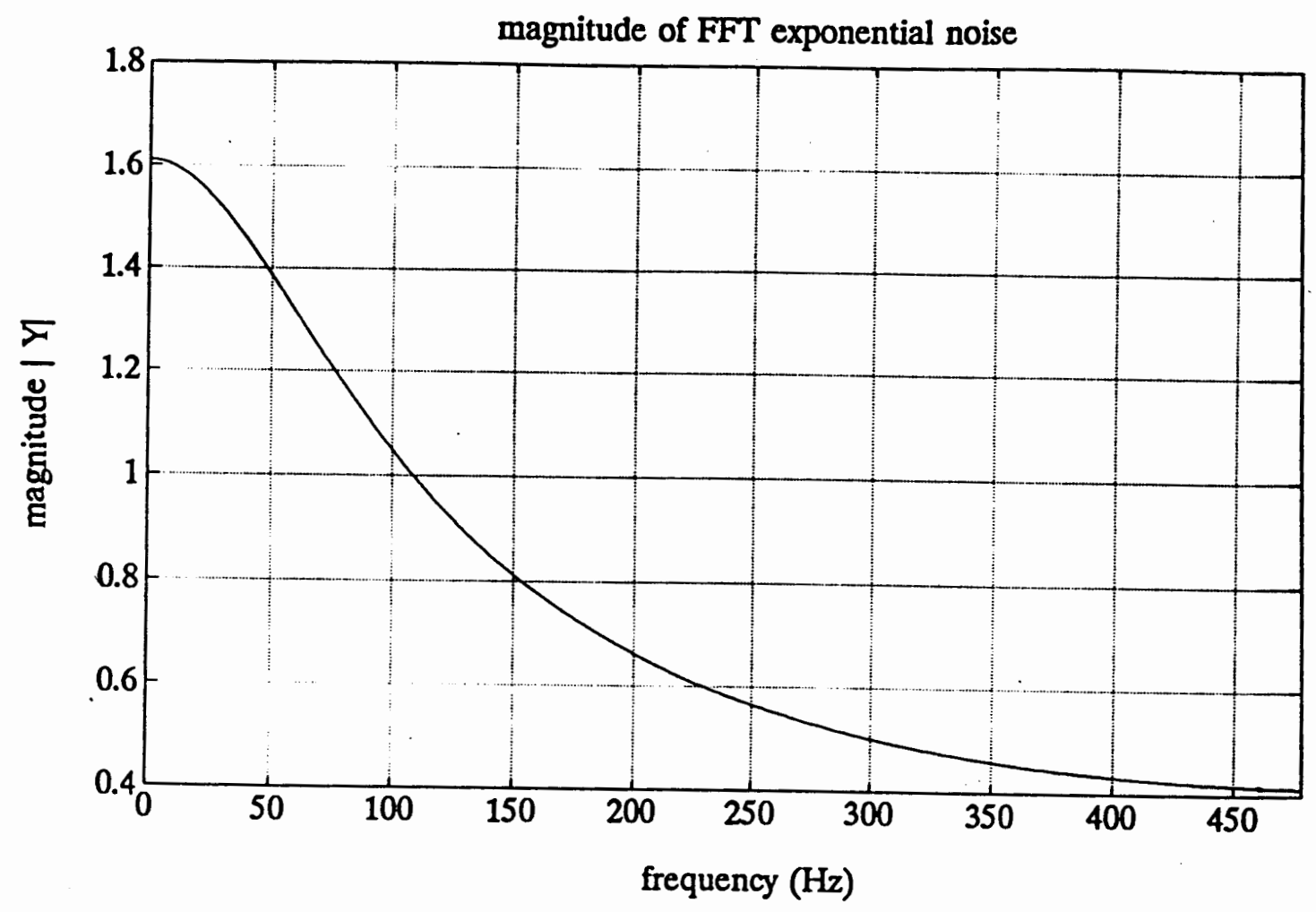

Figure 23. Spectrum of the exponential noise.

\section{SOFTWARE}

The following software listing is the MATLAB code for generating the exponential noise used in the simulation. The FFT is calculated at a sampling frequency of $1000 \mathrm{~Hz}$ and 512 points.

$$
\begin{aligned}
& \text { clear } \\
& \text { step } 1=.1 \\
& \mathrm{t}=0: .001: .7 ; \quad \% \text { time interval of exponential\#1 } \\
& \mathrm{n}=512 ; \quad \% \text { number of point } \\
& \text { fs }=1000 ; \quad \% \text { sampling rate } \\
& \mathrm{ff}=\mathrm{fs} / 2 *(0: n / 2) /(\mathrm{n} / 2) ; \% \text { frequency range }
\end{aligned}
$$




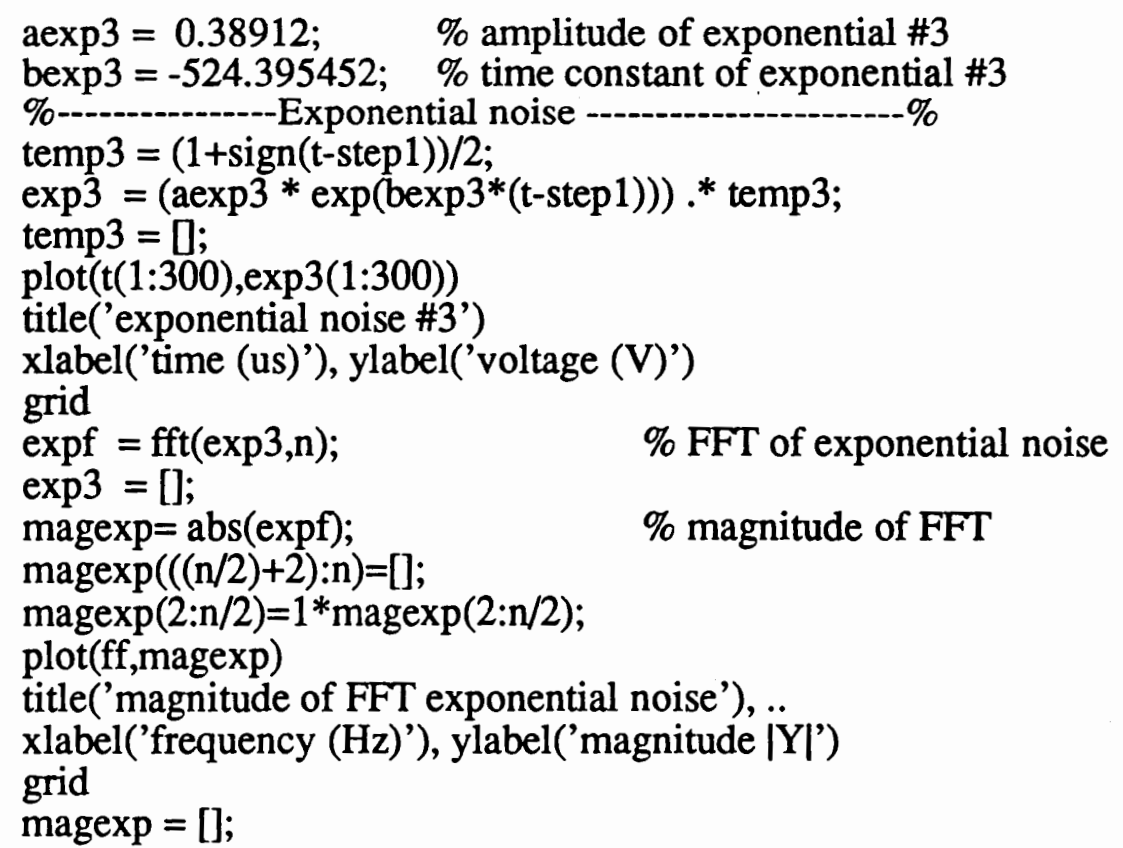




\section{CHAPTER VI}

\section{INPUT SIGNAL}

This chapter describes the test input signal and provides a code sample that combines haversine, exponential, and myopotential signals to create the test input.

The signal used as input to the test filters consists of the haversine signal, exponential noise, and myopotential noise. Figure 24 shows a combination of these signals. The pace pulse is chosen such that the ventricular pace pulse has a pulse width equal to 40 msec, a period equal to $480 \mathrm{msec}$, and an amplitude equal to $10 \mathrm{mV}$. The haversine signal is very difficult to observe in Figure 24 . At $t=.02 \mathrm{sec}$, the presence of haversine signal is seen as a tiny amplitude of the signal.

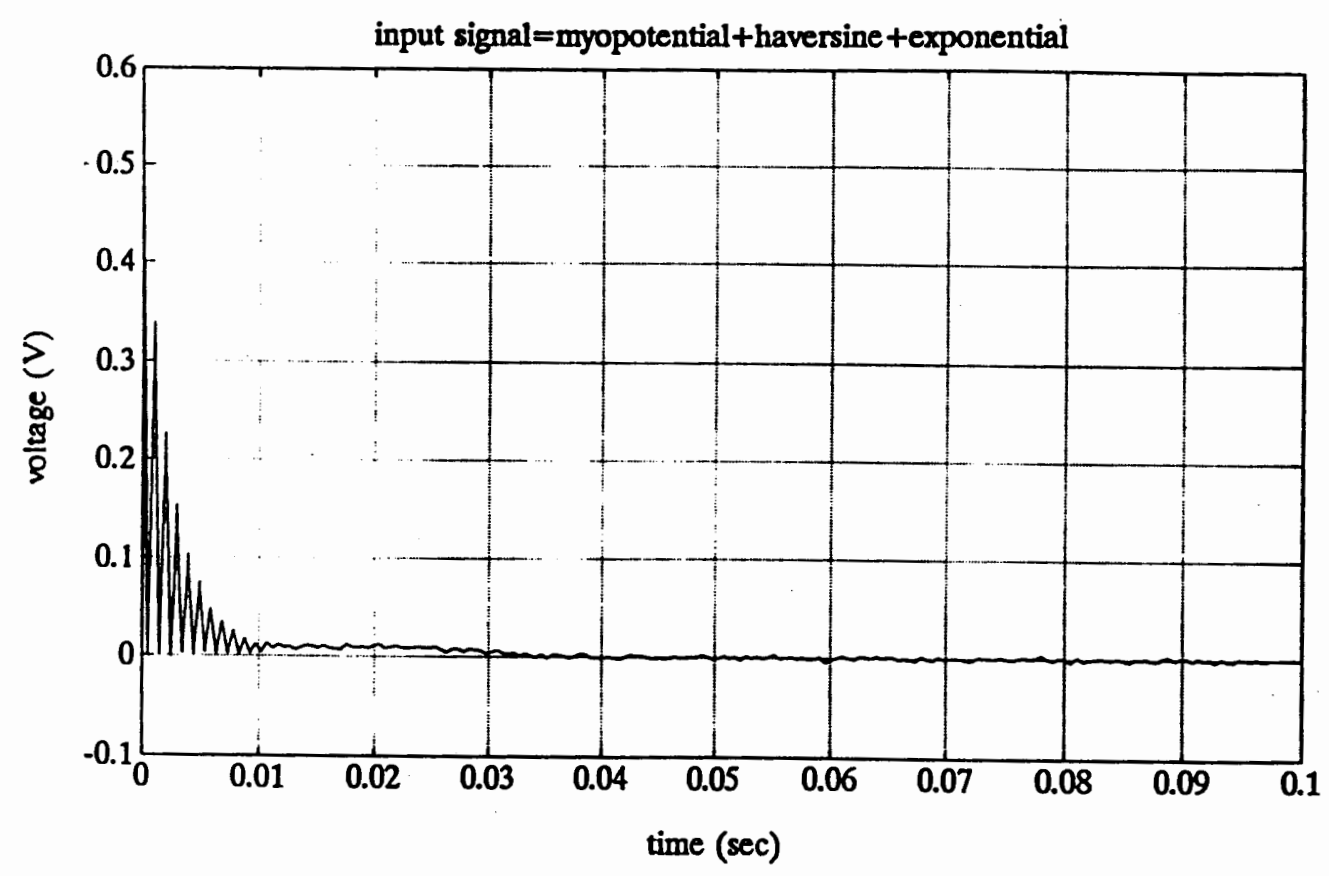

Figure 24. Haversinetexponential+myopotential. 


\section{SOFTWARE}

The following software listing is the MATLAB code which provides a combination of exponential, haversine and myopotential signals for the simulation. This signal is then sent to the amplifier.

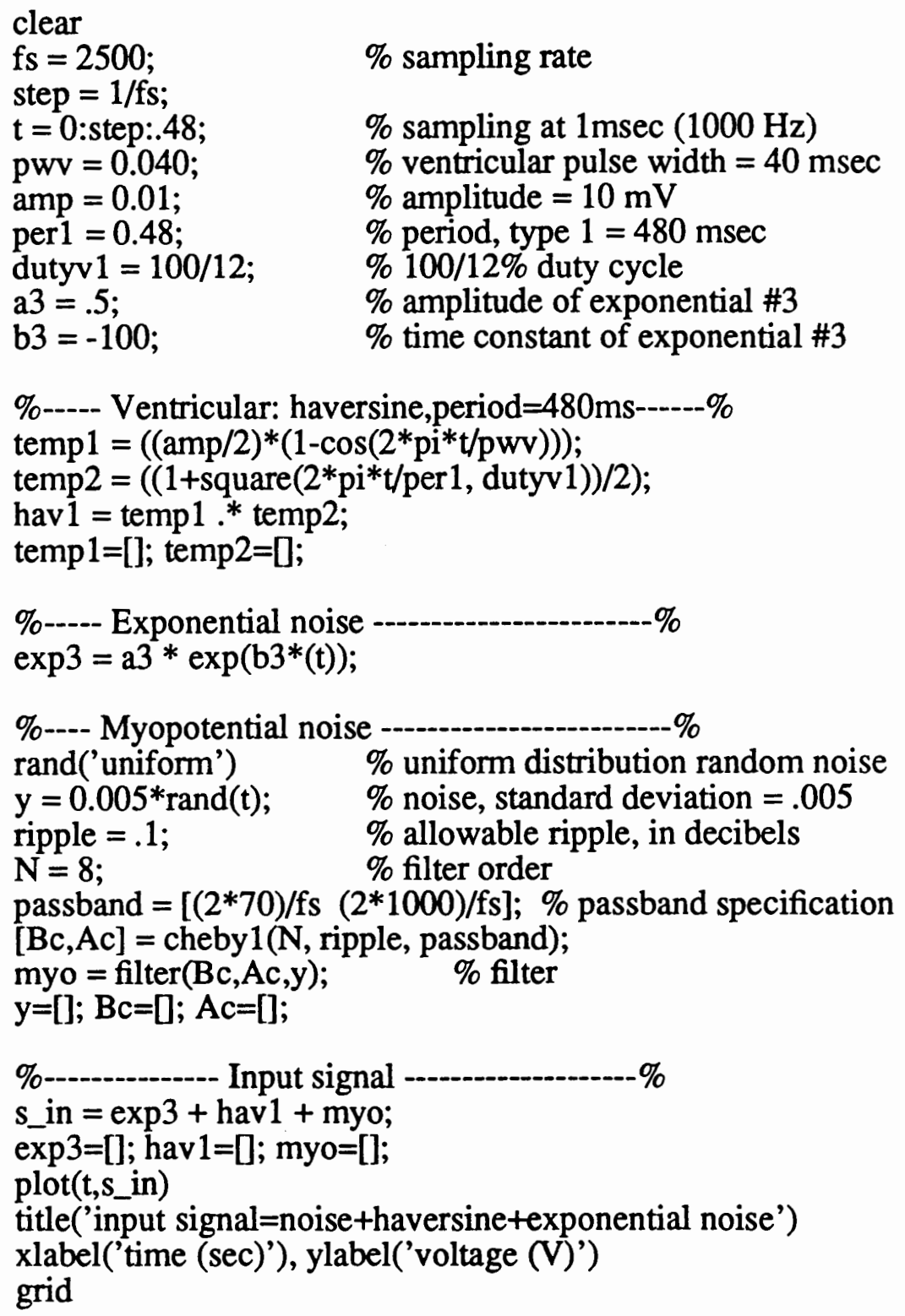




\section{CHAPTER VII}

\section{AMPLIFIER}

This chapter describes the need for a signal amplifier and provides a code sample which simulates the signal amplification done by a normal pacemaker.

Because the haversine signal is so small, an amplifier is used to make the haversine large enough to view after filtering takes place. The maximum gain of commercially available amplifiers is approximately 400 . This number is not a fixed number. It varies from one manufacture to another. For the purposes of the simulation, the gain can be manipulated.

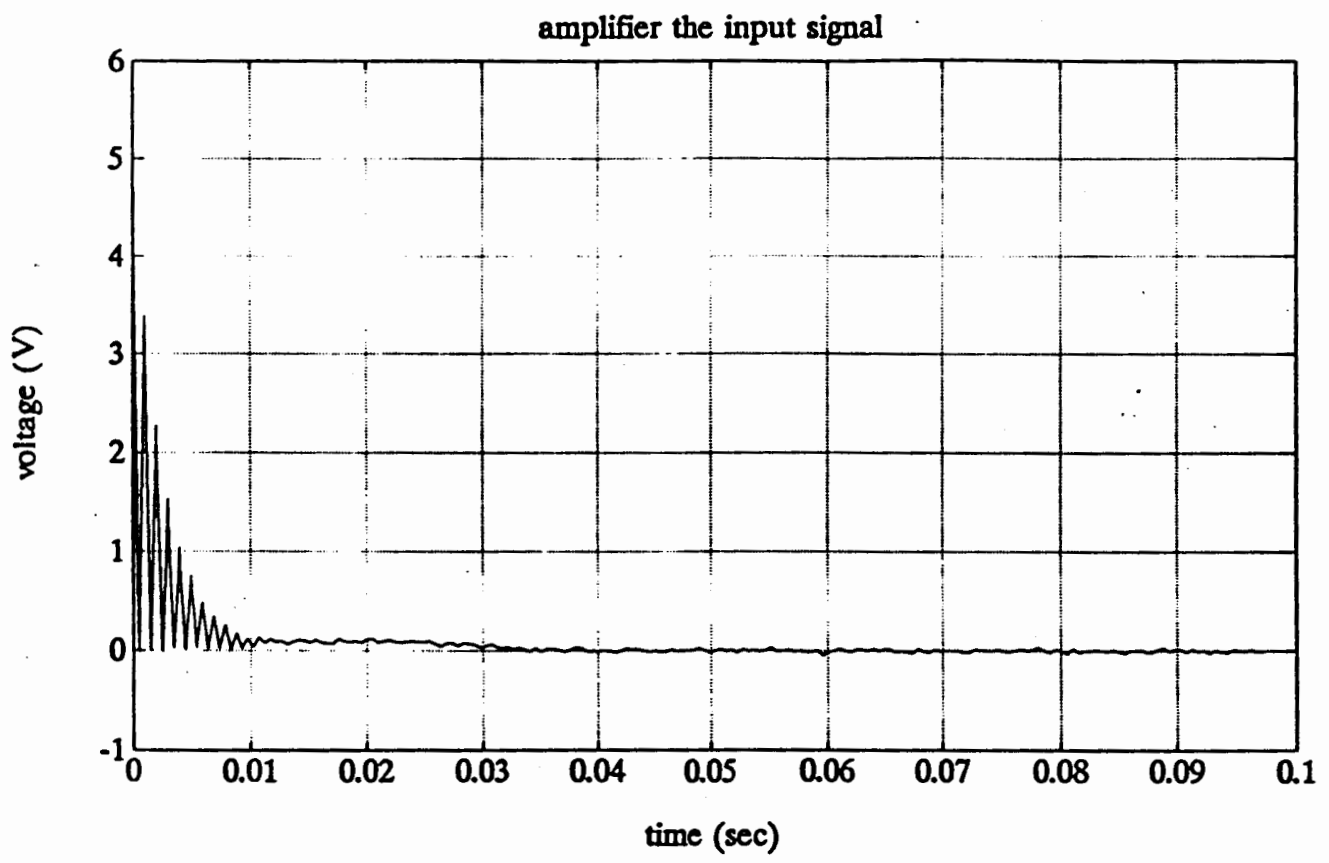

Figure 25. Amplifier the input signal. 


\section{SOFTWARE}

The following software listing presents the simulated amplifier used in the test of the proposed filter. For the purposes of the simulation, assume the input signal is s_in and the amplifier gain is set to 10 .

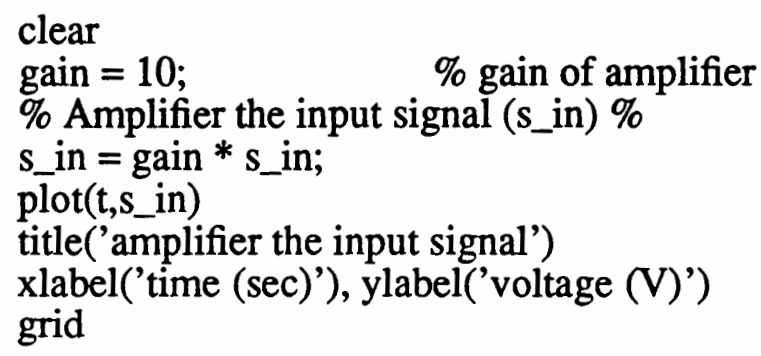




\section{CHAPTER VIII}

\section{A/D CONVERTER}

This chapter describes an analog to digital converter, the sample and hold function, and presents the code listing for the sample and hold functionality. The chapter then describes the quantization process and the introduction of random noise into the quantized signal. Finally, the code which represents the quantization process is presented.

Most pacemakers handle an analog signal. In order to manipulate the pacemaker's signals with digital filters, an analog to digital converter (A/D converter) was used. The A/D converter is a physical device that converts an input voltage amplitude into a binary code representing a quantized amplitude value closest to the amplitude of the input. Because the conversion is not instantaneous, a high performance $A / D$ typically includes a sample and hold function to compensate for the bottleneck caused by processing delays.

\section{SAMPLE AND HOLD}

The sample and hold function is designed to sample an analog signal as nearly instantaneously as possible and to hold the sample value as nearly constant as possible until the next sample is taken. The sample value is held for quantization by the A/D converter. In the test case, the signal is sampling and holding at $2048 \mathrm{~Hz}=2^{11}$. Figure 26 shows the result of the sample and hold. 


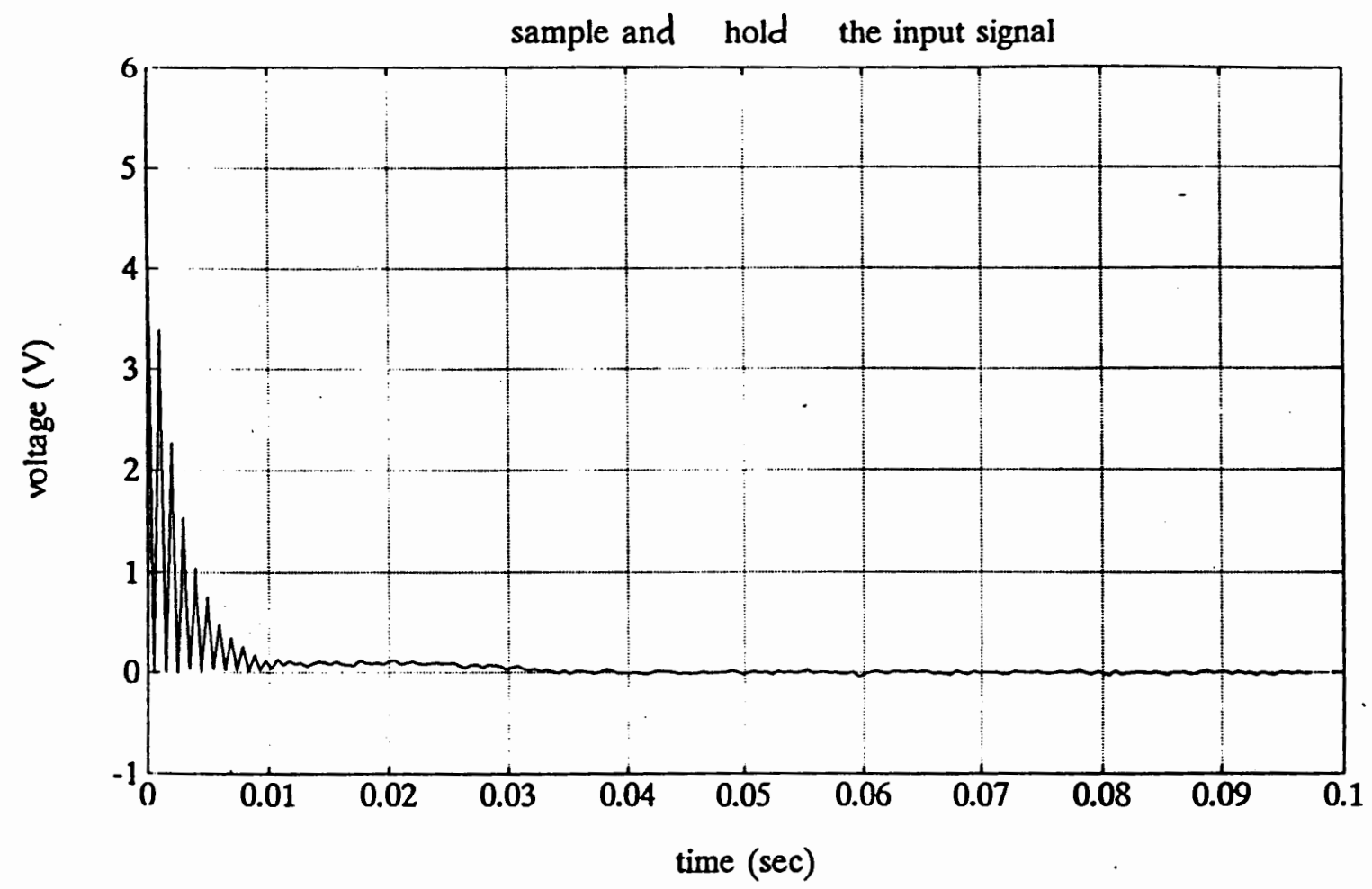

Figure 26. Sample and hold.

\section{Software}

The following listing represents the simulated sample and hold function prepares the signal for the A/D converter. The signal is sampled at a frequency of $2048 \mathrm{~Hz}$, and it holds at the same frequency.

clear

fs = 2048;

step $=1 / \mathrm{fs}$;

$\mathrm{t}=0$ :step:.48;

\% sampling rate

$\%$ sampling at $2048 \mathrm{~Hz}$

\%--------- sample and hold $-\%$

holdtime = step;

holdsample = ceil(holdtime/step);

$\mathrm{m}=$ length(s_in);

s_hold = []; 


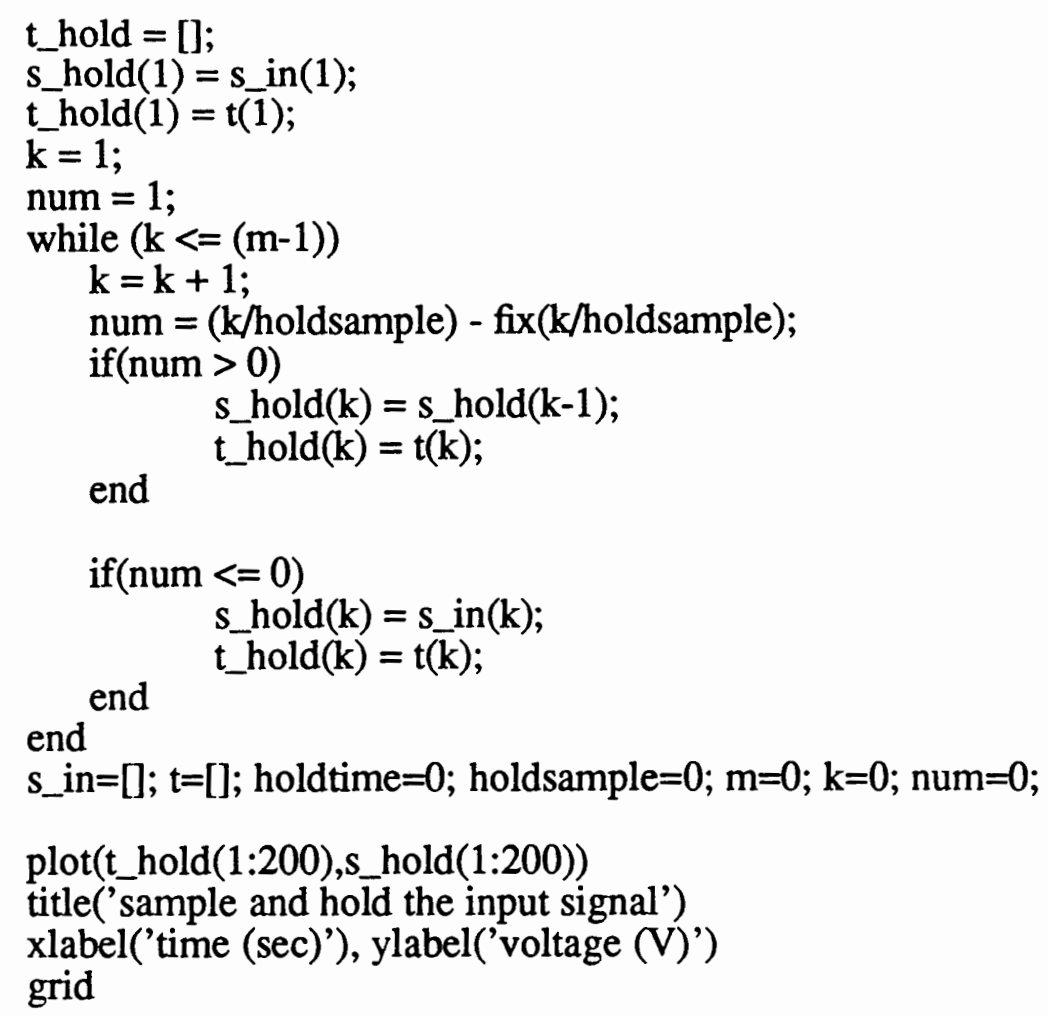

\section{QUANTIZATION}

A quantizer is a nonlinear system that transforms the input sample into one of a finite set of prescribed values. The quantization steps are usually uniform in signal processing.

$$
\begin{aligned}
\text { Let } X & =\text { input signal } \\
\mathrm{X}_{\mathbf{B}} & =\text { quantized input signal } \\
\mathbf{B} & =\text { bits resolution } \\
\mathrm{VFS} & =\text { voltage full scale } \\
\text { delta } & =\text { step size of the quantizer } \\
\text { delta } & =\mathrm{VFS} /\left(2^{\mathrm{B}}-1\right)
\end{aligned}
$$


If the above is true, then the following expression represents the quantization done in the simulation. $\mathrm{X}_{\mathrm{B}}=$ delta $*$ round $\left(\mathrm{X} *\left(2^{\mathrm{B}}-1\right) / \mathrm{VFS}\right)$

Because of the loss of precision due to the round-off function, the quantizer signal gains some random noise.

In this case, the signal is quantized at an 8 bit resolution. The input signal is above voltage full scale (VFS) and does not return to the output data. Figure 27 shows the relationship between the quantizer input signal and a VFS input signal of $10 \mathrm{~V}$ at an 8 bit resolution. Figure 28 shows the result of the input signal after going through the quantization stage.

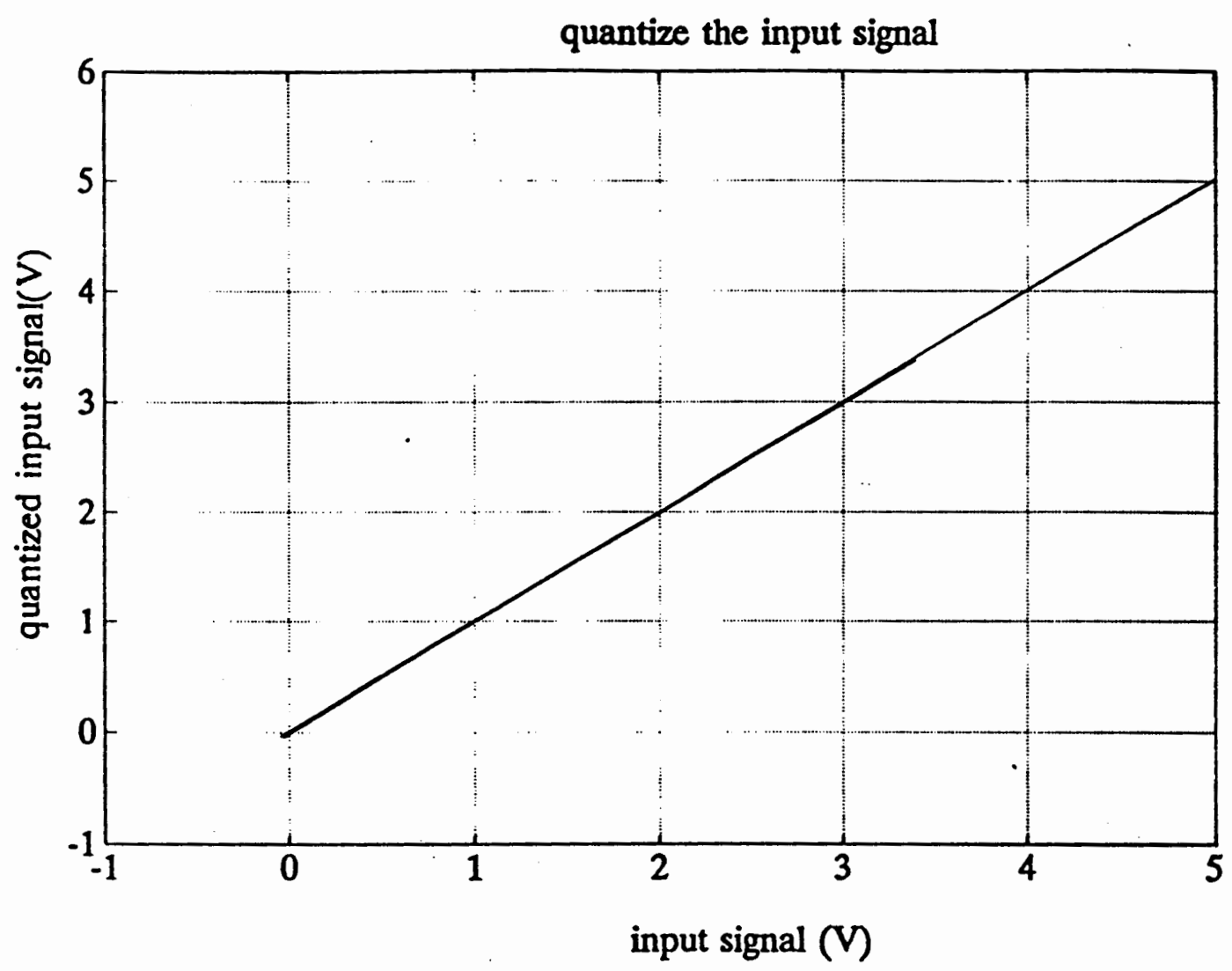

Figure 27. VFS $=10,8$ bits resolution. 


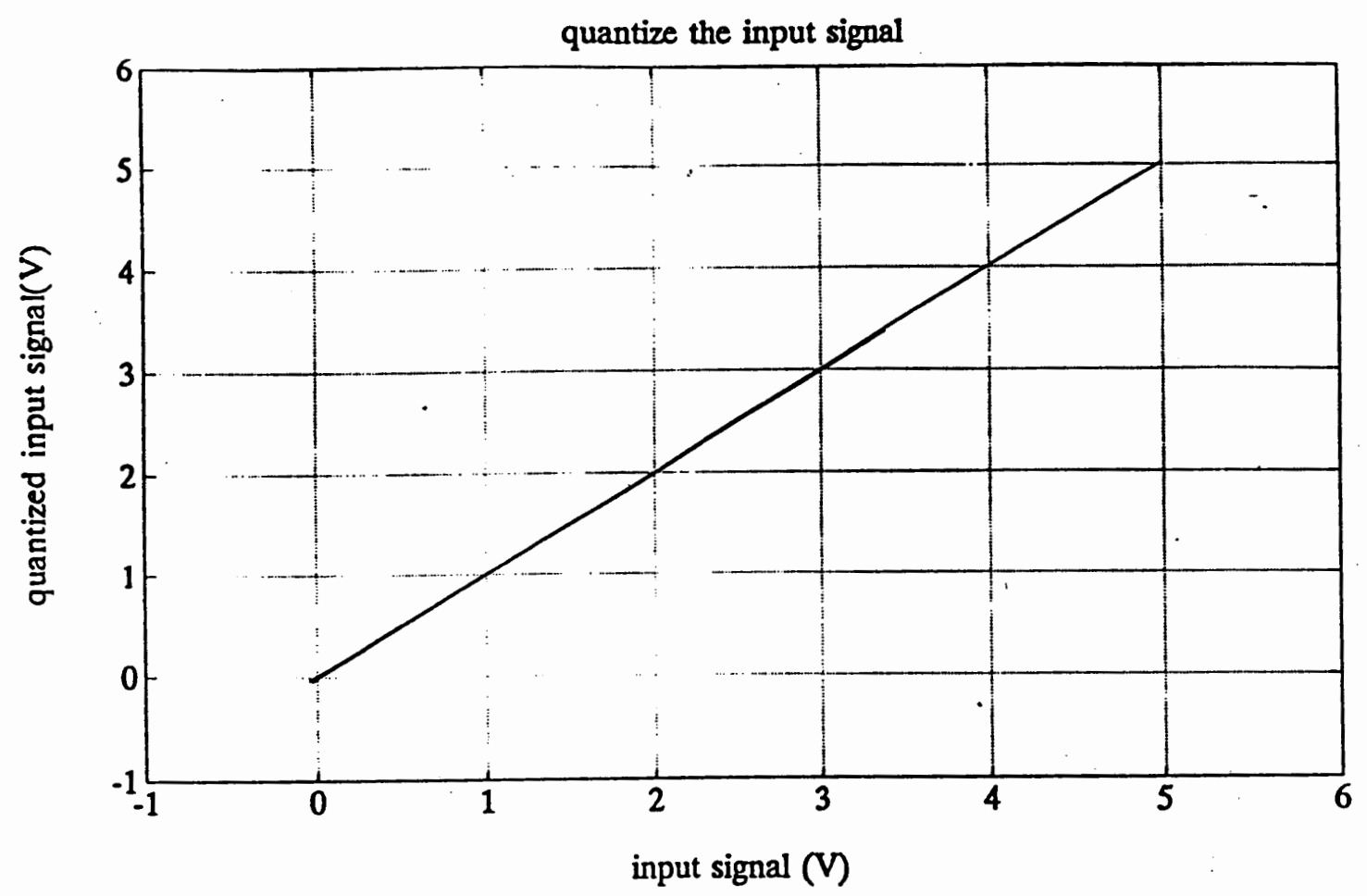

Figure 28. After quantizer, signal gains some random noise.

\section{Software}

The following code listing represents the quantization function of the simulation. After the signal is quantized, it is ready to move through the filters for removal of exponential and myopotential noise.

clear

disp('--..-- Quantization

VFS $=0$; bits $=0$; maxcount $=0$; delta $=0$;

VFS $=$ input('Enter volts full scale (V) $[\mathrm{VFS}]=\Rightarrow$ ');

bits= input('Enter number of bits solution [bits] =>>');

maxcount $=\left(2^{\wedge} b i t s\right)-1 ; \quad \%$ number of quantizer points

delta $=$ VFS/maxcount; $\%$ voltage resolution at quantizer

$1=0$;

$1=$ length(s_hold);

$\mathrm{q}=0$; 


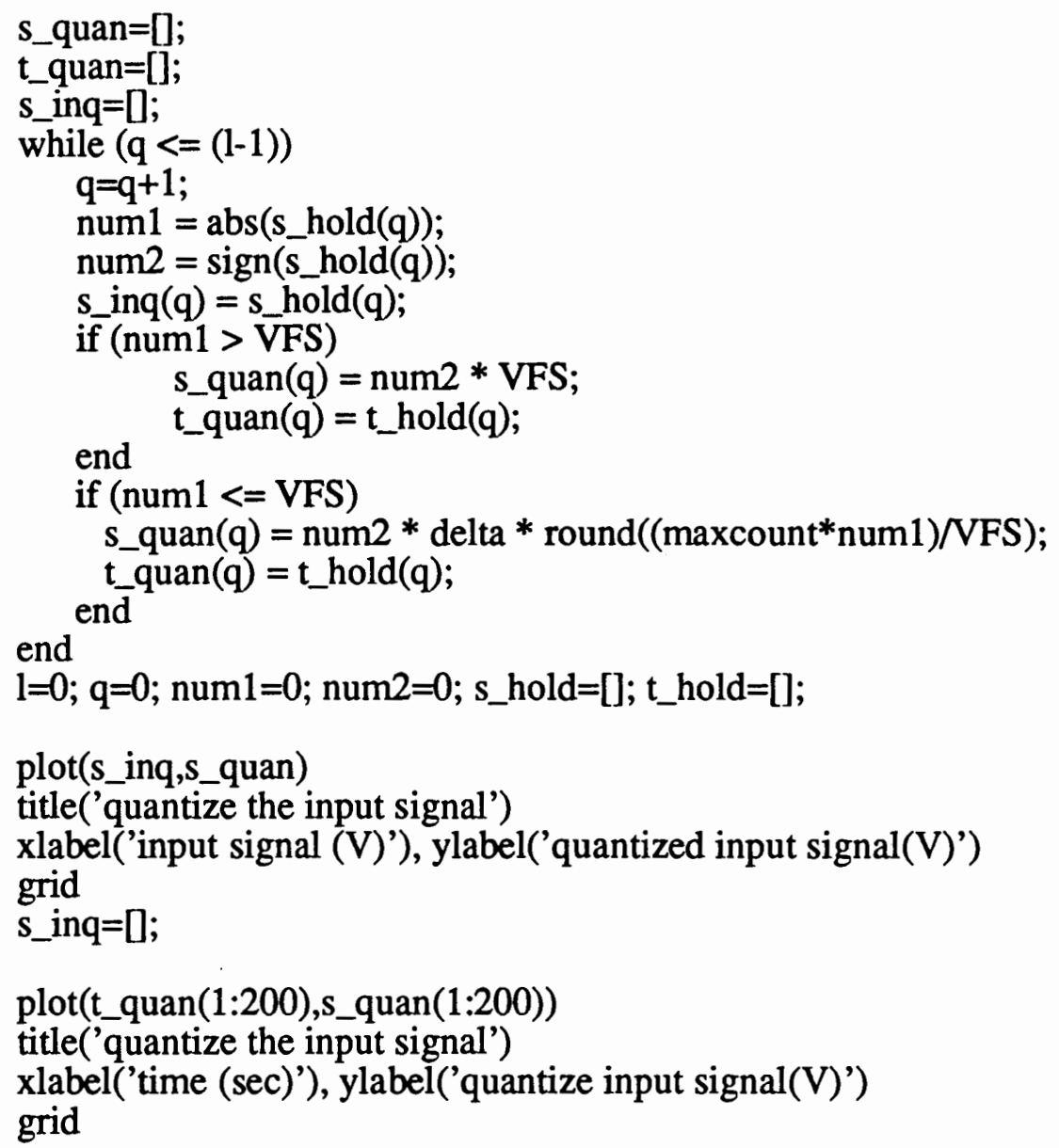




\section{CHAPTER IX}

\section{DIGITAL FILTER}

This chapter describes the need for and inadequacy of digital filters, the instability of inverse digital filters, the use of a stable psuedo-inverse filter to remove the presence of the exponential noise, the effects of the filter on the test signal, and the use of a lowpass digital filter to minimize myopotential noise.

Since the purpose of this thesis is to show how to detect a haversine signal immediately following a pace pulse, the ability of the proposed digital filters to remove or minimize exponential noise and myopotential noise must be demonstrated. To this end, two filters are described here, the inverse digital filter, and the lowpass digital filter. When both filters have been applied to the signal which has been prepared by the simulation code described in previous chapters, the result should be output which contains only the haversine signal.

\section{INVERSE DIGITAL FILTER}

The input to the inverse digital filter is the combined signal containing the nonperiodic haversine signal, non-periodic exponential noise, and myopotential random noise. The spectrum of the haversine is overlapped by the spectrum of and amplitude of the exponential, which is several orders of magnitude larger. So, classical filters like the Chebyshev, the Butterworth, and the Elliptic are not useful.

Based on the characteristics of the exponential noise, an inverse filter was designed to filter out only the exponential noise. The parameters of the exponential noise signal (amplitude and time constant) are a function of time and this makes the inverse filter 
desirable because it is more sensitive to noise. Design of a usable inverse filter is difficult because they are often unstable. A pseudoinverse filter combines characteristics of the inverse filter with characteristics of more stable designs to create a usable and stabilized version of the inverse filter.

Some properties of inverse system:

$\mathrm{H}(\mathrm{z})$ - transfer function of the system

H_i(z) - inverse transfer function

$$
\text { H_i }(z)=1 / H(z)
$$

To meet the definitional characteristics of inverse filters, the region of convergence of $\mathrm{H}(\mathrm{z})$ and $\mathrm{H} \_\mathrm{i}(\mathrm{z})$ must overlap. Poles of $\mathrm{H} \_\mathrm{i}(\mathrm{z})$ are zeros of $\mathrm{H}(\mathrm{z})$. If the region of convergence of $H_{-} i(z)$ includes the unit circle, then the $H \_i(z)$ is stable.

Suppose, the exponential signal is described as:

$$
\begin{aligned}
h(t)= & \frac{A}{2} e^{-b \cdot t}\left(1+\cos \left(\frac{\pi \cdot t}{T s}\right)\right) \\
1)==\Rightarrow & H(z)=\frac{z^{2}}{z^{2}-a^{2}} \\
2)=\Rightarrow & H \_i(z)=\frac{z^{2}-a^{2}}{z^{2}} \\
a & =e^{-b T s}
\end{aligned}
$$

Then the envelope of $h(t)$ is an exponential decay. This is a second order system of the exponential. Since the H_i (z) has only zeros, this filter may be called FIR (finite impulse response), all-zero, non recursive, or moving average(MA). It follows that the system has a finite duration impulse response. Therefore, the system is stable.

Since the $H_{-} i(z)$ is a polynomial with only negative powers of $z$, the system is 
causal. However, if the zeros are outside the unit circle, the system is in non-minimum phase.

Analysis of the above (1)\&(2) yields:

$$
\mathrm{Y}(\mathrm{z})=\mathrm{H}(\mathrm{z}) \cdot \mathrm{H} \_\mathrm{i}(\mathrm{z})=1
$$

In time domain, $y(t)=\delta(t)$ impulse response

Summary:

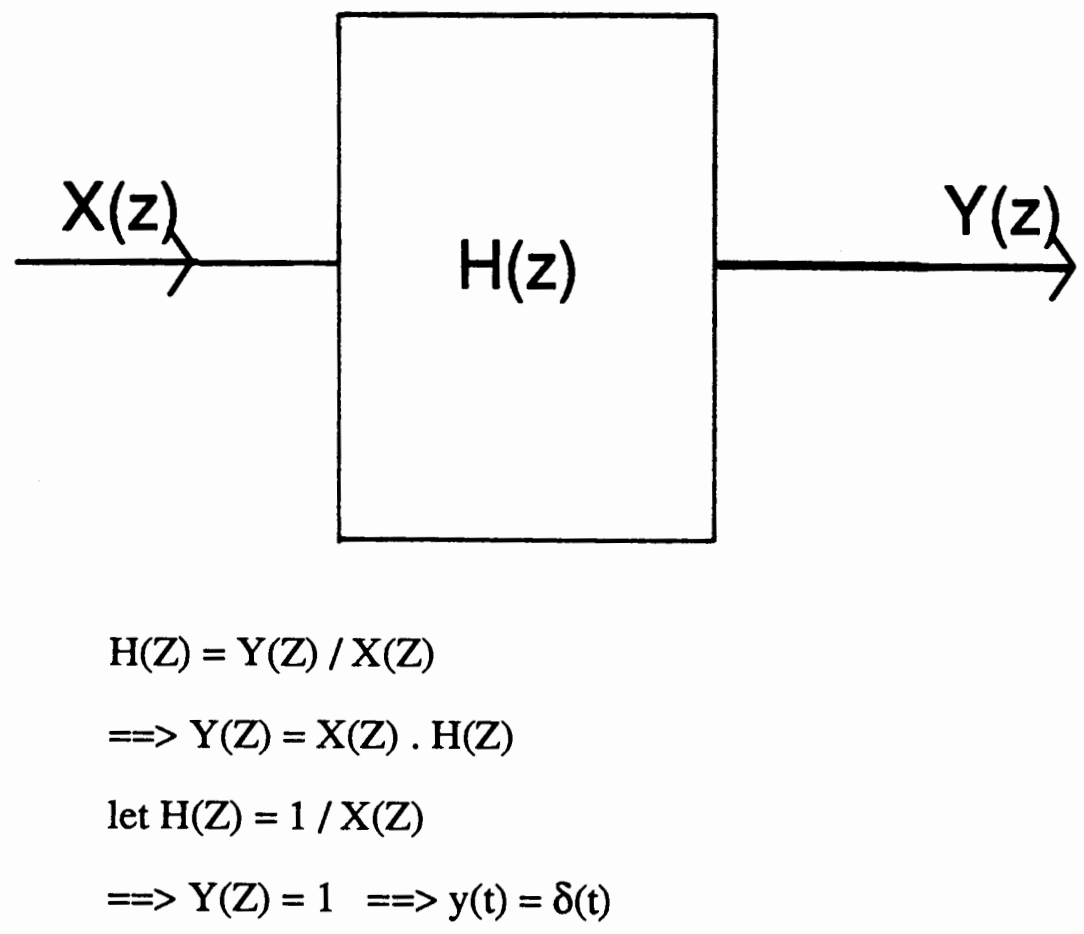

After the signal goes through the inverse filter, the output is the haversine, the myopotential, and the impulse response. Figure 29 illustrates the perfect inverse filter, the exponential is completely removed.

Figures 30 and 31 show the different magnitudes of an inverse filter of 2 nd order and an inverse filter of 1 st order when zero locations change.

By changing the time constant of the exponential noise, the behavior of the inverse filter changes as shown in Tables I, II, III, and IV. 


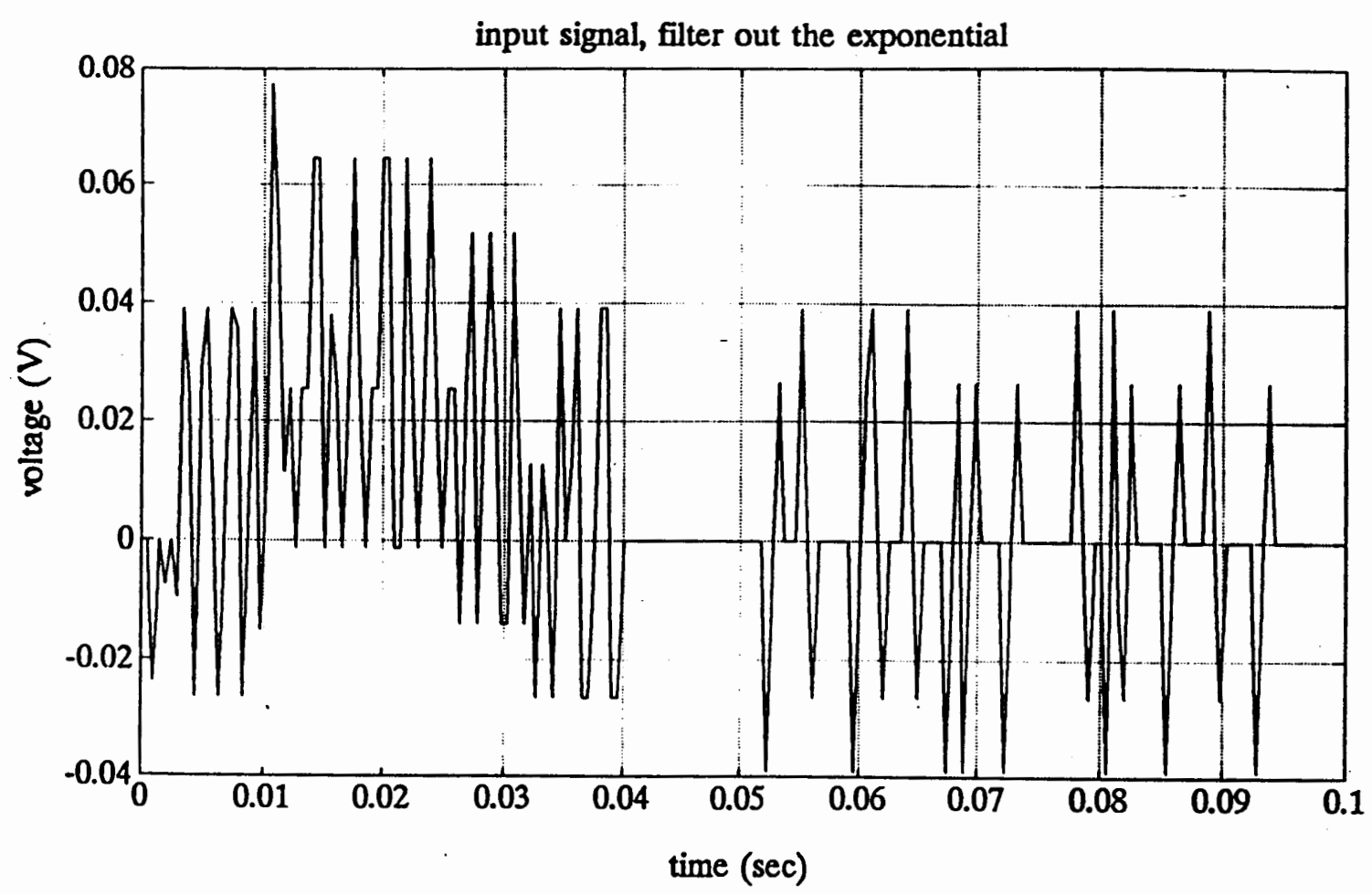

Figure 29. Inverse filter removes the exponential.

Tables I and II show the behavior of 2 nd order inverse filter. By varying the $\mathrm{a}$ and $\mathrm{b}$ constants from the ideal exponential signal, Table I emphasizes the filtered results of the exponential signal and Table II emphasizes the filtered results for the combination of exponential and haversine signal. The difference between Table I and II is the haversine signal and the impulse response. From Table $\mathrm{I}$, at $\mathrm{t}=0 \mathrm{msec}$, the presence of the large amplitude of the filtered signal determines the presence of the impulse response function. At. $0 \%$, a\&b, the amplitude of the filtered signal approaches zero after $0 \mathrm{msec}$. This represents the perfect inverse filter. Increasing the percentage of the $a$ and $b$ coefficients causes the amplitude of the filtered signal to ring after $0 \mathrm{msec}$. This represents the exponential signal is still present after being filtered. Figure 32, 33, and 34, show three special cases describing Table II: Figure 32 shows the filtered signal at $0 \%$ a\&b; 33 
shows the signal at $2 \% \mathrm{a} \& \mathrm{~b}$; and 34 at $5 \%$ a\&b. The haversine in all cases is still clearly observed.

Tables III and IV show the behavior of the 1 st order inverse filter. The presentation is similar to Tables I and II. Figures 35, 36 and 37 show three special cases describing Table IV that are similar to Figures 32, 33, and 34.

Tables V and VI show the sensitivity of the input signal for the second order inverse filter by changing the location of the zeros of the inverse filter. Table VI emphasizes the filtered results of the exponential signal. It describes the starting position of the zeros at 0.1 , and when the zeros move closer to the ideal location $\left(\mathrm{e}^{-\mathrm{bT})}\right.$, the amplitude of the filtered signal decreases after $0 \mathrm{msec}$. But, when the zeros pass through the ideal location, the amplitude of the filter signal is negative, indicating the instability of the inverse filter. Figures 38,39 , and 40 show three special cases describing Table V: Figure 38 shows the filtered signal at zero $=0.7$, Figure 39 shows the filtered signal at zero $=0.8$, and Figure 40 shows the filtered signal at zero $=0.9$. At zero $=0.8$ the haversine signal is clearly observed. Figures 41,42 , and 43 show three special cases describing Table VIII that are similar to Figures 38, 39, and 40 .

Tables VII and VIII display the sensitivity of the input signal for a 1st order inverse filter. The comparison procedure is similar to that of Table V and VI. Figure 39 shows the filtered signal at zero $=0.8$, and Figure 40 shows the filterd signal at zero $=0.9$. At zero $=0.8$ the haversine signal is clearly observed. 


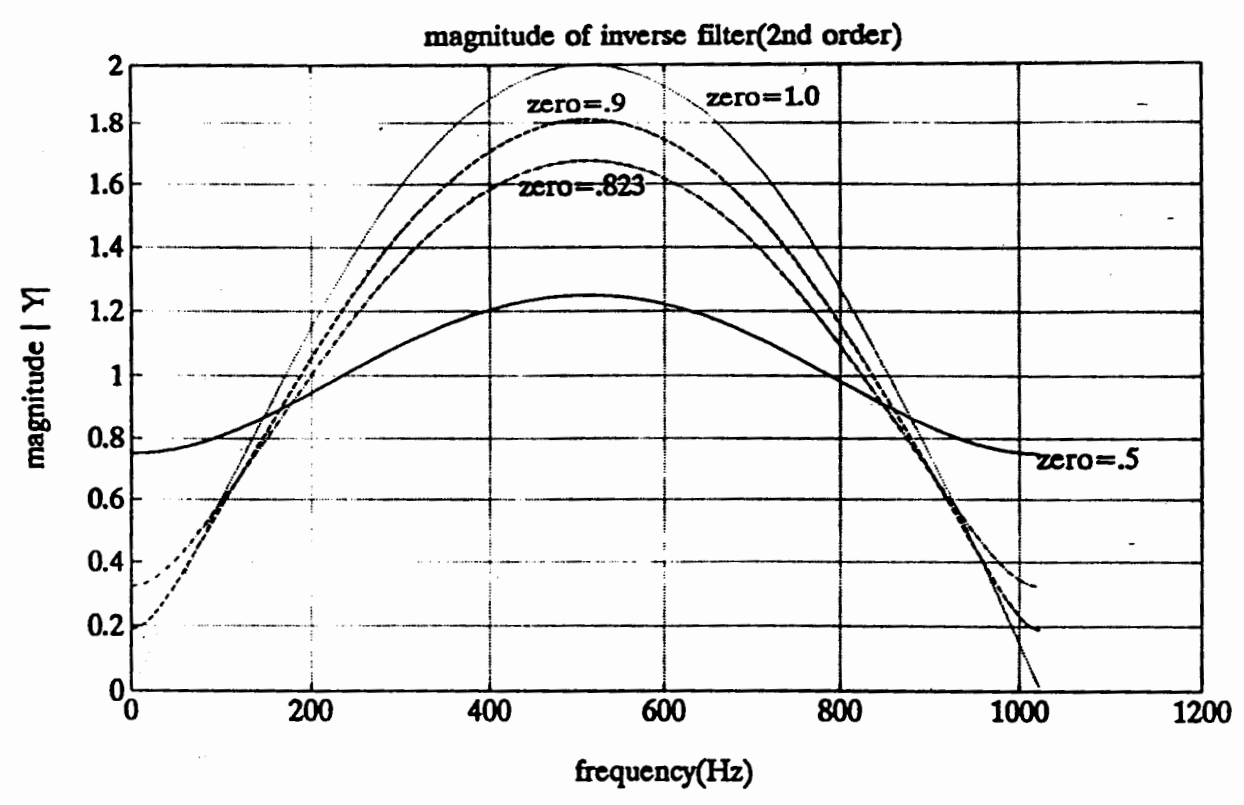

Figure 30. Magnitude of inverse filter (2nd order) at different zero location.

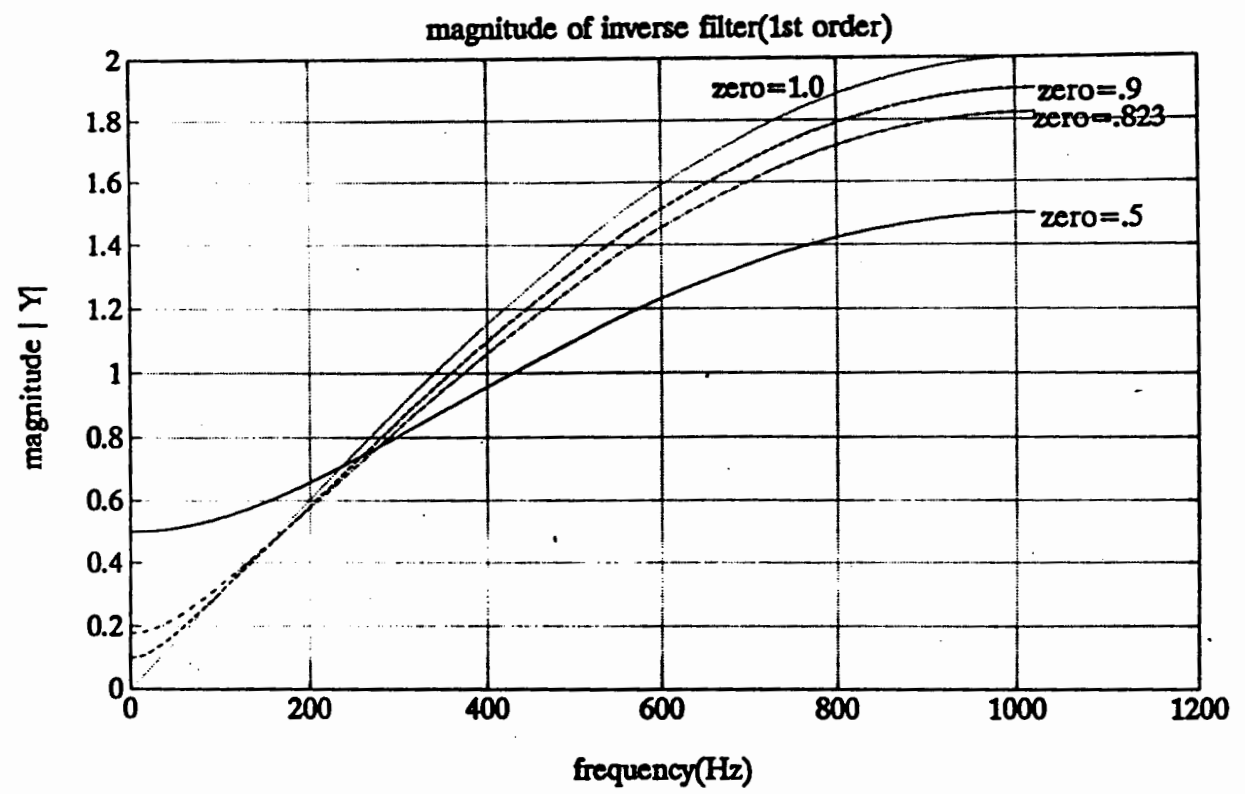

Figure 31. Magnitude of inverse filter (1st order) at different zero location. 


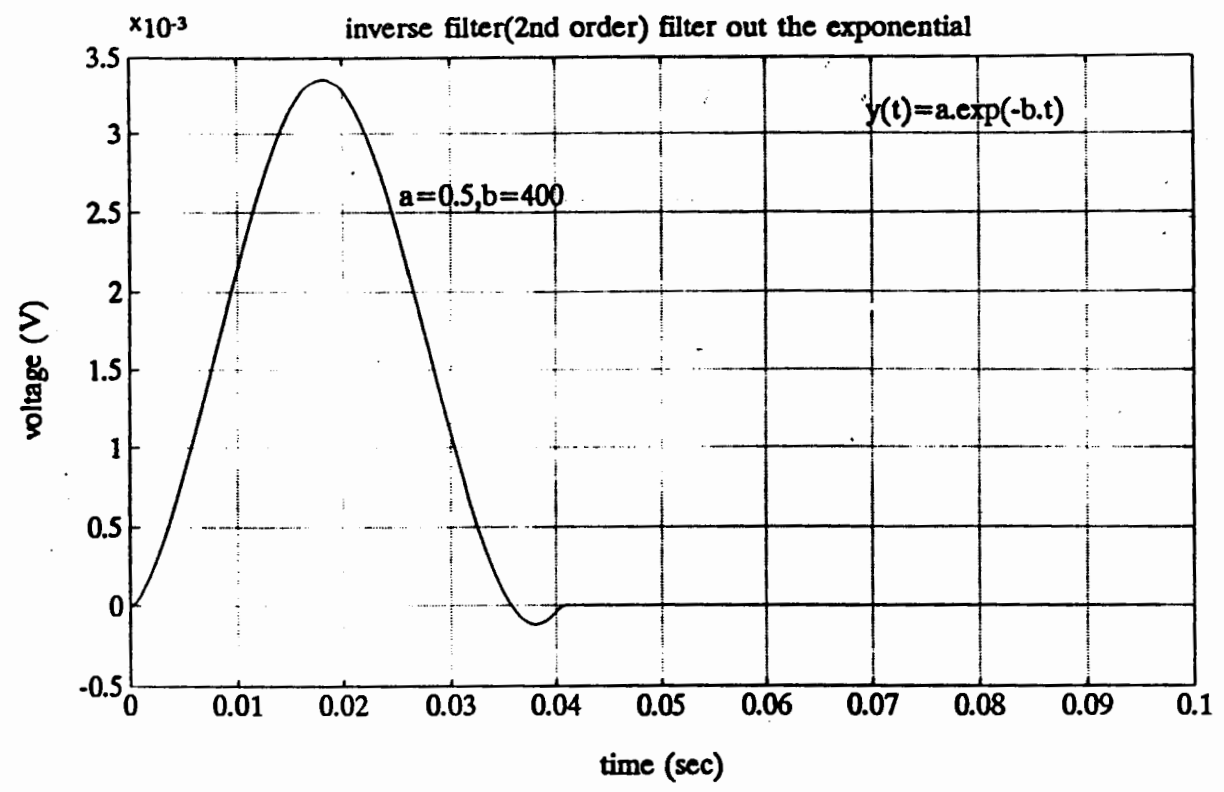

Figure 32. Fixed inverse filter (2nd order) coefficients, $0 \%$ a\&b.

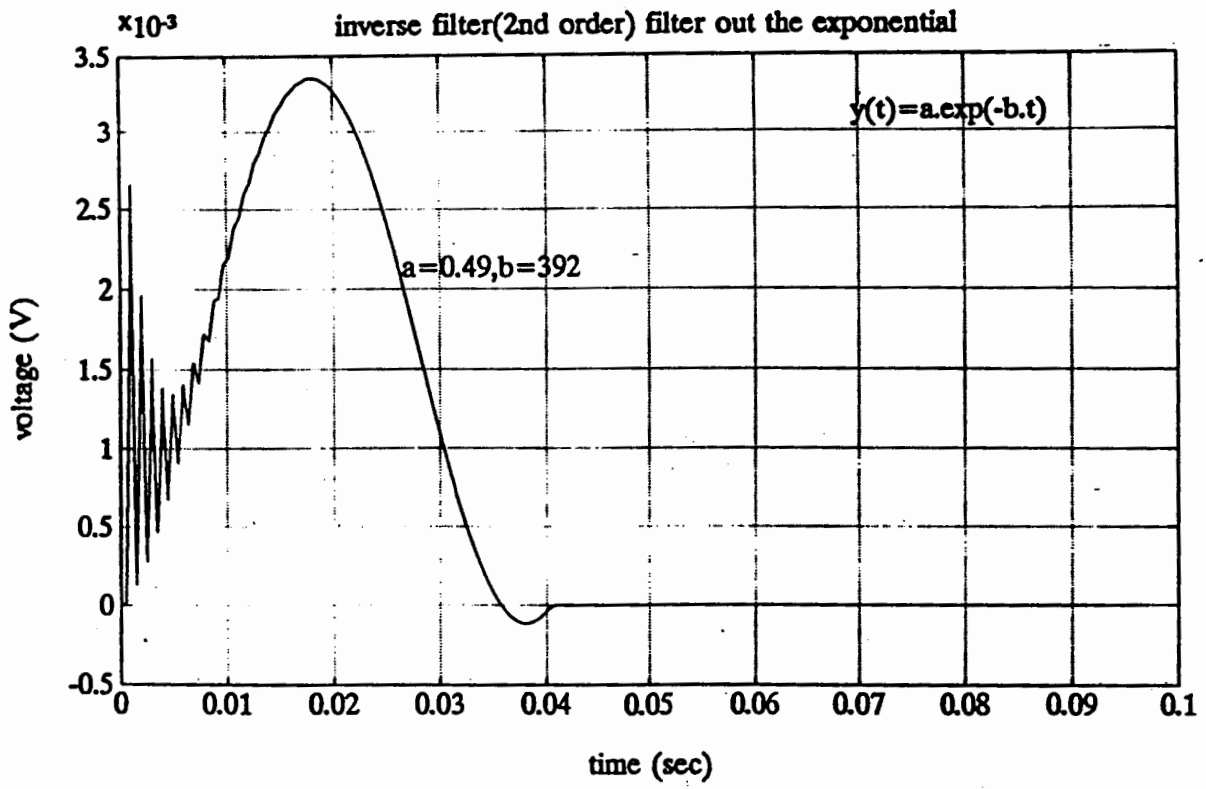

Figure 33. Fixed inverse filter (2nd order) coefficients, $2 \%$ a\&b. 


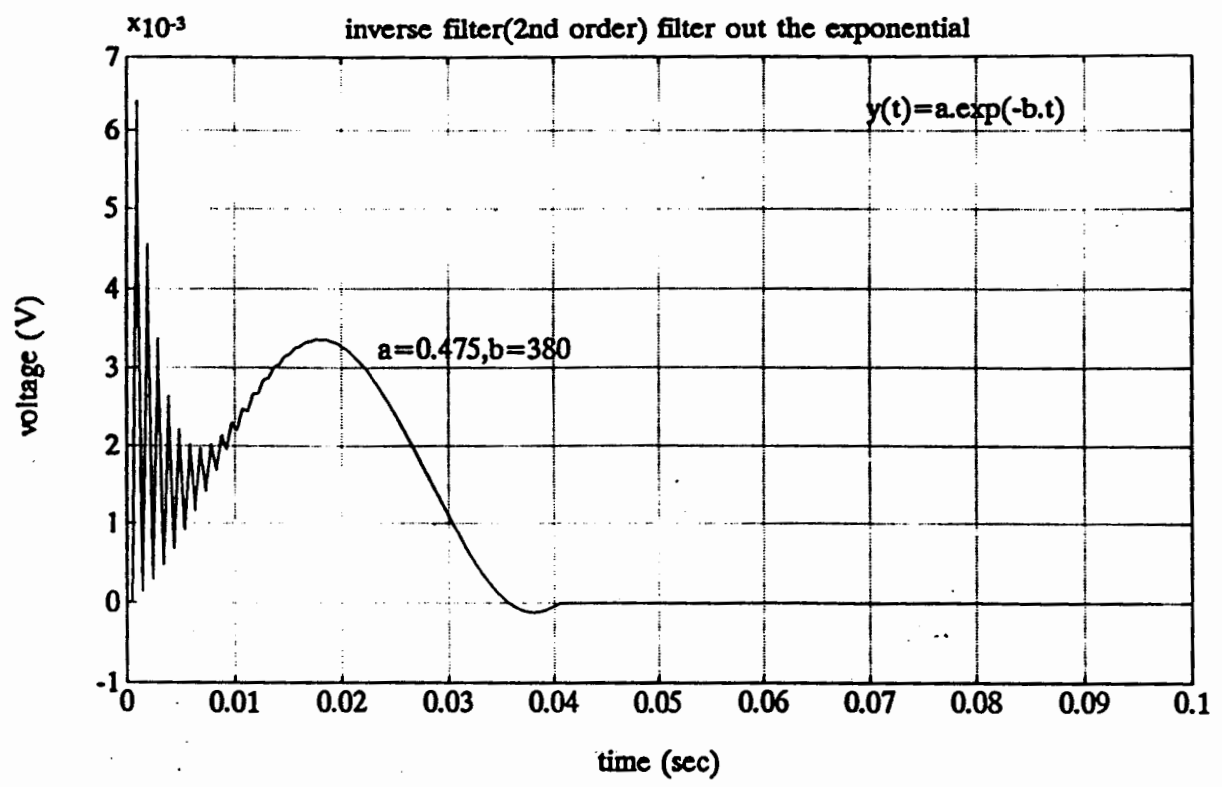

Figure 34. Fixed inverse filter (2nd order) coefficients, $5 \%$ a\&b.

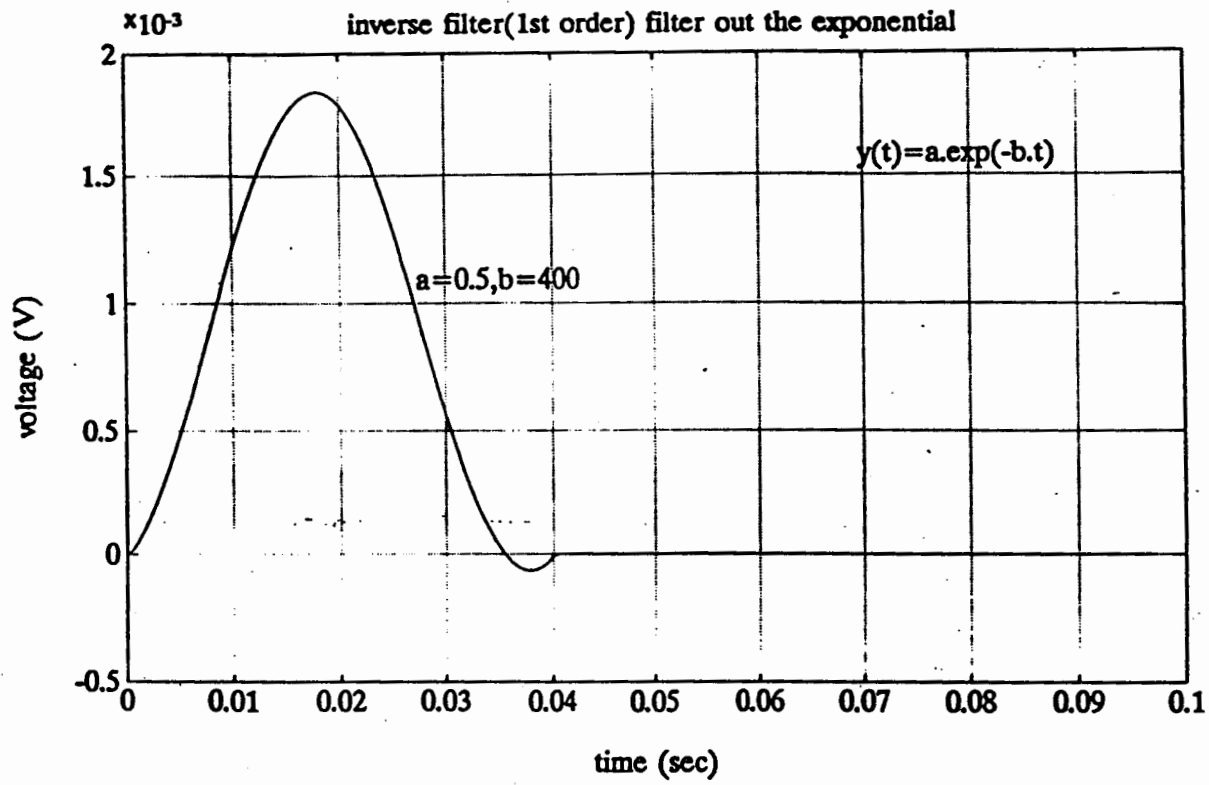

Figure 35. Fixed inverse filter (1st order) coefficients, $0 \%$ a\&b. 


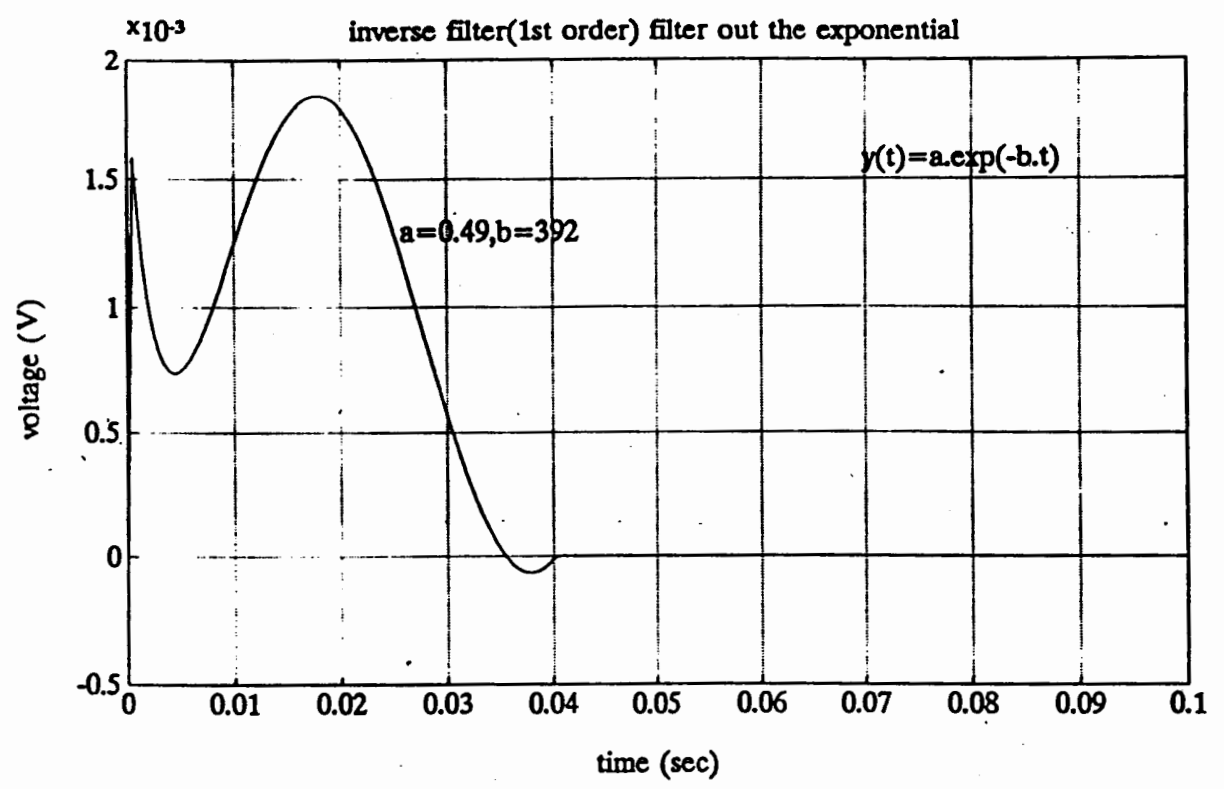

Figure 36. Fixed inverse filter (1st order) coefficients, $2 \%$ a\&b.

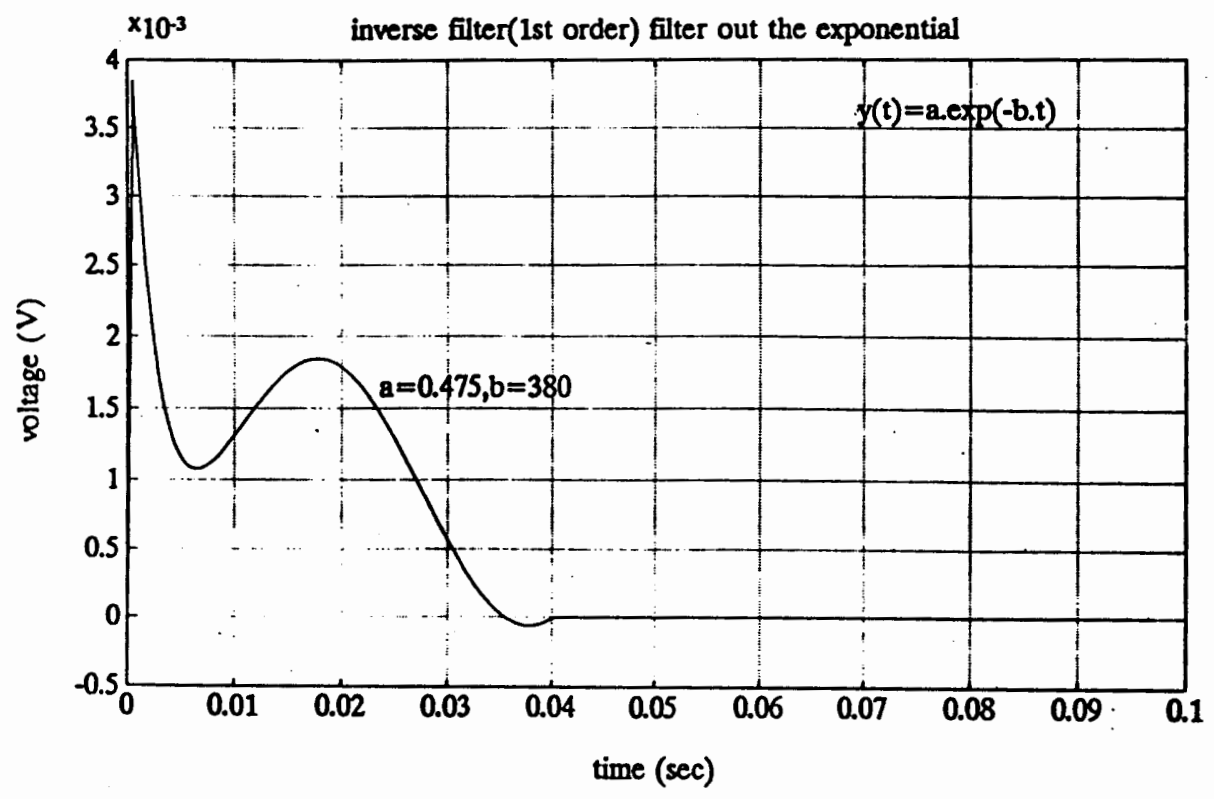

Figure 37. Fixed inverse filter (1st order) coefficients, $5 \% \mathrm{a} \& \mathrm{~b}$. 


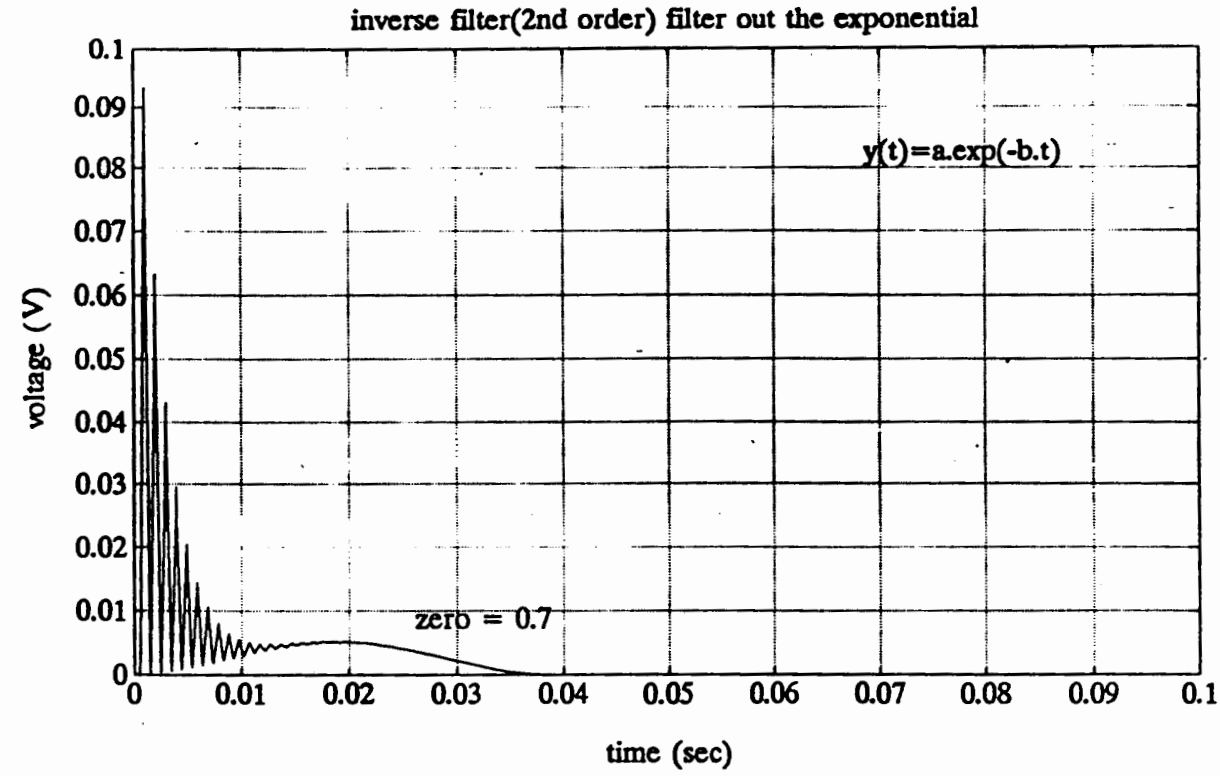

Figure 38. Change zero location (2nd order inverse filter), zero $=0.7$.

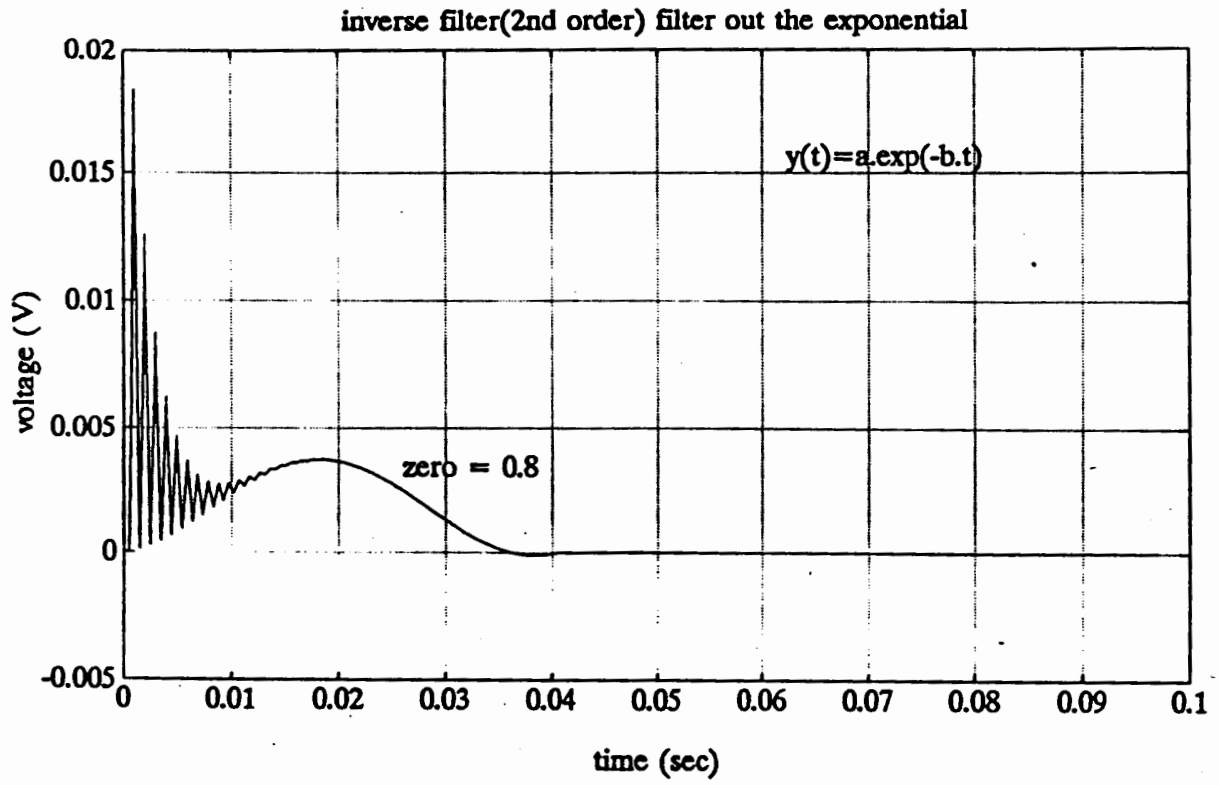

Figure 39. Change zero location (2nd order inverse filter), zero $=0.8$. 


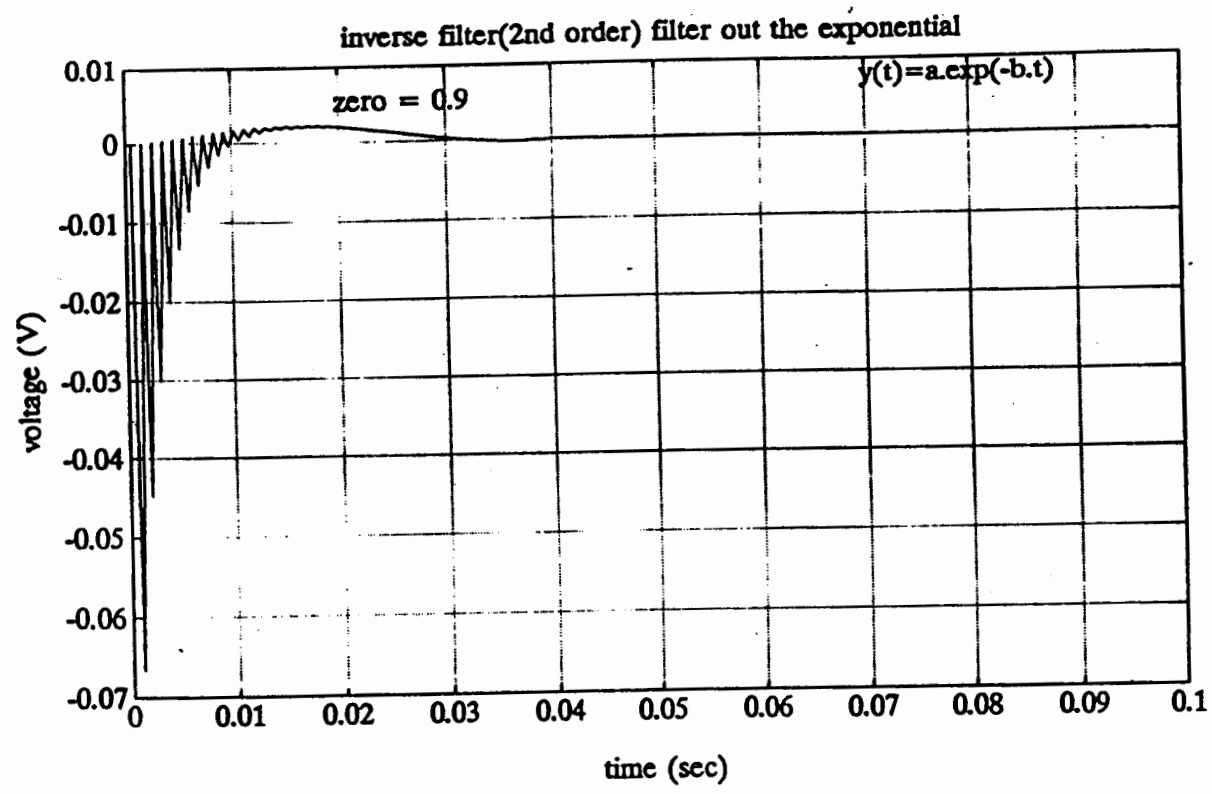

Figure 40. Change zero location (2nd order inverse filter), zero $=0.9$.

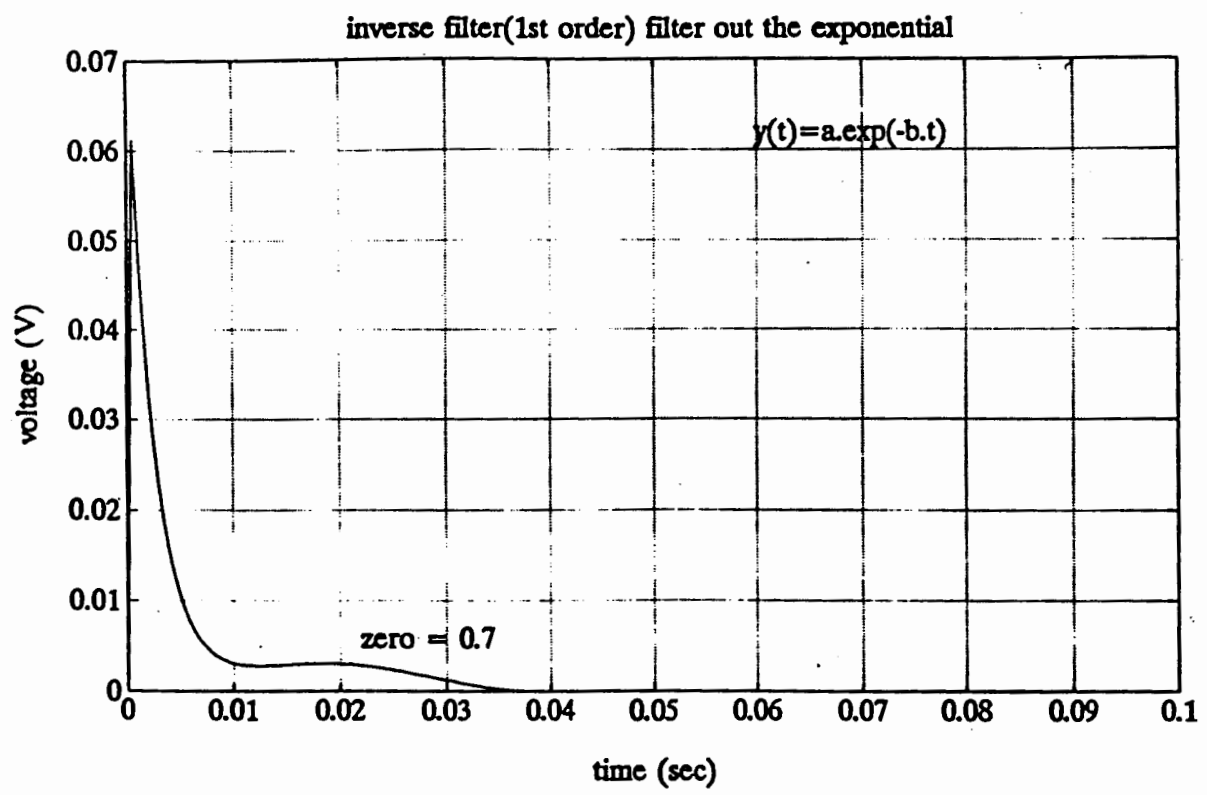

Figure 41. Change zero location (1st order inverse filter), zero $=0.7$. 


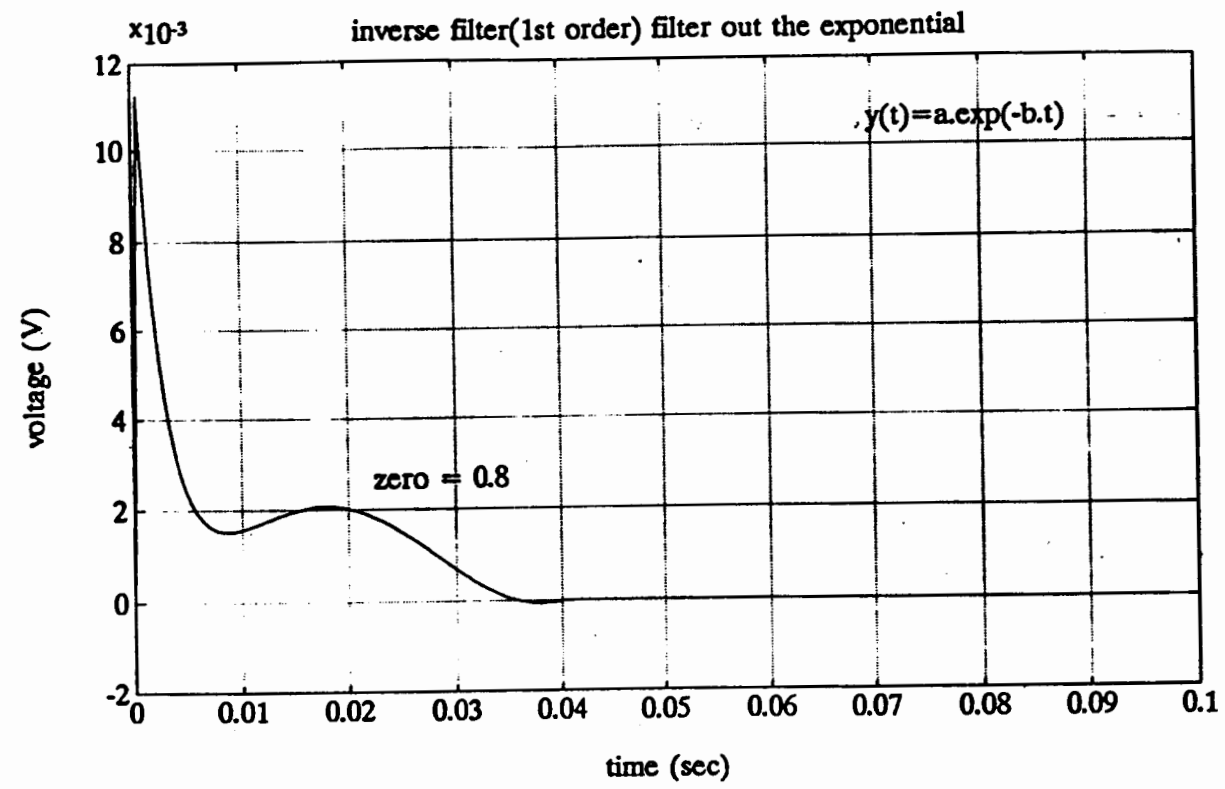

Figure 42. Change zero location (1st order inverse filter), zero $=0.8$.

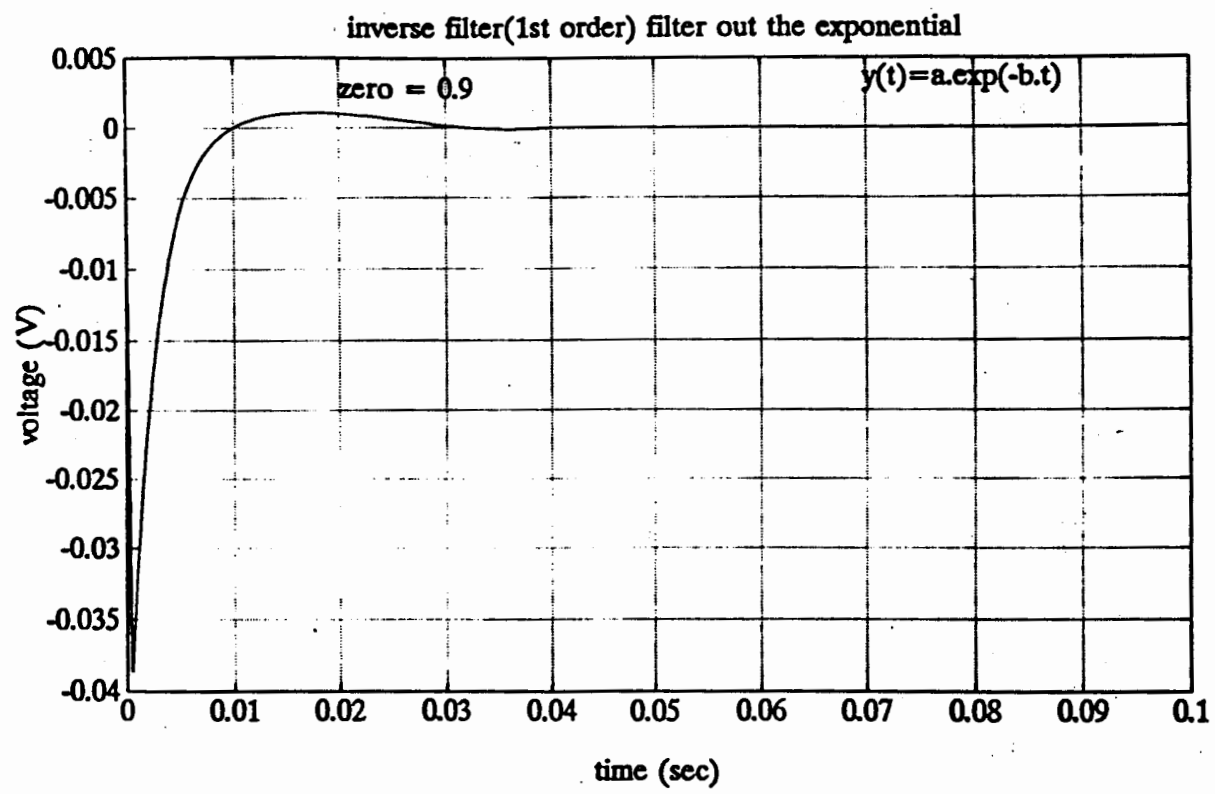

Figure 43. Change zero location (1st order inverse filter), zero $=0.9$. 


\section{TABLE I}

INVERSE FILTER (2ND ORDER) BEHAVIOR, WHERE INPUT SIGNAL = EXPONENTIAL ONLY: AT 0\%, B $=-400(1 / \mathrm{SEC}), \mathrm{A}=0.5 \mathrm{~V}$ IN A*EXP(-BT)

\begin{tabular}{|c|c|c|c|c|c|c|}
\hline $\begin{array}{l}\text { time } \\
\text { msec }\end{array}$ & $\begin{array}{l}08 \\
\mathrm{mV}\end{array}$ & $\begin{array}{l}.258 \\
\mathrm{mV}\end{array}$ & $\begin{array}{r}.5 \frac{9}{8} \\
\mathrm{mV}\end{array}$ & $\begin{array}{l}.758 \\
\mathrm{mV}\end{array}$ & $\begin{array}{l}18 \\
\mathrm{mV}\end{array}$ & $\begin{array}{l}28 \\
\mathrm{mV}\end{array}$ \\
\hline $\begin{array}{r}0.000 \\
0.488 \\
0.977 \\
1.465 \\
1.953 \\
2.441 \\
2.930 \\
3.418 \\
3.906 \\
4.395 \\
4.883 \\
5.371 \\
5.859 \\
6.348 \\
6.836 \\
7.324 \\
7.813 \\
8.301 \\
8.789 \\
9.277 \\
9.766 \\
10.254 \\
10.742 \\
11.230 \\
11.719 \\
12.207 \\
12.695 \\
13.184 \\
13.672 \\
14.160 \\
14.648 \\
15.137 \\
15.625 \\
16.113 \\
16.602 \\
17.090 \\
17.578 \\
18.066 \\
18.555\end{array}$ & $\begin{array}{r}500.000 \\
0.000 \\
-0.000 \\
0.000 \\
-0.000 \\
0.000 \\
-0.000 \\
0.000 \\
-0.000 \\
0.000 \\
0.000 \\
0.000 \\
-0.000 \\
0.000 \\
-0.000 \\
0.0000 \\
0.000 \\
0.000 \\
-0.000 \\
0.000 \\
-0.000 \\
0.000 \\
-0.000 \\
0.000 \\
0.000 \\
0.000 \\
-0.000 \\
0.000 \\
0.000 \\
0.000 \\
-0.000 \\
0.0000 \\
-0.000 \\
0.000 \\
-0.000 \\
0.000 \\
-0.000 \\
0.0000 \\
-0.000\end{array}$ & $\begin{array}{r}498.750 \\
0.000 \\
0.330 \\
0.000 \\
0.223 \\
0.000 \\
0.151 \\
0.000 \\
0.102 \\
0.000 \\
0.069 \\
0.000 \\
0.047 \\
0.000 \\
0.032 \\
0.000 \\
0.022 \\
0.000 \\
0.015 \\
0.000 \\
0.010 \\
0.000 \\
0.0007 \\
0.000 \\
0.005 \\
0.000 \\
0.003 \\
0.000 \\
0.002 \\
0.000 \\
0.001 \\
0.000 \\
0.001 \\
0.000 \\
0.001 \\
0.000 \\
0.000 \\
0.000 \\
0.000\end{array}$ & $\begin{array}{r}497.500 \\
0.000 \\
0.058 \\
0.000 \\
0.446 \\
0.000 \\
0.302 \\
0.000 \\
0.205 \\
0.000 \\
0.139 \\
0.000 \\
0.094 \\
0.000 \\
0.064 \\
0.000 \\
0.043 \\
0.000 \\
0.029 \\
0.000 \\
0.020 \\
0.000 \\
0.013 \\
0.000 \\
0.009 \\
0.000 \\
0.006 \\
0.000 \\
0.004 \\
0.000 \\
0.003 \\
0.000 \\
0.002 \\
0.000 \\
0.001 \\
0.000 \\
0.001 \\
0.000 \\
0.001\end{array}$ & $\begin{array}{r}496.250 \\
0.000 \\
0.985 \\
0.000 \\
0.669 \\
0.000 \\
0.454 \\
0.000 \\
0.308 \\
0.000 \\
0.209 \\
0.000 \\
0.142 \\
0.000 \\
0.096 \\
0.000 \\
0.065 \\
0.000 \\
0.044 \\
0.000 \\
0.030 \\
0.000 \\
0.020 \\
0.000 \\
0.014 \\
0.000 \\
0.009 \\
0.000 \\
0.006 \\
0.000 \\
0.004 \\
0.000 \\
0.003 \\
0.000 \\
0.002 \\
0.000 \\
0.001 \\
0.000 \\
0.001\end{array}$ & $\begin{array}{r}495.000 \\
0.000 \\
1.311 \\
0.000 \\
0.890 \\
0.000 \\
0.605 \\
0.000 \\
0.411 \\
0.000 \\
0.279 \\
0.000 \\
0.190 \\
0.000 \\
0.129 \\
0.000 \\
0.087 \\
0.000 \\
0.055 \\
0.000 \\
0.040 \\
0.000 \\
0.027 \\
0.000 \\
0.019 \\
0.000 \\
0.013 \\
0.000 \\
0.009 \\
0.000 \\
0.006 \\
0.000 \\
0.004 \\
0.000 \\
0.003 \\
0.000 \\
0.002 \\
0.000 \\
0.001\end{array}$ & $\begin{array}{l}490.000 \\
0.000 \\
2.000 \\
0.000 \\
1.773 \\
0.000 \\
1.209 \\
0.000 \\
0.825 \\
0.000 \\
0.562 \\
0.000 \\
0.384 \\
0.000 \\
0.262 \\
0.000 \\
0.178 \\
0.000 \\
0.122 \\
0.000 \\
0.083 \\
0.000 \\
0.057 \\
0.000 \\
0.039 \\
0.000 \\
0.026 \\
0.000 \\
0.018 \\
0.000 \\
0.012 \\
0.000 \\
0.008 \\
0.000 \\
0.006 \\
0.000 \\
0.004 \\
0.000 \\
0.003\end{array}$ \\
\hline
\end{tabular}


TABLE I

INVERSE FILTER (2ND ORDER) BEHAVIOR, WHERE INPUT SIGNAL = EXPONENTIAL ONLY: AT 0\%, $B=-400(1 / \mathrm{SEC}), \mathrm{A}=0.5 \mathrm{~V}$ IN A*EXP(-BT) (continued)

\begin{tabular}{|c|r|c|c|c|c|c|}
\hline $\begin{array}{c}\text { time } \\
\text { msec }\end{array}$ & \multicolumn{1}{c|}{$\begin{array}{c}\text { o8 } \\
\mathrm{mV}\end{array}$} & $\begin{array}{c}.258 \\
\mathrm{mV}\end{array}$ & $\begin{array}{c}.58 \\
\mathrm{mV}\end{array}$ & $\begin{array}{c}.758 \\
\mathrm{mV}\end{array}$ & $\begin{array}{c}18 \\
\mathrm{mV}\end{array}$ & $\begin{array}{c}28 \\
\mathrm{mV}\end{array}$ \\
\hline 19.043 & 0.000 & 0.000 & 0.000 & 0.000 & 0.000 & 0.000 \\
19.531 & -0.000 & 0.000 & 0.000 & 0.001 & 0.001 & 0.002 \\
20.020 & 0.000 & 0.000 & 0.000 & 0.000 & 0.000 & 0.000 \\
20.508 & -0.000 & 0.000 & 0.000 & 0.000 & 0.001 & 0.001 \\
20.996 & 0.000 & 0.000 & 0.000 & 0.000 & 0.000 & 0.000 \\
21.484 & -0.000 & 0.000 & 0.000 & 0.000 & 0.000 & 0.001 \\
21.973 & 0.000 & 0.000 & 0.000 & 0.000 & 0.000 & 0.000 \\
22.461 & -0.000 & 0.000 & 0.000 & 0.000 & 0.000 & 0.001 \\
22.949 & 0.000 & 0.000 & 0.000 & 0.000 & 0.000 & 0.000 \\
\hline
\end{tabular}


TABLE I

INVERSE FILTER (2ND ORDER) BEHAVIOR, WHERE INPUT SIGNAL = EXPONENTIAL ONLY: AT $0 \%, B=-400(1 / \mathrm{SEC}), \mathrm{A}=0.5 \mathrm{~V}$ IN A*EXP(-BT) (continued)

\begin{tabular}{|c|c|c|c|c|c|c|}
\hline $\begin{array}{l}\text { time } \\
\text { msec }\end{array}$ & $\begin{array}{l}3 \% \\
\mathrm{mV}\end{array}$ & $\begin{array}{l}4 \% \\
\mathrm{mV}\end{array}$ & $\begin{array}{l}5 \% \\
\mathrm{mV}\end{array}$ & $\begin{array}{l}68 \\
\mathrm{mV}\end{array}$ & $\begin{array}{l}7 \frac{8}{8} \\
\mathrm{mV}\end{array}$ & $\begin{array}{l}88 \\
\mathrm{mV}\end{array}$ \\
\hline $\begin{array}{l}0.000 \\
0.488 \\
0.977 \\
1.465 \\
1.953 \\
2.441 \\
2.930 \\
3.418 \\
3.906 \\
4.395 \\
4.883 \\
5.371 \\
5.859 \\
6.348 \\
6.836 \\
7.324 \\
7.813 \\
8.301 \\
8.789 \\
9.277 \\
9.766 \\
10.254 \\
10.742 \\
11.230 \\
11.719 \\
12.207 \\
12.695 \\
13.184 \\
13.672 \\
14.160 \\
14.648 \\
15.137 \\
15.625 \\
16.113 \\
16.602 \\
17.090 \\
17.578 \\
18.066\end{array}$ & $\begin{array}{l}485.000 \\
0.000 \\
3.868 \\
0.000 \\
2.648 \\
0.000 \\
1.813 \\
0.000 \\
1.241 \\
0.000 \\
0.850 \\
0.000 \\
0.582 \\
0.000 \\
0.398 \\
0.000 \\
0.273 \\
0.000 \\
0.187 \\
0.000 \\
0.128 \\
0.000 \\
0.087 \\
0.000 \\
0.060 \\
0.000 \\
0.04 \\
0.000 \\
0.028 \\
0.000 \\
0.019 \\
0.000 \\
0.013 \\
0.000 \\
0.000 \\
0.000 \\
0.006 \\
0.000\end{array}$ & $\begin{array}{l}4.80 .000 \\
0.000 \\
5.115 \\
0.000 \\
3.515 \\
0.000 \\
2.416 \\
0.000 \\
1.660 \\
0.000 \\
1.141 \\
0.000 \\
0.784 \\
0.000 \\
0.539 \\
0.000 \\
0.371 \\
0.000 \\
0.255 \\
0.000 \\
0.175 \\
0.000 \\
0.120 \\
0.000 \\
0.083 \\
0.000 \\
0.057 \\
0.000 \\
0.039 \\
0.000 \\
0.027 \\
0.000 \\
0.018 \\
0.000 \\
0.013 \\
0.000 \\
0.009 \\
0.000\end{array}$ & $\begin{array}{l}475.000 \\
0.000 \\
6.339 \\
0.000 \\
4.374 \\
0.000 \\
3.018 \\
0.000 \\
2.082 \\
0.000 \\
1.437 \\
0.000 \\
0.991 \\
0.000 \\
0.684 \\
0.000 \\
0.472 \\
0.000 \\
0.326 \\
0.000 \\
0.225 \\
0.000 \\
0.155 \\
0.000 \\
0.107 \\
0.000 \\
0.074 \\
0.000 \\
0.051 \\
0.000 \\
0.035 \\
0.000 \\
0.024 \\
0.000 \\
0.017 \\
0.000 \\
0.012 \\
0.000\end{array}$ & $\begin{array}{c}470.000 \\
0.000 \\
7.542 \\
0.000 \\
5.224 \\
0.000 \\
3.618 \\
0.000 \\
2.506 \\
0.000 \\
1.736 \\
0.000 \\
1.203 \\
0.000 \\
0.833 \\
0.000 \\
0.577 \\
0.000 \\
0.400 \\
0.000 \\
0.277 \\
0.000 \\
0.192 \\
0.000 \\
0.133 \\
0.000 \\
0.092 \\
0.000 \\
0.064 \\
0.000 \\
0.044 \\
0.000 \\
0.031 \\
0.000 \\
0.021 \\
0.000 \\
0.015 \\
0.000\end{array}$ & $\begin{array}{l}465.000 \\
0.000 \\
8.722 \\
0.000 \\
6.065 \\
0.000 \\
4.218 \\
0.000 \\
2.933 \\
0.000 \\
2.040 \\
0.000 \\
1.418 \\
0.000 \\
0.986 \\
0.000 \\
0.686 \\
0.000 \\
0.477 \\
0.000 \\
0.332 \\
0.000 \\
0.231 \\
0.000 \\
0.160 \\
0.000 \\
0.112 \\
0.000 \\
0.078 \\
0.000 \\
0.054 \\
0.000 \\
0.038 \\
0.000 \\
0.026 \\
0.000 \\
0.018 \\
0.000\end{array}$ & $\begin{array}{l}460.000 \\
0.000 \\
9.880 \\
0.000 \\
6.897 \\
0.000 \\
4.815 \\
0.000 \\
3.362 \\
0.000 \\
2.347 \\
0.000 \\
1.638 \\
0.000 \\
1.144 \\
0.000 \\
0.798 \\
0.000 \\
0.557 \\
0.000 \\
0.389 \\
0.000 \\
0.272 \\
0.000 \\
0.190 \\
0.000 \\
0.132 \\
0.000 \\
0.092 \\
0.000 \\
0.065 \\
0.000 \\
0.045 \\
0.000 \\
0.031 \\
0.000 \\
0.022 \\
0.000\end{array}$ \\
\hline
\end{tabular}


TABLE I

INVERSE FILTER (2ND ORDER) BEHAVIOR, WHERE INPUT SIGNAL = EXPONENTIAL ONLY: AT $0 \%, B=-400(1 / S E C), A=0.5 V$ IN A*EXP(-BT) (continued)

\begin{tabular}{|c|c|c|c|c|c|c|}
\hline $\begin{array}{c}\text { time } \\
\mathrm{msec}\end{array}$ & $\begin{array}{c}38 \\
\mathrm{mV}\end{array}$ & $\begin{array}{c}48 \\
\mathrm{mV}\end{array}$ & $\begin{array}{c}58 \\
\mathrm{mV}\end{array}$ & $\begin{array}{c}68 \\
\mathrm{mV}\end{array}$ & $\begin{array}{c}78 \\
\mathrm{mV}\end{array}$ & $\begin{array}{c}88 \\
\mathrm{mV}\end{array}$ \\
\hline 18.555 & 0.004 & 0.006 & 0.008 & 0.010 & 0.013 & 0.015 \\
19.043 & 0.000 & 0.000 & 0.000 & 0.000 & 0.000 & 0.000 \\
19.531 & 0.003 & 0.004 & 0.005 & 0.007 & 0.009 & 0.011 \\
20.020 & 0.000 & 0.000 & 0.000 & 0.000 & 0.000 & 0.000 \\
20.508 & 0.002 & 0.003 & 0.004 & 0.005 & 0.006 & 0.007 \\
20.996 & 0.000 & 0.000 & 0.000 & 0.000 & 0.000 & 0.000 \\
21.484 & 0.001 & 0.002 & 0.003 & 0.003 & 0.004 & 0.005 \\
21.973 & 0.000 & 0.000 & 0.000 & 0.000 & 0.000 & 0.000 \\
22.461 & 0.001 & 0.001 & 0.002 & 0.002 & 0.003 & 0.004 \\
22.949 & 0.000 & 0.000 & 0.000 & 0.000 & 0.000 & 0.000 \\
23.438 & 0.001 & 0.001 & 0.001 & 0.002 & 0.002 & 0.003 \\
23.926 & 0.000 & 0.000 & 0.000 & 0.000 & 0.000 & 0.000 \\
24.414 & 0.000 & 0.001 & 0.001 & 0.001 & 0.001 & 0.002 \\
24.902 & 0.000 & 0.000 & 0.000 & 0.000 & 0.000 & 0.000 \\
25.391 & 0.000 & 0.000 & 0.001 & 0.001 & 0.001 & 0.001 \\
25.879 & 0.000 & 0.000 & 0.000 & 0.000 & 0.000 & 0.000 \\
26.367 & 0.000 & 0.000 & 0.000 & 0.001 & 0.001 & 0.001 \\
26.855 & 0.000 & 0.000 & 0.000 & 0.000 & 0.000 & 0.000 \\
\hline
\end{tabular}


TABLE I

INVERSE FILTER (2ND ORDER) BEHAVIOR, WHERE INPUT SIGNAL = EXPONENTIAL ONLY: AT 0\%, $B=-400(1 / \mathrm{SEC}), \mathrm{A}=0.5 \mathrm{~V}$ IN A*EXP(-BT)

(continued)

\begin{tabular}{|c|c|c|c|c|c|c|c|}
\hline $\begin{array}{l}\text { time } \\
\text { msec }\end{array}$ & $\begin{array}{l}9 \% \\
\mathrm{mV}\end{array}$ & $\begin{array}{l}10 \% \\
\mathrm{mV}\end{array}$ & $\begin{array}{l}11 \% \\
\mathrm{mV}\end{array}$ & $\begin{array}{l}12 \% \\
\mathrm{mV}\end{array}$ & $\begin{array}{l}13 \% \\
\mathrm{mV}\end{array}$ & $\begin{array}{l}14 \% \\
\mathrm{mV}\end{array}$ & $\begin{array}{l}15 \% \\
\mathrm{mV}\end{array}$ \\
\hline $\begin{array}{r}0.00 \\
0.49 \\
0.98 \\
1.47 \\
1.95 \\
2.44 \\
2.93 \\
3.42 \\
3.91 \\
4.40 \\
4.88 \\
5.37 \\
5.86 \\
6.35 \\
6.84 \\
7.32 \\
7.81 \\
8.30 \\
8.79 \\
9.28 \\
9.77 \\
10.25 \\
10.74 \\
11.23 \\
11.72 \\
12.21 \\
12.70 \\
13.18 \\
13.67 \\
14.16 \\
14.65 \\
15.14 \\
15.62 \\
16.11 \\
16.60 \\
17.10 \\
17.58\end{array}$ & $\begin{array}{r}455.0 \\
0.00 \\
11.02 \\
0.00 \\
7.72 \\
0.00 \\
5.41 \\
0.00 \\
3.79 \\
0.00 \\
2.66 \\
0.00 \\
1.86 \\
0.00 \\
1.31 \\
0.00 \\
0.09 \\
0.00 \\
0.64 \\
0.00 \\
0.45 \\
0.00 \\
0.32 \\
0.00 \\
0.22 \\
0.00 \\
0.16 \\
0.00 \\
0.11 \\
0.00 \\
0.08 \\
0.00 \\
0.00 \\
0.00 \\
0.04 \\
0.00 \\
0.03\end{array}$ & $\begin{array}{r}450.0 \\
0.00 \\
12.13 \\
0.00 \\
8.53 \\
0.00 \\
6.00 \\
0.00 \\
4.23 \\
0.00 \\
2.97 \\
0.00 \\
2.10 \\
0.00 \\
1.47 \\
0.00 \\
1.04 \\
0.00 \\
0.73 \\
0.00 \\
0.51 \\
0.00 \\
0.36 \\
0.00 \\
0.25 \\
0.00 \\
0.18 \\
0.00 \\
0.13 \\
0.00 \\
0.09 \\
0.00 \\
0.06 \\
0.00 \\
0.04 \\
0.00 \\
0.03\end{array}$ & $\begin{array}{r}445.0 \\
0.00 \\
13.22 \\
0.00 \\
9.34 \\
0.00 \\
6.60 \\
0.00 \\
4.60 \\
0.00 \\
3.30 \\
0.00 \\
2.32 \\
0.00 \\
1.64 \\
0.00 \\
1.16 \\
0.00 \\
0.82 \\
0.00 \\
0.58 \\
0.00 \\
0.41 \\
0.00 \\
0.29 \\
0.00 \\
0.20 \\
0.00 \\
0.14 \\
0.00 \\
0.10 \\
0.00 \\
0.07 \\
0.00 \\
0.05 \\
0.00 \\
0.04\end{array}$ & $\begin{array}{r}440.0 \\
0.00 \\
14.29 \\
0.00 \\
10.13 \\
0.00 \\
7.18 \\
0.00 \\
5.09 \\
0.00 \\
3.01 \\
0.00 \\
2.56 \\
0.00 \\
1.82 \\
0.00 \\
1.29 \\
0.00 \\
0.91 \\
0.00 \\
0.65 \\
0.00 \\
0.46 \\
0.00 \\
0.33 \\
0.00 \\
0.23 \\
0.00 \\
0.16 \\
0.00 \\
0.12 \\
0.00 \\
0.08 \\
0.00 \\
0.00 \\
0.00 \\
0.04\end{array}$ & $\begin{array}{r}435.0 \\
0.00 \\
15.33 \\
0.00 \\
10.92 \\
0.00 \\
7.77 \\
0.00 \\
5.53 \\
0.00 \\
3.94 \\
0.00 \\
2.00 \\
0.00 \\
2.00 \\
0.00 \\
1.42 \\
0.00 \\
1.00 \\
0.00 \\
0.72 \\
0.00 \\
0.51 \\
0.01 \\
0.00 \\
0.37 \\
0.00 \\
0.26 \\
0.00 \\
0.16 \\
0.00 \\
0.13 \\
0.00 \\
0.09 \\
0.00 \\
0.00 \\
0.00 \\
0.00\end{array}$ & $\begin{array}{r}430.0 \\
0.00 \\
16.36 \\
0.00 \\
11.09 \\
0.00 \\
8.35 \\
0.00 \\
5.97 \\
0.00 \\
4.27 \\
0.00 \\
3.05 \\
0.00 \\
2.18 \\
0.00 \\
1.05 \\
0.00 \\
1.011 \\
0.00 \\
0.80 \\
0.00 \\
0.57 \\
0.00 \\
0.40 \\
0.00 \\
0.30 \\
0.00 \\
0.00 \\
0.00 \\
0.15 \\
0.00 \\
0.11 \\
0.00 \\
0.00 \\
0.00 \\
0.00\end{array}$ & $\begin{array}{r}425.0 \\
0.00 \\
17.35 \\
0.00 \\
12.45 \\
0.00 \\
8.93 \\
0.00 \\
6.41 \\
0.00 \\
4.60 \\
0.00 \\
3.30 \\
0.00 \\
2.37 \\
0.00 \\
1.70 \\
0.00 \\
1.22 \\
0.00 \\
0.87 \\
0.00 \\
0.63 \\
0.00 \\
0.45 \\
0.00 \\
0.32 \\
0.00 \\
0.23 \\
0.00 \\
0.17 \\
0.00 \\
0.12 \\
0.00 \\
0.09 \\
0.00 \\
0.06\end{array}$ \\
\hline
\end{tabular}


TABLE I

INVERSE FILTER (2ND ORDER) BEHAVIOR, WHERE INPUT SIGNAL = EXPONENTIAL ONLY: AT 0\%, B = -400(1/SEC), A=0.5V IN A*EXP(-BT) (continued)

\begin{tabular}{|c|c|c|c|c|c|c|c|}
\hline $\begin{array}{c}\text { time } \\
\mathrm{msec}\end{array}$ & $\begin{array}{c}9 \% \\
\mathrm{mV}\end{array}$ & $\begin{array}{c}10 \% \\
\mathrm{mV}\end{array}$ & $\begin{array}{c}11 \% \\
\mathrm{mV}\end{array}$ & $\begin{array}{c}12 \% \\
\mathrm{mV}\end{array}$ & $\begin{array}{c}13 \% \\
\mathrm{mV}\end{array}$ & $\begin{array}{c}14 \% \\
\mathrm{mV}\end{array}$ & $\begin{array}{c}15 \% \\
\mathrm{mV}\end{array}$ \\
\hline 18.07 & 0.00 & 0.00 & 0.00 & 0.00 & 0.00 & 0.00 & 0.00 \\
18.56 & 0.02 & 0.02 & 0.03 & 0.03 & 0.03 & 0.04 & 0.04 \\
19.04 & 0.00 & 0.00 & 0.00 & 0.00 & 0.00 & 0.00 & 0.00 \\
19.53 & 0.01 & 0.02 & 0.02 & 0.02 & 0.02 & 0.03 & 0.03 \\
20.02 & 0.00 & 0.00 & 0.00 & 0.00 & 0.00 & 0.00 & 0.00 \\
20.51 & 0.01 & 0.01 & 0.01 & 0.02 & 0.02 & 0.02 & 0.02 \\
21.48 & 0.00 & 0.00 & 0.00 & 0.00 & 0.00 & 0.00 & 0.00 \\
21.97 & 0.01 & 0.01 & 0.01 & 0.01 & 0.01 & 0.01 & 0.02 \\
22.46 & 0.00 & 0.00 & 0.00 & 0.00 & 0.00 & 0.00 & 0.00 \\
22.95 & 0.00 & 0.01 & 0.01 & 0.01 & 0.01 & 0.01 & 0.01 \\
23.44 & 0.00 & 0.00 & 0.00 & 0.00 & 0.00 & 0.00 & 0.00 \\
23.93 & 0.00 & 0.00 & 0.00 & 0.01 & 0.01 & 0.01 & 0.01 \\
24.41 & 0.00 & 0.00 & 0.00 & 0.00 & 0.00 & 0.00 & 0.00 \\
24.90 & 0.00 & 0.00 & 0.00 & 0.00 & 0.00 & 0.01 & 0.01 \\
25.39 & 0.00 & 0.00 & 0.00 & 0.00 & 0.00 & 0.00 & 0.00 \\
25.88 & 0.00 & 0.00 & 0.00 & 0.00 & 0.00 & 0.00 & 0.00 \\
26.37 & 0.00 & 0.00 & 0.00 & 0.00 & 0.00 & 0.00 & 0.00 \\
26.86 & 0.00 & 0.00 & 0.00 & 0.00 & 0.00 & 0.00 & 0.00 \\
\hline
\end{tabular}


TABLE II

INVERSE FILTER BEHAVIOR (2ND ORDER) RESULTING FROM CHANGING A AND B IN A*EXP(-BT). INPUT SIGNAL = EXPONENTIAL + HAVERSINE

\begin{tabular}{|c|c|c|c|c|c|c|}
\hline $\begin{array}{l}\text { time } \\
\text { msec }\end{array}$ & $\begin{array}{l}09 \\
\mathrm{mV}\end{array}$ & $\dot{m V}^{25 \%}$ & $\dot{\mathrm{mV}}^{50 \%}$ & $\dot{\mathrm{mV}}^{.75 \%}$ & $\frac{18}{m V}$ & $\frac{28}{\mathrm{mV}}$ \\
\hline $\begin{array}{l}0.000 \\
0.488 \\
0.977 \\
1.465 \\
1.953 \\
2.441 \\
2.930 \\
3.418 \\
3.906 \\
4.395 \\
4.883 \\
5.371 \\
5.859 \\
6.348 \\
6.836 \\
7.324 \\
7.813 \\
8.301 \\
8.789 \\
9.277 \\
9.766 \\
10.254 \\
10.742 \\
11.230 \\
11.719 \\
12.207 \\
12.695 \\
13.184 \\
13.672 \\
14.160 \\
14.648 \\
15.137 \\
15.625 \\
16.113 \\
16.602 \\
17.090 \\
17.578 \\
18.066 \\
18.555\end{array}$ & $\begin{array}{r}500.000 \\
0.015 \\
0.059 \\
0.122 \\
0.194 \\
0.274 \\
0.362 \\
0.458 \\
0.560 \\
0.669 \\
0.783 \\
0.902 \\
1.025 \\
1.152 \\
1.281 \\
1.413 \\
1.545 \\
1.679 \\
1.811 \\
1.943 \\
2.072 \\
2.199 \\
2.323 \\
2.442 \\
2.557 \\
2.666 \\
2.769 \\
2.865 \\
2.954 \\
3.034 \\
3.107 \\
3.171 \\
3.225 \\
3.270 \\
3.306 \\
3.331 \\
3.347 \\
3.352 \\
3.347\end{array}$ & $\begin{array}{r}498.750 \\
0.015 \\
0.388 \\
0.122 \\
0.417 \\
0.274 \\
0.513 \\
0.458 \\
0.663 \\
0.669 \\
0.852 \\
0.902 \\
1.072 \\
1.152 \\
1.313 \\
1.413 \\
1.567 \\
1.679 \\
1.826 \\
1.943 \\
2.082 \\
2.199 \\
2.330 \\
2.442 \\
2.561 \\
2.666 \\
2.772 \\
2.865 \\
2.956 \\
3.034 \\
3.108 \\
3.171 \\
3.226 \\
3.270 \\
3.307 \\
3.331 \\
3.347 \\
3.352 \\
3.348\end{array}$ & $\begin{array}{r}497.500 \\
0.015 \\
0.717 \\
0.122 \\
0.640 \\
0.274 \\
0.665 \\
0.458 \\
0.765 \\
0.669 \\
0.922 \\
0.902 \\
1.119 \\
1.152 \\
1.345 \\
1.413 \\
1.589 \\
1.679 \\
1.841 \\
1.943 \\
2.092 \\
2.199 \\
2.336 \\
2.442 \\
2.566 \\
2.666 \\
2.775 \\
2.865 \\
2.958 \\
3.034 \\
3.110 \\
3.171 \\
3.227 \\
3.270 \\
3.307 \\
3.331 \\
3.348 \\
3.352 \\
3.348\end{array}$ & $\begin{array}{r}496.250 \\
0.015 \\
1.044 \\
0.122 \\
0.862 \\
0.274 \\
0.816 \\
0.458 \\
0.868 \\
0.669 \\
0.992 \\
0.902 \\
1.167 \\
1.152 \\
1.378 \\
1.413 \\
1.611 \\
1.679 \\
1.856 \\
1.943 \\
2.103 \\
2.199 \\
2.343 \\
2.442 \\
2.571 \\
2.666 \\
2.778 \\
2.865 \\
2.960 \\
3.034 \\
3.111 \\
3.171 \\
3.228 \\
3.270 \\
3.308 \\
3.331 \\
3.348 \\
3.352 \\
3.348\end{array}$ & $\begin{array}{r}495.00 \\
0.015 \\
1.370 \\
0.122 \\
1.084 \\
0.274 \\
0.967 \\
0.458 \\
0.971 \\
0.669 \\
1.062 \\
0.902 \\
1.215 \\
1.152 \\
1.410 \\
1.413 \\
1.633 \\
1.679 \\
1.871 \\
1.943 \\
2.113 \\
2.199 \\
2.350 \\
2.442 \\
2.575 \\
2.666 \\
2.781 \\
2.865 \\
2.962 \\
3.034 \\
3.113 \\
3.171 \\
3.229 \\
3.270 \\
3.309 \\
3.331 \\
3.349 \\
3.352 \\
3.348\end{array}$ & $\begin{array}{r}490.00 \\
0.015 \\
2.659 \\
0.122 \\
1.967 \\
0.274 \\
1.571 \\
0.458 \\
1.385 \\
0.669 \\
1.345 \\
0.902 \\
1.409 \\
1.152 \\
1.543 \\
1.413 \\
1.724 \\
1.679 \\
1.933 \\
1.943 \\
2.155 \\
2.199 \\
2.380 \\
2.442 \\
2.595 \\
2.666 \\
2.795 \\
2.865 \\
2.971 \\
3.034 \\
3.119 \\
3.171 \\
3.234 \\
3.270 \\
3.312 \\
3.331 \\
3.351 \\
3.352 \\
3.350\end{array}$ \\
\hline
\end{tabular}


TABLE II

INVERSE FILTER BEHAVIOR (2ND ORDER) RESULTING FROM CHANGING A AND B IN A*EXP(-BT). INPUT SIGNAL = EXPONENTIAL + HAVERSINE (continued)

\begin{tabular}{|c|c|c|c|c|c|c|}
\hline $\begin{array}{l}\text { time } \\
\text { msec }\end{array}$ & $\mathrm{mV}$ & $\dot{\mathrm{mV}}^{.25 \%}$ & $\begin{array}{l}.508 \\
\mathrm{mV}\end{array}$ & $\dot{\mathrm{mV}}^{.758}$ & $\mathrm{mV}^{18}$ & $\mathrm{mV}^{28}$ \\
\hline $\begin{array}{l}19.043 \\
19.531 \\
20.020 \\
20.508 \\
20.996 \\
21.484 \\
21.973 \\
22.461 \\
22.949 \\
23.438 \\
23.926 \\
24.414 \\
24.902 \\
25.391 \\
25.879 \\
26.367 \\
26.855 \\
27.344 \\
27.832 \\
28.320 \\
28.809 \\
29.297 \\
29.785 \\
30.273 \\
30.762 \\
31.250 \\
31.738 \\
32.227 \\
32.715 \\
33.203 \\
33.691 \\
34.180 \\
34.668 \\
35.156 \\
35.645 \\
36.133 \\
36.621 \\
37.109\end{array}$ & $\begin{array}{r}3.332 \\
3.307 \\
3.272 \\
3.227 \\
3.173 \\
3.109 \\
3.037 \\
2.956 \\
2.868 \\
2.772 \\
2.669 \\
2.561 \\
2.446 \\
2.327 \\
2.203 \\
2.077 \\
1.947 \\
1.816 \\
1.683 \\
1.550 \\
1.417 \\
1.286 \\
1.156 \\
1.029 \\
0.906 \\
0.787 \\
0.672 \\
0.564 \\
0.461 \\
0.365 \\
0.277 \\
0.196 \\
0.124 \\
0.061 \\
0.006 \\
-0.038 \\
-0.073 \\
-0.099\end{array}$ & $\begin{array}{r}3.332 \\
3.307 \\
3.272 \\
3.227 \\
3.173 \\
3.109 \\
3.037 \\
2.956 \\
2.868 \\
2.772 \\
2.669 \\
2.561 \\
2.446 \\
2.327 \\
2.203 \\
2.077 \\
1.947 \\
1.816 \\
1.683 \\
1.550 \\
1.417 \\
1.286 \\
1.156 \\
1.029 \\
0.906 \\
0.787 \\
0.672 \\
0.564 \\
0.461 \\
0.365 \\
0.277 \\
0.196 \\
0.124 \\
0.061 \\
0.006 \\
-0.038 \\
-0.073 \\
-0.099\end{array}$ & $\begin{array}{r}3.332 \\
3.307 \\
3.272 \\
3.227 \\
3.173 \\
3.109 \\
3.037 \\
2.956 \\
2.868 \\
2.772 \\
2.669 \\
2.561 \\
2.446 \\
2.327 \\
2.203 \\
2.077 \\
1.947 \\
1.816 \\
1.683 \\
1.550 \\
1.417 \\
1.286 \\
1.156 \\
1.029 \\
0.906 \\
0.787 \\
0.672 \\
0.564 \\
0.461 \\
0.365 \\
0.277 \\
0.196 \\
0.124 \\
0.061 \\
0.006 \\
-0.038 \\
-0.073 \\
-0.099\end{array}$ & $\begin{array}{r}3.332 \\
3.308 \\
3.272 \\
3.227 \\
3.173 \\
3.109 \\
3.037 \\
2.956 \\
2.868 \\
2.772 \\
2.669 \\
2.561 \\
2.446 \\
2.327 \\
2.203 \\
2.077 \\
1.947 \\
1.816 \\
1.683 \\
1.550 \\
1.417 \\
1.286 \\
1.156 \\
1.029 \\
0.906 \\
0.787 \\
0.672 \\
0.564 \\
0.461 \\
0.365 \\
0.277 \\
0.196 \\
0.124 \\
0.061 \\
0.006 \\
-0.038 \\
-0.073 \\
-0.099\end{array}$ & $\begin{array}{r}3.332 \\
3.308 \\
3.272 \\
3.228 \\
3.173 \\
3.110 \\
3.037 \\
2.957 \\
2.868 \\
2.772 \\
2.669 \\
2.561 \\
2.446 \\
2.327 \\
2.203 \\
2.077 \\
1.947 \\
1.816 \\
1.683 \\
1.550 \\
1.417 \\
1.286 \\
1.156 \\
1.029 \\
0.906 \\
0.787 \\
0.672 \\
0.564 \\
0.461 \\
0.365 \\
0.277 \\
0.196 \\
0.124 \\
0.061 \\
0.006 \\
-0.038 \\
-0.073 \\
-0.099\end{array}$ & $\begin{array}{r}3.332 \\
3.309 \\
3.272 \\
3.228 \\
3.173 \\
3.110 \\
3.037 \\
2.957 \\
2.868 \\
2.772 \\
2.669 \\
2.561 \\
2.446 \\
2.327 \\
2.203 \\
2.077 \\
1.947 \\
1.816 \\
1.683 \\
1.550 \\
1.417 \\
1.286 \\
1.156 \\
1.029 \\
0.906 \\
0.787 \\
0.672 \\
0.564 \\
0.461 \\
0.365 \\
0.277 \\
0.196 \\
0.124 \\
0.061 \\
0.006 \\
-0.038 \\
0.073 \\
-0.099\end{array}$ \\
\hline
\end{tabular}


TABLE II

INVERSE FILTER BEHAVIOR (2ND ORDER) RESULTING FROM CHANGING A AND B IN A*EXP(-BT). INPUT SIGNAL = EXPONENTIAL + HAVERSINE (continued)

\begin{tabular}{|r|r|r|r|r|r|c|}
\hline $\begin{array}{c}\text { time } \\
\mathrm{msec}\end{array}$ & \multicolumn{1}{|c|}{$\begin{array}{c}\text { m8 } \\
\mathrm{mV}\end{array}$} & \multicolumn{1}{|c|}{$\begin{array}{c}\text { mV } \\
\mathrm{mV}\end{array}$} & $\begin{array}{c}.508 \\
\mathrm{mV}\end{array}$ & $\begin{array}{c}.758 \\
\mathrm{mV}\end{array}$ & $\begin{array}{c}18 \\
\mathrm{mV}\end{array}$ & $\begin{array}{c}28 \\
\mathrm{mV}\end{array}$ \\
\hline 37.598 & -0.114 & -0.114 & -0.114 & -0.114 & -0.114 & -0.114 \\
38.086 & -0.119 & -0.119 & -0.119 & -0.119 & -0.119 & -0.119 \\
38.574 & -0.113 & -0.113 & -0.113 & -0.113 & -0.113 & -0.113 \\
39.063 & -0.098 & -0.098 & -0.098 & -0.098 & -0.098 & -0.098 \\
39.551 & -0.072 & -0.072 & -0.072 & -0.072 & -0.072 & -0.072 \\
40.039 & -0.037 & -0.037 & -0.037 & -0.037 & -0.037 & -0.037 \\
40.527 & -0.008 & -0.008 & -0.008 & -0.008 & -0.008 & -0.008 \\
41.016 & -0.000 & 0.000 & 0.000 & 0.000 & 0.000 & 0.000 \\
41.504 & 0.000 & 0.000 & 0.000 & 0.000 & 0.000 & 0.000 \\
41.992 & -0.000 & 0.000 & 0.000 & 0.000 & 0.000 & 0.000 \\
42.480 & 0.000 & 0.000 & 0.000 & 0.000 & 0.000 & 0.000 \\
42.969 & -0.000 & 0.000 & 0.000 & 0.000 & 0.000 & 0.000 \\
43.457 & 0.000 & 0.000 & 0.000 & 0.000 & 0.000 & 0.000 \\
43.945 & -0.000 & 0.000 & 0.000 & 0.000 & 0.000 & 0.000 \\
44.434 & 0.000 & 0.000 & 0.000 & 0.000 & 0.000 & 0.000 \\
44.922 & -0.000 & 0.000 & 0.000 & 0.000 & 0.000 & 0.000 \\
45.410 & 0.000 & 0.000 & 0.000 & 0.000 & 0.000 & 0.000 \\
45.898 & -0.000 & 0.000 & 0.000 & 0.000 & 0.000 & 0.000 \\
46.387 & 0.000 & 0.000 & 0.000 & 0.000 & 0.000 & 0.000 \\
46.875 & -0.000 & 0.000 & 0.000 & 0.000 & 0.000 & 0.000 \\
47.363 & 0.000 & 0.000 & 0.000 & 0.000 & 0.000 & 0.000 \\
47.852 & -0.000 & 0.000 & 0.000 & 0.000 & 0.000 & 0.000 \\
48.340 & 0.000 & 0.000 & 0.000 & 0.000 & 0.000 & 0.000 \\
48.828 & -0.000 & 0.000 & 0.000 & 0.000 & 0.000 & 0.000 \\
49.316 & 0.000 & 0.000 & 0.000 & 0.000 & 0.000 & 0.000 \\
49.805 & -0.000 & 0.000 & 0.000 & 0.000 & 0.000 & 0.000 \\
50.293 & 0.000 & 0.000 & 0.000 & 0.000 & 0.000 & 0.000 \\
50.781 & -0.000 & 0.000 & 0.000 & 0.000 & 0.000 & 0.000 \\
\hline
\end{tabular}


TABLE II

INVERSE FILTER BEHAVIOR (2ND ORDER) RESULTING FROM CHANGING A AND B IN A*EXP(-BT). INPUT SIGNAL = EXPONENTIAL + HAVERSINE (continued)

\begin{tabular}{|c|c|c|c|c|c|c|}
\hline $\begin{array}{l}\text { time } \\
\text { msec }\end{array}$ & $\begin{array}{l}3 \% \\
\mathrm{mV}\end{array}$ & $\begin{array}{l}4 \% \\
\mathrm{mV}\end{array}$ & $\begin{array}{l}5 \% \\
\mathrm{mV}\end{array}$ & $\begin{array}{l}6 \% \\
\mathrm{mV}\end{array}$ & $\begin{array}{l}7 \% \\
\mathrm{mV}\end{array}$ & $\begin{array}{l}8 \% \\
\mathrm{mV}\end{array}$ \\
\hline $\begin{array}{r}0.000 \\
0.488 \\
0.977 \\
1.465 \\
1.953 \\
2.441 \\
2.930 \\
3.418 \\
3.906 \\
4.395 \\
4.883 \\
5.371 \\
5.859 \\
6.348 \\
6.836 \\
7.324 \\
7.813 \\
8.301 \\
8.789 \\
9.277 \\
9.766 \\
10.254 \\
10.742 \\
11.230 \\
11.719 \\
12.207 \\
12.695 \\
13.184 \\
13.672 \\
14.160 \\
14.648 \\
15.137 \\
15.625 \\
16.113 \\
16.602 \\
17.090 \\
17.578 \\
18.066\end{array}$ & $\begin{array}{r}485.000 \\
0.015 \\
3.927 \\
0.122 \\
2.842 \\
0.274 \\
2.175 \\
0.458 \\
1.801 \\
0.669 \\
1.633 \\
0.902 \\
1.607 \\
1.152 \\
1.680 \\
1.413 \\
1.818 \\
1.679 \\
1.998 \\
1.943 \\
2.200 \\
2.199 \\
2.410 \\
2.442 \\
2.617 \\
2.666 \\
2.810 \\
2.865 \\
2.982 \\
3.034 \\
3.126 \\
3.171 \\
3.238 \\
3.270 \\
3.315 \\
3.331 \\
3.353 \\
3.352\end{array}$ & $\begin{array}{r}480.000 \\
0.015 \\
5.173 \\
0.122 \\
3.709 \\
0.274 \\
2.778 \\
0.458 \\
2.221 \\
0.669 \\
1.924 \\
0.902 \\
1.810 \\
1.152 \\
1.820 \\
1.413 \\
1.916 \\
1.679 \\
2.066 \\
1.943 \\
2.247 \\
2.199 \\
2.443 \\
2.442 \\
2.640 \\
2.666 \\
2.826 \\
2.865 \\
2.993 \\
3.034 \\
3.134 \\
3.171 \\
3.244 \\
3.270 \\
3.319 \\
3.331 \\
3.356 \\
3.352\end{array}$ & $\begin{array}{r}475.000 \\
0.015 \\
6.398 \\
0.122 \\
4.568 \\
0.274 \\
3.380 \\
0.458 \\
2.642 \\
0.669 \\
2.220 \\
0.902 \\
2.016 \\
1.152 \\
1.965 \\
1.413 \\
2.017 \\
1.679 \\
2.137 \\
1.943 \\
2.297 \\
2.199 \\
2.478 \\
2.442 \\
2.664 \\
2.666 \\
2.843 \\
2.865 \\
3.004 \\
3.034 \\
3.142 \\
3.171 \\
3.250 \\
3.270 \\
3.323 \\
3.331 \\
3.358 \\
3.352\end{array}$ & $\begin{array}{r}470.000 \\
0.015 \\
7.600 \\
0.122 \\
5.418 \\
0.274 \\
3.981 \\
0.458 \\
3.067 \\
0.669 \\
2.519 \\
0.902 \\
2.228 \\
1.152 \\
2.114 \\
1.413 \\
2.122 \\
1.679 \\
2.211 \\
1.943 \\
2.349 \\
2.199 \\
2.515 \\
2.442 \\
2.690 \\
2.666 \\
2.861 \\
2.865 \\
3.017 \\
3.034 \\
3.151 \\
3.171 \\
3.256 \\
3.270 \\
3.327 \\
3.331 \\
3.362 \\
3.352\end{array}$ & $\begin{array}{r}465.000 \\
0.015 \\
8.781 \\
0.122 \\
6.259 \\
0.274 \\
4.580 \\
0.458 \\
3.493 \\
0.669 \\
2.822 \\
0.902 \\
2.443 \\
1.152 \\
2.268 \\
1.413 \\
2.231 \\
1.679 \\
2.288 \\
1.943 \\
2.404 \\
2.199 \\
2.554 \\
2.442 \\
2.717 \\
2.666 \\
2.880 \\
2.865 \\
3.031 \\
3.034 \\
3.161 \\
3.171 \\
3.263 \\
3.270 \\
3.332 \\
3.331 \\
3.365 \\
3.352\end{array}$ & $\begin{array}{r}460.000 \\
0.015 \\
9.939 \\
0.122 \\
7.091 \\
0.274 \\
5.177 \\
0.458 \\
3.922 \\
0.669 \\
3.130 \\
0.902 \\
2.663 \\
1.152 \\
2.425 \\
1.413 \\
2.344 \\
1.679 \\
2.369 \\
1.943 \\
2.462 \\
2.199 \\
2.595 \\
2.442 \\
2.747 \\
2.666 \\
2.901 \\
2.865 \\
3.046 \\
3.034 \\
3.171 \\
3.171 \\
3.270 \\
3.270 \\
3.337 \\
3.331 \\
3.369 \\
3.352\end{array}$ \\
\hline
\end{tabular}


TABLE II

INVERSE FILTER BEHAVIOR (2ND ORDER) RESULTING FROM CHANGING A AND B IN A*EXP(-BT). INPUT SIGNAL $=$ EXPONENTIAL + HAVERSINE (continued)

\begin{tabular}{|c|c|c|c|c|c|c|}
\hline $\begin{array}{l}\text { time } \\
\text { msec }\end{array}$ & $\begin{array}{l}38 \\
\mathrm{mV}\end{array}$ & $\begin{array}{l}4 \% \\
\mathrm{mV}\end{array}$ & $\begin{array}{l}5 \frac{8}{8} \\
\mathrm{mV}\end{array}$ & $\begin{array}{l}68 \\
\mathrm{mV}\end{array}$ & $\begin{array}{l}7 \% \\
\mathrm{mV}\end{array}$ & $\begin{array}{l}88 \\
\mathrm{mV}\end{array}$ \\
\hline $\begin{array}{l}18.555 \\
19.043 \\
19.531 \\
20.020 \\
20.508 \\
20.996 \\
21.484 \\
21.973 \\
22.461 \\
22.949 \\
23.438 \\
23.926 \\
24.414 \\
24.902 \\
25.391 \\
25.879 \\
26.367 \\
26.855 \\
27.344 \\
27.832 \\
28.320 \\
28.809 \\
29.297 \\
29.785 \\
30.273 \\
30.762 \\
31.250 \\
31.738 \\
32.227 \\
32.715 \\
33.203 \\
33.691 \\
34.180 \\
34.668 \\
35.156 \\
35.645 \\
36.133 \\
36.621\end{array}$ & $\begin{array}{r}3.351 \\
3.332 \\
3.310 \\
3.272 \\
3.229 \\
3.173 \\
3.110 \\
3.037 \\
2.957 \\
2.868 \\
2.773 \\
2.669 \\
2.561 \\
2.446 \\
2.327 \\
2.203 \\
2.077 \\
1.947 \\
1.816 \\
1.683 \\
1.550 \\
1.417 \\
1.286 \\
1.156 \\
1.029 \\
0.906 \\
0.787 \\
0.672 \\
0.564 \\
0.461 \\
0.365 \\
0.277 \\
0.196 \\
0.124 \\
0.061 \\
0.006 \\
-0.038 \\
-0.073\end{array}$ & $\begin{array}{r}3.353 \\
3.332 \\
3.311 \\
3.272 \\
3.230 \\
3.173 \\
3.111 \\
3.037 \\
2.958 \\
2.868 \\
2.773 \\
2.669 \\
2.561 \\
2.446 \\
2.327 \\
2.203 \\
2.077 \\
1.947 \\
1.816 \\
1.683 \\
1.550 \\
1.417 \\
1.286 \\
1.156 \\
1.029 \\
0.906 \\
0.787 \\
0.672 \\
0.564 \\
0.461 \\
0.365 \\
0.277 \\
0.196 \\
0.124 \\
0.061 \\
0.006 \\
-0.038 \\
-0.073\end{array}$ & $\begin{array}{r}3.355 \\
3.332 \\
3.312 \\
3.272 \\
3.231 \\
3.173 \\
3.112 \\
3.037 \\
2.958 \\
2.868 \\
2.773 \\
2.669 \\
2.561 \\
2.446 \\
2.327 \\
2.203 \\
2.077 \\
1.947 \\
1.816 \\
1.683 \\
1.550 \\
1.417 \\
1.286 \\
1.156 \\
1.029 \\
0.906 \\
0.787 \\
0.672 \\
0.564 \\
0.461 \\
0.365 \\
0.277 \\
0.196 \\
0.124 \\
0.061 \\
0.006 \\
-0.038 \\
-0.073\end{array}$ & $\begin{array}{r}3.357 \\
3.332 \\
3.314 \\
3.272 \\
3.232 \\
3.173 \\
3.112 \\
3.037 \\
2.959 \\
2.868 \\
2.774 \\
2.669 \\
2.562 \\
2.446 \\
2.328 \\
2.203 \\
2.077 \\
1.947 \\
1.816 \\
1.683 \\
1.550 \\
1.417 \\
1.286 \\
1.156 \\
1.029 \\
0.906 \\
0.787 \\
0.672 \\
0.564 \\
0.461 \\
0.365 \\
0.277 \\
0.196 \\
0.124 \\
0.061 \\
0.006 \\
-0.038 \\
-0.073\end{array}$ & $\begin{array}{r}3.360 \\
3.332 \\
3.316 \\
3.272 \\
3.233 \\
3.173 \\
3.113 \\
3.037 \\
2.959 \\
2.868 \\
2.774 \\
2.669 \\
2.562 \\
2.446 \\
2.328 \\
2.203 \\
2.077 \\
1.947 \\
1.816 \\
1.683 \\
1.550 \\
1.417 \\
1.286 \\
1.156 \\
1.029 \\
0.906 \\
0.787 \\
0.672 \\
0.564 \\
0.461 \\
0.365 \\
0.277 \\
0.196 \\
0.124 \\
0.061 \\
0.006 \\
-0.038 \\
-0.073\end{array}$ & $\begin{array}{r}3.363 \\
3.332 \\
3.318 \\
3.272 \\
3.234 \\
3.173 \\
3.114 \\
3.037 \\
2.960 \\
2.868 \\
2.774 \\
2.669 \\
2.562 \\
2.446 \\
2.328 \\
2.203 \\
2.077 \\
1.947 \\
1.816 \\
1.683 \\
1.550 \\
1.417 \\
1.286 \\
1.156 \\
1.029 \\
0.906 \\
0.787 \\
0.672 \\
0.564 \\
0.461 \\
0.365 \\
0.277 \\
0.196 \\
0.124 \\
0.061 \\
0.006 \\
-0.038 \\
-0.073\end{array}$ \\
\hline
\end{tabular}


TABLE II

INVERSE FILTER BEHAVIOR (2ND ORDER) RESULTING FROM CHANGING $a$ and $b$ IN $a * \exp (-b t)$. INPUT SIGNAL $=$ EXPONENTIAL + HAVERSINE

(continued)

\begin{tabular}{|r|c|c|c|c|c|c|}
\hline $\begin{array}{r}\text { time } \\
\mathrm{msec}\end{array}$ & $\begin{array}{c}3 \% \\
\mathrm{mV}\end{array}$ & $\begin{array}{c}4 \% \\
\mathrm{mV}\end{array}$ & $\begin{array}{c}5 \% \\
\mathrm{mV}\end{array}$ & $\begin{array}{c}6 \% \\
\mathrm{mV}\end{array}$ & $\begin{array}{c}7 \% \\
\mathrm{mV}\end{array}$ & $\begin{array}{c}8 \% \\
\mathrm{mV}\end{array}$ \\
\hline 37.109 & -0.099 & -0.099 & -0.099 & -0.099 & -0.099 & -0.099 \\
37.598 & -0.114 & -0.114 & -0.114 & -0.114 & -0.114 & -0.114 \\
38.086 & -0.119 & -0.119 & -0.119 & -0.119 & -0.118 & -0.118 \\
38.574 & -0.113 & -0.113 & -0.113 & -0.113 & -0.113 & -0.113 \\
39.063 & -0.098 & -0.098 & -0.098 & -0.098 & -0.098 & -0.098 \\
39.551 & -0.072 & -0.072 & -0.072 & -0.072 & -0.072 & -0.072 \\
40.039 & -0.037 & -0.037 & -0.037 & -0.037 & -0.037 & -0.037 \\
40.527 & -0.008 & -0.008 & -0.008 & -0.008 & -0.008 & -0.008 \\
41.016 & 0.000 & 0.000 & 0.000 & 0.000 & 0.000 & 0.000 \\
\hline
\end{tabular}


TABLE II

INVERSE FILTER BEHAVIOR (2ND ORDER) RESULTTNG FROM CHANGING A AND B IN A*EXP(-BT). INPUT SIGNAL = EXPONENTIAL + HAVERSINE (continued)

\begin{tabular}{|c|c|c|c|c|c|c|c|}
\hline $\begin{array}{l}\text { time } \\
\text { msec }\end{array}$ & $\begin{array}{l}9 \% \\
\mathrm{mV}\end{array}$ & $\begin{array}{l}10 \% \\
\mathrm{mV}\end{array}$ & $\begin{array}{l}11 \% \\
\mathrm{mV}\end{array}$ & $\begin{array}{l}12 \% \\
\mathrm{mV}\end{array}$ & $\begin{array}{l}13 \% \\
\mathrm{mV}\end{array}$ & $\begin{array}{l}14 \% \\
\mathrm{mV}\end{array}$ & $\begin{array}{l}15 \% \\
\mathrm{mV}\end{array}$ \\
\hline $\begin{array}{r}0.00 \\
0.49 \\
0.98 \\
1.47 \\
1.95 \\
2.44 \\
2.93 \\
3.42 \\
3.91 \\
4.40 \\
4.88 \\
5.37 \\
5.86 \\
6.35 \\
6.84 \\
7.32 \\
7.81 \\
8.30 \\
8.79 \\
9.28 \\
9.77 \\
10.25 \\
10.74 \\
11.23 \\
11.72 \\
12.21 \\
12.70 \\
13.18 \\
13.67 \\
14.16 \\
14.65 \\
15.14 \\
15.63 \\
16.11 \\
16.60 \\
17.09 \\
17.58 \\
18.07\end{array}$ & $\begin{array}{r}455.0 \\
0.02 \\
11.08 \\
0.12 \\
7.91 \\
0.27 \\
5.77 \\
0.46 \\
4.35 \\
0.67 \\
3.44 \\
0.90 \\
2.89 \\
1.15 \\
2.59 \\
1.41 \\
2.46 \\
1.68 \\
2.45 \\
1.94 \\
2.52 \\
2.20 \\
2.64 \\
2.44 \\
2.78 \\
2.67 \\
2.92 \\
2.87 \\
3.06 \\
3.03 \\
3.18 \\
3.17 \\
3.28 \\
3.27 \\
3.34 \\
3.33 \\
3.37 \\
3.35\end{array}$ & $\begin{array}{r}450.0 \\
0.02 \\
12.19 \\
0.12 \\
8.73 \\
0.27 \\
6.37 \\
0.46 \\
4.76 \\
0.67 \\
3.76 \\
0.90 \\
3.12 \\
1.15 \\
2.75 \\
1.41 \\
2.58 \\
1.68 \\
2.54 \\
1.94 \\
2.59 \\
2.20 \\
2.68 \\
2.44 \\
2.81 \\
2.67 \\
2.95 \\
2.87 \\
3.08 \\
3.03 \\
3.20 \\
3.17 \\
3.29 \\
3.27 \\
3.35 \\
3.33 \\
3.38 \\
3.35\end{array}$ & $\begin{array}{r}445.0 \\
0.02 \\
13.28 \\
0.12 \\
9.53 \\
0.27 \\
6.96 \\
0.46 \\
5.22 \\
0.67 \\
4.07 \\
0.90 \\
3.35 \\
1.15 \\
2.92 \\
1.41 \\
2.71 \\
1.68 \\
2.63 \\
1.94 \\
2.65 \\
2.20 \\
2.73 \\
2.44 \\
2.84 \\
2.67 \\
2.97 \\
2.86 \\
3.10 \\
3.03 \\
3.21 \\
3.17 \\
3.30 \\
3.27 \\
3.36 \\
3.33 \\
3.38 \\
3.35\end{array}$ & $\begin{array}{r}440.0 \\
0.02 \\
14.35 \\
0.12 \\
10.33 \\
0.27 \\
7.55 \\
0.46 \\
5.66 \\
0.67 \\
4.40 \\
0.90 \\
3.59 \\
1.15 \\
3.10 \\
1.41 \\
2.83 \\
1.68 \\
2.73 \\
1.94 \\
2.72 \\
2.20 \\
2.78 \\
2.44 \\
2.88 \\
2.67 \\
3.00 \\
2.87 \\
3.12 \\
3.03 \\
3.22 \\
3.17 \\
3.31 \\
3.27 \\
3.36 \\
3.33 \\
3.39 \\
3.35\end{array}$ & $\begin{array}{r}435.0 \\
0.02 \\
15.39 \\
0.12 \\
11.11 \\
0.27 \\
8.13 \\
0.46 \\
6.09 \\
0.67 \\
4.72 \\
0.90 \\
3.83 \\
1.15 \\
3.28 \\
1.41 \\
2.97 \\
1.68 \\
2.82 \\
1.94 \\
2.79 \\
2.20 \\
2.84 \\
2.44 \\
2.92 \\
2.67 \\
3.03 \\
2.87 \\
3.14 \\
3.03 \\
3.24 \\
3.17 \\
3.32 \\
3.27 \\
3.37 \\
3.33 \\
3.39 \\
3.35\end{array}$ & $\begin{array}{r}430.0 \\
0.02 \\
16.41 \\
0.12 \\
11.88 \\
0.27 \\
8.72 \\
0.46 \\
6.53 \\
0.67 \\
5.05 \\
0.90 \\
4.07 \\
1.15 \\
3.46 \\
1.41 \\
3.10 \\
3.68 \\
2.92 \\
1.94 \\
2.87 \\
2.20 \\
2.89 \\
2.44 \\
2.96 \\
2.67 \\
3.06 \\
2.87 \\
3.16 \\
3.03 \\
3.26 \\
3.17 \\
3.33 \\
3.27 \\
3.38 \\
3.33 \\
3.40 \\
3.35\end{array}$ & $\begin{array}{r}425.0 \\
0.02 \\
17.41 \\
0.12 \\
12.64 \\
0.27 \\
9.30 \\
0.46 \\
6.97 \\
0.67 \\
5.38 \\
0.90 \\
4.32 \\
1.15 \\
3.65 \\
1.41 \\
3.24 \\
1.68 \\
3.03 \\
1.94 \\
2.95 \\
2.20 \\
2.95 \\
2.44 \\
3.01 \\
2.67 \\
3.09 \\
2.87 \\
3.16 \\
3.03 \\
3.27 \\
3.17 \\
3.35 \\
3.27 \\
3.39 \\
3.33 \\
3.41 \\
3.35\end{array}$ \\
\hline
\end{tabular}


TABLE II

INVERSE FILTER BEHAVIOR (2ND ORDER) RESULTING FROM CHANGING A AND B IN A*EXP(-BT). INPUT SIGNAL = EXPONENTIAL + HAVERSINE (continued)

\begin{tabular}{|c|c|c|c|c|c|c|c|}
\hline $\begin{array}{l}\text { time } \\
\text { msec }\end{array}$ & $\begin{array}{l}9 \% \\
\mathrm{mV}\end{array}$ & $\begin{array}{l}10 \% \\
\mathrm{mV}\end{array}$ & $\begin{array}{l}11 \% \\
\mathrm{mV}\end{array}$ & $\begin{array}{l}12 \% \\
\mathrm{mV}\end{array}$ & $\begin{array}{l}13 \% \\
\mathrm{mV}\end{array}$ & $\begin{array}{l}14 \% \\
\mathrm{mV}\end{array}$ & $\begin{array}{l}15 \% \\
\mathrm{mV}\end{array}$ \\
\hline 18.56 & 3.37 & 3.37 & 3.37 & 3.37 & 3.38 & 3.39 & 3.39 \\
\hline 19.04 & 3.33 & 3.33 & 3.33 & 3.33 & 3.33 & 3.33 & 3.33 \\
\hline 19.53 & 3.32 & 3.32 & 3.33 & 3.33 & 3.33 & 3.34 & 3.34 \\
\hline 20.02 & 3.27 & 3.27 & 3.27 & 3.27 & 3.27 & 3.27 & 3.27 \\
\hline 20.51 & 3.24 & 3.24 & 3.24 & 3.24 & 3.24 & 3.25 & 3.25 \\
\hline 21.00 & 3.17 & 3.17 & 3.17 & 3.17 & 3.17 & 3.17 & 3.17 \\
\hline 21.48 & 3.11 & 3.12 & 3.12 & 3.12 & 3.12 & 3.12 & 3.13 \\
\hline 21.97 & 3.04 & 3.04 & 3.04 & 3.04 & 3.04 & 3.04 & 3.04 \\
\hline 22.46 & 2.96 & 2.96 & 2.96 & 2.96 & 2.97 & 2.97 & 2.98 \\
\hline 22.95 & 2.87 & 2.87 & 2.87 & 2.87 & 2.87 & 2.87 & 2.87 \\
\hline 23.34 & 2.77 & 2.78 & 2.78 & 2.77 & 2.77 & 2.78 & 2.78 \\
\hline 23.93 & 2.67 & 2.67 & 2.67 & 2.67 & 2.67 & 2.67 & 2.67 \\
\hline 24.41 & 2.56 & 2.56 & 2.56 & 2.56 & 2.57 & 2.57 & 2.57 \\
\hline 24.90 & 2.45 & 2.44 & 2.45 & 2.45 & 2.45 & 2.45 & 2.45 \\
\hline 25.39 & 2.33 & 2.33 & 2.33 & 2.33 & 2.33 & 2.33 & 2.33 \\
\hline 25.88 & 2.20 & 2.20 & 2.20 & 2.20 & 2.20 & 2.20 & 2.20 \\
\hline 26.37 & 2.08 & 2.08 & 2.08 & 2.08 & 2.08 & 2.08 & 2.08 \\
\hline 26.86 & 1.95 & 1.95 & 1.95 & 1.95 & 1.95 & 1.95 & 1.95 \\
\hline 27.34 & 1.82 & 1.81 & 1.82 & 1.82 & 1.82 & 1.82 & 1.82 \\
\hline 27.83 & 1.68 & 1.68 & 1.68 & 1.68 & 1.68 & 1.68 & 1.68 \\
\hline 28.32 & 1.55 & 1.55 & 1.55 & 1.55 & 1.55 & 1.55 & 1.55 \\
\hline 28.91 & 1.42 & 1.42 & 1.42 & 1.42 & 1.42 & 1.42 & 1.42 \\
\hline 29.30 & 1.27 & 1.29 & 1.29 & 1.27 & 1.27 & 1.29 & 1.29 \\
\hline 29.78 & 1.15 & 1.17 & 1.17 & 1.16 & 1.16 & 1.17 & 1.17 \\
\hline 30.27 & 1.03 & 1.03 & 1.03 & 1.03 & 1.03 & 1.03 & 1.03 \\
\hline 30.76 & 0.91 & 0.91 & 0.91 & 0.91 & 0.91 & 0.91 & 0.91 \\
\hline 31.25 & 0.78 & 0.79 & 0.79 & 0.79 & 0.79 & 0.79 & 0.79 \\
\hline 31.74 & 0.67 & 0.67 & 0.67 & 0.67 & 0.67 & 0.67 & 0.67 \\
\hline 32.23 & 0.56 & 0.56 & 0.56 & 0.56 & 0.56 & 0.56 & 0.56 \\
\hline 32.72 & 0.46 & 0.46 & 0.46 & 0.46 & 0.46 & 0.46 & 0.46 \\
\hline 33.20 & 0.37 & 0.37 & 0.36 & 0.36 & 0.37 & 0.37 & 0.37 \\
\hline 33.69 & 0.28 & 0.28 & 0.28 & 0.27 & 0.28 & 0.28 & 0.28 \\
\hline 34.18 & 0.20 & 0.20 & 0.20 & 0.20 & 0.20 & 0.20 & 0.20 \\
\hline 34.67 & 0.12 & 0.12 & 0.12 & 0.12 & 0.12 & 0.12 & 0.12 \\
\hline 35.17 & 0.06 & 0.06 & 0.06 & 0.06 & 0.06 & 0.06 & 0.06 \\
\hline 35.65 & 0.01 & 0.01 & 0.01 & 0.01 & 0.01 & 0.01 & 0.01 \\
\hline 36.13 & -0.04 & -0.04 & -0.04 & -0.04 & -0.04 & -0.04 & -0.04 \\
\hline 36.62 & -0.07 & -0.07 & -0.07 & -0.07 & -0.07 & -0.07 & -0.07 \\
\hline
\end{tabular}


TABLE II

INVERSE FILTER BEHAVIOR (2ND ORDER) RESULTING FROM CHANGING A AND B IN A*EXP(-BT). INPUT SIGNAL = EXPONENTIAL + HAVERSINE (continued)

\begin{tabular}{|c|c|c|c|c|c|c|c|}
\hline $\begin{array}{c}\text { time } \\
\mathrm{msec}\end{array}$ & $\begin{array}{c}9 \% \\
\mathrm{mV}\end{array}$ & $\begin{array}{c}10 \% \\
\mathrm{mV}\end{array}$ & $\begin{array}{c}11 \% \\
\mathrm{mV}\end{array}$ & $\begin{array}{c}12 \% \\
\mathrm{mV}\end{array}$ & $\begin{array}{c}13 \% \\
\mathrm{mV}\end{array}$ & $\begin{array}{c}14 \% \\
\mathrm{mV}\end{array}$ & $\begin{array}{c}15 \% \\
\mathrm{mV}\end{array}$ \\
\hline 37.12 & -0.10 & -0.10 & -0.10 & -0.10 & -0.10 & -0.10 & -0.10 \\
37.60 & -0.11 & -0.11 & -0.11 & -0.11 & -0.11 & -0.11 & -0.11 \\
38.09 & -0.12 & -0.12 & -0.12 & -0.12 & -0.12 & -0.12 & -0.12 \\
38.57 & -0.11 & -0.11 & -0.11 & -0.11 & -0.11 & -0.11 & -0.11 \\
39.06 & -0.10 & -0.10 & -0.10 & -0.10 & -0.10 & -0.10 & -0.10 \\
39.55 & -0.07 & -0.07 & -0.07 & -0.07 & -0.07 & -0.07 & -0.07 \\
40.04 & -0.04 & -0.04 & -0.04 & -0.04 & -0.04 & -0.04 & -0.04 \\
40.53 & -0.01 & -0.01 & -0.01 & -0.01 & -0.01 & -0.01 & -0.01 \\
41.02 & 0.00 & 0.00 & 0.00 & 0.00 & 0.00 & 0.00 & 0.00 \\
41.50 & 0.00 & 0.00 & 0.00 & 0.00 & 0.00 & 0.00 & 0.00 \\
& & & & & & & \\
\hline
\end{tabular}


TABLE III

INVERSE FIL TER (1ST ORDER) BEHAVIOR RESULTING FROM CHANGING A AND B IN A*EXP(-BT). INPUT SIGNAL = EXPONENTIAL ONLY

\begin{tabular}{|c|c|c|c|c|c|c|}
\hline $\begin{array}{l}\text { time } \\
\text { msec }\end{array}$ & $\begin{array}{l}08 \\
\mathrm{mV}\end{array}$ & $\begin{array}{l}.25 \% \\
\mathrm{mV}\end{array}$ & & $\begin{array}{l}.75 \% \\
\mathrm{mV}\end{array}$ & $\begin{array}{l}18 \\
\mathrm{mV}\end{array}$ & $\begin{array}{l}2 \% \\
\mathrm{mV}\end{array}$ \\
\hline $\begin{array}{l}0.000 \\
0.488 \\
0.977 \\
1.465 \\
1.953 \\
2.441 \\
2.930 \\
3.418 \\
3.906 \\
4.395 \\
4.883 \\
5.371 \\
5.859 \\
6.348 \\
6.836 \\
7.324 \\
7.813 \\
8.301 \\
8.789 \\
9.277 \\
9.766 \\
10.254 \\
10.742 \\
11.230 \\
11.719 \\
12.207 \\
12.695 \\
13.184 \\
13.672 \\
14.160 \\
14.648 \\
15.137 \\
15.625 \\
16.113 \\
16.602 \\
17.090 \\
17.578 \\
18.066 \\
18.555\end{array}$ & $\begin{array}{r}500.000 \\
0.000 \\
-0.000 \\
0.000 \\
0.000 \\
0.000 \\
0.000 \\
-0.000 \\
0.000 \\
0.000 \\
0.000 \\
0.000 \\
0.000 \\
0.000 \\
-0.000 \\
0.000 \\
0.000 \\
0.000 \\
-0.000 \\
-0.000 \\
0.000 \\
0.000 \\
-0.000 \\
0.000 \\
0.000 \\
-0.000 \\
-0.000 \\
0.000 \\
0.000 \\
-0.000 \\
0.000 \\
0.0000 \\
-0.000 \\
0.000 \\
-0.000 \\
-0.000 \\
0.000 \\
0.000 \\
-0.000\end{array}$ & $\begin{array}{l}98.750 \\
0.200 \\
0.165 \\
0.136 \\
0.112 \\
0.092 \\
0.076 \\
0.062 \\
0.051 \\
0.042 \\
0.035 \\
0.029 \\
0.024 \\
0.019 \\
0.016 \\
0.013 \\
0.011 \\
0.009 \\
0.007 \\
0.006 \\
0.005 \\
0.004 \\
0.003 \\
0.003 \\
0.002 \\
0.002 \\
0.002 \\
0.001 \\
0.001 \\
0.001 \\
0.001 \\
0.001 \\
0.000 \\
0.000 \\
0.000 \\
0.000 \\
0.000 \\
0.000 \\
0.000\end{array}$ & $\begin{array}{r}497.500 \\
0.400 \\
0.329 \\
0.271 \\
0.223 \\
0.184 \\
0.151 \\
0.125 \\
0.103 \\
0.084 \\
0.070 \\
0.057 \\
0.047 \\
0.039 \\
0.032 \\
0.026 \\
0.022 \\
0.018 \\
0.015 \\
0.012 \\
0.010 \\
0.008 \\
0.007 \\
0.006 \\
0.005 \\
0.004 \\
0.003 \\
0.003 \\
0.002 \\
0.002 \\
0.001 \\
0.001 \\
0.001 \\
0.001 \\
0.001 \\
0.001 \\
0.000 \\
0.000 \\
0.000\end{array}$ & $\begin{array}{l}96.250 \\
0.598 \\
0.493 \\
0.406 \\
0.335 \\
0.276 \\
0.227 \\
0.187 \\
0.154 \\
0.127 \\
0.105 \\
0.086 \\
0.071 \\
0.058 \\
0.048 \\
0.040 \\
0.033 \\
0.027 \\
0.022 \\
0.018 \\
0.015 \\
0.012 \\
0.010 \\
0.008 \\
0.007 \\
0.006 \\
0.005 \\
0.004 \\
0.003 \\
0.003 \\
0.002 \\
0.002 \\
0.001 \\
0.001 \\
0.001 \\
0.001 \\
0.001 \\
0.001 \\
0.000\end{array}$ & $\begin{array}{r}495.000 \\
0.796 \\
0.656 \\
0.541 \\
0.446 \\
0.367 \\
0.303 \\
0.250 \\
0.206 \\
0.169 \\
0.140 \\
0.115 \\
0.095 \\
0.078 \\
0.064 \\
0.053 \\
0.044 \\
0.036 \\
0.030 \\
0.025 \\
0.020 \\
0.017 \\
0.014 \\
0.011 \\
0.009 \\
0.008 \\
0.006 \\
0.005 \\
0.004 \\
0.004 \\
0.003 \\
0.002 \\
0.002 \\
0.002 \\
0.001 \\
0.001 \\
0.001 \\
0.001 \\
0.001\end{array}$ & $\begin{array}{r}490.000 \\
1.578 \\
1.303 \\
1.076 \\
0.888 \\
0.734 \\
0.606 \\
0.500 \\
0.413 \\
0.341 \\
0.282 \\
0.233 \\
0.192 \\
0.159 \\
0.131 \\
0.108 \\
0.089 \\
0.074 \\
0.061 \\
0.050 \\
0.042 \\
0.034 \\
0.028 \\
0.023 \\
0.019 \\
0.016 \\
0.013 \\
0.011 \\
0.009 \\
0.007 \\
0.006 \\
0.005 \\
0.004 \\
0.003 \\
0.003 \\
0.002 \\
0.002 \\
0.002 \\
0.001\end{array}$ \\
\hline
\end{tabular}


TABLE III

INVERSE FILTER (1ST ORDER) BEHAVIOR RESULTING FROM CHANGING $A$ AND B IN A*EXP(-BT). INPUT SIGNAL = EXPONENTIAL ONLY (continued)

\begin{tabular}{|c|r|c|c|c|c|c|}
\hline $\begin{array}{c}\text { time } \\
\text { msec }\end{array}$ & $\begin{array}{c}\text { 08 } \\
\mathrm{mV}\end{array}$ & $\begin{array}{c}.25 \% \\
\mathrm{mV}\end{array}$ & $\begin{array}{c}.508 \\
\mathrm{mV}\end{array}$ & $\begin{array}{c}.758 \\
\mathrm{mV}\end{array}$ & $\begin{array}{c}1 \% \\
\mathrm{mV}\end{array}$ & $\begin{array}{c}28 \\
\mathrm{mV}\end{array}$ \\
\hline 19.043 & 0.000 & 0.000 & 0.000 & 0.000 & 0.001 & 0.001 \\
19.531 & 0.000 & 0.000 & 0.000 & 0.000 & 0.000 & 0.001 \\
20.020 & -0.000 & 0.000 & 0.000 & 0.000 & 0.000 & 0.001 \\
20.508 & 0.000 & 0.000 & 0.000 & 0.000 & 0.000 & 0.001 \\
20.996 & 0.000 & 0.000 & 0.000 & 0.000 & 0.000 & 0.001 \\
21.484 & -0.000 & 0.000 & 0.000 & 0.000 & 0.000 & 0.000 \\
21.973 & 0.000 & 0.000 & 0.000 & 0.000 & 0.000 & 0.000 \\
\hline
\end{tabular}


TABLE III

INVERSE FILTER (1ST ORDER) BEHAVIOR RESULTING FROM CHANGING A AND B IN A*EXP(-BT). INPUT SIGNAL = EXPONENTIAL ONLY (continued)

\begin{tabular}{|c|c|c|c|c|c|c|}
\hline $\begin{array}{l}\text { time } \\
\text { msec }\end{array}$ & $\begin{array}{l}3 \% \\
\mathrm{mV}\end{array}$ & $\begin{array}{l}48 \\
\mathrm{mV}\end{array}$ & $\begin{array}{l}5 \frac{8}{8} \\
\mathrm{mV}\end{array}$ & $\begin{array}{l}6 \% \\
\mathrm{mV}\end{array}$ & $\begin{array}{l}78 \\
\mathrm{mV}\end{array}$ & $\begin{array}{l}8 q \\
\mathrm{mV}\end{array}$ \\
\hline $\begin{array}{l}0.000 \\
0.488 \\
0.977 \\
1.465 \\
1.953 \\
2.441 \\
2.930 \\
3.418 \\
3.906 \\
4.395 \\
4.883 \\
5.371 \\
5.859 \\
6.348 \\
6.836 \\
7.324 \\
7.813 \\
8.301 \\
8.789 \\
9.277 \\
9.766 \\
10.254 \\
10.742 \\
11.230 \\
11.719 \\
12.207 \\
12.695 \\
13.184 \\
13.672 \\
14.160 \\
14.648 \\
15.137 \\
15.625 \\
16.113 \\
16.602 \\
17.090 \\
17.578 \\
18.066\end{array}$ & $\begin{array}{r}485.000 \\
2.344 \\
1.940 \\
1.605 \\
1.328 \\
1.099 \\
0.909 \\
0.752 \\
0.622 \\
0.515 \\
0.426 \\
0.353 \\
0.292 \\
0.241 \\
0.200 \\
0.165 \\
0.137 \\
0.113 \\
0.094 \\
0.077 \\
0.064 \\
0.053 \\
0.044 \\
0.036 \\
0.030 \\
0.025 \\
0.021 \\
0.017 \\
0.014 \\
0.012 \\
0.010 \\
0.008 \\
0.007 \\
0.005 \\
0.005 \\
0.004 \\
0.003 \\
0.003\end{array}$ & $\begin{array}{r}480.000 \\
3.097 \\
2.567 \\
2.128 \\
1.764 \\
1.463 \\
1.213 \\
1.005 \\
0.833 \\
0.691 \\
0.573 \\
0.475 \\
0.394 \\
0.326 \\
0.271 \\
0.224 \\
0.186 \\
0.154 \\
0.128 \\
0.106 \\
0.088 \\
0.073 \\
0.060 \\
0.050 \\
0.041 \\
0.034 \\
0.029 \\
0.024 \\
0.020 \\
0.016 \\
0.013 \\
0.011 \\
0.009 \\
0.008 \\
0.006 \\
0.005 \\
0.004 \\
0.004\end{array}$ & $\begin{array}{r}475.000 \\
3.834 \\
3.185 \\
2.646 \\
2.198 \\
1.825 \\
1.516 \\
1.260 \\
1.046 \\
0.869 \\
0.722 \\
0.600 \\
0.498 \\
0.414 \\
0.344 \\
0.285 \\
0.237 \\
0.197 \\
0.164 \\
0.136 \\
0.113 \\
0.094 \\
0.078 \\
0.065 \\
0.054 \\
0.045 \\
0.037 \\
0.031 \\
0.026 \\
0.021 \\
0.018 \\
0.015 \\
0.012 \\
0.010 \\
0.008 \\
0.007 \\
0.006 \\
0.005\end{array}$ & $\begin{array}{r}470.000 \\
4.557 \\
3.793 \\
3.157 \\
2.627 \\
2.187 \\
1.820 \\
1.515 \\
1.261 \\
1.049 \\
0.873 \\
0.727 \\
0.605 \\
0.503 \\
0.419 \\
0.349 \\
0.290 \\
0.242 \\
0.201 \\
0.167 \\
0.139 \\
0.116 \\
0.096 \\
0.080 \\
0.067 \\
0.056 \\
0.046 \\
0.039 \\
0.032 \\
0.027 \\
0.022 \\
0.018 \\
0.015 \\
0.013 \\
0.011 \\
0.009 \\
0.007 \\
0.006\end{array}$ & $\begin{array}{r}465.000 \\
5.265 \\
4.391 \\
3.662 \\
3.053 \\
2.546 \\
2.123 \\
1.771 \\
1.476 \\
1.231 \\
1.027 \\
0.856 \\
0.714 \\
0.595 \\
0.496 \\
0.414 \\
0.345 \\
0.288 \\
0.240 \\
0.200 \\
0.167 \\
0.139 \\
0.116 \\
0.097 \\
0.081 \\
0.067 \\
0.056 \\
0.047 \\
0.039 \\
0.033 \\
0.027 \\
0.023 \\
0.019 \\
0.016 \\
0.013 \\
0.011 \\
0.009 \\
0.008\end{array}$ & $\begin{array}{l}460.000 \\
5.959 \\
4.979 \\
4.160 \\
3.476 \\
2.904 \\
2.426 \\
2.027 \\
1.694 \\
1.415 \\
1.183 \\
0.988 \\
0.826 \\
0.690 \\
0.576 \\
0.482 \\
0.402 \\
0.336 \\
0.281 \\
0.235 \\
0.196 \\
0.164 \\
0.137 \\
0.114 \\
0.096 \\
0.080 \\
0.067 \\
0.056 \\
0.047 \\
0.039 \\
0.033 \\
0.027 \\
0.023 \\
0.019 \\
0.016 \\
0.013 \\
0.011 \\
0.009\end{array}$ \\
\hline
\end{tabular}


TABLE III

INVERSE FIL TER (1ST ORDER) BEHAVIOR RESULTING FROM CHANGING A AND B IN A*EXP(-BT). INPUT SIGNAL = EXPONENTIAL ONLY (continued)

\begin{tabular}{|c|c|c|c|c|c|c|}
\hline $\begin{array}{c}\text { time } \\
\mathrm{msec}\end{array}$ & $\begin{array}{l}38 \\
\mathrm{mV}\end{array}$ & $\begin{array}{l}4 \% \\
\mathrm{mV}\end{array}$ & $\begin{array}{l}58 \\
\mathrm{mV}\end{array}$ & $\begin{array}{l}68 \\
\mathrm{mV}\end{array}$ & $\begin{array}{l}7 \% \\
\mathrm{mV}\end{array}$ & $\begin{array}{l}88 \\
\mathrm{mV}\end{array}$ \\
\hline 18.555 & 0.002 & 0.003 & 0.004 & 0.005 & 0.006 & 0.008 \\
19.043 & 0.002 & 0.002 & 0.003 & 0.004 & 0.005 & 0.006 \\
19.531 & 0.001 & 0.002 & 0.003 & 0.004 & 0.004 & 0.005 \\
20.020 & 0.001 & 0.002 & 0.002 & 0.003 & 0.004 & 0.005 \\
20.508 & 0.001 & 0.001 & 0.002 & 0.002 & 0.003 & 0.004 \\
20.996 & 0.001 & 0.001 & 0.002 & 0.002 & 0.003 & 0.003 \\
21.484 & 0.001 & 0.001 & 0.001 & 0.002 & 0.002 & 0.003 \\
21.973 & 0.001 & 0.001 & 0.001 & 0.001 & 0.002 & 0.002 \\
22.461 & 0.000 & 0.001 & 0.001 & 0.001 & 0.001 & 0.002 \\
22.949 & 0.000 & 0.001 & 0.001 & 0.001 & 0.001 & 0.002 \\
23.438 & 0.000 & 0.000 & 0.001 & 0.001 & 0.001 & 0.001 \\
23.926 & 0.000 & 0.000 & 0.001 & 0.001 & 0.001 & 0.001 \\
24.414 & 0.000 & 0.000 & 0.000 & 0.001 & 0.001 & 0.001 \\
24.902 & 0.000 & 0.000 & 0.000 & 0.000 & 0.001 & 0.001 \\
25.391 & 0.000 & 0.000 & 0.000 & 0.000 & 0.000 & 0.001 \\
25.879 & 0.000 & 0.000 & 0.000 & 0.000 & 0.000 & 0.001 \\
26.367 & 0.000 & 0.000 & 0.000 & 0.000 & 0.000 & 0.000 \\
\hline
\end{tabular}


TABLE III

INVERSE FILTER (1ST ORDER) BEHAVIOR RESULTING FROM CHANGING A AND B IN A*EXP(-BT). INPUT SIGNAL = EXPONENTIAL ONLY

(continued)

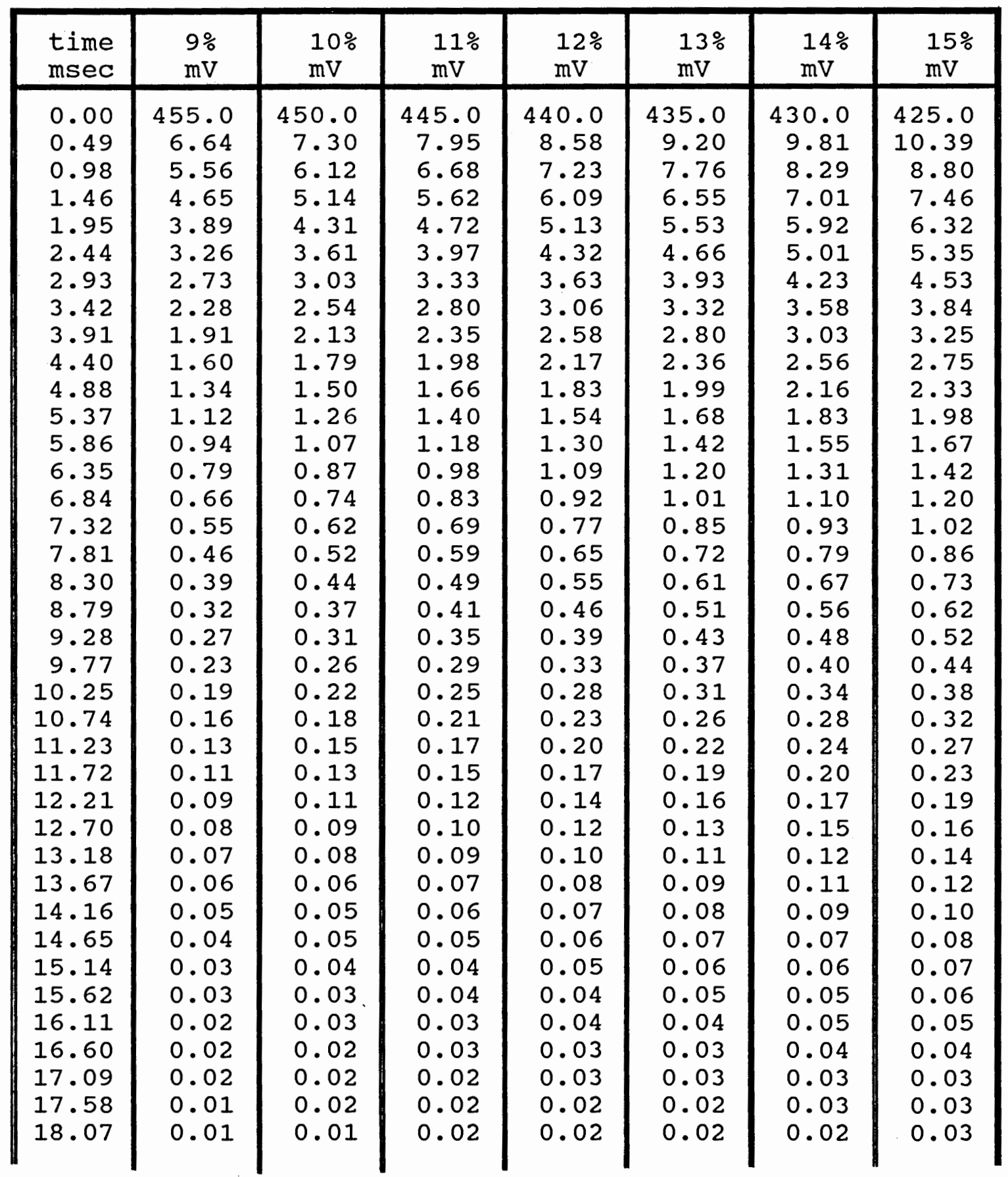


TABLE III

INVERSE FILTER (1ST ORDER) BEHAVIOR RESULTING FROM CHANGING A AND B IN A*EXP(-BT). INPUT SIGNAL = EXPONENTIAL ONLY (continued)

\begin{tabular}{|c|c|c|c|c|c|c|c|}
\hline $\begin{array}{c}\text { time } \\
\mathrm{msec}\end{array}$ & $\begin{array}{c}9 \% \\
\mathrm{mV}\end{array}$ & $\begin{array}{c}10 \% \\
\mathrm{mV}\end{array}$ & $\begin{array}{c}11 \% \\
\mathrm{mV}\end{array}$ & $\begin{array}{c}12 \% \\
\mathrm{mV}\end{array}$ & $\begin{array}{c}13 \% \\
\mathrm{mV}\end{array}$ & $\begin{array}{c}14 \% \\
\mathrm{mV}\end{array}$ & $\begin{array}{c}15 \% \\
\mathrm{mV}\end{array}$ \\
\hline 18.56 & 0.01 & 0.01 & 0.01 & 0.02 & 0.02 & 0.02 & 0.02 \\
19.04 & 0.01 & 0.01 & 0.01 & 0.01 & 0.01 & 0.02 & 0.02 \\
19.53 & 0.01 & 0.01 & 0.01 & 0.01 & 0.01 & 0.01 & 0.02 \\
20.02 & 0.01 & 0.01 & 0.01 & 0.01 & 0.01 & 0.01 & 0.01 \\
20.51 & 0.01 & 0.01 & 0.01 & 0.01 & 0.01 & 0.01 & 0.01 \\
21.00 & 0.00 & 0.01 & 0.01 & 0.01 & 0.01 & 0.01 & 0.01 \\
21.48 & 0.00 & 0.00 & 0.01 & 0.01 & 0.01 & 0.01 & 0.01 \\
21.97 & 0.00 & 0.00 & 0.00 & 0.00 & 0.01 & 0.01 & 0.01 \\
22.46 & 0.00 & 0.00 & 0.00 & 0.00 & 0.00 & 0.01 & 0.01 \\
22.95 & 0.00 & 0.00 & 0.00 & 0.00 & 0.00 & 0.00 & 0.01 \\
23.44 & 0.00 & 0.00 & 0.00 & 0.00 & 0.00 & 0.00 & 0.00 \\
23.93 & 0.00 & 0.00 & 0.00 & 0.00 & 0.00 & 0.00 & 0.00 \\
24.41 & 0.00 & 0.00 & 0.00 & 0.00 & 0.00 & 0.00 & 0.00 \\
24.90 & 0.00 & 0.00 & 0.00 & 0.00 & 0.00 & 0.00 & 0.00 \\
25.39 & 0.00 & 0.00 & 0.00 & 0.00 & 0.00 & 0.00 & 0.00 \\
25.88 & 0.00 & 0.00 & 0.00 & 0.00 & 0.00 & 0.00 & 0.00 \\
26.37 & 0.00 & 0.00 & 0.00 & 0.00 & 0.00 & 0.00 & 0.00 \\
26.86 & 0.00 & 0.00 & 0.00 & 0.00 & 0.00 & 0.00 & 0.00 \\
\hline
\end{tabular}


TABLE IV

INVERSE FILTER (1ST ORDER) BEHAVIOR RESULTING FROM CHANGING A AND B IN A*EXP(-BT). INPUT SIGNAL = EXPONENTIAL + HAVERSINE

\begin{tabular}{|c|c|c|c|c|c|c|}
\hline $\begin{array}{l}\text { time } \\
\text { msec }\end{array}$ & $\begin{array}{l}08 \\
\mathrm{mV}\end{array}$ & $\begin{array}{l}.258 \\
\mathrm{mV}\end{array}$ & $\begin{array}{c}.50 \% \\
\mathrm{mV}\end{array}$ & $\begin{array}{c}.758 \\
\mathrm{mV}\end{array}$ & $\begin{array}{l}18 \\
\mathrm{mV}\end{array}$ & $\begin{array}{l}28 \\
\mathrm{mV}\end{array}$ \\
\hline $\begin{array}{r}0.000 \\
0.488 \\
0.977 \\
1.465 \\
1.953 \\
2.441 \\
2.930 \\
3.418 \\
3.906 \\
4.395 \\
4.883 \\
5.371 \\
5.859 \\
6.348 \\
6.836 \\
7.324 \\
7.813 \\
8.301 \\
8.789 \\
9.277 \\
9.766 \\
10.254 \\
10.742 \\
11.230 \\
11.719 \\
12.207 \\
12.695 \\
13.184 \\
13.672 \\
14.160 \\
14.648 \\
15.137 \\
15.625 \\
16.113 \\
16.602 \\
17.090 \\
17.578 \\
18.066\end{array}$ & $\begin{array}{l}0.000 \\
0.015 \\
0.047 \\
0.083 \\
0.125 \\
0.171 \\
0.221 \\
0.276 \\
0.333 \\
0.394 \\
0.458 \\
0.525 \\
0.593 \\
0.664 \\
0.735 \\
0.808 \\
0.881 \\
0.954 \\
1.027 \\
1.098 \\
1.169 \\
1.238 \\
1.305 \\
1.369 \\
1.431 \\
1.489 \\
1.544 \\
1.595 \\
1.642 \\
1.684 \\
1.722 \\
1.754 \\
1.782 \\
1.805 \\
1.822 \\
1.833 \\
1.839 \\
1.839 \\
1.834\end{array}$ & $\begin{array}{r}498.750 \\
0.215 \\
0.212 \\
0.219 \\
0.237 \\
0.263 \\
0.297 \\
0.338 \\
0.385 \\
0.437 \\
0.493 \\
0.553 \\
0.617 \\
0.683 \\
0.751 \\
0.821 \\
0.892 \\
0.963 \\
1.034 \\
1.104 \\
1.174 \\
1.242 \\
1.308 \\
1.372 \\
1.433 \\
1.491 \\
1.545 \\
1.596 \\
1.643 \\
1.685 \\
1.722 \\
1.755 \\
1.783 \\
1.805 \\
1.822 \\
1.833 \\
1.839 \\
1.840 \\
1.834\end{array}$ & $\begin{array}{r}497.500 \\
0.415 \\
0.376 \\
0.355 \\
0.348 \\
0.355 \\
0.373 \\
0.400 \\
0.436 \\
0.479 \\
0.528 \\
0.582 \\
0.641 \\
0.703 \\
0.767 \\
0.834 \\
0.903 \\
0.972 \\
1.041 \\
1.110 \\
1.179 \\
1.246 \\
1.311 \\
1.375 \\
1.435 \\
1.493 \\
1.547 \\
1.597 \\
1.644 \\
1.686 \\
1.723 \\
1.756 \\
1.783 \\
1.805 \\
1.822 \\
1.834 \\
1.839 \\
1.840 \\
1.834\end{array}$ & $\begin{array}{r}496.250 \\
0.613 \\
0.540 \\
0.490 \\
0.460 \\
0.447 \\
0.448 \\
0.463 \\
0.487 \\
0.521 \\
0.563 \\
0.611 \\
0.664 \\
0.722 \\
0.784 \\
0.848 \\
0.914 \\
0.981 \\
1.049 \\
1.117 \\
1.184 \\
1.250 \\
1.315 \\
1.378 \\
1.438 \\
1.495 \\
1.549 \\
1.599 \\
1.645 \\
1.687 \\
1.724 \\
1.756 \\
1.784 \\
1.806 \\
1.823 \\
1.834 \\
1.840 \\
1.840 \\
1.835\end{array}$ & $\begin{array}{r}495.000 \\
0.811 \\
0.703 \\
0.624 \\
0.571 \\
0.538 \\
0.524 \\
0.525 \\
0.539 \\
0.564 \\
0.598 \\
0.640 \\
0.688 \\
0.742 \\
0.800 \\
0.861 \\
0.925 \\
0.990 \\
1.056 \\
1.123 \\
1.189 \\
1.255 \\
1.318 \\
1.380 \\
1.440 \\
1.497 \\
1.550 \\
1.600 \\
1.646 \\
1.688 \\
1.725 \\
1.757 \\
1.784 \\
1.806 \\
1.823 \\
1.834 \\
1.840 \\
1.840 \\
1.835\end{array}$ & $\begin{array}{l}190.000 \\
1.592 \\
1.349 \\
1.159 \\
1.013 \\
0.905 \\
0.827 \\
0.776 \\
0.747 \\
0.736 \\
0.740 \\
0.758 \\
0.786 \\
0.822 \\
0.866 \\
0.916 \\
0.970 \\
1.028 \\
1.087 \\
1.149 \\
1.210 \\
1.272 \\
1.333 \\
1.393 \\
1.450 \\
1.505 \\
1.557 \\
1.606 \\
1.651 \\
1.691 \\
1.728 \\
1.760 \\
1.786 \\
1.808 \\
1.824 \\
1.835 \\
1.841 \\
1.841 \\
1.836\end{array}$ \\
\hline
\end{tabular}


TABLE IV

INVERSE FILTER (1ST ORDER) BEHAVIOR RESULTING FROM CHANGING A AND B IN A*EXP(-BT). INPUT SIGNAL = EXPONENTIAL + HAVERSINE (continued)

\begin{tabular}{|c|c|c|c|c|c|c|}
\hline $\begin{array}{l}\text { time } \\
\text { msec }\end{array}$ & $\begin{array}{l}08 \\
\mathrm{mV}\end{array}$ & .258 & $\begin{array}{c}.508 \\
\mathrm{mV}\end{array}$ & $\begin{array}{c}.758 \\
\mathrm{mV}\end{array}$ & $\begin{array}{l}18 \\
\mathrm{mV}\end{array}$ & $\begin{array}{l}28 \\
\mathrm{mV}\end{array}$ \\
\hline $\begin{array}{l}19.043 \\
19.531 \\
20.020 \\
20.508 \\
20.996 \\
21.484 \\
21.973 \\
22.461 \\
22.949 \\
23.438 \\
23.926 \\
24.414 \\
24.902 \\
25.391 \\
25.879 \\
26.367 \\
26.855 \\
27.344 \\
27.832 \\
28.320 \\
28.809 \\
29.297 \\
29.785 \\
30.273 \\
30.762 \\
31.250 \\
31.738 \\
32.227 \\
32.715 \\
33.203 \\
33.691 \\
34.180 \\
34.668 \\
35.156 \\
35.645 \\
36.133 \\
36.621 \\
37.109 \\
37.598\end{array}$ & $\begin{array}{r}1.823 \\
1.807 \\
1.785 \\
1.758 \\
1.726 \\
1.689 \\
1.647 \\
1.601 \\
1.551 \\
1.496 \\
1.438 \\
1.377 \\
1.313 \\
1.247 \\
1.178 \\
1.108 \\
1.036 \\
0.963 \\
0.890 \\
0.817 \\
0.745 \\
0.673 \\
0.602 \\
0.534 \\
0.467 \\
0.403 \\
0.341 \\
0.283 \\
0.228 \\
0.177 \\
0.131 \\
0.089 \\
0.051 \\
0.019 \\
-0.009 \\
-0.031 \\
-0.048 \\
-0.059 \\
-0.065\end{array}$ & $\begin{array}{r}1.823 \\
1.807 \\
1.785 \\
1.758 \\
1.726 \\
1.689 \\
1.647 \\
1.601 \\
1.551 \\
1.496 \\
1.438 \\
1.377 \\
1.313 \\
1.247 \\
1.178 \\
1.108 \\
1.036 \\
0.963 \\
0.890 \\
0.817 \\
0.745 \\
0.673 \\
0.602 \\
0.534 \\
0.467 \\
0.403 \\
0.341 \\
0.283 \\
0.228 \\
0.177 \\
0.131 \\
0.089 \\
0.051 \\
0.019 \\
-0.009 \\
-0.031 \\
-0.048 \\
-0.059 \\
-0.065\end{array}$ & $\begin{array}{r}1.824 \\
1.807 \\
1.786 \\
1.758 \\
1.726 \\
1.689 \\
1.647 \\
1.601 \\
1.551 \\
1.496 \\
1.438 \\
1.377 \\
1.313 \\
1.247 \\
1.178 \\
1.108 \\
1.036 \\
0.963 \\
0.890 \\
0.817 \\
0.745 \\
0.673 \\
0.602 \\
0.534 \\
0.467 \\
0.403 \\
0.341 \\
0.283 \\
0.228 \\
0.177 \\
0.131 \\
0.089 \\
0.051 \\
0.019 \\
-0.009 \\
-0.031 \\
-0.048 \\
-0.059 \\
-0.065\end{array}$ & $\begin{array}{r}1.824 \\
1.807 \\
1.786 \\
1.759 \\
1.726 \\
1.689 \\
1.648 \\
1.601 \\
1.551 \\
1.496 \\
1.438 \\
1.377 \\
1.313 \\
1.247 \\
1.178 \\
1.108 \\
1.036 \\
0.963 \\
0.890 \\
0.817 \\
0.745 \\
0.673 \\
0.602 \\
0.534 \\
0.467 \\
0.403 \\
0.341 \\
0.283 \\
0.228 \\
0.177 \\
0.131 \\
0.089 \\
0.051 \\
0.019 \\
-0.009 \\
-0.031 \\
-0.048 \\
-0.059 \\
-0.065\end{array}$ & $\begin{array}{r}1.824 \\
1.807 \\
1.786 \\
1.759 \\
1.726 \\
1.689 \\
1.648 \\
1.601 \\
1.551 \\
1.496 \\
1.439 \\
1.377 \\
1.313 \\
1.247 \\
1.178 \\
1.108 \\
1.036 \\
0.963 \\
0.890 \\
0.817 \\
0.745 \\
0.673 \\
0.602 \\
0.534 \\
0.467 \\
0.403 \\
0.341 \\
0.283 \\
0.228 \\
0.177 \\
0.131 \\
0.089 \\
0.051 \\
0.019 \\
-0.009 \\
-0.031 \\
-0.048 \\
-0.059 \\
-0.065\end{array}$ & $\begin{array}{r}1.824 \\
1.808 \\
1.786 \\
1.759 \\
1.727 \\
1.690 \\
1.648 \\
1.601 \\
1.551 \\
1.497 \\
1.439 \\
1.377 \\
1.313 \\
1.247 \\
1.178 \\
1.108 \\
1.036 \\
0.963 \\
0.890 \\
0.817 \\
0.745 \\
0.673 \\
0.603 \\
0.534 \\
0.467 \\
0.403 \\
0.341 \\
0.283 \\
0.228 \\
0.177 \\
0.131 \\
0.089 \\
0.051 \\
0.019 \\
-0.009 \\
-0.031 \\
-0.048 \\
-0.059 \\
-0.065\end{array}$ \\
\hline
\end{tabular}


TABLE IV

INVERSE FILTER (1ST ORDER) BEHAVIOR RESULTING FROM CHANGING A AND B IN A*EXP(-BT). INPUT SIGNAL = EXPONENTIAL + HAVERSINE (continued)

\begin{tabular}{|c|c|c|c|c|c|c|}
\hline $\begin{array}{c}\text { time } \\
\mathrm{msec}\end{array}$ & $\begin{array}{c}08 \\
\mathrm{mV}\end{array}$ & $\begin{array}{c}.25 \% \\
\mathrm{mV}\end{array}$ & $\begin{array}{c}.50 \% \\
\mathrm{mV}\end{array}$ & $\begin{array}{c}.75 \% \\
\mathrm{mV}\end{array}$ & $\begin{array}{c}1 \% \\
\mathrm{mV}\end{array}$ & $\begin{array}{c}28 \\
\mathrm{mV}\end{array}$ \\
\hline 38.086 & -0.065 & -0.065 & -0.065 & -0.065 & -0.065 & -0.065 \\
38.574 & -0.060 & -0.060 & -0.060 & -0.060 & -0.060 & -0.060 \\
39.063 & -0.049 & -0.049 & -0.049 & -0.049 & -0.049 & -0.049 \\
39.551 & -0.032 & -0.032 & -0.032 & -0.032 & -0.032 & -0.032 \\
40.039 & -0.010 & -0.010 & -0.010 & -0.010 & -0.010 & -0.010 \\
40.527 & 0.000 & 0.000 & 0.000 & 0.000 & 0.000 & 0.000 \\
41.016 & 0.000 & 0.000 & 0.000 & 0.000 & 0.000 & 0.000 \\
\hline
\end{tabular}


TABLE IV

INVERSE FILTER (1ST ORDER) BEHAVIOR RESULTING FROM CHANGING A AND B IN A*EXP(-BT). INPUT SIGNAL = EXPONENTIAL + HAVERSINE (continued)

\begin{tabular}{|c|c|c|c|c|c|c|}
\hline $\begin{array}{l}\text { time } \\
\text { msec }\end{array}$ & $\begin{array}{l}3 \% \\
\mathrm{mV}\end{array}$ & $\begin{array}{l}4 \% 8 \\
\mathrm{mV}\end{array}$ & $\begin{array}{l}5 \% \\
\mathrm{mV}\end{array}$ & $\begin{array}{l}6 \% \\
\mathrm{mV}\end{array}$ & $\begin{array}{l}7 \% \\
\mathrm{mV}\end{array}$ & $\begin{array}{l}8 \% \\
\mathrm{mV}\end{array}$ \\
\hline $\begin{array}{l}0.000 \\
0.488 \\
0.977 \\
1.465 \\
1.953 \\
2.441 \\
2.930 \\
3.418 \\
3.906 \\
4.395 \\
4.883 \\
5.371 \\
5.859 \\
6.348 \\
6.836 \\
7.324 \\
7.813 \\
8.301 \\
8.789 \\
9.277 \\
9.766 \\
10.254 \\
10.742 \\
11.230 \\
11.719 \\
12.207 \\
12.695 \\
13.184 \\
13.672 \\
14.160 \\
14.648 \\
15.137 \\
15.625 \\
16.113 \\
16.602 \\
17.090 \\
17.578 \\
18.066\end{array}$ & $\begin{array}{r}485.000 \\
2.359 \\
1.986 \\
1.689 \\
1.453 \\
1.270 \\
1.131 \\
1.028 \\
0.956 \\
0.909 \\
0.885 \\
0.877 \\
0.885 \\
0.905 \\
0.935 \\
0.973 \\
1.018 \\
1.067 \\
1.120 \\
1.176 \\
1.233 \\
1.291 \\
1.349 \\
1.405 \\
1.461 \\
1.514 \\
1.564 \\
1.612 \\
1.656 \\
1.696 \\
1.731 \\
1.762 \\
1.789 \\
1.810 \\
1.826 \\
1.837 \\
1.842 \\
1.842\end{array}$ & $\begin{array}{r}480.000 \\
3.111 \\
2.614 \\
2.212 \\
1.890 \\
1.634 \\
1.434 \\
1.281 \\
1.167 \\
1.085 \\
1.031 \\
1.000 \\
0.987 \\
0.990 \\
1.006 \\
1.032 \\
1.067 \\
1.108 \\
1.154 \\
1.204 \\
1.257 \\
1.311 \\
1.365 \\
1.419 \\
1.472 \\
1.523 \\
1.572 \\
1.618 \\
1.661 \\
1.700 \\
1.735 \\
1.766 \\
1.791 \\
1.812 \\
1.828 \\
1.838 \\
1.843 \\
1.843\end{array}$ & $\begin{array}{r}475.000 \\
3.849 \\
3.232 \\
2.729 \\
2.323 \\
1.997 \\
1.738 \\
1.535 \\
1.380 \\
1.263 \\
1.180 \\
1.124 \\
1.092 \\
1.077 \\
1.079 \\
1.093 \\
1.118 \\
1.151 \\
1.190 \\
1.234 \\
1.282 \\
1.332 \\
1.383 \\
1.434 \\
1.484 \\
1.534 \\
1.581 \\
1.626 \\
1.667 \\
1.705 \\
1.739 \\
1.769 \\
1.794 \\
1.815 \\
1.830 \\
1.840 \\
1.845 \\
1.844\end{array}$ & $\begin{array}{r}470.000 \\
4.572 \\
3.840 \\
3.240 \\
2.752 \\
2.358 \\
2.041 \\
1.790 \\
1.594 \\
1.444 \\
1.332 \\
1.252 \\
1.198 \\
1.167 \\
1.154 \\
1.157 \\
1.171 \\
1.195 \\
1.228 \\
1.266 \\
1.308 \\
1.354 \\
1.401 \\
1.449 \\
1.497 \\
1.545 \\
1.590 \\
1.633 \\
1.674 \\
1.711 \\
1.744 \\
1.773 \\
1.798 \\
1.817 \\
1.832 \\
1.842 \\
1.846 \\
1.846\end{array}$ & $\begin{array}{r}465.000 \\
5.280 \\
4.437 \\
3.745 \\
3.178 \\
2.717 \\
2.345 \\
2.046 \\
1.810 \\
1.626 \\
1.485 \\
1.381 \\
1.307 \\
1.259 \\
1.232 \\
1.222 \\
1.226 \\
1.242 \\
1.267 \\
1.299 \\
1.336 \\
1.377 \\
1.421 \\
1.466 \\
1.511 \\
1.556 \\
1.600 \\
1.642 \\
1.681 \\
1.717 \\
1.749 \\
1.777 \\
1.801 \\
1.820 \\
1.835 \\
1.844 \\
1.848 \\
1.847\end{array}$ & $\begin{array}{r}460.000 \\
5.973 \\
5.025 \\
4.243 \\
3.601 \\
3.075 \\
2.648 \\
1.303 \\
2.027 \\
1.810 \\
1.641 \\
1.513 \\
1.419 \\
1.354 \\
1.312 \\
1.289 \\
1.283 \\
1.290 \\
1.307 \\
1.333 \\
1.365 \\
1.402 \\
1.442 \\
1.483 \\
1.526 \\
1.569 \\
1.611 \\
1.651 \\
1.688 \\
1.723 \\
1.754 \\
1.782 \\
1.805 \\
1.824 \\
1.837 \\
1.846 \\
1.850 \\
1.849\end{array}$ \\
\hline
\end{tabular}


TABLE IV

INVERSE FIL TER (1ST ORDER) BEHAVIOR RESULTING FROM CHANGING A AND B IN A*EXP(-BT). INPUT SIGNAL = EXPONENTIAL + HAVERSINE (continued)

\begin{tabular}{|c|c|c|c|c|c|c|}
\hline $\begin{array}{l}\text { time } \\
\text { msec }\end{array}$ & $\begin{array}{l}38 \\
\mathrm{mV}\end{array}$ & $\begin{array}{l}48 \\
\mathrm{mV}\end{array}$ & $\begin{array}{l}5 \% \\
\mathrm{mV}\end{array}$ & $\begin{array}{l}68 \\
\mathrm{mV}\end{array}$ & $\begin{array}{l}78 \\
\mathrm{mV}\end{array}$ & $\begin{array}{l}88 \\
\mathrm{mV}\end{array}$ \\
\hline $\begin{array}{l}18.555 \\
19.043 \\
19.531 \\
20.020 \\
20.508 \\
20.996 \\
21.484 \\
21.973 \\
22.461 \\
22.949 \\
23.438 \\
23.926 \\
24.414 \\
24.902 \\
25.391 \\
25.879 \\
26.367 \\
26.855 \\
27.344 \\
27.832 \\
28.320 \\
28.809 \\
29.297 \\
29.785 \\
30.273 \\
30.762 \\
31.250 \\
31.738 \\
32.227 \\
32.715 \\
33.203 \\
33.691 \\
34.180 \\
34.668 \\
35.156 \\
35.645 \\
36.133 \\
36.621\end{array}$ & $\begin{array}{l}1.836 \\
1.825 \\
1.809 \\
1.787 \\
1.759 \\
1.727 \\
1.690 \\
1.648 \\
1.602 \\
1.551 \\
1.497 \\
1.439 \\
1.377 \\
1.313 \\
1.247 \\
1.178 \\
1.108 \\
1.036 \\
0.963 \\
0.890 \\
0.817 \\
0.745 \\
0.673 \\
0.603 \\
0.534 \\
0.467 \\
0.403 \\
0.341 \\
0.283 \\
0.228 \\
0.177 \\
0.131 \\
0.089 \\
0.051 \\
0.019 \\
-0.009 \\
-0.031 \\
-0.048\end{array}$ & $\begin{array}{r}1.837 \\
1.826 \\
1.809 \\
1.787 \\
1.760 \\
1.727 \\
1.690 \\
1.648 \\
1.602 \\
1.551 \\
1.497 \\
1.439 \\
1.378 \\
1.313 \\
1.247 \\
1.178 \\
1.108 \\
1.036 \\
0.964 \\
0.890 \\
0.817 \\
0.745 \\
0.673 \\
0.603 \\
0.534 \\
0.467 \\
0.403 \\
0.341 \\
0.283 \\
0.228 \\
0.177 \\
0.131 \\
0.089 \\
0.051 \\
0.019 \\
-0.009 \\
-0.031 \\
-0.048\end{array}$ & $\begin{array}{r}1.838 \\
1.827 \\
1.810 \\
1.788 \\
1.760 \\
1.728 \\
1.690 \\
1.648 \\
1.602 \\
1.551 \\
1.497 \\
1.439 \\
1.378 \\
1.314 \\
1.247 \\
1.178 \\
1.108 \\
1.036 \\
0.964 \\
0.891 \\
0.817 \\
0.745 \\
0.673 \\
0.603 \\
0.534 \\
0.467 \\
0.403 \\
0.341 \\
0.283 \\
0.228 \\
0.177 \\
0.131 \\
0.089 \\
0.051 \\
0.019 \\
-0.009 \\
-0.031 \\
-0.048\end{array}$ & $\begin{array}{l}1.839 \\
1.828 \\
1.811 \\
1.788 \\
1.761 \\
1.728 \\
1.691 \\
1.649 \\
1.602 \\
1.552 \\
1.497 \\
1.439 \\
1.378 \\
1.314 \\
1.247 \\
1.178 \\
1.108 \\
1.036 \\
0.964 \\
0.891 \\
0.818 \\
0.745 \\
0.673 \\
0.603 \\
0.534 \\
0.467 \\
0.403 \\
0.341 \\
0.283 \\
0.228 \\
0.177 \\
0.131 \\
0.089 \\
0.051 \\
0.019 \\
-0.009 \\
-0.031 \\
-0.048\end{array}$ & $\begin{array}{r}1.841 \\
1.829 \\
1.811 \\
1.789 \\
1.761 \\
1.729 \\
1.691 \\
1.649 \\
1.603 \\
1.552 \\
1.497 \\
1.439 \\
1.378 \\
1.314 \\
1.247 \\
1.178 \\
1.108 \\
1.036 \\
0.964 \\
0.891 \\
0.818 \\
0.745 \\
0.673 \\
0.603 \\
0.534 \\
0.467 \\
0.403 \\
0.341 \\
0.283 \\
0.228 \\
0.177 \\
0.131 \\
0.089 \\
0.051 \\
0.019 \\
-0.009 \\
-0.031 \\
-0.048\end{array}$ & $\begin{array}{r}1.842 \\
1.830 \\
1.812 \\
1.790 \\
1.762 \\
1.729 \\
1.692 \\
1.650 \\
1.603 \\
1.552 \\
1.498 \\
1.440 \\
1.378 \\
1.314 \\
1.247 \\
1.179 \\
1.108 \\
1.036 \\
0.964 \\
0.891 \\
0.818 \\
0.745 \\
0.673 \\
0.603 \\
0.534 \\
0.467 \\
0.403 \\
0.341 \\
0.283 \\
0.228 \\
0.177 \\
0.131 \\
0.089 \\
0.051 \\
0.019 \\
-0.009 \\
-0.031 \\
-0.048\end{array}$ \\
\hline
\end{tabular}


TABLE IV

INVERSE FILTER (1ST ORDER) BEHAVIOR RESULTING FROM CHANGING A AND B IN A*EXP(-BT). INPUT SIGNAL = EXPONENTIAL + HAVERSINE (continued)

\begin{tabular}{|c|c|c|c|c|c|c|}
\hline $\begin{array}{c}\text { time } \\
\mathrm{msec}\end{array}$ & $\begin{array}{c}3 \% \\
\mathrm{mV}\end{array}$ & $\begin{array}{l}4 \% \\
\mathrm{mV}\end{array}$ & $\begin{array}{c}5 \% \\
\mathrm{mV}\end{array}$ & $\begin{array}{c}6 \% \\
\mathrm{mV}\end{array}$ & $\begin{array}{c}7 \% \\
\mathrm{mV}\end{array}$ & $\begin{array}{c}8 \% \\
\mathrm{mV}\end{array}$ \\
\hline 37.109 & -0.059 & -0.059 & -0.059 & -0.059 & -0.059 & -0.059 \\
37.598 & -0.065 & -0.065 & -0.065 & -0.065 & -0.065 & -0.065 \\
38.086 & -0.065 & -0.065 & -0.065 & -0.065 & -0.065 & -0.065 \\
38.574 & -0.060 & -0.060 & -0.060 & -0.060 & -0.060 & -0.060 \\
39.063 & -0.049 & -0.049 & -0.049 & -0.049 & -0.049 & -0.049 \\
39.551 & -0.032 & -0.032 & -0.032 & -0.032 & -0.032 & -0.032 \\
40.039 & -0.010 & -0.010 & -0.010 & -0.010 & -0.010 & -0.010 \\
40.527 & 0.000 & 0.000 & 0.000 & 0.000 & 0.000 & 0.000 \\
41.016 & 0.000 & 0.000 & 0.000 & 0.000 & 0.000 & 0.000 \\
\hline
\end{tabular}


TABLE IV

INVERSE FILTER (1st order) BEHAVIOR RESULTING FROM CHANGING A AND B IN A*EXP(-BT). INPUT SIGNAL = EXPONENTIAL + HAVERSINE (continued)

\begin{tabular}{|c|c|c|c|c|c|c|c|}
\hline $\begin{array}{l}\text { time } \\
\text { msec }\end{array}$ & $\begin{array}{l}9 \% \\
\mathrm{mV}\end{array}$ & $\begin{array}{l}10 \% \\
\mathrm{mV}\end{array}$ & $\begin{array}{l}11 \% \\
\mathrm{mV}\end{array}$ & $\begin{array}{l}12 \% \\
\mathrm{mV}\end{array}$ & $\begin{array}{l}13 \% \\
\mathrm{mV}\end{array}$ & $\begin{array}{l}14 \% \\
\mathrm{mV}\end{array}$ & $\begin{array}{l}15 \% \\
\mathrm{mV}\end{array}$ \\
\hline $\begin{array}{r}0.00 \\
0.49 \\
0.98 \\
1.47 \\
1.95 \\
2.44 \\
2.93 \\
3.42 \\
3.91 \\
4.40 \\
4.88 \\
5.37 \\
5.86 \\
6.35 \\
6.84 \\
7.32 \\
7.81 \\
8.30 \\
8.79 \\
9.28 \\
9.77 \\
10.25 \\
10.74 \\
11.23 \\
11.72 \\
12.21 \\
12.70 \\
13.18 \\
13.67 \\
14.16 \\
14.65 \\
15.14 \\
15.63 \\
16.11 \\
16.60 \\
17.10 \\
17.58 \\
18.07\end{array}$ & $\begin{array}{r}455.0 \\
6.65 \\
5.60 \\
4.73 \\
4.02 \\
3.43 \\
2.95 \\
1.56 \\
2.25 \\
1.00 \\
1.80 \\
1.65 \\
1.53 \\
1.45 \\
1.39 \\
1.36 \\
1.34 \\
1.34 \\
1.35 \\
1.37 \\
1.40 \\
1.43 \\
1.46 \\
1.50 \\
1.54 \\
1.58 \\
1.62 \\
1.66 \\
1.70 \\
1.73 \\
1.76 \\
1.79 \\
1.81 \\
1.83 \\
1.84 \\
1.85 \\
1.85 \\
1.85\end{array}$ & $\begin{array}{r}450.0 \\
7.32 \\
6.17 \\
5.22 \\
4.43 \\
3.78 \\
3.25 \\
2.82 \\
1.47 \\
1.18 \\
1.96 \\
1.78 \\
1.65 \\
1.55 \\
1.48 \\
1.43 \\
1.40 \\
1.39 \\
1.39 \\
1.40 \\
1.43 \\
1.46 \\
1.49 \\
1.52 \\
1.56 \\
1.60 \\
1.63 \\
1.67 \\
1.71 \\
1.74 \\
1.77 \\
1.79 \\
1.81 \\
1.83 \\
1.84 \\
1.85 \\
1.86 \\
1.85\end{array}$ & $\begin{array}{r}445.0 \\
7.96 \\
6.73 \\
5.69 \\
4.84 \\
4.14 \\
3.56 \\
3.08 \\
1.69 \\
1.37 \\
1.12 \\
1.92 \\
1.77 \\
1.65 \\
1.56 \\
1.51 \\
1.47 \\
1.45 \\
1.44 \\
1.45 \\
1.46 \\
1.48 \\
1.51 \\
1.54 \\
1.57 \\
1.61 \\
1.65 \\
1.68 \\
1.71 \\
1.75 \\
1.77 \\
1.80 \\
1.82 \\
1.84 \\
1.85 \\
1.86 \\
1.87 \\
1.86\end{array}$ & $\begin{array}{r}440.0 \\
8.60 \\
7.27 \\
6.17 \\
5.25 \\
4.49 \\
3.85 \\
3.34 \\
1.91 \\
2.57 \\
2.29 \\
2.06 \\
1.89 \\
1.76 \\
1.65 \\
1.58 \\
1.53 \\
1.50 \\
1.49 \\
1.48 \\
1.50 \\
1.51 \\
1.54 \\
1.57 \\
1.60 \\
1.63 \\
1.67 \\
1.70 \\
1.72 \\
1.75 \\
1.78 \\
1.80 \\
1.82 \\
1.84 \\
1.85 \\
1.86 \\
1.86 \\
1.86\end{array}$ & $\begin{array}{r}435.0 \\
9.22 \\
7.81 \\
6.63 \\
5.65 \\
4.83 \\
4.17 \\
3.59 \\
3.13 \\
2.76 \\
2.45 \\
2.21 \\
1.01 \\
1.86 \\
1.75 \\
1.66 \\
1.60 \\
1.56 \\
1.54 \\
1.53 \\
1.53 \\
1.55 \\
1.56 \\
1.59 \\
1.61 \\
1.64 \\
1.67 \\
1.71 \\
1.74 \\
1.76 \\
1.79 \\
1.81 \\
1.83 \\
1.86 \\
1.86 \\
1.86 \\
1.86 \\
1.86\end{array}$ & $\begin{array}{r}430.0 \\
9.82 \\
8.34 \\
7.09 \\
6.05 \\
5.18 \\
4.46 \\
3.86 \\
3.36 \\
2.95 \\
1.62 \\
2.35 \\
1.14 \\
1.97 \\
1.84 \\
1.74 \\
1.67 \\
1.62 \\
1.59 \\
1.58 \\
1.57 \\
1.58 \\
1.59 \\
1.61 \\
1.64 \\
1.66 \\
1.69 \\
1.72 \\
1.75 \\
1.77 \\
1.80 \\
1.82 \\
1.84 \\
1.85 \\
1.86 \\
1.87 \\
1.87 \\
1.86\end{array}$ & $\begin{array}{r}425.0 \\
10.41 \\
8.85 \\
7.54 \\
6.44 \\
5.52 \\
4.75 \\
4.11 \\
3.59 \\
3.15 \\
1.79 \\
1.50 \\
1.27 \\
1.08 \\
1.94 \\
1.82 \\
1.74 \\
1.68 \\
1.64 \\
1.62 \\
1.61 \\
1.61 \\
1.62 \\
1.64 \\
1.66 \\
1.68 \\
1.71 \\
1.73 \\
1.76 \\
1.78 \\
1.81 \\
1.83 \\
1.84 \\
1.86 \\
1.87 \\
1.87 \\
1.87 \\
1.87\end{array}$ \\
\hline
\end{tabular}


TABLE IV

INVERSE FILTER (1ST ORDER) BEHAVIOR RESULTING FROM CHANGING A AND B IN A*EXP(-BT). INPUT SIGNAL = EXPONENTIAL + HAVERSINE (continued)

\begin{tabular}{|c|c|c|c|c|c|c|c|}
\hline $\begin{array}{l}\text { time } \\
\text { msec }\end{array}$ & $\begin{array}{l}9 \% \\
\mathrm{mV}\end{array}$ & $\begin{array}{l}10 \% \\
\mathrm{mV}\end{array}$ & $\begin{array}{l}11 \% \\
\mathrm{mV}\end{array}$ & $\begin{array}{l}12 \% \\
\mathrm{mV}\end{array}$ & $\begin{array}{l}13 \% \\
\mathrm{mV}\end{array}$ & $\begin{array}{l}14 \% \\
\mathrm{mV}\end{array}$ & $\begin{array}{l}15 \% \\
\mathrm{mV}\end{array}$ \\
\hline $\begin{array}{l}18.56 \\
19.04 \\
19.53 \\
20.02 \\
20.51 \\
21.00 \\
21.48 \\
21.97 \\
22.46 \\
22.95 \\
23.44 \\
23.93 \\
24.41 \\
24.90 \\
25.39 \\
25.88 \\
26.37 \\
26.86 \\
27.34 \\
27.83 \\
28.32 \\
28.81 \\
29.30 \\
29.79 \\
30.27 \\
30.76 \\
31.25 \\
31.74 \\
32.23 \\
32.72 \\
33.20 \\
33.70 \\
34.18 \\
34.67 \\
35.16 \\
35.65 \\
36.13 \\
36.21\end{array}$ & $\begin{array}{r}1.84 \\
1.83 \\
1.81 \\
1.79 \\
1.76 \\
1.73 \\
1.69 \\
1.65 \\
1.60 \\
1.55 \\
1.50 \\
1.44 \\
1.38 \\
1.31 \\
1.25 \\
1.18 \\
1.11 \\
1.04 \\
0.96 \\
0.89 \\
0.82 \\
0.75 \\
0.67 \\
0.60 \\
0.53 \\
0.47 \\
0.40 \\
0.38 \\
0.28 \\
0.23 \\
0.18 \\
0.13 \\
0.09 \\
0.05 \\
0.02 \\
-0.01 \\
-0.03 \\
-0.05\end{array}$ & $\begin{array}{r}1.86 \\
1.83 \\
1.82 \\
1.79 \\
1.76 \\
1.73 \\
1.69 \\
1.65 \\
1.60 \\
1.55 \\
1.50 \\
1.44 \\
1.38 \\
1.31 \\
1.25 \\
1.18 \\
1.11 \\
1.04 \\
0.96 \\
0.89 \\
0.82 \\
0.75 \\
0.67 \\
0.60 \\
0.53 \\
0.47 \\
0.40 \\
0.34 \\
0.28 \\
0.23 \\
0.17 \\
0.13 \\
0.09 \\
0.05 \\
0.02 \\
-0.01 \\
-0.03 \\
-0.05\end{array}$ & $\begin{array}{r}1.85 \\
1.83 \\
1.82 \\
1.79 \\
1.76 \\
1.73 \\
1.69 \\
1.65 \\
1.60 \\
1.55 \\
1.50 \\
1.44 \\
1.40 \\
1.31 \\
1.25 \\
1.18 \\
1.11 \\
1.04 \\
0.96 \\
0.89 \\
0.82 \\
0.72 \\
0.67 \\
0.60 \\
0.53 \\
0.47 \\
0.40 \\
0.34 \\
0.28 \\
0.23 \\
0.18 \\
0.13 \\
0.09 \\
0.05 \\
0.02 \\
-0.01 \\
-0.03 \\
-0.05\end{array}$ & 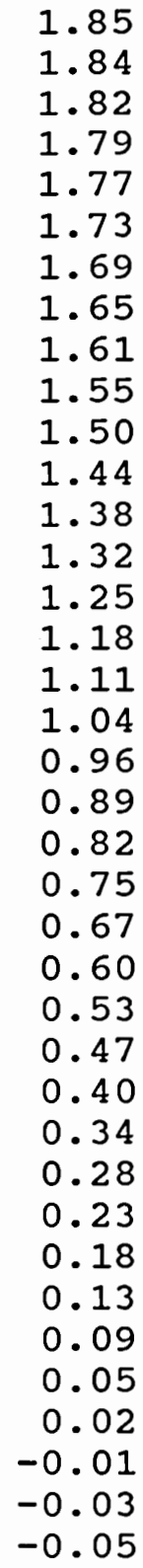 & $\begin{array}{r}1.85 \\
1.84 \\
1.82 \\
1.80 \\
1.77 \\
1.73 \\
1.70 \\
1.65 \\
1.61 \\
1.55 \\
1.50 \\
1.44 \\
1.38 \\
1.32 \\
1.25 \\
1.18 \\
1.11 \\
1.04 \\
0.96 \\
0.89 \\
0.82 \\
0.75 \\
0.67 \\
0.60 \\
0.53 \\
0.47 \\
0.40 \\
0.34 \\
0.28 \\
0.23 \\
0.18 \\
0.13 \\
0.01 \\
0.05 \\
0.02 \\
-0.01 \\
-0.03 \\
-0.05\end{array}$ & $\begin{array}{r}1.85 \\
1.84 \\
1.82 \\
1.80 \\
1.77 \\
1.74 \\
1.70 \\
1.65 \\
1.61 \\
1.56 \\
1.50 \\
1.44 \\
1.38 \\
1.32 \\
1.25 \\
1.18 \\
1.11 \\
1.04 \\
0.96 \\
0.89 \\
0.82 \\
0.75 \\
0.67 \\
0.60 \\
0.53 \\
0.47 \\
0.40 \\
0.34 \\
0.28 \\
0.23 \\
0.18 \\
0.13 \\
0.09 \\
0.05 \\
0.03 \\
-0.01 \\
-0.03 \\
-0.03\end{array}$ & $\begin{array}{r}1.86 \\
1.84 \\
1.82 \\
1.80 \\
1.77 \\
1.74 \\
1.70 \\
1.65 \\
1.61 \\
1.56 \\
1.50 \\
1.44 \\
1.38 \\
1.32 \\
1.25 \\
1.18 \\
1.11 \\
1.04 \\
0.96 \\
0.89 \\
0.82 \\
0.75 \\
0.67 \\
0.60 \\
0.53 \\
0.47 \\
0.40 \\
0.34 \\
0.28 \\
0.23 \\
0.18 \\
0.13 \\
0.09 \\
0.05 \\
0.02 \\
-0.01 \\
-0.03 \\
-0.05\end{array}$ \\
\hline
\end{tabular}


TABLE IV

INVERSE FIL TER (1ST ORDER) BEHAVIOR RESULTING FROM CHANGING A AND B IN A*EXP(-BT). INPUT SIGNAL = EXPONENTIAL + HAVERSINE (continued)

\begin{tabular}{|c|c|c|c|c|c|c|c|}
\hline $\begin{array}{c}\text { time } \\
\mathrm{msec}\end{array}$ & $\begin{array}{c}9 \% \\
\mathrm{mV}\end{array}$ & $\begin{array}{c}10 \% \\
\mathrm{mV}\end{array}$ & $\begin{array}{c}11 \% \\
\mathrm{mV}\end{array}$ & $\begin{array}{c}12 \% \\
\mathrm{mV}\end{array}$ & $\begin{array}{c}13 \% \\
\mathrm{mV}\end{array}$ & $\begin{array}{c}14 \% \\
\mathrm{mV}\end{array}$ & $\begin{array}{c}15 \% \\
\mathrm{mV}\end{array}$ \\
\hline 37.11 & -0.06 & -0.06 & -0.06 & -0.06 & -0.06 & -0.06 & -0.06 \\
37.60 & -0.07 & -0.07 & -0.07 & -0.07 & -0.07 & -0.07 & -0.07 \\
38.09 & -0.07 & -0.07 & -0.07 & -0.07 & -0.07 & -0.07 & -0.07 \\
38.57 & -0.06 & -0.06 & -0.06 & -0.06 & -0.06 & -0.06 & -0.06 \\
39.06 & -0.05 & -0.05 & -0.05 & -0.05 & -0.05 & -0.05 & -0.05 \\
39.55 & -0.03 & -0.03 & -0.03 & -0.03 & -0.03 & -0.03 & -0.03 \\
40.04 & -0.01 & -0.01 & -0.01 & -0.01 & -0.01 & -0.01 & -0.01 \\
40.53 & 0.00 & 0.00 & 0.00 & 0.00 & 0.00 & 0.00 & 0.00 \\
41.02 & 0.00 & 0.00 & 0.00 & 0.00 & 0.00 & 0.00 & 0.00 \\
\hline
\end{tabular}


TABLE V

INVERSE FILTER (2ND ORDER) BEHAVIOR RESULTING FROM CHANGING THE LOCATION OF ZEROS. INPUT = EXPONENTIAL + HAVERSINE

\begin{tabular}{|c|c|c|c|c|c|}
\hline $\begin{array}{c}\text { time } \\
\text { msec }\end{array}$ & $\begin{array}{l}z=.1 \\
m V\end{array}$ & $\begin{array}{l}z=.2 \\
m V\end{array}$ & $\begin{array}{l}\mathrm{z}=.3 \\
\mathrm{mV}\end{array}$ & $\begin{array}{l}z=.4 \\
m V\end{array}$ & $\begin{array}{l}\mathrm{z}=.5 \\
\mathrm{mV}\end{array}$ \\
\hline $\begin{array}{c}0.000 \\
0.488 \\
0.977 \\
1.465 \\
1.953 \\
2.441 \\
2.930 \\
3.418 \\
3.906 \\
4.395 \\
4.883 \\
5.371 \\
5.859 \\
6.348 \\
6.836 \\
7.324 \\
7.813 \\
8.301 \\
8.789 \\
9.277 \\
9.766 \\
10.254 \\
10.742 \\
11.230 \\
11.719 \\
12.207 \\
12.695 \\
13.184 \\
13.672 \\
14.160 \\
14.648 \\
15.137 \\
15.625 \\
16.113 \\
16.602 \\
17.090\end{array}$ & $\begin{array}{r}500.000 \\
0.015 \\
333.376 \\
0.132 \\
225.766 \\
0.362 \\
153.121 \\
0.700 \\
104.164 \\
1.138 \\
71.258 \\
1.665 \\
49.233 \\
2.269 \\
34.584 \\
2.937 \\
24.933 \\
3.652 \\
18.666 \\
4.397 \\
14.685 \\
5.155 \\
12.238 \\
5.908 \\
10.815 \\
6.639 \\
10.061 \\
7.330 \\
9.733 \\
7.966 \\
9.663 \\
8.530 \\
9.733 \\
9.011 \\
9.859 \\
9.396\end{array}$ & $\begin{array}{r}500.000 \\
0.015 \\
318.376 \\
0.131 \\
215.615 \\
0.358 \\
146.247 \\
0.689 \\
99.501 \\
1.117 \\
68.086 \\
1.631 \\
47.063 \\
2.219 \\
33.085 \\
2.868 \\
23.881 \\
3.563 \\
17.908 \\
4.286 \\
14.117 \\
5.022 \\
11.792 \\
5.752 \\
10.443 \\
6.460 \\
9.732 \\
7.130 \\
9.428 \\
7.744 \\
9.368 \\
8.289 \\
9.440 \\
8.752 \\
9.564 \\
9.123\end{array}$ & $\begin{array}{r}500.000 \\
0.015 \\
293.376 \\
0.130 \\
198.696 \\
0.351 \\
134.789 \\
0.671 \\
91.731 \\
1.081 \\
62.800 \\
1.573 \\
43.448 \\
2.135 \\
30.587 \\
2.754 \\
22.127 \\
3.415 \\
16.644 \\
4.102 \\
13.171 \\
4.800 \\
11.048 \\
5.492 \\
9.824 \\
6.162 \\
9.186 \\
6.795 \\
8.920 \\
7.374 \\
8.876 \\
7.887 \\
8.952 \\
8.322 \\
9.073 \\
8.668\end{array}$ & $\begin{array}{r}500.000 \\
0.015 \\
258.376 \\
0.129 \\
175.010 \\
0.342 \\
118.749 \\
0.645 \\
80.852 \\
1.032 \\
55.400 \\
1.493 \\
38.386 \\
2.018 \\
27.090 \\
2.594 \\
19.671 \\
3.208 \\
14.874 \\
3.845 \\
11.847 \\
4.490 \\
10.007 \\
5.129 \\
8.956 \\
5.745 \\
8.420 \\
6.326 \\
8.208 \\
6.856 \\
8.188 \\
7.324 \\
8.268 \\
7.719 \\
8.385 \\
8.031\end{array}$ & $\begin{array}{r}500.000 \\
0.015 \\
213.376 \\
0.128 \\
144.556 \\
0.330 \\
98.125 \\
0.613 \\
66.865 \\
0.969 \\
45.886 \\
1.390 \\
31.877 \\
1.867 \\
22.594 \\
2.388 \\
16.513 \\
2.941 \\
12.598 \\
3.513 \\
10.144 \\
4.091 \\
8.669 \\
4.661 \\
7.842 \\
5.209 \\
7.435 \\
5.723 \\
7.292 \\
6.190 \\
7.303 \\
6.601 \\
7.390 \\
6.944 \\
7.500 \\
7.212\end{array}$ \\
\hline
\end{tabular}


TABLE V

INVERSE FILTER (2ND ORDER) BEHAVIOR RESULTING FROM CHANGING THE LOCATION OF ZEROS. INPUT = EXPONENTIAL + HAVERSINE (continued)

\begin{tabular}{|c|r|l|l|l|l|}
\hline time & \multicolumn{1}{c|}{$\begin{array}{l}\mathrm{z}=.1 \\
\mathrm{mV}\end{array}$} & $\begin{array}{l}\mathrm{z}=.2 \\
\mathrm{mV}\end{array}$ & $\begin{array}{l}\mathrm{z}=.3 \\
\mathrm{mV}\end{array}$ & $\begin{array}{l}\mathrm{z}=.4 \\
\mathrm{mV}\end{array}$ & $\begin{array}{l}\mathrm{z}=.5 \\
\mathrm{mV}\end{array}$ \\
\hline 17.578 & 9.985 & 9.686 & 9.188 & 8.491 & 7.595 \\
18.066 & 9.676 & 9.392 & 8.917 & 8.253 & 7.399 \\
18.555 & 10.070 & 9.767 & 9.263 & 8.557 & 7.650 \\
19.043 & 9.846 & 9.553 & 9.064 & 8.380 & 7.501 \\
19.531 & 10.087 & 9.782 & 9.273 & 8.561 & 7.646 \\
20.020 & 9.901 & 9.602 & 9.105 & 8.409 & 7.514 \\
20.508 & 10.019 & 9.713 & 9.204 & 8.491 & 7.574 \\
20.996 & 9.839 & 9.539 & 9.039 & 8.339 & 7.439 \\
21.484 & 9.856 & 9.552 & 9.046 & 8.338 & 7.427 \\
21.973 & 9.662 & 9.364 & 8.867 & 8.172 & 7.277 \\
22.461 & 9.594 & 9.295 & 8.798 & 8.101 & 7.204 \\
22.949 & 9.375 & 9.083 & 8.594 & 7.911 & 7.033 \\
23.438 & 9.234 & 8.943 & 8.459 & 7.780 & 6.908 \\
23.926 & 8.984 & 8.700 & 8.227 & 7.563 & 6.711 \\
24.414 & 8.781 & 8.501 & 8.034 & 7.381 & 6.541 \\
24.902 & 8.499 & 8.226 & 7.772 & 7.137 & 6.320 \\
25.391 & 8.243 & 7.977 & 7.533 & 6.912 & 6.113 \\
25.879 & 7.929 & 7.672 & 7.242 & 6.641 & 5.868 \\
26.367 & 7.631 & 7.381 & 6.964 & 6.381 & 5.631 \\
26.855 & 7.290 & 7.050 & 6.649 & 6.088 & 5.367 \\
27.344 & 6.958 & 6.727 & 6.341 & 5.801 & 5.107 \\
27.832 & 6.596 & 6.375 & 6.007 & 5.491 & 4.827 \\
28.320 & 6.240 & 6.029 & 5.677 & 5.184 & 4.551 \\
28.809 & 5.864 & 5.663 & 5.330 & 4.863 & 4.263 \\
29.297 & 5.492 & 5.303 & 4.987 & 4.546 & 3.978 \\
29.785 & 5.109 & 4.931 & 4.635 & 4.220 & 3.686 \\
30.273 & 4.733 & 4.566 & 4.288 & 3.899 & 3.399 \\
30.762 & 4.351 & 4.196 & 3.938 & 3.576 & 3.111 \\
31.250 & 3.979 & 3.835 & 3.595 & 3.260 & 2.829 \\
31.738 & 3.608 & 3.476 & 3.255 & 2.947 & 2.551 \\
32.227 & 3.248 & 3.127 & 2.926 & 2.644 & 2.281 \\
32.715 & 2.895 & 2.786 & 2.603 & 2.348 & 2.019 \\
33.203 & 2.557 & 2.458 & 2.294 & 2.064 & 1.768 \\
33.691 & 2.231 & 2.143 & 1.997 & 1.791 & 1.528 \\
34.180 & 1.923 & 1.845 & 1.716 & 1.534 & 1.301 \\
34.668 & 1.631 & 1.563 & 1.450 & 1.292 & 1.088 \\
35.156 & 1.360 & 1.301 & 1.204 & 1.067 & 0.892 \\
35.645 & 1.109 & 1.059 & 0.976 & 0.861 & 0.712
\end{tabular}


TABLE V

INVERSE FILTER (2ND ORDER) BEHAVIOR RESULTING FROM CHANGING

THE LOCATION OF ZEROS. INPUT = EXPONENTIAL + HAVERSINE (continued)

\begin{tabular}{|c|c|r|r|r|r|}
\hline $\begin{array}{r}\text { time } \\
\text { msec }\end{array}$ & $\begin{array}{l}\mathrm{z}=.1 \\
\mathrm{mV}\end{array}$ & $\begin{array}{l}\mathrm{z}=.2 \\
\mathrm{mV}\end{array}$ & $\begin{array}{l}\mathrm{z}=.3 \\
\mathrm{mV}\end{array}$ & $\begin{array}{l}\mathrm{z}=.4 \\
\mathrm{mV}\end{array}$ & \multicolumn{1}{c|}{$\begin{array}{l}\mathrm{z}=.5 \\
\mathrm{mV}\end{array}$} \\
\hline 36.133 & 0.881 & 0.840 & 0.771 & 0.674 & 0.550 \\
36.621 & 0.677 & 0.643 & 0.587 & 0.508 & 0.407 \\
37.109 & 0.498 & 0.471 & 0.426 & 0.364 & 0.283 \\
37.598 & 0.345 & 0.324 & 0.290 & 0.242 & 0.180 \\
38.086 & 0.219 & 0.204 & 0.179 & 0.143 & 0.098 \\
38.574 & 0.121 & 0.111 & 0.093 & 0.069 & 0.037 \\
39.063 & 0.052 & 0.045 & 0.034 & 0.018 & -0.002 \\
39.551 & 0.011 & 0.007 & 0.001 & -0.008 & -0.019 \\
40.039 & -0.000 & -0.002 & -0.005 & -0.009 & -0.013 \\
40.527 & -0.000 & -0.000 & -0.001 & -0.002 & -0.003 \\
41.016 & 0.000 & 0.000 & 0.000 & 0.000 & 0.000 \\
\hline
\end{tabular}


TABLE V

INVERSE FILTER (2ND ORDER) BEHAVIOR RESULTING FROM CHANGING THE LOCATION OF ZEROS. INPUT = EXPONENTIAL + HAVERSINE (continued)

\begin{tabular}{|c|c|c|c|c|c|}
\hline $\begin{array}{l}\text { time } \\
\text { msec }\end{array}$ & $\begin{array}{c}z=.6 \\
m V\end{array}$ & $\begin{array}{c}\mathrm{z}=.7 \\
\mathrm{mV}\end{array}$ & $\begin{array}{c}z=.8 \\
m V\end{array}$ & $\begin{array}{c}z=.9 \\
\mathrm{mV}\end{array}$ & $\begin{array}{l}z=1 \\
m V\end{array}$ \\
\hline $\begin{array}{l}0.000 \\
0.488 \\
0.977 \\
1.465 \\
1.953 \\
2.441 \\
2.930 \\
3.418 \\
3.906 \\
4.395 \\
4.883 \\
5.371 \\
5.859 \\
6.348 \\
6.836 \\
7.324 \\
7.813 \\
8.301 \\
8.789 \\
9.277 \\
9.766 \\
10.254 \\
10.742 \\
11.230 \\
11.719 \\
12.207 \\
12.695 \\
13.184 \\
13.672 \\
14.160 \\
14.648 \\
15.137 \\
15.625 \\
16.113 \\
16.602 \\
17.090 \\
17.578 \\
18.066\end{array}$ & $\begin{array}{r}500.000 \\
0.015 \\
158.376 \\
0.126 \\
107.335 \\
0.316 \\
72.919 \\
0.573 \\
49.769 \\
0.891 \\
34.257 \\
1.264 \\
23.923 \\
1.683 \\
17.099 \\
2.137 \\
12.654 \\
2.616 \\
9.817 \\
3.108 \\
8.063 \\
3.603 \\
7.033 \\
4.089 \\
6.479 \\
4.553 \\
6.232 \\
4.986 \\
6.174 \\
5.377 \\
6.221 \\
5.716 \\
6.316 \\
5.997 \\
6.419 \\
6.212 \\
6.500 \\
6.356\end{array}$ & $\begin{array}{r}500.000 \\
0.015 \\
93.376 \\
0.125 \\
63.346 \\
0.299 \\
43.129 \\
0.526 \\
29.565 \\
0.800 \\
20.513 \\
1.116 \\
14.522 \\
1.465 \\
10.605 \\
1.840 \\
8.093 \\
2.231 \\
6.530 \\
2.630 \\
5.603 \\
3.027 \\
5.099 \\
3.413 \\
4.869 \\
3.778 \\
4.810 \\
4.115 \\
4.852 \\
4.415 \\
4.942 \\
4.671 \\
5.047 \\
4.878 \\
5.141 \\
5.029 \\
5.205 \\
5.123\end{array}$ & $\begin{array}{r}500.000 \\
0.015 \\
18.376 \\
0.122 \\
12.590 \\
0.279 \\
8.757 \\
0.471 \\
6.253 \\
0.694 \\
4.656 \\
0.944 \\
3.674 \\
1.213 \\
3.111 \\
1.497 \\
2.831 \\
1.787 \\
2.737 \\
2.078 \\
2.766 \\
2.362 \\
2.868 \\
2.633 \\
3.011 \\
2.884 \\
3.169 \\
3.110 \\
3.326 \\
3.305 \\
3.467 \\
3.465 \\
3.583 \\
3.586 \\
3.666 \\
3.665 \\
3.712 \\
3.700\end{array}$ & $\begin{array}{r}500.000 \\
0.015 \\
-66.624 \\
0.120 \\
-44.934 \\
0.256 \\
-30.199 \\
0.409 \\
-20.167 \\
0.575 \\
-13.316 \\
0.749 \\
-8.619 \\
0.928 \\
-5.381 \\
1.108 \\
-3.133 \\
1.284 \\
-1.561 \\
1.452 \\
-0.451 \\
1.608 \\
0.339 \\
1.749 \\
0.905 \\
1.871 \\
1.310 \\
1.971 \\
1.597 \\
2.048 \\
1.795 \\
2.098 \\
1.923 \\
2.122 \\
1.995 \\
2.118 \\
2.019 \\
2.087\end{array}$ & $\begin{array}{r}500.000 \\
0.015 \\
-161.624 \\
0.117 \\
-109.225 \\
0.231 \\
-73.737 \\
0.340 \\
-49.695 \\
0.441 \\
-33.403 \\
0.532 \\
-22.359 \\
0.610 \\
-14.873 \\
0.674 \\
-9.799 \\
0.721 \\
-6.365 \\
0.752 \\
-4.045 \\
0.766 \\
-2.487 \\
0.761 \\
-1.449 \\
0.738 \\
-0.768 \\
0.699 \\
-0.335 \\
0.642 \\
-0.073 \\
0.571 \\
0.069 \\
0.486 \\
0.127 \\
0.390 \\
0.127 \\
0.285\end{array}$ \\
\hline
\end{tabular}


TABLE V

INVERSE FILTER (2ND ORDER) BEHAVIOR RESULTING FROM CHANGING THE LOCATION OF ZEROS. INPUT = EXPONENTIAL + HAVERSINE (continued)

\begin{tabular}{|c|c|c|c|c|c|}
\hline $\begin{array}{l}\text { time } \\
\text { msec }\end{array}$ & $\begin{array}{c}z=.6 \\
m V\end{array}$ & $\begin{array}{c}z=.7 \\
m V\end{array}$ & $\begin{array}{c}z=.8 \\
m V\end{array}$ & $\begin{array}{c}z=.9 \\
m V\end{array}$ & $\begin{array}{l}z=1 \\
m V\end{array}$ \\
\hline $\begin{array}{l}18.555 \\
19.043 \\
19.531 \\
20.020 \\
20.508 \\
20.996 \\
21.484 \\
21.973 \\
22.461 \\
22.949 \\
23.438 \\
23.926 \\
24.414 \\
24.902 \\
25.391 \\
25.879 \\
26.367 \\
26.855 \\
27.344 \\
27.832 \\
28.320 \\
28.809 \\
29.297 \\
29.785 \\
30.273 \\
30.762 \\
31.250 \\
31.738 \\
32.227 \\
32.715 \\
33.203 \\
33.691 \\
34.180 \\
34.668 \\
35.156 \\
35.645 \\
36.133 \\
36.621\end{array}$ & $\begin{array}{l}6.540 \\
6.426 \\
6.527 \\
6.420 \\
6.453 \\
6.339 \\
6.314 \\
6.184 \\
6.109 \\
5.959 \\
5.841 \\
5.669 \\
5.515 \\
5.321 \\
5.137 \\
4.923 \\
4.715 \\
4.485 \\
4.258 \\
4.017 \\
3.777 \\
3.529 \\
3.284 \\
3.034 \\
2.788 \\
2.542 \\
2.303 \\
2.067 \\
1.838 \\
1.617 \\
1.406 \\
1.205 \\
1.016 \\
0.840 \\
0.678 \\
0.530 \\
0.398 \\
0.283\end{array}$ & $\begin{array}{l}5.229 \\
5.156 \\
5.205 \\
5.128 \\
5.129 \\
5.039 \\
4.998 \\
4.892 \\
4.815 \\
4.690 \\
4.581 \\
4.437 \\
4.302 \\
4.141 \\
3.983 \\
3.807 \\
3.632 \\
3.443 \\
3.255 \\
3.058 \\
2.863 \\
2.662 \\
2.463 \\
2.263 \\
2.066 \\
1.871 \\
1.680 \\
1.494 \\
1.315 \\
1.142 \\
0.979 \\
0.824 \\
0.680 \\
0.546 \\
0.424 \\
0.315 \\
0.219 \\
0.137\end{array}$ & $\begin{array}{r}3.717 \\
3.690 \\
3.680 \\
3.636 \\
3.600 \\
3.539 \\
3.480 \\
3.401 \\
3.321 \\
3.225 \\
3.127 \\
3.016 \\
2.902 \\
2.779 \\
2.652 \\
2.518 \\
2.382 \\
2.241 \\
2.098 \\
1.953 \\
1.808 \\
1.661 \\
1.517 \\
1.373 \\
1.233 \\
1.095 \\
0.962 \\
0.834 \\
0.711 \\
0.595 \\
0.486 \\
0.384 \\
0.291 \\
0.207 \\
0.132 \\
0.067 \\
0.012 \\
-0.032\end{array}$ & $\begin{array}{l}2.002 \\
2.029 \\
1.950 \\
1.946 \\
1.868 \\
1.839 \\
1.759 \\
1.711 \\
1.628 \\
1.566 \\
1.479 \\
1.406 \\
1.316 \\
1.235 \\
1.143 \\
1.058 \\
0.965 \\
0.878 \\
0.787 \\
0.700 \\
0.612 \\
0.528 \\
0.444 \\
0.365 \\
0.288 \\
0.217 \\
0.148 \\
0.085 \\
0.027 \\
-0.026 \\
-0.073 \\
-0.114 \\
-0.149 \\
-0.177 \\
-0.199 \\
-0.214 \\
-0.222 \\
-0.224\end{array}$ & $\begin{array}{r}0.086 \\
0.172 \\
0.018 \\
0.056 \\
-0.068 \\
-0.061 \\
-0.164 \\
-0.177 \\
-0.264 \\
-0.289 \\
-0.363 \\
-0.394 \\
-0.457 \\
-0.490 \\
-0.543 \\
-0.574 \\
-0.618 \\
-0.645 \\
-0.679 \\
-0.701 \\
-0.725 \\
-0.740 \\
-0.755 \\
-0.762 \\
-0.767 \\
-0.766 \\
-0.762 \\
-0.752 \\
-0.738 \\
-0.720 \\
-0.698 \\
-0.671 \\
-0.641 \\
-0.607 \\
-0.570 \\
-0.528 \\
-0.484 \\
-0.437\end{array}$ \\
\hline
\end{tabular}


TABLE V

INVERSE FILTER (2ND ORDER) BEHAVIOR RESULTING FROM CHANGING THE LOCATION OF ZEROS. INPUT = EXPONENTIAL + HAVERSINE (continued)

\begin{tabular}{|c|c|c|c|c|c|}
\hline $\begin{array}{c}\text { time } \\
\text { msec }\end{array}$ & $\begin{array}{c}z=.6 \\
\mathrm{mV}\end{array}$ & $\begin{array}{c}\mathrm{z}=.7 \\
\mathrm{mV}\end{array}$ & $\begin{array}{c}\mathrm{z}=.8 \\
\mathrm{mV}\end{array}$ & $\begin{array}{c}\mathrm{z}=.9 \\
\mathrm{mV}\end{array}$ & $\begin{array}{c}\mathrm{z}=1 \\
\mathrm{mV}\end{array}$ \\
\hline 37.109 & 0.185 & 0.068 & -0.066 & -0.218 & -0.388 \\
37.598 & 0.104 & 0.015 & -0.088 & -0.205 & -0.336 \\
38.086 & 0.042 & -0.024 & -0.100 & -0.186 & -0.282 \\
38.574 & -0.002 & -0.048 & -0.100 & -0.160 & -0.227 \\
39.063 & -0.027 & -0.056 & -0.089 & -0.128 & -0.170 \\
39.551 & -0.033 & -0.049 & -0.067 & -0.089 & -0.112 \\
40.039 & -0.019 & -0.027 & -0.035 & -0.044 & -0.054 \\
40.527 & -0.004 & -0.006 & -0.008 & -0.010 & -0.012 \\
41.016 & 0.000 & 0.000 & 0.000 & -0.000 & -0.000 \\
41.504 & 0.000 & 0.000 & 0.000 & 0.000 & 0.000 \\
41.992 & 0.000 & 0.000 & 0.000 & -0.000 & -0.000 \\
\hline
\end{tabular}


TABLE VI

INVERSE FILTER (2ND ORDER) BEHAVIOR RESULTING FROM CHANGING THE LOCATION OF ZEROS. INPUT = EXPONENTIAL ONLY

\begin{tabular}{|c|c|c|c|c|c|}
\hline $\begin{array}{l}\text { time } \\
\text { msec }\end{array}$ & $\begin{array}{r}z=.1 \\
m V\end{array}$ & $\begin{array}{r}z=.2 \\
m V\end{array}$ & $\begin{array}{r}\mathrm{z}=.3 \\
\mathrm{mV}\end{array}$ & $\begin{array}{r}z=.4 \\
m V\end{array}$ & $\begin{array}{r}z=.5 \\
m V\end{array}$ \\
\hline $\begin{array}{l}0.000 \\
0.488 \\
0.977 \\
1.465 \\
1.953 \\
2.441 \\
2.930 \\
3.418 \\
3.906 \\
4.395 \\
4.883 \\
5.371 \\
5.859 \\
6.348 \\
6.836 \\
7.324 \\
7.813 \\
8.301 \\
8.789 \\
9.277 \\
9.766 \\
10.254 \\
10.742 \\
11.230 \\
11.719 \\
12.207 \\
12.695 \\
13.184 \\
13.672 \\
14.160 \\
14.648 \\
15.137 \\
15.625 \\
16.113 \\
16.602 \\
17.090 \\
17.578 \\
18.066 \\
18.555\end{array}$ & $\begin{array}{r}500.000 \\
0.000 \\
333.317 \\
0.000 \\
225.534 \\
0.000 \\
152.604 \\
0.000 \\
103.257 \\
0.000 \\
69.867 \\
0.000 \\
47.274 \\
0.000 \\
31.987 \\
0.000 \\
21.644 \\
0.000 \\
14.645 \\
0.000 \\
9.909 \\
0.000 \\
6.705 \\
0.000 \\
4.537 \\
0.000 \\
3.070 \\
0.000 \\
2.077 \\
0.000 \\
1.405 \\
0.000 \\
0.951 \\
0.000 \\
0.643 \\
0.000 \\
0.435 \\
0.000 \\
0.295\end{array}$ & $\begin{array}{r}500.000 \\
0.000 \\
318.317 \\
0.000 \\
215.384 \\
0.000 \\
145.736 \\
0.000 \\
98.610 \\
0.000 \\
66.723 \\
0.000 \\
45.147 \\
0.000 \\
30.548 \\
0.000 \\
20.670 \\
0.000 \\
13.986 \\
0.000 \\
9.463 \\
0.000 \\
6.403 \\
0.000 \\
4.333 \\
0.000 \\
2.932 \\
0.000 \\
1.984 \\
0.000 \\
1.342 \\
0.000 \\
0.908 \\
0.000 \\
0.614 \\
0.000 \\
0.416 \\
0.000 \\
0.281\end{array}$ & $\begin{array}{r}500.000 \\
0.000 \\
293.317 \\
0.000 \\
198.468 \\
0.000 \\
134.290 \\
0.000 \\
90.865 \\
0.000 \\
61.483 \\
0.000 \\
41.601 \\
0.000 \\
28.149 \\
0.000 \\
19.046 \\
0.000 \\
12.887 \\
0.000 \\
8.720 \\
0.000 \\
5.900 \\
0.000 \\
3.992 \\
0.000 \\
2.701 \\
0.000 \\
1.828 \\
0.000 \\
1.237 \\
0.000 \\
0.837 \\
0.000 \\
0.566 \\
0.000 \\
0.383 \\
0.000 \\
0.259\end{array}$ & $\begin{array}{r}500.000 \\
0.000 \\
258.317 \\
0.000 \\
174.786 \\
0.000 \\
118.266 \\
0.000 \\
80.023 \\
0.000 \\
54.146 \\
0.000 \\
36.637 \\
0.000 \\
24.790 \\
0.000 \\
16.774 \\
0.000 \\
11.350 \\
0.000 \\
7.680 \\
0.000 \\
5.196 \\
0.000 \\
3.516 \\
0.000 \\
2.379 \\
0.000 \\
1.610 \\
0.000 \\
1.089 \\
0.000 \\
0.737 \\
0.000 \\
0.499 \\
0.000 \\
0.337 \\
0.000 \\
0.228\end{array}$ & $\begin{array}{r}500.000 \\
0.000 \\
213.317 \\
0.000 \\
144.337 \\
0.000 \\
97.664 \\
0.000 \\
66.083 \\
0.000 \\
44.714 \\
0.000 \\
30.255 \\
0.000 \\
20.471 \\
0.000 \\
13.852 \\
0.000 \\
9.372 \\
0.000 \\
6.342 \\
0.000 \\
4.291 \\
0.000 \\
2.903 \\
0.000 \\
1.965 \\
0.000 \\
1.329 \\
0.000 \\
0.899 \\
0.000 \\
0.609 \\
0.000 \\
0.412 \\
0.000 \\
0.279 \\
0.000 \\
0.189\end{array}$ \\
\hline
\end{tabular}


TABLE VI

INVERSE FILTER (2ND ORDER) BEHAVIOR RESULTING FROM CHANGING THE LOCATION OF ZEROS. INPUT = EXPONENTIAL ONLY

(continued)

\begin{tabular}{|c|c|c|c|c|c|}
\hline $\begin{array}{c}\text { time } \\
\text { msec }\end{array}$ & $\begin{array}{c}z=.1 \\
\mathrm{mV}\end{array}$ & $\begin{array}{c}z=.2 \\
\mathrm{mV}\end{array}$ & $\begin{array}{c}z=.3 \\
\mathrm{mV}\end{array}$ & $\begin{array}{c}z=.4 \\
\mathrm{mV}\end{array}$ & $\begin{array}{c}z=.5 \\
\mathrm{mV}\end{array}$ \\
\hline 19.043 & 0.000 & 0.000 & 0.000 & 0.000 & 0.000 \\
19.531 & 0.199 & 0.190 & 0.175 & 0.154 & 0.128 \\
20.020 & 0.000 & 0.000 & 0.000 & 0.000 & 0.000 \\
20.508 & 0.135 & 0.129 & 0.119 & 0.105 & 0.086 \\
20.996 & 0.000 & 0.000 & 0.000 & 0.000 & 0.000 \\
21.484 & 0.091 & 0.087 & 0.080 & 0.071 & 0.058 \\
21.973 & 0.000 & 0.000 & 0.000 & 0.000 & 0.000 \\
22.461 & 0.062 & 0.059 & 0.054 & 0.048 & 0.040 \\
22.949 & 0.000 & 0.000 & 0.000 & 0.000 & 0.000 \\
23.438 & 0.042 & 0.040 & 0.037 & 0.032 & 0.027 \\
23.926 & 0.000 & 0.000 & 0.000 & 0.000 & 0.000 \\
24.414 & 0.028 & 0.027 & 0.025 & 0.022 & 0.018 \\
24.902 & 0.000 & 0.000 & 0.000 & 0.000 & 0.000 \\
25.391 & 0.019 & 0.018 & 0.017 & 0.015 & 0.012 \\
25.879 & 0.000 & 0.000 & 0.000 & 0.000 & 0.000 \\
26.367 & 0.013 & 0.012 & 0.011 & 0.010 & 0.008 \\
26.855 & 0.000 & 0.000 & 0.000 & 0.000 & 0.000 \\
27.344 & 0.009 & 0.008 & 0.008 & 0.007 & 0.006 \\
27.832 & 0.000 & 0.000 & 0.000 & 0.000 & 0.000 \\
28.320 & 0.006 & 0.006 & 0.005 & 0.005 & 0.004 \\
28.809 & 0.000 & 0.000 & 0.000 & 0.000 & 0.000 \\
29.297 & 0.004 & 0.004 & 0.004 & 0.003 & 0.003 \\
29.785 & 0.000 & 0.000 & 0.000 & 0.000 & 0.000 \\
30.273 & 0.003 & 0.003 & 0.002 & 0.002 & 0.002 \\
30.762 & 0.000 & 0.000 & 0.000 & 0.000 & 0.000 \\
31.250 & 0.002 & 0.002 & 0.002 & 0.001 & 0.001 \\
31.738 & 0.000 & 0.000 & 0.000 & 0.000 & 0.000 \\
32.227 & 0.001 & 0.001 & 0.001 & 0.001 & 0.001 \\
32.715 & 0.000 & 0.000 & 0.000 & 0.000 & 0.000 \\
33.203 & 0.001 & 0.001 & 0.001 & 0.001 & 0.001 \\
33.691 & 0.000 & 0.000 & 0.000 & 0.000 & 0.000 \\
34.180 & 0.001 & 0.001 & 0.001 & 0.000 & 0.000 \\
34.668 & 0.000 & 0.000 & 0.000 & 0.000 & 0.000 \\
\hline & & & & & \\
\hline
\end{tabular}


TABLE VI

INVERSE FILTER (2ND ORDER) BEHAVIOR RESULTING FROM CHANGING THE LOCATION OF ZEROS. INPUT = EXPONENTIAL ONLY (continued)

\begin{tabular}{|c|c|c|c|c|c|}
\hline $\begin{array}{l}\text { time } \\
\text { msec }\end{array}$ & $\begin{array}{c}z=.6 \\
m V\end{array}$ & $\begin{array}{c}z=.7 \\
m V\end{array}$ & $\begin{array}{c}z=.8 \\
m V\end{array}$ & $\begin{array}{c}z=.9 \\
m V\end{array}$ & $\begin{array}{c}\mathrm{z}=1.0 \\
\mathrm{mV}\end{array}$ \\
\hline $\begin{array}{l}0.000 \\
0.488 \\
0.977 \\
1.465 \\
1.953 \\
2.441 \\
2.930 \\
3.418 \\
3.906 \\
4.395 \\
4.883 \\
5.371 \\
5.859 \\
6.348 \\
6.836 \\
7.324 \\
7.813 \\
8.301 \\
8.789 \\
9.277 \\
9.766 \\
10.254 \\
10.742 \\
11.230 \\
11.719 \\
12.207 \\
12.695 \\
13.184 \\
13.672 \\
14.160 \\
14.648 \\
15.137 \\
15.625 \\
16.113 \\
16.602 \\
17.090 \\
17.578 \\
18.066\end{array}$ & $\begin{array}{r}500.000 \\
0.000 \\
158.317 \\
0.000 \\
107.123 \\
0.000 \\
72.483 \\
0.000 \\
49.044 \\
0.000 \\
33.185 \\
0.000 \\
22.454 \\
0.000 \\
15.193 \\
0.000 \\
10.280 \\
0.000 \\
6.956 \\
0.000 \\
4.707 \\
0.000 \\
3.185 \\
0.000 \\
2.155 \\
0.000 \\
1.458 \\
0.000 \\
0.987 \\
0.000 \\
0.668 \\
0.000 \\
0.452 \\
0.000 \\
0.306 \\
0.000 \\
0.207 \\
0.000\end{array}$ & $\begin{array}{r}500.000 \\
0.000 \\
93.317 \\
0.000 \\
63.141 \\
0.000 \\
42.724 \\
0.000 \\
28.908 \\
0.000 \\
19.560 \\
0.000 \\
13.235 \\
0.000 \\
8.955 \\
0.000 \\
6.059 \\
0.000 \\
4.100 \\
0.000 \\
2.774 \\
0.000 \\
1.877 \\
0.000 \\
1.270 \\
0.000 \\
0.859 \\
0.000 \\
0.582 \\
0.000 \\
0.393 \\
0.000 \\
0.266 \\
0.000 \\
0.180 \\
0.000 \\
0.122 \\
0.000\end{array}$ & $\begin{array}{r}500.000 \\
0.000 \\
18.317 \\
0.000 \\
12.394 \\
0.000 \\
8.386 \\
0.000 \\
5.674 \\
0.000 \\
3.839 \\
0.000 \\
2.598 \\
0.000 \\
1.758 \\
0.000 \\
1.189 \\
0.000 \\
0.805 \\
0.000 \\
0.545 \\
0.000 \\
0.368 \\
0.000 \\
0.249 \\
0.000 \\
0.169 \\
0.000 \\
0.114 \\
0.000 \\
0.077 \\
0.000 \\
0.052 \\
0.000 \\
0.035 \\
0.000 \\
0.024 \\
0.000\end{array}$ & $\begin{array}{r}500.000 \\
0.000 \\
-66.683 \\
0.000 \\
-45.120 \\
0.000 \\
-30.530 \\
0.000 \\
-20.657 \\
0.000 \\
-13.978 \\
0.000 \\
-9.458 \\
0.000 \\
-6.399 \\
0.000 \\
-4.330 \\
0.000 \\
-2.930 \\
0.000 \\
-1.982 \\
0.000 \\
-1.341 \\
0.000 \\
-0.908 \\
0.000 \\
-0.614 \\
0.000 \\
-0.416 \\
0.000 \\
-0.281 \\
0.000 \\
-0.190 \\
0.000 \\
-0.129 \\
0.000 \\
-0.087 \\
0.000\end{array}$ & $\begin{array}{r}500.000 \\
0.000 \\
-161.683 \\
0.000 \\
-109.400 \\
0.000 \\
-74.024 \\
0.000 \\
-50.087 \\
0.000 \\
-33.891 \\
0.000 \\
-22.932 \\
0.000 \\
-15.516 \\
0.000 \\
-10.499 \\
0.000 \\
-7.104 \\
0.000 \\
-4.807 \\
0.000 \\
-3.252 \\
0.000 \\
-2.201 \\
0.000 \\
-1.489 \\
0.000 \\
-1.008 \\
0.0000 \\
-0.682 \\
0.000 \\
-0.461 \\
0.000 \\
-0.312 \\
0.000 \\
-0.211 \\
0.000\end{array}$ \\
\hline
\end{tabular}


TABLE VI

INVERSE FILTER (2ND ORDER) BEHAVIOR RESULTING FROM CHANGING THE LOCATION OF ZEROS. INPUT = EXPONENTIAL ONLY (continued)

\begin{tabular}{|c|c|c|c|r|r|}
\hline $\begin{array}{c}\text { time } \\
\text { msec }\end{array}$ & $\begin{array}{c}\mathrm{z}=.6 \\
\mathrm{mV}\end{array}$ & $\begin{array}{c}\mathrm{z}=.7 \\
\mathrm{mV}\end{array}$ & $\begin{array}{c}\mathrm{z}=.8 \\
\mathrm{mV}\end{array}$ & \multicolumn{1}{c|}{$\begin{array}{c}\mathrm{z}=.9 \\
\mathrm{mV}\end{array}$} & \multicolumn{1}{c|}{$\mathrm{z}=1.0$} \\
\hline 18.555 & 0.140 & 0.082 & 0.016 & -0.059 & -0.143 \\
19.043 & 0.000 & 0.000 & 0.000 & 0.000 & 0.000 \\
19.531 & 0.095 & 0.056 & 0.011 & -0.040 & -0.097 \\
20.020 & 0.000 & 0.000 & 0.000 & 0.000 & 0.000 \\
20.508 & 0.064 & 0.038 & 0.007 & -0.027 & -0.065 \\
20.996 & 0.000 & 0.000 & 0.000 & 0.000 & 0.000 \\
21.484 & 0.043 & 0.026 & 0.005 & -0.018 & -0.044 \\
21.973 & 0.000 & 0.000 & 0.000 & 0.000 & 0.000 \\
22.461 & 0.029 & 0.017 & 0.003 & -0.012 & -0.030 \\
22.949 & 0.000 & 0.000 & 0.000 & 0.000 & 0.000 \\
23.438 & 0.020 & 0.012 & 0.002 & -0.008 & -0.020 \\
23.926 & 0.000 & 0.000 & 0.000 & 0.000 & 0.000 \\
24.414 & 0.013 & 0.008 & 0.002 & -0.006 & -0.014 \\
24.902 & 0.000 & 0.000 & 0.000 & 0.000 & 0.000 \\
25.391 & 0.009 & 0.005 & 0.001 & -0.004 & -0.009 \\
25.879 & 0.000 & 0.000 & 0.000 & 0.000 & 0.000 \\
26.367 & 0.006 & 0.004 & 0.001 & -0.003 & -0.006 \\
26.855 & 0.000 & 0.000 & 0.000 & 0.000 & 0.000 \\
27.344 & 0.004 & 0.002 & 0.000 & -0.002 & -0.004 \\
27.832 & 0.000 & 0.000 & 0.000 & 0.000 & 0.000 \\
28.320 & 0.003 & 0.002 & 0.000 & -0.001 & -0.003 \\
28.809 & 0.000 & 0.000 & 0.000 & 0.000 & 0.000 \\
29.297 & 0.002 & 0.001 & 0.000 & -0.001 & -0.002 \\
29.785 & 0.000 & 0.000 & 0.000 & 0.000 & 0.000 \\
30.273 & 0.001 & 0.001 & 0.000 & -0.001 & -0.001 \\
30.762 & 0.000 & 0.000 & 0.000 & 0.000 & 0.000 \\
31.250 & 0.001 & 0.001 & 0.000 & -0.000 & -0.001 \\
31.738 & 0.000 & 0.000 & 0.000 & 0.000 & 0.000 \\
32.227 & 0.001 & 0.000 & 0.000 & -0.000 & -0.001 \\
32.715 & 0.000 & 0.000 & 0.000 & 0.000 & 0.000 \\
33.203 & 0.000 & 0.000 & 0.000 & -0.000 & -0.000 \\
33.691 & 0.000 & 0.000 & 0.000 & 0.000 & 0.000 \\
34.180 & 0.000 & 0.000 & 0.000 & -0.000 & -0.000 \\
34.668 & 0.000 & 0.000 & 0.000 & 0.000 & 0.000 \\
\hline
\end{tabular}


TABLE VII

INVERSE FIL TER (1ST ORDER) BEHAVIOR RESULTING FROM CHANGING THE LOCATION OF ZEROS. INPUT = EXPONENTIAL ONLY

\begin{tabular}{|c|c|c|c|c|c|}
\hline $\begin{array}{l}\text { time } \\
\text { msec }\end{array}$ & $\begin{array}{c}z=.1 \\
m V\end{array}$ & $\begin{array}{c}z=.2 \\
m V\end{array}$ & $\begin{array}{c}z=.3 \\
m V\end{array}$ & $\begin{array}{c}z=.4 \\
m V\end{array}$ & $\begin{array}{c}z=.5 \\
\mathrm{mV}\end{array}$ \\
\hline $\begin{array}{l}0.000 \\
0.488 \\
0.977 \\
1.465 \\
1.953 \\
2.441 \\
2.930 \\
3.418 \\
3.906 \\
4.395 \\
4.883 \\
5.371 \\
5.859 \\
6.348 \\
6.836 \\
7.324 \\
7.813 \\
8.301 \\
8.789 \\
9.277 \\
9.766 \\
10.254 \\
10.742 \\
11.230 \\
11.719 \\
12.207 \\
12.695 \\
13.184 \\
13.672 \\
14.160 \\
14.648 \\
15.137 \\
15.625 \\
16.113 \\
16.602 \\
17.090 \\
17.578 \\
18.066 \\
18.555\end{array}$ & $\begin{array}{r}500.000 \\
361.289 \\
297.188 \\
244.460 \\
201.087 \\
165.410 \\
136.063 \\
111.922 \\
92.065 \\
75.730 \\
62.294 \\
51.242 \\
42.150 \\
34.672 \\
28.520 \\
23.460 \\
19.298 \\
15.874 \\
13.058 \\
10.741 \\
8.835 \\
7.268 \\
5.978 \\
4.918 \\
4.045 \\
3.327 \\
2.737 \\
2.251 \\
1.852 \\
1.523 \\
1.253 \\
1.031 \\
0.848 \\
0.697 \\
0.574 \\
0.472 \\
0.388 \\
0.319 \\
0.263\end{array}$ & $\begin{array}{r}500.000 \\
311.289 \\
256.059 \\
210.629 \\
173.258 \\
142.518 \\
117.232 \\
96.433 \\
79.323 \\
65.250 \\
53.673 \\
44.150 \\
36.317 \\
29.873 \\
24.573 \\
20.213 \\
16.627 \\
13.677 \\
11.250 \\
9.254 \\
7.612 \\
6.262 \\
5.151 \\
4.237 \\
3.485 \\
2.867 \\
2.358 \\
1.940 \\
1.596 \\
1.313 \\
1.080 \\
0.888 \\
0.731 \\
0.601 \\
0.494 \\
0.407 \\
0.334 \\
0.275 \\
0.226\end{array}$ & $\begin{array}{r}500.000 \\
261.289 \\
214.930 \\
176.797 \\
145.429 \\
119.627 \\
98.402 \\
80.943 \\
66.582 \\
54.769 \\
45.052 \\
37.059 \\
30.484 \\
25.075 \\
20.626 \\
16.967 \\
13.956 \\
11.480 \\
9.443 \\
7.768 \\
6.390 \\
5.256 \\
4.323 \\
3.556 \\
2.925 \\
2.406 \\
1.979 \\
1.628 \\
1.339 \\
1.102 \\
0.906 \\
0.745 \\
0.613 \\
0.504 \\
0.415 \\
0.341 \\
0.281 \\
0.231 \\
0.190\end{array}$ & $\begin{array}{r}500.000 \\
211.289 \\
173.801 \\
142.965 \\
117.600 \\
96.735 \\
79.572 \\
65.454 \\
53.841 \\
44.289 \\
36.431 \\
29.967 \\
24.650 \\
20.277 \\
16.679 \\
13.720 \\
11.286 \\
9.283 \\
7.636 \\
6.281 \\
5.167 \\
4.250 \\
3.496 \\
2.876 \\
2.366 \\
1.946 \\
1.601 \\
1.317 \\
1.083 \\
0.891 \\
0.733 \\
0.603 \\
0.496 \\
0.408 \\
0.336 \\
0.276 \\
0.227 \\
0.187 \\
0.154\end{array}$ & $\begin{array}{l}500.000 \\
161.289 \\
132.673 \\
109.133 \\
89.771 \\
73.843 \\
60.742 \\
49.965 \\
41.100 \\
33.808 \\
27.810 \\
22.876 \\
18.817 \\
15.478 \\
12.732 \\
10.473 \\
8.615 \\
7.087 \\
5.829 \\
4.795 \\
3.944 \\
3.244 \\
2.669 \\
2.195 \\
1.806 \\
1.485 \\
1.222 \\
1.005 \\
0.827 \\
0.680 \\
0.559 \\
0.460 \\
0.379 \\
0.311 \\
0.256 \\
0.211 \\
0.173 \\
0.143 \\
0.117\end{array}$ \\
\hline
\end{tabular}


TABLE VII

INVERSE FILTER (1ST ORDER) BEHAVIOR RESULTING FROM CHANGING THE LOCATION OF ZEROS. INPUT = EXPONENTIAL ONLY (continued)

\begin{tabular}{|c|c|c|c|c|c|}
\hline $\begin{array}{c}\text { time } \\
\mathrm{msec}\end{array}$ & $\begin{array}{c}\mathrm{z}=.1 \\
\mathrm{mV}\end{array}$ & $\begin{array}{c}\mathrm{z}=.2 \\
\mathrm{mV}\end{array}$ & $\begin{array}{c}z=.3 \\
\mathrm{mV}\end{array}$ & $\begin{array}{c}z=.4 \\
\mathrm{mV}\end{array}$ & $\begin{array}{c}z=.5 \\
\mathrm{mV}\end{array}$ \\
\hline 19.043 & 0.216 & 0.186 & 0.156 & 0.126 & 0.096 \\
19.531 & 0.178 & 0.153 & 0.129 & 0.104 & 0.079 \\
20.020 & 0.146 & 0.126 & 0.106 & 0.085 & 0.065 \\
20.508 & 0.120 & 0.104 & 0.087 & 0.070 & 0.054 \\
20.996 & 0.099 & 0.085 & 0.072 & 0.058 & 0.044 \\
21.484 & 0.081 & 0.070 & 0.059 & 0.048 & 0.036 \\
21.973 & 0.067 & 0.058 & 0.048 & 0.039 & 0.030 \\
22.461 & 0.055 & 0.047 & 0.040 & 0.032 & 0.025 \\
22.949 & 0.045 & 0.039 & 0.033 & 0.026 & 0.020 \\
23.438 & 0.037 & 0.032 & 0.027 & 0.022 & 0.017 \\
23.926 & 0.031 & 0.026 & 0.022 & 0.018 & 0.014 \\
24.414 & 0.025 & 0.022 & 0.018 & 0.015 & 0.011 \\
24.902 & 0.021 & 0.018 & 0.015 & 0.012 & 0.009 \\
25.391 & 0.017 & 0.015 & 0.012 & 0.010 & 0.008 \\
25.879 & 0.014 & 0.012 & 0.010 & 0.008 & 0.006 \\
26.367 & 0.012 & 0.010 & 0.008 & 0.007 & 0.005 \\
26.855 & 0.009 & 0.008 & 0.007 & 0.006 & 0.004 \\
27.344 & 0.008 & 0.007 & 0.006 & 0.005 & 0.003 \\
27.832 & 0.006 & 0.006 & 0.005 & 0.004 & 0.003 \\
28.320 & 0.005 & 0.005 & 0.004 & 0.003 & 0.002 \\
28.809 & 0.004 & 0.004 & 0.003 & 0.003 & 0.002 \\
29.297 & 0.004 & 0.003 & 0.003 & 0.002 & 0.002 \\
29.785 & 0.003 & 0.003 & 0.002 & 0.002 & 0.001 \\
30.273 & 0.002 & 0.002 & 0.002 & 0.001 & 0.001 \\
30.762 & 0.002 & 0.002 & 0.001 & 0.001 & 0.001 \\
31.250 & 0.002 & 0.001 & 0.001 & 0.001 & 0.001 \\
31.738 & 0.001 & 0.001 & 0.001 & 0.001 & 0.001 \\
32.227 & 0.001 & 0.001 & 0.001 & 0.001 & 0.000 \\
32.715 & 0.001 & 0.001 & 0.001 & 0.001 & 0.000 \\
33.203 & 0.001 & 0.001 & 0.001 & 0.000 & 0.000 \\
33.691 & 0.001 & 0.001 & 0.000 & 0.000 & 0.000 \\
34.180 & 0.001 & 0.000 & 0.000 & 0.000 & 0.000 \\
34.668 & 0.000 & 0.000 & 0.000 & 0.000 & 0.000 \\
\hline
\end{tabular}


103

\section{TABLE VII}

INVERSE FILTER (1ST ORDER) BEHAVIOR RESULTING FROM CHANGING THE LOCATION OF ZEROS. INPUT = EXPONENTIAL ONLY

(continued)

\begin{tabular}{|c|c|c|c|c|c|}
\hline $\begin{array}{l}\text { time } \\
\text { msec }\end{array}$ & $\begin{array}{c}z=.6 \\
m V\end{array}$ & $\begin{array}{c}z=.7 \\
m V\end{array}$ & $\begin{array}{c}z=.8 \\
m V\end{array}$ & $\begin{array}{c}z=.9 \\
m V\end{array}$ & $\begin{array}{c}\mathrm{z}=1.0 \\
\mathrm{mV}\end{array}$ \\
\hline $\begin{array}{l}0.000 \\
0.488 \\
0.977 \\
1.465 \\
1.953 \\
2.441 \\
2.930 \\
3.418 \\
3.906 \\
4.395 \\
4.883 \\
5.371 \\
5.859 \\
6.348 \\
6.836 \\
7.324 \\
7.813 \\
8.301 \\
8.789 \\
9.277 \\
9.766 \\
10.254 \\
10.742 \\
11.230 \\
11.719 \\
12.207 \\
12.695 \\
13.184 \\
13.672 \\
14.160 \\
14.648 \\
15.137 \\
15.625 \\
16.113 \\
16.602 \\
17.090 \\
17.578 \\
18.066\end{array}$ & $\begin{array}{r}500.000 \\
111.289 \\
91.544 \\
75.302 \\
61.942 \\
50.952 \\
41.912 \\
34.476 \\
28.359 \\
23.327 \\
19.189 \\
15.784 \\
12.984 \\
10.680 \\
8.785 \\
7.226 \\
5.944 \\
4.890 \\
4.022 \\
3.309 \\
2.722 \\
2.239 \\
1.841 \\
1.515 \\
1.246 \\
1.025 \\
0.843 \\
0.694 \\
0.570 \\
0.469 \\
0.386 \\
0.318 \\
0.261 \\
0.215 \\
0.177 \\
0.145 \\
0.120 \\
0.098\end{array}$ & $\begin{array}{r}500.000 \\
61.289 \\
50.415 \\
41.470 \\
34.112 \\
28.060 \\
23.082 \\
18.986 \\
15.618 \\
12.847 \\
10.568 \\
8.693 \\
7.150 \\
5.882 \\
4.838 \\
3.980 \\
3.274 \\
2.693 \\
2.215 \\
1.822 \\
1.499 \\
1.233 \\
1.014 \\
0.834 \\
0.686 \\
0.564 \\
0.464 \\
0.382 \\
0.314 \\
0.258 \\
0.213 \\
0.175 \\
0.144 \\
0.118 \\
0.097 \\
0.080 \\
0.066 \\
0.054\end{array}$ & $\begin{array}{r}500.000 \\
11.289 \\
9.286 \\
7.638 \\
6.283 \\
5.168 \\
4.251 \\
3.497 \\
2.877 \\
2.366 \\
1.946 \\
1.601 \\
1.317 \\
1.083 \\
0.891 \\
0.733 \\
0.603 \\
0.496 \\
0.408 \\
0.336 \\
0.276 \\
0.227 \\
0.187 \\
0.154 \\
0.126 \\
0.104 \\
0.086 \\
0.070 \\
0.058 \\
0.048 \\
0.039 \\
0.032 \\
0.026 \\
0.022 \\
0.018 \\
0.015 \\
0.012 \\
0.010\end{array}$ & $\begin{array}{r}500.000 \\
-38.711 \\
-31.843 \\
-26.193 \\
-21.546 \\
-17.723 \\
-14.579 \\
-11.992 \\
-9.864 \\
-8.114 \\
-6.675 \\
-5.490 \\
-4.516 \\
-3.715 \\
-3.056 \\
-2.514 \\
-2.068 \\
-1.701 \\
-1.399 \\
-1.151 \\
-0.947 \\
-0.779 \\
-0.641 \\
-0.527 \\
-0.433 \\
-0.357 \\
-0.293 \\
-0.241 \\
-0.198 \\
-0.163 \\
-0.134 \\
-0.110 \\
-0.091 \\
-0.075 \\
-0.061 \\
-0.051 \\
-0.042 \\
-0.034\end{array}$ & $\begin{array}{l}500.000 \\
-88.711 \\
-72.972 \\
-60.025 \\
-49.375 \\
-40.615 \\
-33.409 \\
-27.481 \\
-22.606 \\
-18.595 \\
-15.296 \\
-12.582 \\
-10.350 \\
-8.513 \\
-7.003 \\
-5.760 \\
-4.738 \\
-3.898 \\
-3.206 \\
-2.637 \\
-2.169 \\
-1.784 \\
-1.468 \\
-1.207 \\
-0.993 \\
-0.817 \\
-0.672 \\
-0.553 \\
-0.455 \\
-0.374 \\
-0.308 \\
-0.253 \\
-0.208 \\
-0.171 \\
-0.141 \\
-0.116 \\
-0.095 \\
-0.078\end{array}$ \\
\hline
\end{tabular}


TABLE VII

INVERSE FILTER (1ST ORDER) BEHAVIOR RESULTING FROM CHANGING THE LOCATION OF ZEROS. INPUT $=$ EXPONENTIAL ONLY (continued)

\begin{tabular}{|c|c|c|c|c|c|}
\hline $\begin{array}{c}\text { time } \\
\text { msec }\end{array}$ & $\begin{array}{c}z=.6 \\
\mathrm{mV}\end{array}$ & $\begin{array}{c}z=.7 \\
\mathrm{mV}\end{array}$ & $\begin{array}{c}z=.8 \\
\mathrm{mV}\end{array}$ & $\begin{array}{c}z=.9 \\
\mathrm{mV}\end{array}$ & $\begin{array}{c}z=1.0 \\
\mathrm{mV}\end{array}$ \\
\hline 18.555 & 0.081 & 0.045 & 0.008 & -0.028 & -0.064 \\
19.043 & 0.067 & 0.037 & 0.007 & -0.023 & -0.053 \\
19.531 & 0.055 & 0.030 & 0.006 & -0.019 & -0.044 \\
20.020 & 0.045 & 0.025 & 0.005 & -0.016 & -0.036 \\
20.508 & 0.037 & 0.020 & 0.004 & -0.013 & -0.030 \\
20.996 & 0.030 & 0.017 & 0.003 & -0.011 & -0.024 \\
21.484 & 0.025 & 0.014 & 0.003 & -0.009 & -0.020 \\
21.973 & 0.021 & 0.011 & 0.002 & -0.007 & -0.016 \\
22.461 & 0.017 & 0.009 & 0.002 & -0.006 & -0.014 \\
22.949 & 0.014 & 0.008 & 0.001 & -0.005 & -0.011 \\
23.438 & 0.011 & 0.006 & 0.001 & -0.004 & -0.009 \\
23.926 & 0.009 & 0.005 & 0.001 & -0.003 & -0.008 \\
24.414 & 0.008 & 0.004 & 0.001 & -0.003 & -0.006 \\
24.902 & 0.006 & 0.004 & 0.001 & -0.002 & -0.005 \\
25.391 & 0.005 & 0.003 & 0.001 & -0.002 & -0.004 \\
25.879 & 0.004 & 0.002 & 0.000 & -0.002 & -0.003 \\
26.367 & 0.004 & 0.002 & 0.000 & -0.001 & -0.003 \\
26.855 & 0.003 & 0.002 & 0.000 & -0.001 & -0.002 \\
27.344 & 0.002 & 0.001 & 0.000 & -0.001 & -0.002 \\
27.832 & 0.002 & 0.001 & 0.000 & -0.001 & -0.002 \\
28.320 & 0.002 & 0.001 & 0.000 & -0.001 & -0.001 \\
28.809 & 0.001 & 0.001 & 0.000 & -0.000 & -0.001 \\
29.297 & 0.001 & 0.001 & 0.000 & -0.000 & -0.001 \\
29.785 & 0.001 & 0.000 & 0.000 & -0.000 & -0.001 \\
30.273 & 0.001 & 0.000 & 0.000 & -0.000 & -0.001 \\
30.762 & 0.001 & 0.000 & 0.000 & -0.000 & -0.000 \\
31.250 & 0.001 & 0.000 & 0.000 & -0.000 & -0.000 \\
31.738 & 0.000 & 0.000 & 0.000 & -0.000 & -0.000 \\
32.227 & 0.000 & 0.000 & 0.000 & -0.000 & -0.000 \\
32.715 & 0.000 & 0.000 & 0.000 & -0.000 & -0.000 \\
33.203 & 0.000 & 0.000 & 0.000 & -0.000 & -0.000 \\
\hline
\end{tabular}


TABLE VIII

INVERSE FILTER (1ST ORDER) BEHAVIOR RESULTING FROM CHANGING THE LOCATION OF ZEROS. INPUT = EXPONENTIAL + HAVERSINE

\begin{tabular}{|c|c|c|c|c|c|}
\hline time & $\begin{array}{c}\mathrm{z}=.1 \\
\mathrm{msec}\end{array}$ & $\begin{array}{l}\mathrm{z}=.2 \\
\mathrm{mV}\end{array}$ & $\begin{array}{c}\mathrm{z}=.3 \\
\mathrm{mV}\end{array}$ & $\begin{array}{c}\mathrm{z}=.4 \\
\mathrm{mV}\end{array}$ & $\begin{array}{c}\mathrm{z}=.5 \\
\mathrm{mV}\end{array}$ \\
\hline 0.000 & 500.000 & 500.000 & 500.000 & 500.000 & 500.000 \\
0.488 & 361.303 & 311.303 & 261.303 & 211.303 & 161.303 \\
0.977 & 297.245 & 256.115 & 214.985 & 173.854 & 132.724 \\
1.465 & 244.586 & 210.749 & 176.911 & 143.073 & 109.236 \\
1.953 & 201.308 & 173.465 & 145.623 & 117.781 & 89.938 \\
2.441 & 165.750 & 142.835 & 119.920 & 97.005 & 74.090 \\
2.930 & 136.546 & 117.680 & 98.813 & 79.947 & 61.080 \\
3.418 & 112.574 & 97.032 & 81.491 & 65.950 & 50.408 \\
3.906 & 92.906 & 80.095 & 67.283 & 54.472 & 41.660 \\
4.395 & 76.784 & 66.212 & 55.640 & 45.068 & 34.497 \\
4.883 & 63.580 & 54.844 & 46.108 & 37.373 & 28.637 \\
5.371 & 52.778 & 45.547 & 38.315 & 31.084 & 23.852 \\
5.859 & 43.955 & 37.954 & 31.953 & 25.952 & 19.951 \\
6.348 & 36.761 & 31.765 & 26.770 & 21.774 & 16.778 \\
6.836 & 30.908 & 26.732 & 22.556 & 18.381 & 14.205 \\
7.324 & 26.158 & 22.650 & 19.142 & 15.633 & 12.125 \\
7.813 & 22.317 & 19.351 & 16.384 & 13.417 & 10.451 \\
8.301 & 19.224 & 16.695 & 14.167 & 11.638 & 9.110 \\
8.789 & 16.744 & 14.569 & 12.394 & 10.218 & 8.043 \\
9.277 & 14.769 & 12.877 & 10.985 & 9.093 & 7.201 \\
9.766 & 13.208 & 11.542 & 9.876 & 8.209 & 6.543 \\
10.254 & 11.985 & 10.498 & 9.011 & 7.523 & 6.036 \\
10.742 & 11.040 & 9.693 & 8.345 & 6.998 & 5.651 \\
11.230 & 10.320 & 9.081 & 7.842 & 6.604 & 5.365 \\
11.719 & 9.783 & 8.627 & 7.471 & 6.315 & 5.159 \\
12.207 & 9.393 & 8.299 & 7.205 & 6.111 & 5.018 \\
12.695 & 9.121 & 8.073 & 7.024 & 5.975 & 4.927 \\
13.184 & 8.943 & 7.926 & 6.909 & 5.892 & 4.875 \\
13.672 & 8.839 & 7.843 & 6.847 & 5.851 & 4.855 \\
14.160 & 8.790 & 7.807 & 6.823 & 5.840 & 4.857 \\
14.648 & 8.784 & 7.807 & 6.829 & 5.852 & 4.875 \\
15.137 & 8.808 & 7.832 & 6.856 & 5.879 & 4.903 \\
15.625 & 8.852 & 7.873 & 6.895 & 5.917 & 4.938 \\
16.113 & 8.908 & 7.925 & 6.942 & 5.959 & 4.976 \\
16.602 & 8.968 & 7.979 & 6.990 & 6.001 & 5.012 \\
17.090 & 9.028 & 8.032 & 7.037 & 6.041 & 5.045 \\
17.578 & 9.082 & 8.080 & 7.077 & 6.075 & 5.073 \\
18.066 & 9.126 & 8.118 & 7.109 & 6.101 & 5.092 \\
18.555 & 9.157 & 8.144 & 7.130 & 6.117 & 5.103
\end{tabular}


TABLE VIII

INVERSE FIL TER (1ST ORDER) BEHAVIOR RESULTING FROM CHANGING THE LOCATION OF ZEROS. INPUT = EXPONENTIAL + HA VERSINE (continued)

\begin{tabular}{|c|c|c|c|c|c|}
\hline time & $z=.1$ & $\begin{array}{l}z=.2 \\
\mathrm{~m} s e c\end{array}$ & $\begin{array}{c}\mathrm{z}=.3 \\
\mathrm{mV}\end{array}$ & $\begin{array}{l}\mathrm{z}=.4 \\
\mathrm{mV}\end{array}$ & $\begin{array}{l}\mathrm{z}=.5 \\
\mathrm{mV}\end{array}$ \\
\hline 19.043 & 9.172 & 8.155 & 7.138 & 6.121 & 5.104 \\
19.531 & 9.170 & 8.151 & 7.132 & 6.113 & 5.094 \\
20.020 & 9.148 & 8.129 & 7.110 & 6.091 & 5.072 \\
20.508 & 9.104 & 8.088 & 7.071 & 6.054 & 5.038 \\
20.996 & 9.039 & 8.027 & 7.015 & 6.003 & 4.991 \\
21.484 & 8.952 & 7.947 & 6.942 & 5.937 & 4.932 \\
21.973 & 8.842 & 7.847 & 6.851 & 5.855 & 4.859 \\
22.461 & 8.710 & 7.726 & 6.742 & 5.758 & 4.775 \\
22.949 & 8.555 & 7.586 & 6.616 & 5.647 & 4.678 \\
23.438 & 8.379 & 7.426 & 6.474 & 5.521 & 4.569 \\
23.926 & 8.181 & 7.248 & 6.315 & 5.382 & 4.448 \\
24.414 & 7.963 & 7.051 & 6.140 & 5.229 & 4.317 \\
24.902 & 7.726 & 6.838 & 5.951 & 5.063 & 4.176 \\
25.391 & 7.470 & 6.609 & 5.748 & 4.886 & 4.025 \\
25.879 & 7.198 & 6.365 & 5.532 & 4.699 & 3.866 \\
26.367 & 6.911 & 6.108 & 5.305 & 4.501 & 3.698 \\
26.855 & 6.610 & 5.839 & 5.067 & 4.296 & 3.524 \\
27.344 & 6.297 & 5.559 & 4.821 & 4.083 & 3.344 \\
27.832 & 5.974 & 5.270 & 4.567 & 3.863 & 3.160 \\
28.320 & 5.642 & 4.975 & 4.307 & 3.639 & 2.971 \\
28.809 & 5.304 & 4.673 & 4.042 & 3.411 & 2.780 \\
29.297 & 4.962 & 4.368 & 3.775 & 3.181 & 2.588 \\
29.785 & 4.617 & 4.061 & 3.505 & 2.950 & 2.394 \\
30.273 & 4.271 & 3.754 & 3.236 & 2.719 & 2.202 \\
30.762 & 3.927 & 3.448 & 2.969 & 2.490 & 2.011 \\
31.250 & 3.586 & 3.145 & 2.705 & 2.264 & 1.824 \\
31.738 & 3.251 & 2.848 & 2.445 & 2.043 & 1.640 \\
32.227 & 2.923 & 2.557 & 2.192 & 1.827 & 1.461 \\
32.715 & 2.604 & 2.275 & 1.946 & 1.618 & 1.289 \\
33.203 & 2.297 & 2.003 & 1.710 & 1.417 & 1.124 \\
33.691 & 2.002 & 1.743 & 1.484 & 1.225 & 0.966 \\
34.180 & 1.723 & 1.496 & 1.270 & 1.044 & 0.818 \\
34.668 & 1.459 & 1.264 & 1.069 & 0.875 & 0.680 \\
35.156 & 1.214 & 1.048 & 0.883 & 0.718 & 0.552 \\
35.645 & 0.988 & 0.850 & 0.712 & 0.574 & 0.436 \\
36.133 & 0.782 & 0.670 & 0.557 & 0.445 & 0.332 \\
36.621 & 0.599 & 0.509 & 0.420 & 0.330 & 0.241 \\
37.109 & 0.438 & 0.369 & 0.300 & 0.232 & 0.163 \\
\hline
\end{tabular}


TABLE VIII

INVERSE FILTER (1ST ORDER) BEHAVIOR RESULTING FROM CHANGING THE LOCATION OF ZEROS. INPUT = EXPONENTIAL + HAVERSINE (continued)

\begin{tabular}{|c|r|r|r|r|r|}
\hline $\begin{array}{c}\text { time } \\
\mathrm{msec}\end{array}$ & $\begin{array}{c}\mathrm{z}=.1 \\
\mathrm{mV}\end{array}$ & \multicolumn{1}{c|}{$\begin{array}{c}\mathrm{z}=.2 \\
\mathrm{mV}\end{array}$} & \multicolumn{1}{c|}{$\begin{array}{c}\mathrm{z}=.3 \\
\mathrm{mV}\end{array}$} & \multicolumn{1}{c|}{$\begin{array}{c}\mathrm{z}=.4 \\
\mathrm{mV}\end{array}$} & \multicolumn{1}{c|}{$\begin{array}{c}\mathrm{z}=.5 \\
\mathrm{mV}\end{array}$} \\
\hline 37.598 & 0.301 & 0.251 & 0.200 & 0.149 & 0.099 \\
38.086 & 0.189 & 0.154 & 0.119 & 0.084 & 0.048 \\
38.574 & 0.103 & 0.080 & 0.058 & 0.035 & 0.013 \\
39.063 & 0.042 & 0.029 & 0.017 & 0.004 & -0.008 \\
39.551 & 0.007 & 0.002 & -0.004 & -0.009 & -0.015 \\
40.039 & -0.001 & -0.002 & -0.004 & -0.005 & -0.006 \\
40.527 & 0.000 & 0.000 & 0.000 & 0.000 & 0.000 \\
41.016 & 0.000 & 0.000 & 0.000 & 0.000 & 0.000 \\
41.504 & 0.000 & 0.000 & 0.000 & 0.000 & 0.000 \\
41.992 & 0.000 & 0.000 & 0.000 & 0.000 & 0.000 \\
\hline
\end{tabular}


TABLE VIII

INVERSE FILTER (1ST ORDER) BEHAVIOR RESULTING FROM CHANGING THE LOCATION OF ZEROS. INPUT = EXPONENTIAL + HA VERSINE (continued)

\begin{tabular}{|c|c|c|c|c|c|}
\hline $\begin{array}{l}\text { time } \\
\text { msec }\end{array}$ & $\begin{array}{c}z=.6 \\
m V\end{array}$ & $\begin{array}{c}z=.7 \\
m V\end{array}$ & $\begin{array}{c}z=.8 \\
m V\end{array}$ & $\begin{array}{c}z=.9 \\
m V\end{array}$ & $\begin{array}{c}\mathrm{z}=1.0 \\
\mathrm{mV}\end{array}$ \\
\hline $\begin{array}{l}0.000 \\
0.488 \\
0.977 \\
1.465 \\
1.953 \\
2.441 \\
2.930 \\
3.418 \\
3.906 \\
4.395 \\
4.883 \\
5.371 \\
5.859 \\
6.348 \\
6.836 \\
7.324 \\
7.813 \\
8.301 \\
8.789 \\
9.277 \\
9.766 \\
10.254 \\
10.742 \\
11.230 \\
11.719 \\
12.207 \\
12.695 \\
13.184 \\
13.672 \\
14.160 \\
14.648 \\
15.137 \\
15.625 \\
16.113 \\
16.602 \\
17.090 \\
17.578 \\
18.066\end{array}$ & $\begin{array}{r}500.000 \\
111.303 \\
91.594 \\
75.398 \\
62.096 \\
51.175 \\
42.214 \\
34.867 \\
28.849 \\
23.925 \\
19.902 \\
16.621 \\
13.950 \\
11.783 \\
10.029 \\
8.617 \\
7.484 \\
6.582 \\
5.868 \\
5.309 \\
4.877 \\
4.548 \\
4.303 \\
4.126 \\
4.003 \\
3.924 \\
3.878 \\
3.858 \\
3.859 \\
3.873 \\
3.897 \\
3.927 \\
3.960 \\
3.993 \\
4.023 \\
4.049 \\
4.070 \\
4.084\end{array}$ & $\begin{array}{r}500.000 \\
61.303 \\
50.463 \\
41.561 \\
34.254 \\
28.260 \\
23.348 \\
19.326 \\
16.037 \\
13.353 \\
11.166 \\
9.389 \\
7.949 \\
6.787 \\
5.854 \\
5.108 \\
4.517 \\
4.053 \\
3.693 \\
3.417 \\
3.211 \\
3.061 \\
2.956 \\
2.887 \\
2.847 \\
2.830 \\
2.829 \\
2.841 \\
2.863 \\
2.890 \\
2.920 \\
2.951 \\
2.981 \\
3.010 \\
3.034 \\
3.054 \\
3.068 \\
3.076\end{array}$ & $\begin{array}{r}500.000 \\
11.303 \\
9.333 \\
7.723 \\
6.411 \\
5.345 \\
4.481 \\
3.784 \\
3.226 \\
2.781 \\
2.431 \\
2.158 \\
1.948 \\
1.792 \\
1.678 \\
1.600 \\
1.551 \\
1.525 \\
1.518 \\
1.526 \\
1.545 \\
1.574 \\
1.609 \\
1.649 \\
1.692 \\
1.736 \\
1.781 \\
1.824 \\
1.867 \\
1.906 \\
1.942 \\
1.975 \\
2.003 \\
2.026 \\
2.045 \\
2.058 \\
2.065 \\
2.067\end{array}$ & $\begin{array}{r}500.000 \\
-38.697 \\
-31.797 \\
-26.114 \\
-21.431 \\
-17.570 \\
-14.385 \\
-11.757 \\
-9.586 \\
-7.790 \\
-6.305 \\
-5.074 \\
-4.053 \\
-3.204 \\
-2.497 \\
-1.908 \\
-1.416 \\
-1.004 \\
-0.658 \\
-0.366 \\
-0.121 \\
0.086 \\
0.262 \\
0.410 \\
0.536 \\
0.642 \\
0.732 \\
0.807 \\
0.870 \\
0.923 \\
0.965 \\
0.999 \\
1.025 \\
1.043 \\
1.056 \\
1.062 \\
1.063 \\
1.059\end{array}$ & $\begin{array}{r}500.000 \\
-88.697 \\
-72.928 \\
-59.952 \\
-49.274 \\
-40.485 \\
-33.252 \\
-27.298 \\
-22.397 \\
-18.362 \\
-15.040 \\
-12.305 \\
-10.054 \\
-8.200 \\
-6.673 \\
-5.417 \\
-4.383 \\
-3.532 \\
-2.833 \\
-2.258 \\
-1.787 \\
-1.401 \\
-1.086 \\
-0.829 \\
-0.620 \\
-0.452 \\
-0.317 \\
-0.210 \\
-0.126 \\
-0.061 \\
-0.012 \\
0.023 \\
0.046 \\
0.060 \\
0.067 \\
0.066 \\
0.061 \\
0.050\end{array}$ \\
\hline
\end{tabular}


TABLE VIII

INVERSE FILTER (1ST ORDER) BEHAVIOR RESULTING FROM CHANGING THE LOCATION OF ZEROS. INPUT $=$ EXPONENTIAL + HAVERSINE (continued)

\begin{tabular}{|c|c|c|c|c|c|}
\hline $\begin{array}{l}\text { time } \\
\text { msec }\end{array}$ & $\begin{array}{c}\mathrm{z}=.6 \\
\mathrm{mV}\end{array}$ & $\begin{array}{c}z=.7 \\
m V\end{array}$ & $\begin{array}{c}z=.8 \\
m V\end{array}$ & $\begin{array}{c}z=.9 \\
m V\end{array}$ & $\begin{array}{c}\mathrm{z}=1.0 \\
\mathrm{mV}\end{array}$ \\
\hline $\begin{array}{l}18.555 \\
19.043 \\
19.531 \\
20.020 \\
20.508 \\
20.996 \\
21.484 \\
21.973 \\
22.461 \\
22.949 \\
23.438 \\
23.926 \\
24.414 \\
24.902 \\
25.391 \\
25.879 \\
26.367 \\
26.855 \\
27.344 \\
27.832 \\
28.320 \\
28.809 \\
29.297 \\
29.785 \\
30.273 \\
30.762 \\
31.250 \\
31.738 \\
32.227 \\
32.715 \\
33.203 \\
33.691 \\
34.180 \\
34.668 \\
35.156 \\
35.645 \\
36.133 \\
36.621\end{array}$ & $\begin{array}{l}4.090 \\
4.087 \\
4.075 \\
4.053 \\
4.021 \\
3.979 \\
3.926 \\
3.864 \\
3.791 \\
3.708 \\
3.616 \\
3.515 \\
3.406 \\
3.288 \\
3.164 \\
3.032 \\
2.895 \\
2.753 \\
2.606 \\
2.456 \\
2.304 \\
2.149 \\
1.994 \\
1.839 \\
1.685 \\
1.533 \\
1.383 \\
1.237 \\
1.096 \\
0.960 \\
0.830 \\
0.707 \\
0.592 \\
0.485 \\
0.387 \\
0.298 \\
0.219 \\
0.151\end{array}$ & $\begin{array}{l}3.076 \\
3.070 \\
3.056 \\
3.034 \\
3.005 \\
2.967 \\
2.921 \\
2.868 \\
2.807 \\
2.739 \\
2.664 \\
2.582 \\
2.494 \\
2.401 \\
2.302 \\
2.199 \\
2.092 \\
1.982 \\
1.868 \\
1.753 \\
1.636 \\
1.518 \\
1.401 \\
1.283 \\
1.168 \\
1.054 \\
0.943 \\
0.835 \\
0.731 \\
0.631 \\
0.537 \\
0.448 \\
0.366 \\
0.290 \\
0.221 \\
0.160 \\
0.107 \\
0.062\end{array}$ & $\begin{array}{r}2.063 \\
2.053 \\
2.037 \\
2.015 \\
1.988 \\
1.955 \\
1.916 \\
1.872 \\
1.823 \\
1.770 \\
1.711 \\
1.649 \\
1.583 \\
1.514 \\
1.441 \\
1.366 \\
1.289 \\
1.210 \\
1.130 \\
1.049 \\
0.968 \\
0.887 \\
0.807 \\
0.728 \\
0.650 \\
0.575 \\
0.502 \\
0.432 \\
0.365 \\
0.302 \\
0.244 \\
0.189 \\
0.140 \\
0.095 \\
0.056 \\
0.022 \\
-0.006 \\
-0.028\end{array}$ & $\begin{array}{r}1.050 \\
1.036 \\
1.018 \\
0.997 \\
0.971 \\
0.943 \\
0.911 \\
0.876 \\
0.839 \\
0.800 \\
0.759 \\
0.716 \\
0.672 \\
0.626 \\
0.580 \\
0.533 \\
0.486 \\
0.439 \\
0.392 \\
0.346 \\
0.300 \\
0.256 \\
0.213 \\
0.172 \\
0.133 \\
0.096 \\
0.062 \\
0.029 \\
0.000 \\
-0.026 \\
-0.050 \\
-0.070 \\
-0.086 \\
-0.100 \\
-0.110 \\
-0.116 \\
-0.118 \\
-0.117\end{array}$ & $\begin{array}{r}0.036 \\
0.019 \\
-0.001 \\
-0.022 \\
-0.045 \\
-0.069 \\
-0.094 \\
-0.119 \\
-0.144 \\
-0.169 \\
-0.194 \\
-0.217 \\
-0.240 \\
-0.261 \\
-0.281 \\
-0.300 \\
-0.317 \\
-0.333 \\
-0.346 \\
-0.358 \\
-0.367 \\
-0.375 \\
-0.380 \\
-0.383 \\
-0.384 \\
-0.383 \\
-0.379 \\
-0.373 \\
-0.365 \\
-0.355 \\
-0.343 \\
-0.329 \\
-0.313 \\
-0.295 \\
-0.275 \\
-0.254 \\
-0.231 \\
-0.207\end{array}$ \\
\hline
\end{tabular}


TABLE VIII

INVERSE FILTER (1ST ORDER) BEHAVIOR RESULTING FROM CHANGING THE LOCATION OF ZEROS. INPUT = EXPONENTIAL + HAVERSINE (continued)

\begin{tabular}{|c|c|c|c|c|c|}
\hline $\begin{array}{c}\text { time } \\
\mathrm{msec}\end{array}$ & $\begin{array}{c}\mathrm{z}=.6 \\
\mathrm{mV}\end{array}$ & $\begin{array}{c}\mathrm{z}=.7 \\
\mathrm{mV}\end{array}$ & $\begin{array}{c}\mathrm{z}=.8 \\
\mathrm{mV}\end{array}$ & $\begin{array}{c}\mathrm{z}=.9 \\
\mathrm{mV}\end{array}$ & $\begin{array}{c}\mathrm{z}=1.0 \\
\mathrm{mV}\end{array}$ \\
\hline 37.109 & 0.094 & 0.025 & -0.044 & -0.112 & -0.181 \\
37.598 & 0.048 & -0.003 & -0.054 & -0.104 & -0.155 \\
38.086 & 0.013 & -0.022 & -0.057 & -0.092 & -0.128 \\
38.574 & -0.010 & -0.032 & -0.055 & -0.077 & -0.099 \\
39.063 & -0.021 & -0.033 & -0.046 & -0.058 & -0.071 \\
39.551 & -0.020 & -0.025 & -0.031 & -0.036 & -0.042 \\
40.039 & -0.007 & -0.009 & -0.010 & -0.011 & -0.012 \\
40.527 & 0.000 & 0.000 & 0.000 & -0.000 & -0.000 \\
41.016 & 0.000 & 0.000 & 0.000 & -0.000 & -0.000 \\
41.504 & 0.000 & 0.000 & 0.000 & -0.000 & -0.000 \\
\hline
\end{tabular}


Software

The following code are listing represents the inverse filter (1st order and 2 nd order). After the exponential noise is filtered out, it is ready to move through the lowpass filter for removal of myopotential noise.

\%-------Filter \#1: filter the exponential noise--.---.-\%

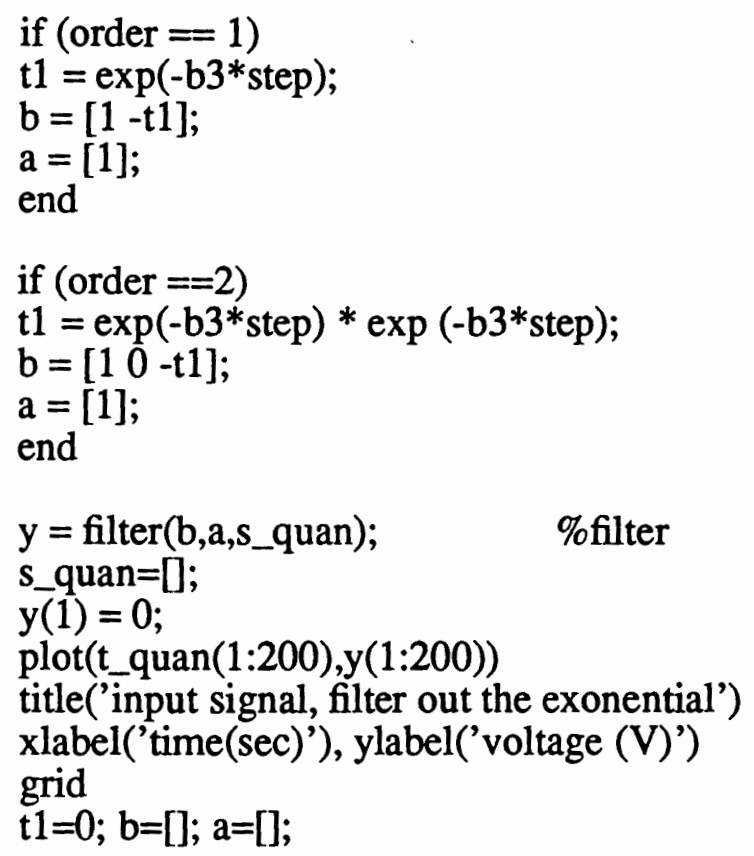

\section{LOWPASS DIGITAL FILTER}

To minimize myopotential noise, the output signal from the inverse filter is filtered by a lowpass digital filter. Myopotential noise has a wide band spectrum from 70 to 1000 $\mathrm{Hz}$ (see Figure 13). A lowpass Chebyshev type I filter has a pass band of $50 \mathrm{~Hz}$, or order $2,4,6$, or 8 , is used to filter the myopotential noise. 
TABLE IX

LOCATION OF POLES, AND ZEROS BY ORDER

\begin{tabular}{|c|c|c|c|c|c|}
\hline order & $i$ & $b i$ & ai & zerós & poles \\
\hline \multirow{3}{*}{$\begin{array}{l}N= \\
2\end{array}$} & 1 & .0163 & 1.0 & -1 & $.8157+j .1766$ \\
\hline & 2 & .0326 & -1.6315 & -1 & $.8157-j .1766$ \\
\hline & 3 & .0163 & .6966 & & \\
\hline \multirow{5}{*}{$\begin{array}{l}N= \\
4\end{array}$} & 1 & $.025 \quad \mathrm{e}-3$ & 1.0 & -1 & $.9044+j .0649$ \\
\hline & 2 & $.1001 \mathrm{e}-3$ & -3.7013 & -1 & $.9044-j .0649$ \\
\hline & 3 & $.1501 \mathrm{e}-3$ & 5.1677 & -1 & $.9463+j .1646$ \\
\hline & 4 & $.1001 \mathrm{e}-3$ & -3.2244 & -1 & $.9463-j .1646$ \\
\hline & 5 & $.025 \quad \mathrm{e}-3$ & .7584 & & \\
\hline \multirow{7}{*}{$\begin{array}{l}N= \\
6\end{array}$} & 1 & $.0371 \quad e-6$ & 1.0 & -1 & $.9354+j .0408$ \\
\hline & 2 & .2225 e-6 & -5.7033 & $-.998-j .0016$ & $.9354-j .0408$ \\
\hline & 3 & $.5563 e^{-6}$ & 13.5919 & $-.979+j .0014$ & $.9464+j .1130$ \\
\hline & 4 & $.7418 \quad e-6$ & -17.3241 & $-1.0009-j .0024$ & $.9464-j .1130$ \\
\hline & 5 & $.5563 e-6$ & 12.4547 & $-1.0007+j .0025$ & $.9698+j .1585$ \\
\hline & 6 & $.2225 e-6$ & -4.7883 & $-1.0026+j .0001$ & $.9698-j .1585$ \\
\hline & 7 & $.0371 \quad e-6$ & .7691 & & \\
\hline \multirow{6}{*}{$\begin{array}{l}N= \\
8\end{array}$} & 1 & $.0055 \quad e-8$ & -1.0 & -1.0 & $.9513+j .0300$ \\
\hline & 2 & $.0438 \quad e-8$ & -7.6962 & $-1.0124-j .0157$ & $.9513-j .0300$ \\
\hline & 3 & $.1532 \mathrm{e}^{-8}$ & 25.9629 & $-.9954-j .0193$ & $.9552+j .0860$ \\
\hline & 4 & $.3065 \quad \mathrm{e}-8$ & -50.1425 & -1.0200 & $.9552-j .0860$ \\
\hline & 5 & $.3831 \quad e-8$ & 60.6377 & $-.9822-j .0085$ & $.9779+j .1561$ \\
\hline & 6 & $.3065 \quad e-8$ & -47.0169 & $-1.0124+j .0157$ & $.9779-j .1561$ \\
\hline
\end{tabular}


TABLE IX

LOCATION OF POLES, AND ZEROS BY ORDER

(continued)

\begin{tabular}{|l|c|cc|c|c|c|}
\hline order & $i$ & bi & ai & zeros & poles \\
\hline \multirow{2}{*}{$\begin{array}{l}\mathrm{N}= \\
8\end{array}$} & 7 & .1532 & $\mathrm{e}-8$ & 22.8261 & $-.9822+j .0085$ & $.9637+j .1302$ \\
\cline { 2 - 7 } & 8 & .0438 & $\mathrm{e}-8$ & -6.3438 & $-.9954+j .0193$ & $.9637-j .1302$ \\
\cline { 2 - 7 } & 9 & .0055 & $\mathrm{e}-8$ & .7727 & & \\
\hline
\end{tabular}

\section{Software}

The folowing code listing represents the lowpass filter Chebyshev type I of the stimulation. After the myopotential noise is filtered out, it is ready to move through the threshold level detector.

\%-------Filter \#2: filter the myopotential noise---.---\%

$y=$ filter(b,a,s_quan); $\quad$ \%filter

s_quan=0;

$y(1)=0$;

plot(t_quan(1:200),y(1:200))

title('input signal, filter out the exonential')

xlabel('time(sec)'), ylabel('voltage (V)')

grid

$\mathrm{t} 1=0 ; \mathrm{b}=[\mathrm{[} ; \mathrm{a}=[\mathrm{]} ;$

$\mathrm{rp} 2=.1 ; \mathrm{Wn} 2=(2 * 50) / \mathrm{fs} ;$

[Bc2,Ac2] = chebyl (Nc2, rp2, Wn2);

$\mathrm{yf}=$ filter $(\mathrm{Bc} 2, \mathrm{Ac2}, \mathrm{y})$;

$\mathrm{y}=[\mathrm{]} ;$

$\mathrm{Nc2}=0 ; \mathrm{Wn} 2=0 ; \mathrm{Rp} 2=0 ; \mathrm{Bc2}=[] ; \mathrm{Ac2}=[]$;

plot(t_quan(1:200),yf(1:200))

title('input signal, filter out the myopotential')

xlabel('time (sec)'), ylabel('voltage (V)')

grid 
A z-transform of a differential equation for a digital filter yields the following frequency domain or transfer function model description:

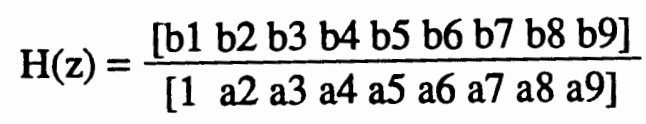

Table IX shows the filter coefficients, location of poles and the zeros of the lowpass filter for order $2,4,6$, and 8 . Figure 44 shows the magnitude reskponse of the lowpass digital filter with different orders $2,4,6$, and 8 . Figure 36 shows the lowpass filter's output is clear of myopotential noise.

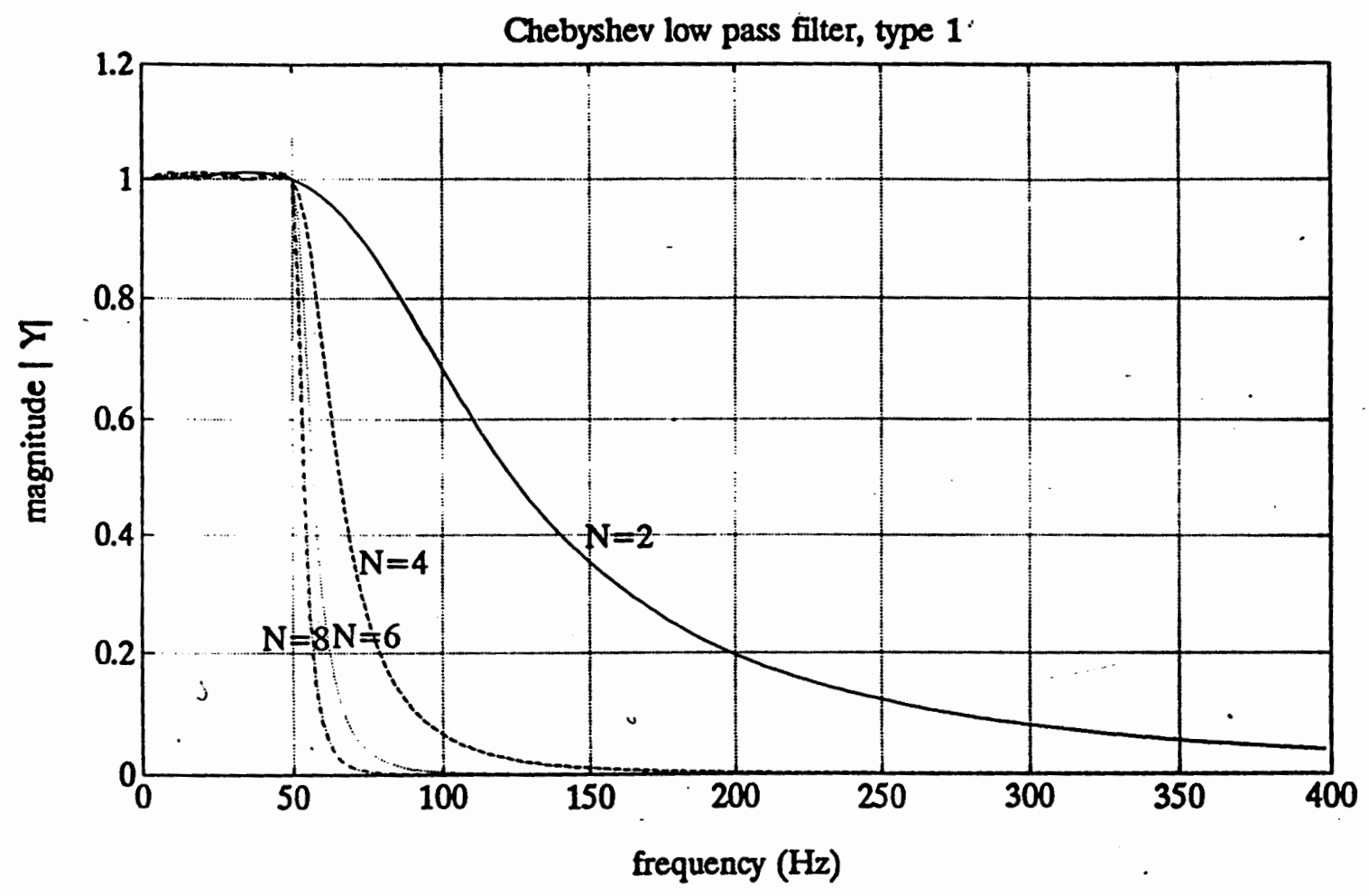

Figure 44. Magnitude of lowpass filter Chebyshev type I. 


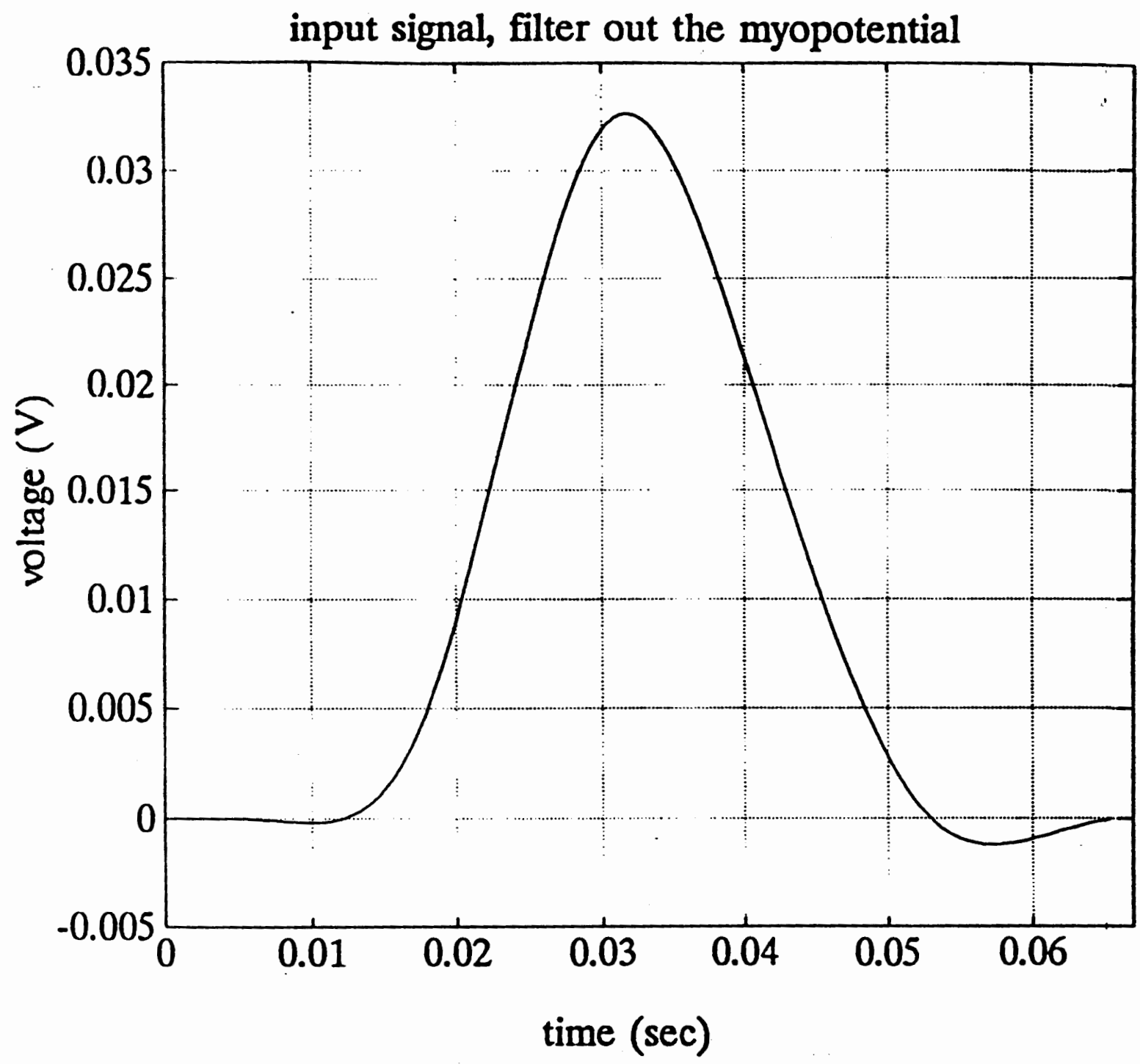

Figure 45. Lowpass filter filter out myopotential.

THRESHOLD LEVEL DETECTOR

The threshold level detector in the simulation can be set to any level. Signals that exceed this level are detected. In the simulation, this function corresponds to the pacemaker's sensor function. Figure 46 below shows the results of running the simulation as seen by the threshold level detector. 


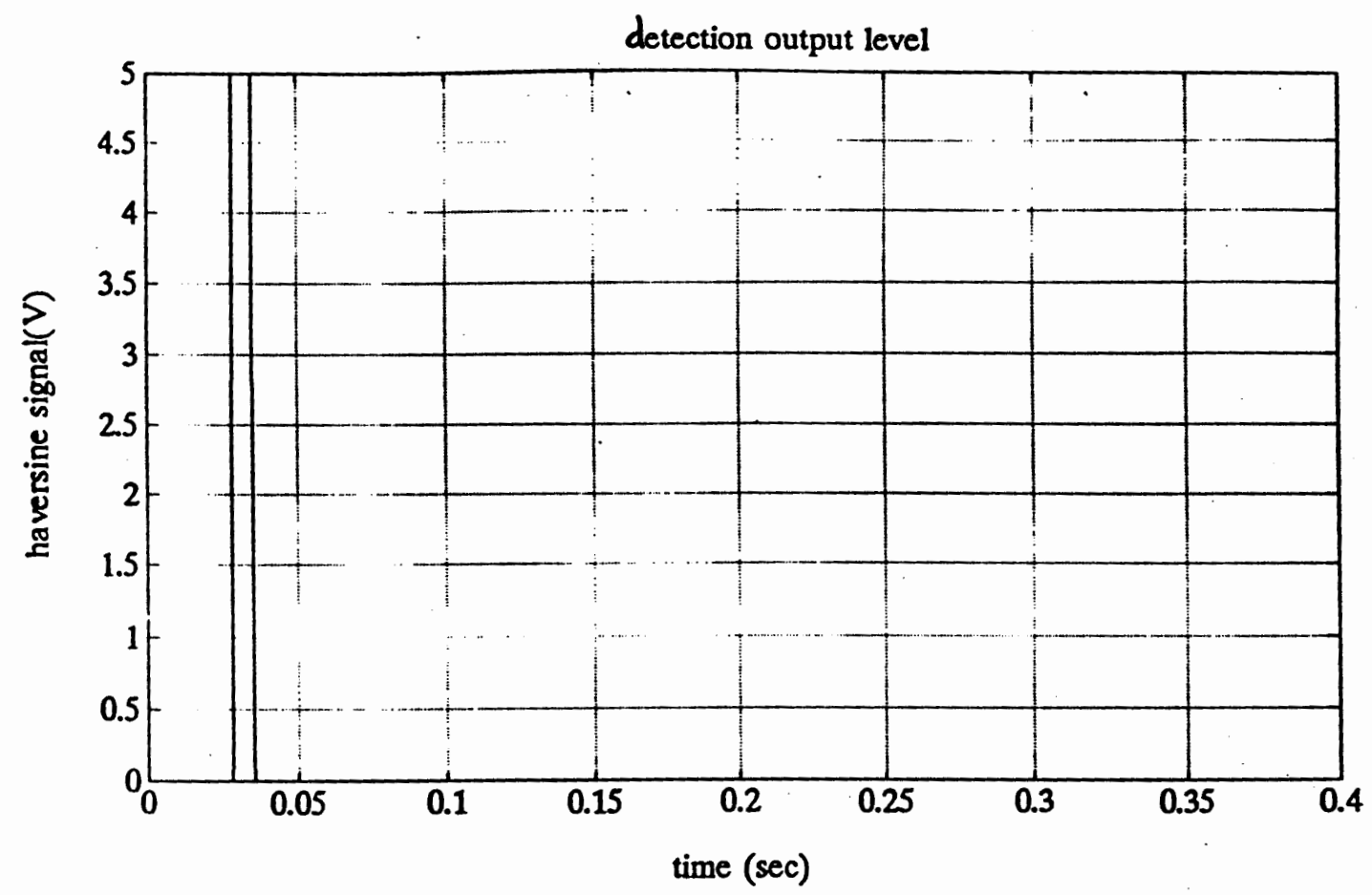

Figure 46. Detect output level.

Software

The following code lisitng represent the threshold level detector of the simulation.

\%------othreshold level $=+1-.2 \mathrm{~V}$

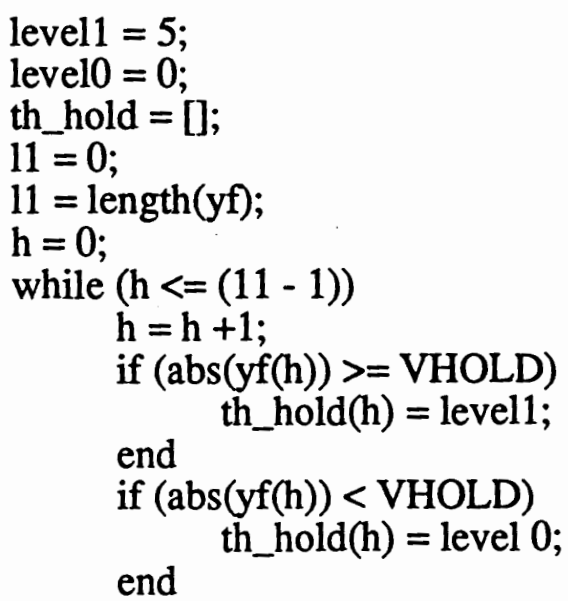


end

$\mathrm{h}=0$;

yf $=[]$;

plot(t_quan,th_hold)

title('detection output level')

xlabel('time (sec)'), ylabel('haversine signal (V)')

grid

t_quan=[]; th_hold=[]; $h=0 ; 11=0$; 


\section{CHAPTER X}

\section{CONCLUSIONS}

This chapter presents conclusions based on the test system. The conclusions include a description of limitations suggested by test runs of the simulation.

\section{PROCEDURE SUMMARY}

Using MATLAB as supporting software, the simulation program is written for operation in a DOS environment. The program generates a haversine signal, myopotential noise (random noise), and exponential noise. All three signals are combined and sent through an amplifier stage and an $A / D$ converter stage. The exponential noise is filter out by an inverse digital filter, and the myopotential noise is filtered out by a lowpass digital filter. The output signal is deemed "detected" if its waveform exceeds threshold level.

\section{CONCLUSIONS}

The inverse filter is designed to eliminate the effects of the exponential response following a pace pulse, such that the resultant haversine signal is recognized. First order and second order systems are used to represent the exponential signal. An inverse filter is used to filter out the exponential signal.

Tests show that the haversine signal can be clearly sensed if there is a 5\% change in the time constant of the exponential. Within a 5 to $15 \%$ change of the time constant, the filtered exponential amplitude swamps out the haversine. See Tables I, II, III, and IV.

The sensitivity of the inverse filter was also studied:when using a fixed exponential time constant but changing the location of the zeros, the effect of the exponential noise 
on the haversine signal is minimal when zeros are located between 0.75 to 0.85 of the unit circle. See Tables V, VI, VII, and VIII.

The lowpass digital filter is used to filter out the myopotential noise. Tests showed that an order of 8 for the lowpass filter was most successful for this purpose. 


\section{REFERENCES}

Alan V. Oppenheim \& Ronald W. Schafer. "Discrete Time Signal Processing".

Journal of the North American Society of Pacing and Electrophysiology, November 1987 , volume 10 , no. 6 , page $1235-1409$

Journal of the North American Society of Pacing and Electrophysiology, January 1987, volume 10 , no. 1 , part 1 , page 1 - 159

Max Schaldasch. "Electrotherapy of the Heart". Technical Aspects in Cardiac Pacing.

Max Schaldasch \& S. Furman. "Advances in Pacemaker Technology", p.9

Thomas Morton \& William Jakobi. "Introduction to Pacing".

Yoshio Watanabe, Tokyo March 14 - 18, 1976. "Cardiac Pacing" Proceeding of the Vth International Symposium. 
APPENDIX A

SOFTWARE 
This program is using MATLAB tool. It is written by Merry Tran.

It includes:

1. create a haversine signal

2. create a exponential noise

3. create a myopotential noise

4. amplifier signal

5. sample and hold

6. quantization

7. filter out the exponential noise

8. filter out the myopotential noise

9. threshold

clear

$\% * * * * * * * * * * * * * * * * * * * * *$ Input information

fs = input ('Enter sampling frequency $\left.(\mathrm{Hz})[\mathrm{fs}]={ }^{\prime}\right)$;

$\mathrm{tf}=$ input ('Enter max on time axis $(\mathrm{sec})[\mathrm{tf}] \Rightarrow$ ');

step $=1 / \mathrm{fs}$

$\mathrm{t}=0$ :step:tf;

$\%$ time axis

$\mathrm{n}=512$;

$\%$ number of point

$\mathrm{ff}=\mathrm{fs} /(2 * \mathrm{n}) *(0: \mathrm{n}-1) ; \%$ sampling frequency $(\mathrm{Hz})$

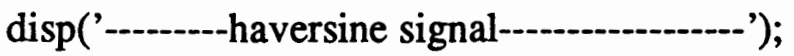

$\mathrm{amp}=0 ; \mathrm{pw}=0$; per $=0$;

amp = input ('Enter the amplitude (V) [amp] $\Rightarrow$ ');

$\mathrm{pw}=$ input ('Enter the pulse width (sec) $[\mathrm{pw}] \Rightarrow$ ');

per = input ('Enter the period (sec) [per] $\Rightarrow$ ');

disp('--Exponential signal : 1st \& 2nd order-----');

$\mathrm{a} 3=0 ; \mathrm{b} 3=0$; order $=0$;

a3 = input ('Enter the amplitude (V) [a3] $\Rightarrow$ ');

b3 = input ('Enter the time constant $(1 / \mathrm{sec})[\mathrm{b} 3]=>$ );

order $=$ input ('Enter the order of system [order] $\Longrightarrow$ ');

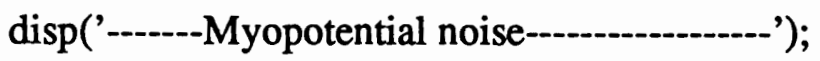

amy $=0$;

amy $=$ input ('Enter the amplitude $(\max =.005 \mathrm{~V})$ [amy] $\Rightarrow>$ '); 


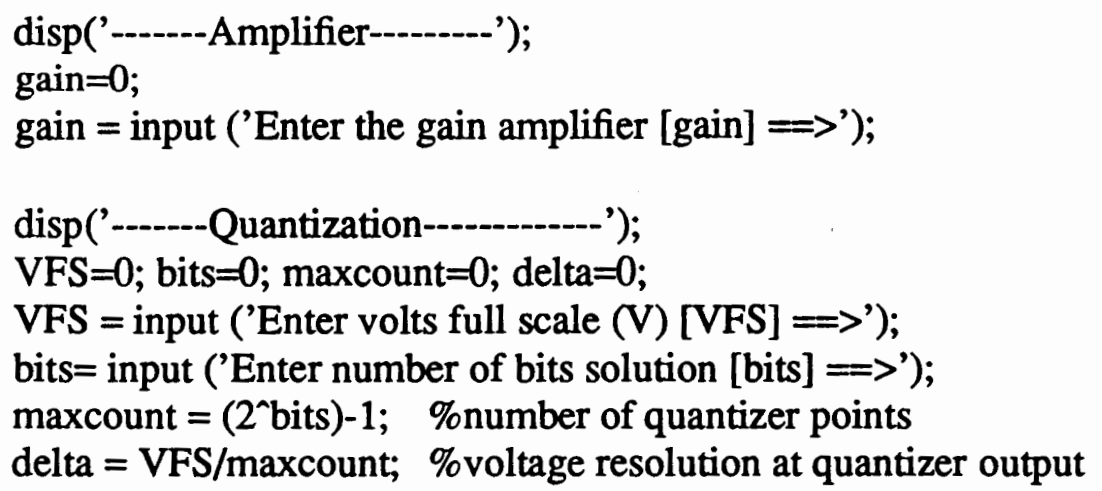

disp ('--Filter out the myopotential,Chebyshev lowpass filter--');

$\mathrm{Nc2}=0$

Nc2 = input ('Enter the order of filter [Nc2] $\Rightarrow$ ');

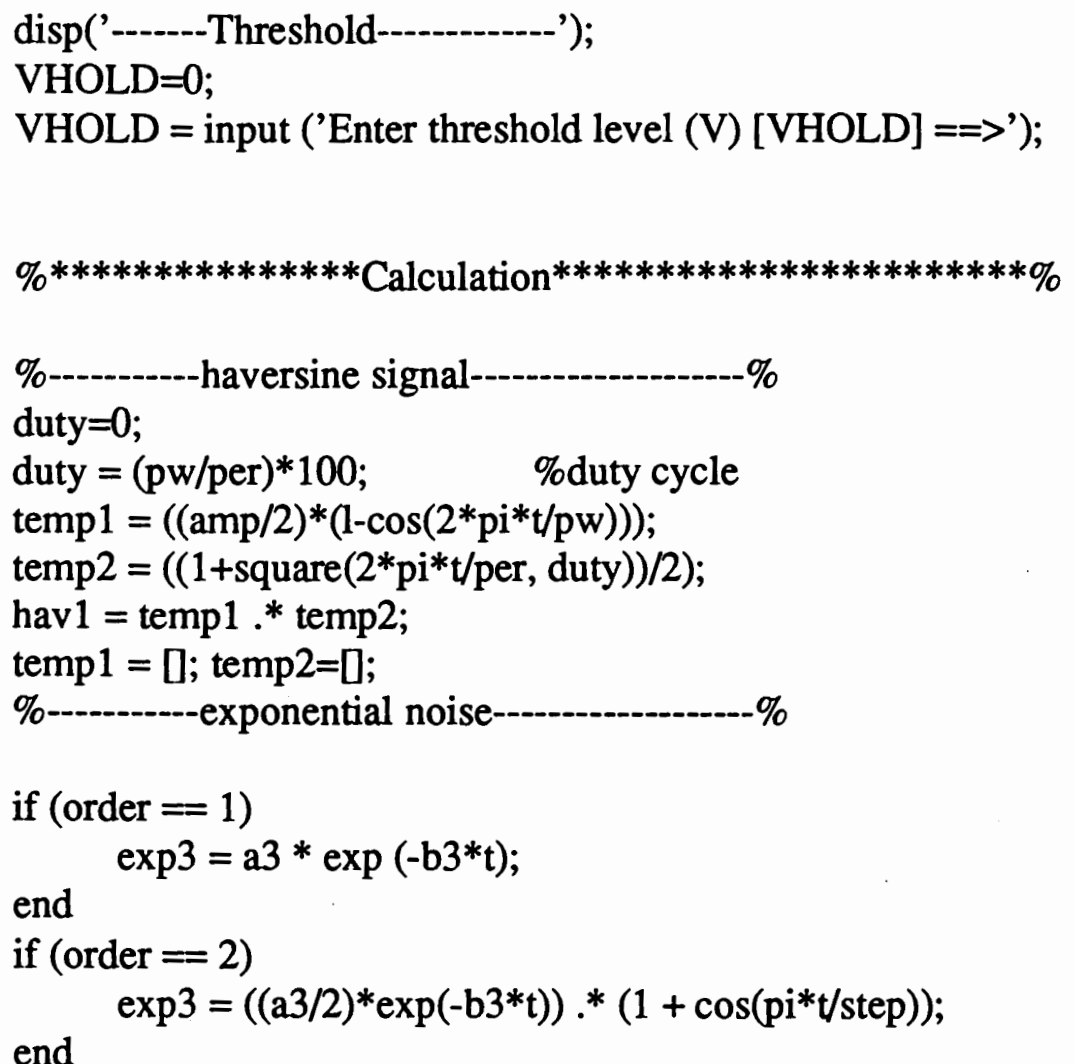


$\%$

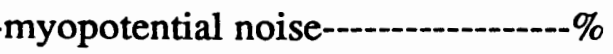

rand ('uniform') \% uniformly distributed random noise

$\mathrm{y}=$ amy $^{*}$ rand $(\mathrm{t}) ; \%$ noise, standard deviation $=.005$

ripple $=.1 ; \quad \%$ allowable ripple, in decibels

$\mathrm{N}=8$;

\%filter order

passband $=[(2 * 70) / \mathrm{fs}(2 * 1000) / \mathrm{fs}] ; \%$ passband specification

$[\mathrm{Bc}, \mathrm{Ac}]=$ chebyl $(\mathrm{N}$, ripple, passband);

myo = filter (Bc,Ac,y); \% filter

$\mathrm{y}=[] ; \mathrm{Bc}=\mathrm{D} ; \mathrm{Ac}=[]$;

\%---- Input signal $=$ haversine + exponential + myopotential -..-\%

disp('you can test filters by following menu:');

$\operatorname{disp}($ ' $1=$ exponential, $2=$ haversine, $3=$ myopotential');

$\operatorname{disp}$ ('4=exponential +haversine, $5=\exp$. thaversine+myo.');

no $=$ input('enter number, [no] $=\Rightarrow$ ');

if (no $==1$ )

end

$$
\text { s_in = exp3; }
$$

if (no $==2$ )

end

$$
\text { s_in = hav1; }
$$

if (no $==3$ )

end

s_in = myo;

if(no $==4$ )

end

$$
\text { s_in = hav1 + exp3: }
$$

if(no $=5$ )

end

$$
\text { s_in = exp3+hav } 1+\text { myo; }
$$

no=0;

plot(t(1:200),s_in(1:200))

title('input signal=myopotential +haversinetexponential')

xlable('time (sec)'), ylabel('voltage (V) ')

grid

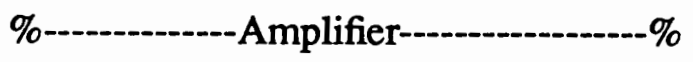

s_in = gain *s_in; 


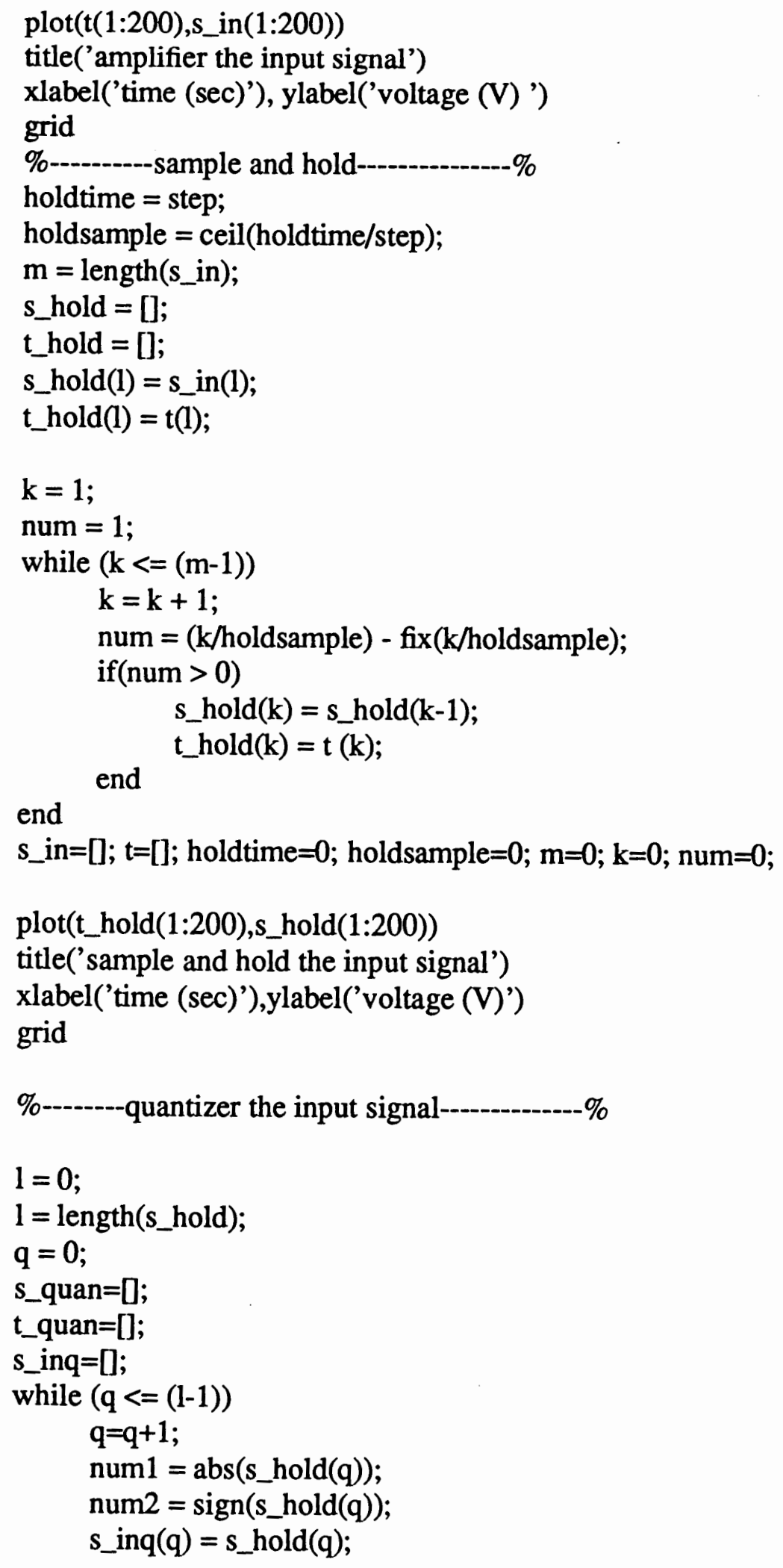

$\mathrm{s} \_$in $=[] ; \mathrm{t}=[] ;$ holdtime $=0$; holdsample $=0 ; \mathrm{m}=0 ; \mathrm{k}=0$; num $=0$;

plot(t_hold(1:200),s_hold(1:200))

title('sample and hold the input signal')

xlabel('time (sec)'), ylabel('voltage (V)')

grid

\%-------quantizer the input signal---.-.-.---.-\% 
if(num1 > VFS)

$$
\text { s_quan }(q)=\text { num } 2 * \text { VFS; }
$$

end

$$
\mathrm{t} \_q \text { quan }(q)=t \_ \text {hold }(q) \text {; }
$$

if (num1 <= VFS)

s_quan $(q)=$ num $2 *$ delta $*$ round $((\operatorname{maxcount} *$ num 1$) / V F S$;

$\mathrm{t} \_q u a n(q)=t \_h o l d(q)$

end

end

$1=0 ; \mathrm{q}=0 ;$ num $1=0 ;$ num2 $=0 ; \mathrm{s} \_$hold $=[] ; \mathrm{t} \_$hold $=[] ;$

plot(s_inq,s_quan)

title('quantize the input signal')

xlabel('input signal (V)'), ylabel('quantized input signal (V)')

grid

s_inq=0;

plot(t_quan(1:200),s_quan(1:200))

title('quantize the input signal')

xlabel('time (sec)'), ylabel('quantize input signal(V)')

grid

\%--------Filter \#1: filter the exponential noise----.---\%

if $($ order $==1)$

$\mathrm{t} 1=\exp (-\mathrm{b} 3 *$ step $)$

$\mathrm{b}=[1-\mathrm{t} 1]$;

$\mathrm{a}=[1]$

end

if (order $==2$ )

$\mathrm{t} 1=\exp (-\mathrm{b} 3 *$ step $) * \exp (-\mathrm{b} 3 *$ step $)$

$\mathrm{b}=\left[\begin{array}{lll}1 & 0 & -\mathrm{t} 1\end{array}\right]$;

$\mathrm{a}=[1]$;

end

$y=$ filter(b,a,s_quan);

\%filter

s_quan=[;

$y(1)=0$;

$\operatorname{plot}\left(t \_q u a n(1: 200), y(1: 200)\right)$

title('input signal, filter out the exonential')

xlabel('time(sec)'), ylabel('voltage (V)')

grid

$\mathrm{t} 1=0 ; \mathrm{b}=[\mathrm{a} ; \mathrm{a}=[]$; 
\%-------Filter \#2: filter the myopotential noise--..---\%

$\mathrm{rp} 2=.1 ; \mathrm{Wn} 2=(2 * 50) / \mathrm{fs} ;$

[Bc2,Ac2] = chebyl (Nc2, rp2, Wn2);

$\mathrm{yf}=$ filter(Bc2,Ac2,y);

$\mathrm{y}=[\mathrm{]}$;

$\mathrm{Nc} 2=0 ; \mathrm{Wn} 2=0 ; \mathrm{Rp} 2=0 ; \mathrm{Bc} 2=[] ; \mathrm{Ac2}=[] ;$

plot(t_quan(1:200),yf(1:200))

title('input signal, filter out the myopotential')

xlabel('time (sec)'), ylabel('voltage (V)')

grid

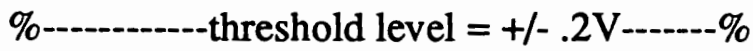

level1 $=5$;

level0 $=0$;

th_hold = [];

$11=0$;

$11=$ length $(y)$;

$\mathrm{h}=0$;

while $(\mathrm{h}<=(11-1))$

$h=h+1$;

if (abs(yf(h)) >= VHOLD)

end

th_hold $(\mathrm{h})=$ level1;

if $(\operatorname{abs}(\mathrm{yf}(\mathrm{h}))<$ VHOLD)

th_hold $(\mathrm{h})=$ level 0 ;

end

end

$\mathrm{h}=0$;

$\mathrm{yf}=\mathrm{D}$;

plot(t_quan,th_hold)

title('detection output level')

xlabel('time (sec)'), ylabel('haversine signal (V)')

grid

t_quan=[]; th_hold $=[] ; \mathrm{h}=0 ; 11=0$; 
APPENDIX B

GLOSSARY 


\section{GLOSSARY}

- amplifier, The signal amplification stage. The amplifier increases the visibility of the haversine signal.

- analog to digital converter ( $\mathrm{A} / \mathrm{D}$ converter), The $\mathrm{A} / \mathrm{D}$ converter transforms an analog signal into a binary signal.

- Atrial representation, Atrial contracts and produces a P wave that is simulated with the haversine waveform.

- Bandpass filter, A signal filter which allows only signals that fall within a preset band to pass through.

- Bipolar configuration, A pacemaker with two leads.

- Cardiac Cycle. The rhythmic contraction and expansion of the heart muscle. For the purposes of this paper, the signals which result from depolarization and repolarization.

- Depolarization, A muscle cell receiving a stimulus and contracting or a nerve cell receiving stimulus and transmitting the stimulus to the next nerve.

- Digital Filter, A signal filter designed to evaluate a binary signal, identify some component of that signal and remove interfering components.

- Duty cycle, The peak of the square wave used to create the haversine signal.

- ECG, An Electro Cardio Graph records signals from the cardiac cycle on a trace sheet.

- Exponential noise, Exponential signal decay after the trailing edge of a pace pulse. 
- Implanted Leads, Electrodes which extend from the pacemaker and have been surgically attached to the trigger nodes of the heart.

- myocardium, Tissue of the wall of the heart to which the implanted leads are connected.

- myopotential noise, Myopotential noise is interfering noise generated by the contraction of skeletal muscles.

- Pace pulse, The electrical charge sent by the pacemaker to the heart.

- Pulse generator, The part of a pacemaker that actually creates the electrical pulse. Usually the pulse generator consists of a timer and a battery.

- pulse interval, The time periodic between pulses of electrical energy, or the distance between two pacings.

- pulse width,The time during which electrical energy is being delivered to the heart, it is measured from the leading edge to the trailing edge of the pace pulse.

- $Q R S$, or simply an $\mathrm{R}$ wave, is a large signal generated during depolarization of the ventricular. This is the beginning of ventricular contraction.

- $R$ wave, or simply a QRS wave, is a large signal generated during depolarization of the ventricular. This is the beginning of ventricular contraction.

- Repolarization, Recovery of a cell from depolarization so that it is ready to receive the next stimulus.

- $\quad S_{-}$A node, The Sino-Atrial is the point at which depolarization begins in the atrium.

- $\quad S \_V$ node, The Sino-ventricular node is the point at which depolarization begins in a ventricular contraction. 
- Threshold detector, The threshold detector examines the returning signal for the haversine signal.

- Unipolar pacing, A pacemaker with a single implanted lead which is used for both sending the pace pulse and sensing responses.

- Ventricular representation, The Ventricular contracts and produces a QRS wave that is simulated with the haversine waveform. 